\title{
Cycles, economic structures and external constraints
}

Citation for published version (APA):

Spinola, D. S. (2020). Cycles, economic structures and external constraints: a structuralist study on the causes of economic volatility in Latin America. [Doctoral Thesis, Maastricht University]. ProefschriftMaken Maastricht. https://doi.org/10.26481/dis.20200304ds

Document status and date:

Published: 01/01/2020

DOI:

$10.26481 /$ dis.20200304ds

Document Version:

Publisher's PDF, also known as Version of record

\section{Please check the document version of this publication:}

- A submitted manuscript is the version of the article upon submission and before peer-review. There can be important differences between the submitted version and the official published version of record.

People interested in the research are advised to contact the author for the final version of the publication, or visit the DOI to the publisher's website.

- The final author version and the galley proof are versions of the publication after peer review.

- The final published version features the final layout of the paper including the volume, issue and page numbers.

Link to publication

\footnotetext{
General rights rights.

- You may freely distribute the URL identifying the publication in the public portal. please follow below link for the End User Agreement:

www.umlib.nl/taverne-license

Take down policy

If you believe that this document breaches copyright please contact us at:

repository@maastrichtuniversity.nl

providing details and we will investigate your claim.
}

Copyright and moral rights for the publications made accessible in the public portal are retained by the authors and/or other copyright owners and it is a condition of accessing publications that users recognise and abide by the legal requirements associated with these

- Users may download and print one copy of any publication from the public portal for the purpose of private study or research.

- You may not further distribute the material or use it for any profit-making activity or commercial gain

If the publication is distributed under the terms of Article $25 \mathrm{fa}$ of the Dutch Copyright Act, indicated by the "Taverne" license above, 
Cycles, Economic Structures and External Contraints

A Structuralist Study on the Causes of

Economic Volatily in Latin America

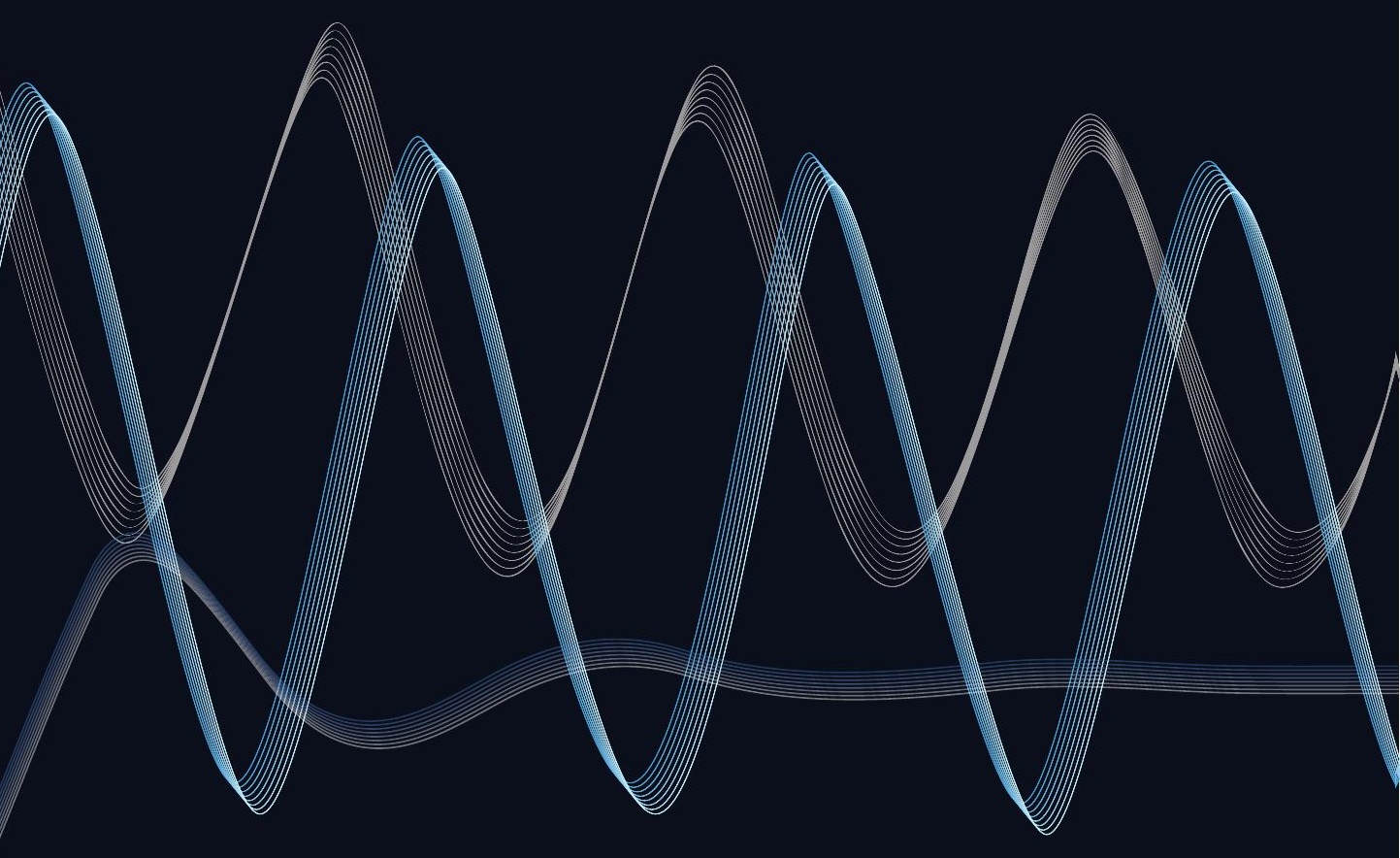

DaniloS. Spinola 

Cycles, Economic Structures and External Constraints:

A Structuralist Study on the Causes of Economic Volatility in Latin America

Danilo Sartorello Spinola 
Copyright (C) Danilo Sartorello Spinola 2020

ISBN 978-94-6380-698-5

Cover Design: Melanie Weidler

Printing: ProefschriftMaken | | www.proefschriftmaken.n|

All rights reserved. No part of this publication may be reproduced, stored in retrieval system or transmitted, in any form or by any means, electronic, mechanical, photocopying, recording or otherwise, without prior permission of the author or the copyright-owning journals for previous published chapters. 
Cycles, Economic Structures and External Constraints:

\section{A Structuralist Study on the Causes of Economic Volatility in Latin America}

\section{DISSERTATION}

To obtain the degree of Doctor at Maastricht University, on the authority of the Rector Magnificus Prof. Dr. Rianne M. Letschert, in accordance with the decision of the Board of Deans, to be defended in public on Wednesday 4 March 2020 at 10:00 hours

by

Danilo Sartorello Spinola 


\section{Supervisors}

Prof. Dr. Bart Verspagen

Prof. Dr. Neil Foster-McGregor

\section{Assessment Committee}

Prof. Dr. Adam Szirmai (chair)

Dr. Alberto Botta (Greenwich University, United Kingdom)

Prof. Dr. Maria Savona (University of Sussex, United Kingdom)

Dr. Thomas Ziesemer 


\section{Summary}

The main objective of this thesis is to understand the causes behind the endogenous volatile behavior of Latin American economies in a New-Structuralist perspective. Many distinct authors (Caldentey \& Vernengo, 2010; Cimoli, Porcile, \& Rovira, 2010; Botta, 2009; Ocampo, 2002) argue that the repetition of strong boom-bust dynamics is a structural problem in the economic development of Latin America. In this research we search for the underlying causes of this behavior, discussing volatility as an endogenous phenomenon, intrinsic to the characteristics of these fragile economies.

We assess this research question following empirical and theoretical approaches. The empirical approach initially consists on identifying the main characteristics of economic growth cycles in Latin America from real Gross Domestic Product (GDP) data. Secondly, we test the assumptions of the models developed in this thesis. Thirdly we check how the economic system behaves when there are exogenous shocks to some specific variables.

The theoretical part of this research develops itself from growth models, offering explanations of the causes of Latin American endogenous volatility based on the growth cycle theory literature. In terms of the theoretical framework, this thesis is based on three main classic pillars, all somehow related to the Structuralist theory: (1) The Goodwin model (Goodwin, 1967), composed of endogenous cycles that emerge in the relationship between economic growth and income distribution; (2) The Balance of Payments Constrained Model (BPCM) (Thirlwall, 1979), that relates economic growth to external constraints, and (3) The Prebisch-Singer hypothesis (Prebisch, 1950) (center-periphery framework), relating economic growth and development traps to the position of a developing economy in the international division of labor (global economic system). Since the early contributions figuring as pillars of this thesis, a whole tradition of Structuralist, Post-Keynesian, and Evolutionary works has been developed forming the core of the New-Structuralist framework (Cimoli \& Porcile, 2014; Cimoli et al., 2010; Botta, 2009; Ocampo, Rada, \& Taylor, 2009; Porcile \& Yajima, 2019). In this thesis we interrelate these approaches using more recent models developed in the New-Structuralist framework to the Latin American case. Our research is based on the open-economy growth models of La Marca (2010) and Dutt (2002). 
This thesis is divided in four independent articles. Despite their independence, their topics are considered as different parts of a puzzle, searching to answer the main research questions of this thesis: what are the conditions and causes of structural volatility in Latin America?

Initially, using GDP growth data from the Maddison Project Database we apply in Chapter 1 an asymmetric band-pass filter to extract growth GDP cycles for 136 different countries. After extracting 4 different types of cycles and the residual, we classify our country sample in categorical groups, doing a cluster analysis on the cyclical results. We observe the main cyclical characteristic of Latin American countries in terms of their volatility patterns. We argue that Latin America is a continent in which half of its countries are rather homogeneous in terms of the long-run economic cycle (Kondratiev) relevance to explain the causes of volatility. This indicates a high sensitivity of these economies to changes in the industrial/technological paradigm (Perez, 2010). As commodity-driven producers, a change in the international environment forces the Latin American economies to reshuffle their productive structure, resulting in high economic costs. On the other hand, some specific countries in the region show a high relative participation in short-run Juglar-type cycles, caused by the maturity of investment cycles, which are driven by the foreign-sector induction of investments in developing countries (external constraints block investment projects). We highlight that in Latin American economies for both short- and long-run cycles there is a high dependence on the behavior of the external sector, as well as the characteristics of productive structure, to sustain GDP growth (FosterMcGregor, Kaba, \& Szirmai, 2015).

In this sense, we observe that the productive structure, technological change and the external sector are central elements associated to the high volatility of Latin American economies.

In Chapter 2 we change the perspective to a theoretical one, working with dynamic systems, expanding the open-economy growth model of La Marca (2010). This model builds a dynamic system capable of reproducing dampened cycles in the relationship between growth and distribution (Goodwin, 1967) to an open economy. We study this complex model, adding to the perspective some of the main BPCM (Thirlwall model) assumptions. We also add a productivity dynamics à la Kaldor and a technology catching-up simple structure. We observe that when changing the parameters to a more fragile economy, we observe a high increase in volatility. 
Focusing on the peripheral insertion of a developing economy in the international global environment, we expand, in Chapter 3, the North-South Dutt (2002) model. Based on the old structuralist center-periphery framework, we discuss the topic of uneven development between countries in the center of the system (North) and countries in the periphery (South). From the Thirlwall's BPCM ideas, Dutt (2002) endogenizes the long-run behavior of terms of trade. In this way it is possible to discuss the Prebisch-Singer hypothesis (theory of the decline in terms of trade) inside the BPCM framework. In this work we expand the system by creating a Goodwin dynamics in the Dutt model, modelling the labor market (Phillips curve) and applying a technological/productivity gap dynamics. The result is a dynamic system capable of reproducing a balance of payments constrained type of cycle (with neutral stability) in the context of terms of trade increases/decreases and technological catching-up or lagging-behind.

Finally, we present a second empirical paper in Chapter 4. Using data from the Penn World Tables 9.0 (Feenstra, Inklaar, \& Timmer, 2015) we apply a Vector Error Correction model (VECM) on the main BPCM-related macroeconomic variables for the four largest Latin American economies (Argentina, Brazil, Colombia, and Mexico). We apply impulse-response analysis on selected variables, testing the main assumption of the BPCM. This chapter also aims to look how exogenous shocks affect the economic system, observing the adjustment dynamics and the short- to long-run trajectory. This highlights the endogenous pattern of volatility and how the system answers to shocks in their key variables: trade balance, domestic growth and the real exchange rate (terms of trade).

Keywords: Economic Cycles, Latin America, Economic Development, Structuralism 


\section{Acknowledgements}

$\mathrm{A} \mathrm{PhD} \mathrm{consists} \mathrm{of} \mathrm{an} \mathrm{intensive} \mathrm{period} \mathrm{of} \mathrm{self-reflection.} \mathrm{Doing} \mathrm{a} \mathrm{thesis} \mathrm{is} \mathrm{a} \mathrm{huge} \mathrm{challenge} \mathrm{on}$ itself, especially when you are around $10.000 \mathrm{~km}$ distance from your family and loved ones. In order to face such challenges, a huge support is necessary - in academic and personal terms. I would like to be grateful to all the fundamental support I received during this four and a half years living in Maastricht.

Firstly of all, the most fundamental support a $\mathrm{PhD}$ candidate needs to receive is the institutional one. In that regard I was very lucky and grateful to UNU-Merit and Maastricht University for not only sponsoring my studies, but also offering me a really good work environment, a great office, the opportunity to work with an outstanding network of top researchers, and all the psychological support during these years.

I would like to thank my promoter Bart Verspagen for the careful supervision and fundamental guidance. Our long meetings were fundamental to define the directions of the research and to inspire me on keep moving with my decision of continuing the academic research track. I thank my co-supervisor Neil Foster-McGregor for all the support you always gave me, keeping an open door policy. I thank you two for the opportunity of working for UNIDO, for being part of the Structural Change research group, and participating in the Structural Change handbook meetings. I would like to thank also Gabriel Porcile, who has always been my academic guru, always supporting my research and my work, as a boss, a co-author, and a friend.

I would like to thank the reading committee for the careful and relevant comments. I thank Eddy Szirmai for always supporting my $\mathrm{PhD}$ since the very tough first year of $\mathrm{PhD}$ and to Thomas Ziesemer for his patience in teaching me so much about time series analysis. I also thank the external members Maria Savona and Alberto Botta for kindly accepting the invitation to be part of the committee. I would like to thank the other members of my corona as well.

Eddy very recently left us. He was a truly special person. Someone that managed to be at the same time an outstanding scholar and have an unique human touch. Eddy always had his room open for all his students, being the father of our institute, and I remember our long conversations about research, music, culture, politics. He was a great master, being one of my biggest 
inspirations in academia and in life. His depart is the saddest moment experienced here in the institute. Eddy's presence will always be alive to us, his students, and his thought about economic development will definitely survive for generations.

In terms of institutional support, I would like to mention some specific people at UNU-Merit.

First of all I would like to thank Eveline in de Braek. Eveline is the heart and soul of our PhD program, our foster mom. I have to thank you Eveline for all your support, even during the hardest moments of the $\mathrm{PhD}$ you were there with a nice word to comfort. Our regular chat is something I look forward every week. You have the gift to make us feel like we are at home, even being so far away. Thank you for everything,

I would also like to thank the $\mathrm{PhD}$ coordinators Robin and Tatiana for guiding us during this $\mathrm{PhD}$ process. I thank you both for being always fair and understandable in every situation. I am grateful for receiving the opportunity of tutoring introduction to data science, and econometrics, in the Master of Public Policy at UNU-Merit, and for working as academic advisor at UCM.

Thanks to Marc for his patience with all my (many) requests and for all the information and tips regarding the Dutch tax system. Thanks to the "IT guys" Herman and Mourik for always solving every technical problem. Thanks Ad for the support with the library, and for always solving my requests for publications. Thanks to Monique, that always helped me with my supervision meetings. Thanks to Ingrid, for our daily chitchats (that made my morning happier), and for always helping me so kindly with the reception - even when I had to receive ten students a day. I also thank all the other ladies in the reception - Ingeborg and Mieke - and the cleaning ladies, especially Jeanne, that always keep my desk and office clean, and allow me to try a bit of my (still very basic) Dutch. Finally I thank the great people from communication, my fellow countrywoman Sueli, Howard, and my friend Diego.

An important part of my $\mathrm{PhD}$ was done when visiting another institution under the CatChain (Catching up along the Global Value Chains) project - in which I spent almost one year in Brazil working at the University of Campinas. I would like to thank the UNU-Merit coordinator of the project, Micheline Goedhuys, and its project manager Liesbeth Noben, for such important support. I also thank those in Brazil who received me so well, especially Luciana Lenhari and Bruno Fisher. This visit was fundamental for me to finish my thesis. 
I would like to thank ECLAC (Economics Commission for Latin America and the Caribbean), where I previously worked in Santiago, Chile - I still regularly teach in their summer school. I thank the figures of Gabriel Porcile and Mario Cimoli for always leaving the door open to me.

Thanks to Fernando Sarti and to NEIT (Center for Innovation and Industrial Economics) of the University of Campinas, for teaching me the basics of research, and for the support before and during my PhD.

I thank the Young Scholars Initiative (YSI), a network of engaged young researchers I have been very happy to participate as coordinator of the Complexity Economics Working Group (CEWG), and as a member of the advisory board, during my $\mathrm{PhD}$. YSI broadened my academic horizons and allowed me to reach another level of academic perspective - allowing me to contact top institutions in the world and to meet great researchers, stimulating me to pursue the academic career. A special big thank to the YSI manager and my good friend Jay Pocklington, that helped me so much academically, and showed himself a great friend during the toughest periods of my $\mathrm{PhD}$. To Marcos Reis, who introduced me to the YSI events and gave me all the tips. To Cecilia Rikap, who involved me in many interesting activities, and stimulated me to keep moving forward with YSI activities, and finally to the coordinators and organizers of the CEWG (Mary, Vanessa, Cristiano, Lorenzo, Mariana, Gustavo, among others).

I also thank the LALICS (Latin America's Knowledge Systems, Innovation and Capacity Building Research Network) network for bringing me closer to innovation studies. To my hermano José Miguel Natera, who since our times in Santiago has been a major source of academic and personal inspiration, and guidance in my academic career. I thank Gabriela Dutrénit, for carefully guiding us in developing this relevant network. Thanks also to my Uruguayan friend Marcos Segantini, who convinced and companied me to South Korea for the International Schumpeter Society Conference, a moment that had a major impact on my life.

I would like to thank my special paranimfs Beatriz Calzada and Giulia Rossello. We were together part of this $\mathrm{PhD}$ journey since day one and managed to face all difficulties as a group.

At Maastricht and UNU-Merit I met a lot of great people, so many it is hard to mention everyone. First I thank those who were with me during all the hard moments, especially the ones in the first year, my friends of the 2015 cohort. I thank Bea for becoming my sister, confident, 
Mexican accent teacher, for developing our sitcons "la vida de Bi”, "La vida de Ramiro", for the laughs, the debates, for our fights, and for putting some spiciness in the $\mathrm{PhD}$ life. I thank my eternal office mate Giulia, always so kind, who taught me all about Italian politics, Italian cuisine, Tuscany and network analysis. To Joseph, my Korean mate, who took me to an amazing tour to visit his country and culture, and who is a big inspiration for us all. To Bart, my Dutch comrade, law advisor and company for evening football matches (and beer). To Patima, for the times of laugh, cry and complain about Game of Thrones. To Tamara, our dear most organized person, our $\mathrm{PhD}$ representative, and the one who taught me the little Dutch I learned. I thank my good friends Halefom, my first office mate, and Kaleab, you two guys have an immense heart, and I hope to be able to visit you both in Ethiopia. To Emmanuel, the football superstar and author of the Mensah database, my source for African data, and to Victor, who helped a lot in the mock defenses during our first year.

A special thanks to Juanca (Juan Carlos Castillo), my friend since day one in Maastricht. Hermano, you showed me the path to succeed in the institute. I miss our long conversations my friend. It was an honor to be your paranimf and to visit you in Milan.

I thank other important groups that were fundamental for my life here in Maastricht: the Wives Lunch Club - Thank you Paula, who since the beginning of my first year made sure I was not going to freeze in the north of the world, taking me to Aachen for winter clothes (and chocolates!). Our great "tía Eli”, Elisa dear, you are the best, I will never forget when you and Mary helped me during two times: when my house was taken by wild animals while I was abroad, and during the most difficult moment of my life. And also our trip to Trento and the Garda lake! Mary, my sister, fellow coordinator, my friend, I miss a lot our long conversations, Thanksgiving, Christmas, and our daily hard headed debates. Jenny, my eternal office mate, I miss a lot your comments about everything in life. I thank Iulia for our always nice conversations, and for the great company in Boston. To Alison, who introduced me to the life changing "slaap lekker" tea. Also thanks to Shivani, for offering the best coffee in town, and all other male and female wives from the Lunch Club.

Thank you to the Guapachosos group, to Mario, el papo, a person I am happy to call a great friend, who I spent more Christmas time together besides my family. To Flor, the kindest person I possibly met in my life, bringing some chamuchos to the Dutch system; to Michelle, the 
Ravenclaw scholar who brings us the funniest stories, and to Lore, whose presence makes our everyday better and more beautiful.

Thanks to my other friends in Maastricht, to Hugo, my fellow countrymen friend, company to Portuguese football matches, and one of my academic inspiration, to Cho for teaching me how to enjoy life while being at the same time so academically productive, to Sheng, my former office mate, who baptized a sequence of fish in the office, to Ibrahima, our math expert, who taught us so much, and Elvis, my mate in Finnish lands during Globelics Academy; Alejandro, for being an academic inspiration, and for helping me to decide where to do the $\mathrm{PhD}$; Fernando for the help during proposal period, and for the great talks about our region, and to Julien, for the friendship and astrological consultancies. Thanks to many other friends I made these years at UNU-Merit: Maty, Michiko, Davina, Bruhan, Francesca R., Shuan, Solomon, Charlotte K., Racky, Michele D., Uri, Sabrina, Maisha, Hiwot, Inez, Francesca G., Tobias, Hamton, Clotilde, Serdar, Eszter, Mueid, Gintare, Iman, Julieta, Stephan, JuanK, Marijo, Gideon, Wondi, Carmen, Andi, Simone, Michelle M., Dachi, Lika, Praachi, and all the others that made this place such a special one.

Thank you to the Brazilian PhD crew here in Maastricht. Speaking Portuguese with you guys made me feel closer to home. To Eduardo, who helped me a lot when I just arrived to Maastricht. To Flavia and Ale, my friends since Brazilian times, now moms to a beautiful child. Thanks to Caio, for the great conversations, and for being such a great friend here in Maastricht.

A special thanks to Fernanda, my lovely partner, who I met in the middle of this long journey, in South Korea. Fer, you are a source of great support, inspiration, and company.

During your PhD you need something that always makes you feel better, or just laugh in any situation. I thank the YSI Myths (Guilherme, Julia, Marcos, Miriam, Rafael, Renan), the Inimigas vida longa (Granada, Harry, Jotaro, Yoki), and the Almoço do Zé (Dani, Kapi, Zizi, and Zé) whatsapp groups for always playing this role, making my $\mathrm{PhD}$ life much less stressful for sure.

Finally, and most important, I thank my family, the central pillar of my life. My mother Liliane, who always protected, loved, supported, and disciplined us, and my father Pedro, for always taking care we have everything we need. You always supported me in all my decisions, even not 
understanding the academic career, which consists of a choice that takes so much time to bring financial reward. Still, you were always there to help me. I thank my sister Caroline and my brother Thiago. Thank to my aunt, Marcia and uncle, João; and my cousin, Vivian. And all the large family from my father's part - too big to name it all - including my family in Australia, my grandmother Celeste and my grandfather Manuel, he who left us some years ago.

I dedicate this thesis in the memory of my grandfather Tulio Sartorello and my grandmother Marlene Sartorello. Both left this world during the writing period of my thesis, in 2018. They have always been the strongest supporters of my studies. Without them to guide me, to push me forward with their love, I would have never been able to advance so far.

Being the first in the history of a humble family, which two or three generations before was illiterate; to have a $\mathrm{PhD}$ is something that posed quite a challenge and responsibility. It was necessary to explore everything in academia from zero... And I would have never been able to do so without my family's emotional support. You will always live in my heart.

Maastricht, The Netherlands January, 2020 
Poverty is not written in the stars; under development is not one of God's mysterious designs.

Eduardo Galeano, "Open veins of Latin America"

Dedicated to the memory of Tulio Sartorello, Marlene Sartorello, and Adam Szirmai 


\section{List of Figures}

Figure 1.1. Volatility, cycles and residual in selected LAC countries....................................... 27

Figure 1.2. Share of each cycle variance from total variance (average per cluster group).......... 28

Figure 1.3. Map of volatility patterns in Latin America by cluster group................................... 33

Figure 1.4. Map of volatility patterns by cluster group, World Level. Groups 1 to 9 ................. 35

Figure 2.1. Reproduction of the La Marca (2010) original results. .............................................. 57

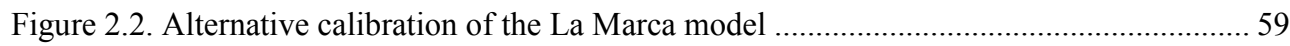

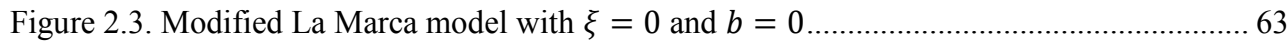

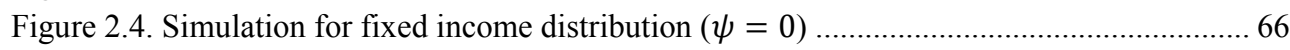

Figure 2.5. Simulation 1 - Modified La Marca results with productivity dynamics, original

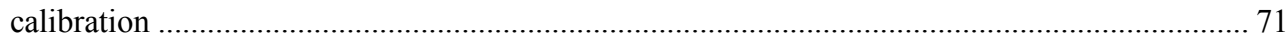

Figure 2.6. Simulation 2 - Modified La Marca results with productivity dynamics, Hopf

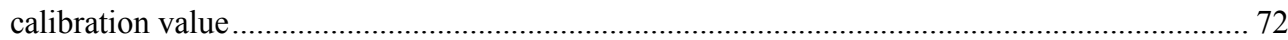

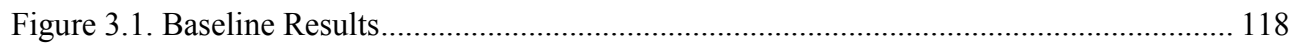

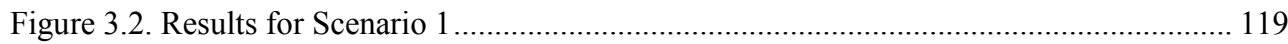

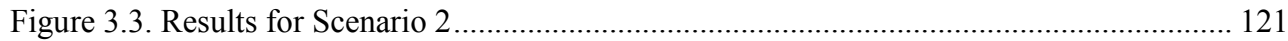

Figure 4.1. Current account as \% of GDP. Selected Countries (1979-2017) ............................ 139



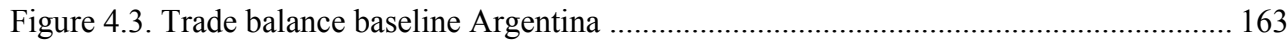

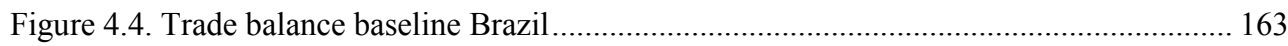

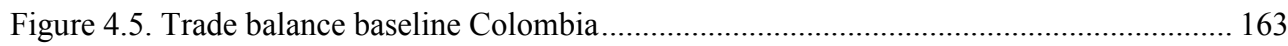

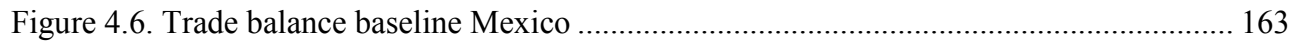

Figure 4.7. Impulse-response: effects of depreciation on the trade balance (spec 1) ................. 165

Figure 4.8. Impulse-response: effects of depreciation on trade balance $(\operatorname{spec} 2)$...................... 165

Figure 4.9. Impulse response: effects of a rise in exports on the trade balance (specification 1)

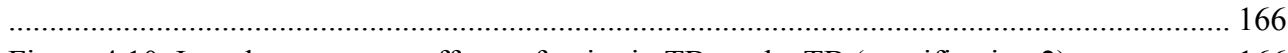

Figure 4.10. Impulse response: effects of a rise in TB on the TB (specification 2) ................... 166

Figure 4.11. Impulse-Response: rise in GDP effects on the trade balance (specification 1)...... 167

Figure 4.12. Impulse-Response: rise in GDP effects on the trade balance (specification 2)...... 167

Figure 4.13. Impulse-response: Investment effects on the trade balance (Specification 1) ....... 168

Figure 4.14. Impulse-Response: rise in foreign growth impacts on trade balance (spec. 1) ...... 168

Figure 4.15. Impulse-Response: rise in foreign growth impacts on trade balance (spec. 1) ...... 168



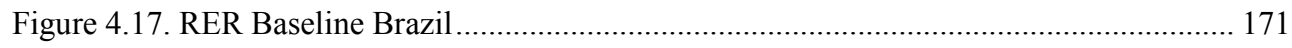

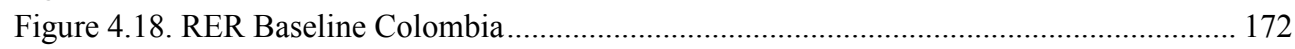

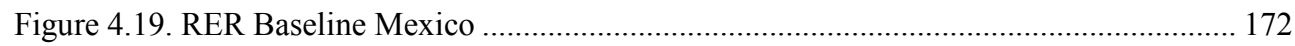

Figure 4.20. Impulse response: effects of a depreciation on the RER (Specification 1) ............ 173

Figure 4.21. Impulse-response: effects of a depreciation on RER (Specification 2)................ 173

Figure 4.22. Impulse-response: rise in exports effects on the RER (specification 1)................ 173 
Figure 4.23. Impulse-response: rise in trade balance effects on the RER (specification 2) ....... 173

Figure 4.24. Impulse-response: rise of GDP effects on the RER (Specification 1).................... 174

Figure 4.25. Impulse-response: rise of GDP effects on the RER (Specification 2).................... 174

Figure 4.26. Impulse-Response: rise of investment effects on the RER (specification 1) ......... 175

Figure 4.27. Impulse-response: rise of foreign income in RER (spec. 1)................................... 175

Figure 4.28. Impulse-response: rise of foreign income in RER (spec. 2)................................ 175

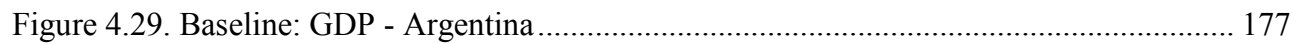

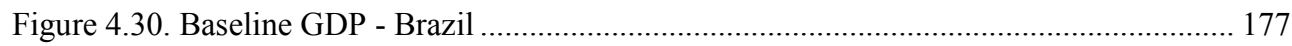

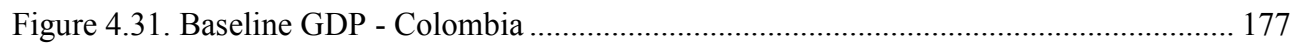

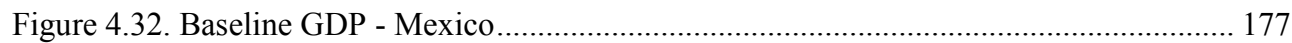

Figure 4.33. Impulse-response: effects of depreciation on domestic income (specification 1).. 178

Figure 4.34. Impulse-response: effects of depreciation on domestic income (specification 2).. 178

Figure 4.35. Impulse-response: effects of exports on domestic income (specification 1)......... 179

Figure 4.36. Impulse-response: effects of trade balance on domestic income (specification 2) 179

Figure 4.37. Impulse-response: effects of GDP on domestic Income (specification 1) ............. 179

Figure 4.38. Impulse-response: effect of GDP on domestic income (specification 2) .............. 179

Figure 4.39. Impulse-response: effects of investment on domestic income (specification 1) .... 180

Figure 4.40. Impulse-Response: rise foreign growth impacts on domestic income (spec. 1) .... 180

Figure 4.41. Impulse-Response: rise foreign growth impacts on domestic income (spec. 2) .... 180

Figure 4.42. Effects of Permanent Foreign Growth shocks on Domestic Growth. 1950-2014

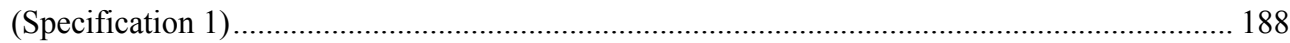

Figure 4.43. Effects of Permanent Foreign Growth shocks on Domestic Growth. 1950-2014

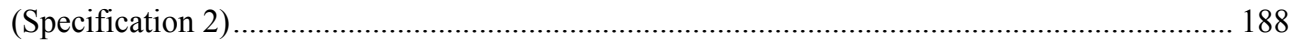




\section{List of Tables}

Table 1.1. Cycles in economic theory and their respective time periods ................................... 24

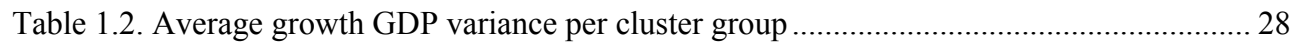

Table 1.3. Summary of the relative characteristics per cluster group .............................................. 30

Table 1.4. Cluster Analysis applied on the Standard Deviation of the Juglar, Kuznets and

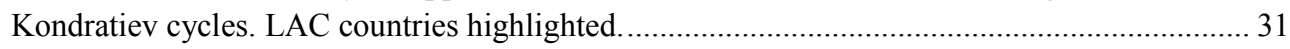

Table 1.5. Latin American countries by cycle dominance......................................................... 32

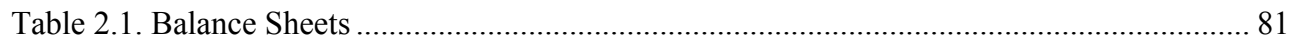

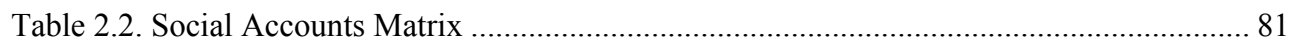

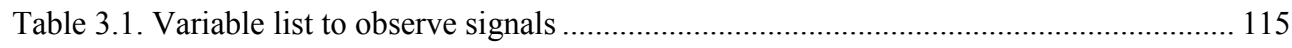

Table 3.2. Capital-output estimation average for the period 2000-2014. Selected countries..... 115

Table 3.3. Number of persons engaged (in dozens) divided by the output-sided real GDP at

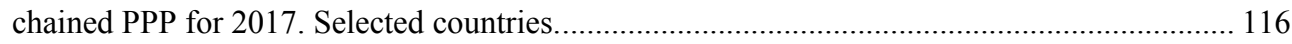

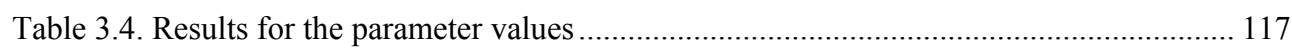

Table 3.5. Baseline Model: Parameter Values and initial values ............................................... 118

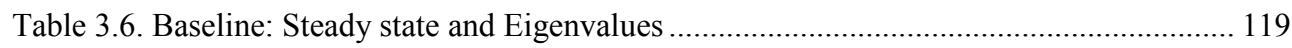

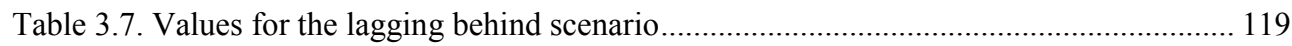

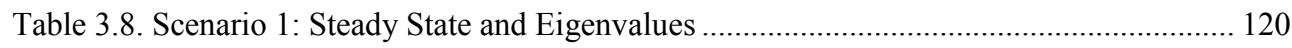

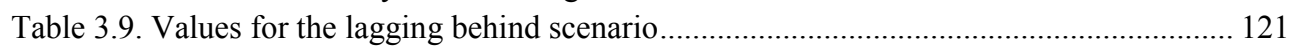

Table 3.10. Scenario 2: Steady State and Eigenvalues ......................................................... 121

Table 4.1. Years in current account surplus or deficit. Selected countries. 1979-2017.............. 139

Table 4.2. Literature review on the main critiques to the BPCM ............................................... 145

Table 4.3. Estimations of the Thirlwall Law for Latin America .................................................. 148

Table 4.4. Latin America: Actual versus predicted growth rates (1977-2002) .......................... 151

Table 4.5. VAR estimations in López \& Cruz (2000), normalized cointegration vector for Latin

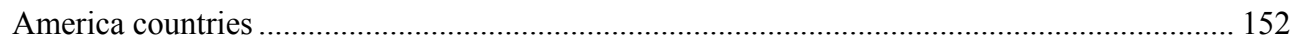

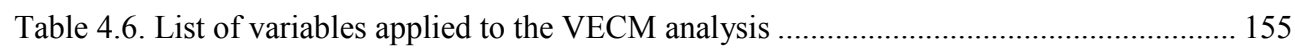

Table 4.7. VECM specification models, endogenous and exogenous variables ........................ 158

Table 4.8. Models attributes: Lag Numbers, Number of Cointegration Equations, Type of VEC

159

Table 4.9. Scenarios shocks applied on the baseline of the VECM. ......................................... 159

Table 4.10. Impulse Response Analysis - Effects on Trade Balance.......................................... 164

Table 4.11 - Permanent Effects on Trade Balance........................................................................ 170

Table 4.12. Impulse Response Analysis - Effects on the Real Exchange Rate.......................... 172

Table 4.13. Permanent effects on the Real Exchange Rate ................................................... 176

Table 4.14. Impulse Response Analysis - Effects on Domestic Income..................................... 178

Table 4.15. Permanent Effects in Domestic Income.............................................................. 182 


\section{Table of contents}

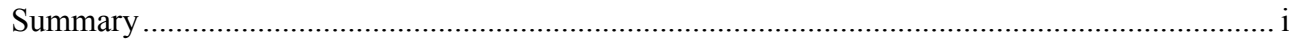

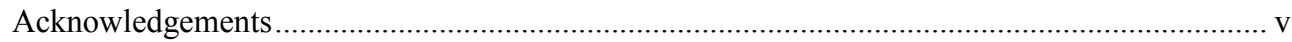

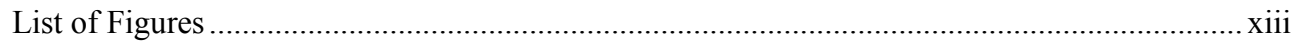

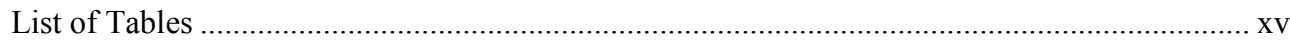

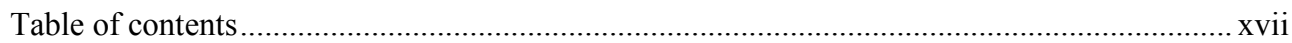

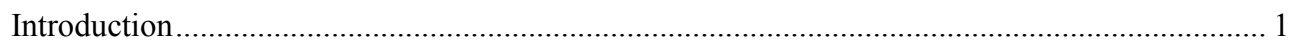

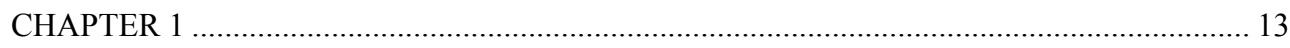

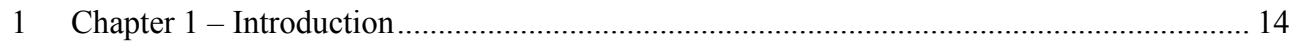

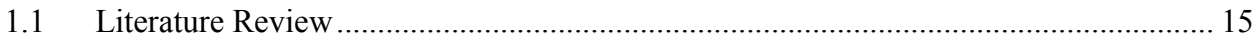

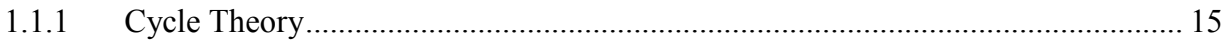

1.1.2 Structuralism and volatility - Why are developing countries so volatile? What is the insertion of Latin America? ......................................................................................... 17

1.1.3 Methodologies used for cycle analysis and empirical evidence for economic cycles 20

1.2 Data

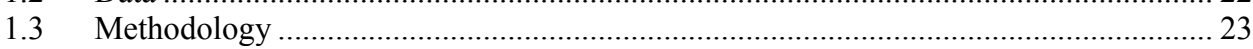

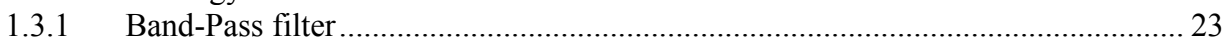

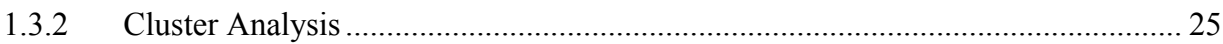

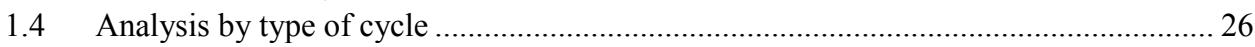

1.5 Results of the cluster analysis applied on Cycles........................................................ 28

1.5.1 Kondratiev-dominance: the importance of the long-run cycles.............................. 35

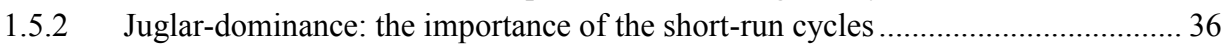

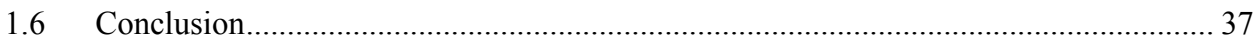

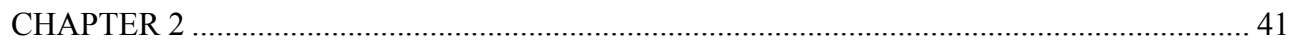

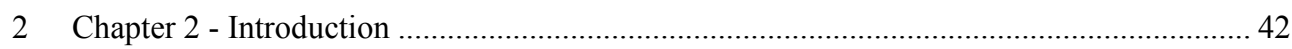

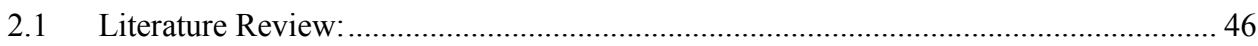

2.1.1 Demand side cycles: Richard Goodwin and the Lotka Volterra Cycles.................. 46

2.1.2 Supply-side cycles: productivity, Schumpeterian cycles, structural change and

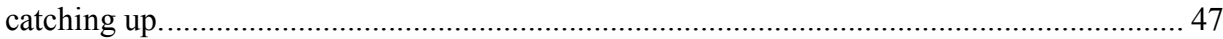

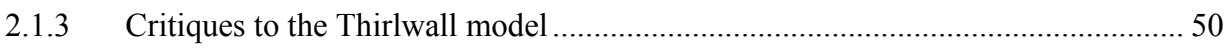

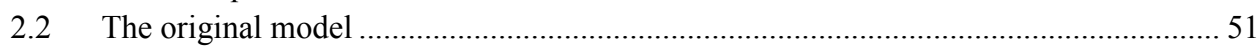

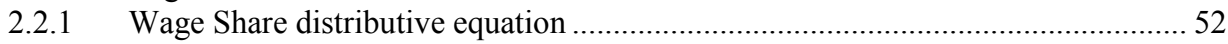

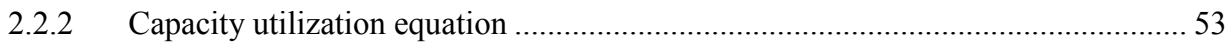

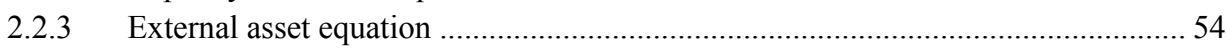

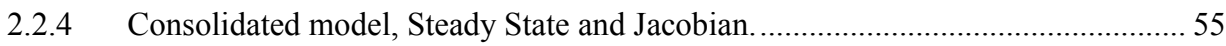

2.2.5 Calibrations of the La Marca (2010) model.......................................................... 57 
2.3 Model Analysis

2.3.1 Changing the clusure of the model: BPCM Assumptions - price neutrality and fixed

RER 61

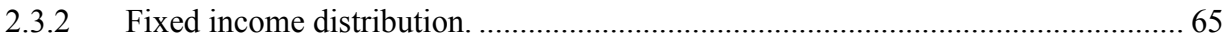

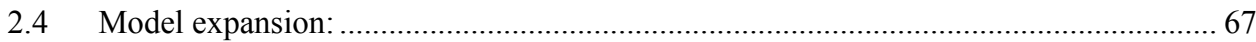

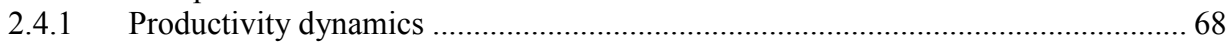

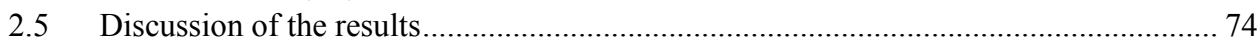

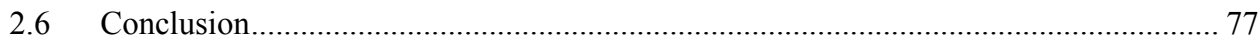

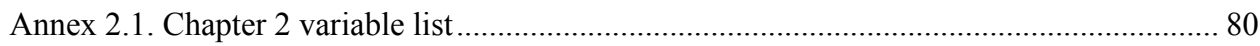

Annex 2.2. Mathematical appendix (Chapter 2) .................................................................... 81

Annex 2.3. Labor Discipline Theory - From Bowles \& Boyer $(1988,1989)$............................ 84

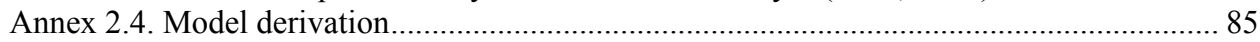

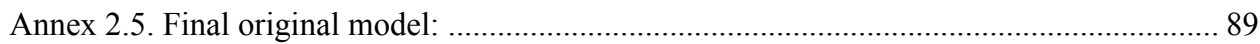

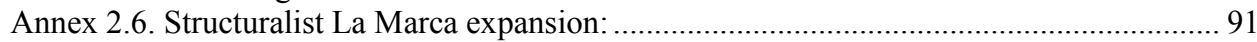

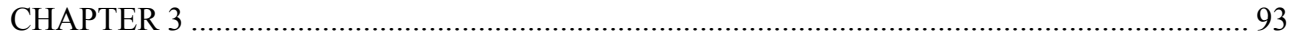

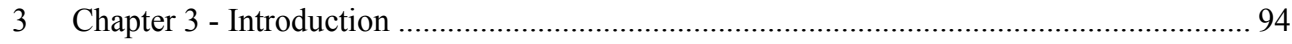

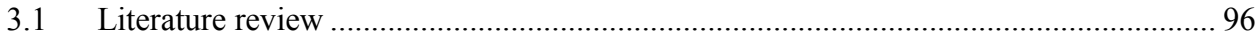

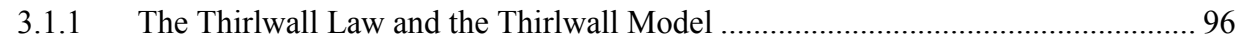

3.1.2 Uneven Development and the Transitional Dynamics ........................................... 98

3.1.3 Assumptions and Empirical validity of the Thirlwall Law.................................... 99

3.1.4 The role of price effects and the incompatibility between Prebisch and Thirlwall 100

3.1.5 Cycles: Labor market and the Goodwin dynamics ............................................. 100



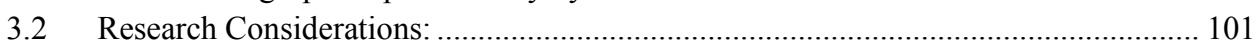

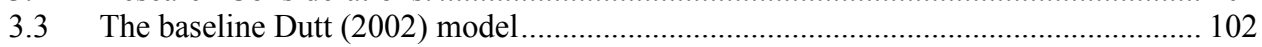

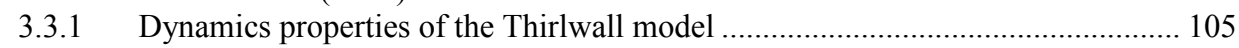

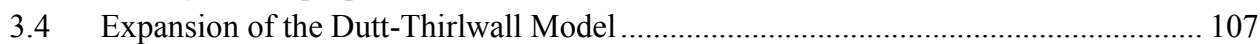

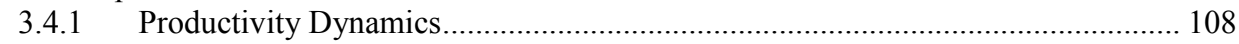

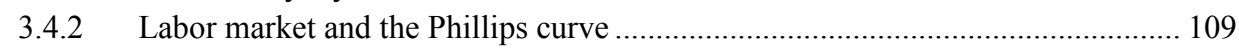

3.4.3 Employment rate, population growth and the Lewis dynamics............................. 110

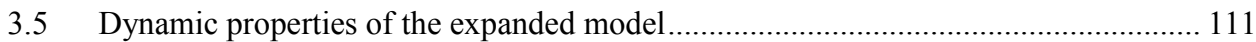

3.5.1 Values for the Lagrangean in the Steady State (Stability conditions) ................... 112

3.6 Defining values for each of the parameters for a Latin American and a developed



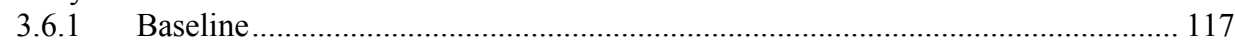

3.6.2 Scenario 1: Declining terms of trade and lagging behind .................................... 119

3.6.3 Scenario 2: Increases in the Terms of Trade and Catching-Up. .......................... 120

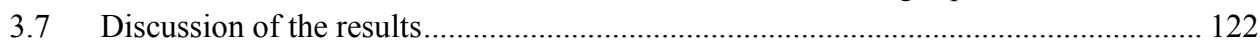

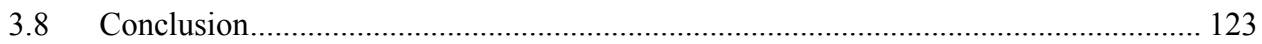

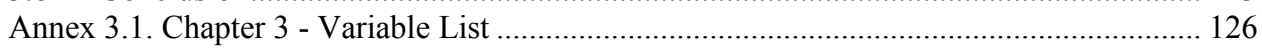

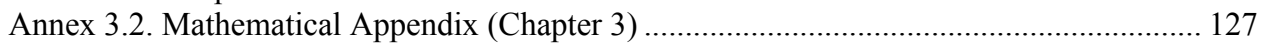

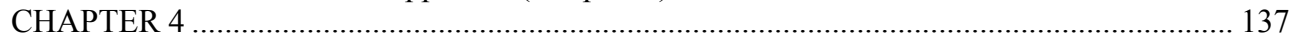




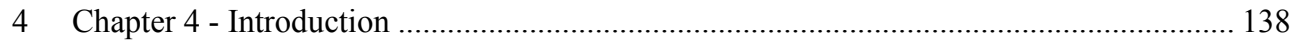

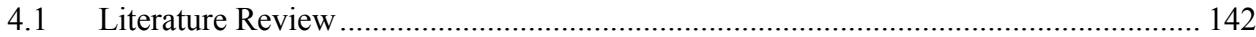

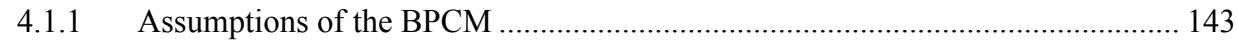

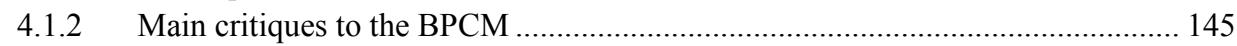

4.1.3 Empirical works, cointegration and Error Correction Models.............................. 149

4.1.4 Estimations of the BPCM for Latin American countries..................................... 150

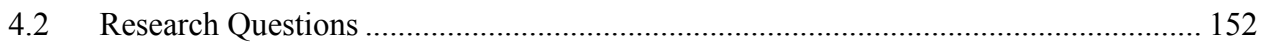

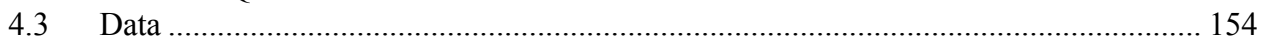

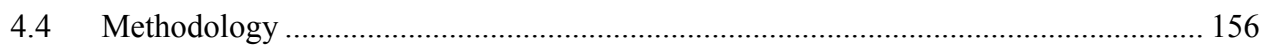

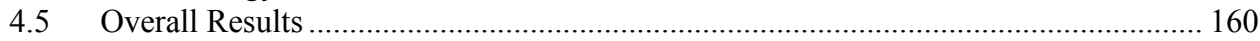

4.5.1 Baselines, Impulse-Response Analysis and Permanent Shocks ........................... 161

4.5.2 Trade Balance: baseline and scenarios ............................................................. 163

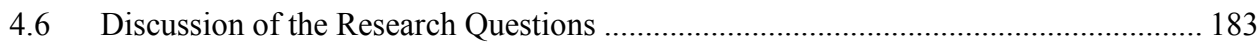

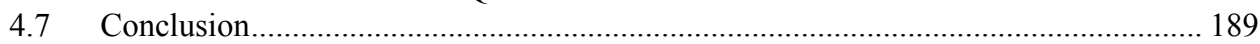

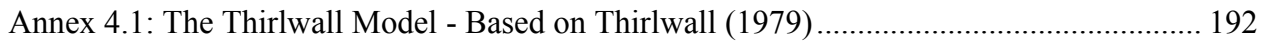

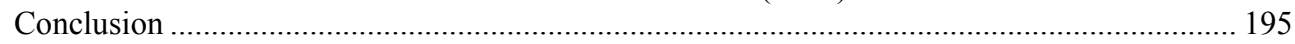

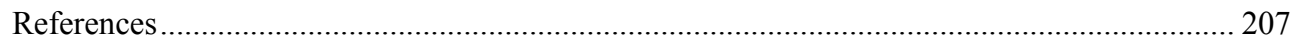

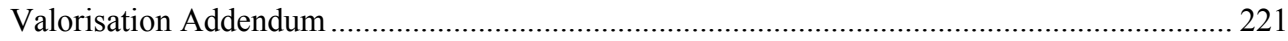

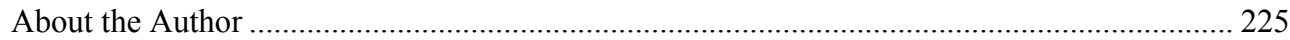





\section{Introduction}

This introduction offers a guide to read this $\mathrm{PhD}$ thesis.

Latin America is a particular region in which economic instability has always been a characteristic of its development process. Periods of short-term booms and harsh crises alternate repeatedly, creating a permanently unstable environment that is one of the central causes of the lack of long-run development perspective in the region (Hausmann \& Gavin, 2011). The mainstream discussion of the real business cycle theory (Hodrick \& Prescott, 1997) relates the causes of the volatile behavior to the presence of exogenous shocks, focusing on how changes in commodity prices, political shocks, and individual decision mistakes affect the growth process. However, the repetition of this oscillatory pattern in the development process let us raise the following questions: Is this constant behavior caused only by external shocks? Or, as claimed initially in the classical work of Schumpeter (1939), is there also an endogenous element, that is structural and intrinsic to these economies, from which this volatile pattern emerges? In this thesis we follow an empirical (chapters 1 and 4) and a theoretical (chapters 2 and 3) approach to identify, question, debate and explain some underlying mechanisms behind the cyclical endogenous dynamics of economic systems, with a special focus in Latin America.

As described by Hausmann \& Gavin (2011), in the case of exogenous shocks, the diagnostic should focus on how to reduce exposure and increase resilience (absorbing exogenous disturbances). As those authors argue, there is no consensus yet about the underlying causes of macroeconomic volatility. This is a very important knowledge gap that motivates this thesis, and this lack of consensus results in many widely disparate views. These views come both from the mainstream perspective, which argues that erratic policy is the only significant source of macroeconomic volatility, to those with a more heterodox approach attributing this volatility to external shocks affecting vulnerable economies (no role for domestic policies).

Endogenous volatility - repetitive oscillations directly related to cycles - has its roots in a number of characteristics that are part of the "DNA" of economic systems. These characteristics are related to the institutional (Acemoglu \& Robinson, 2012) and structural (Bertola \& Ocampo, 
2012) conditions of the economies, to their historical development, political structure, geographical conditions, among others. Those elements define patterns of fragility, and how the internal boom-bust dynamics operates. Exogenously, a weak fragile economy has a low resilience to external shocks. As an example, a commodity shock such as a huge decrease in oil prices, generates a strong recessive effect in countries in which economic structure is mainly focused and specialized in natural resources, especially oil extraction. The effect is however much smaller in a diversified industrial economy. Endogenously, fragile economies generate oscillatory cyclical patterns related to their own economic behavior, caused by balance of payments constraints (Thirlwall, 1979), financial instability (Minsky, 2016), growth and distribution dynamics (Goodwin, 1967), technological innovation-diffusion (Perez, 2010) among other possible explanations.

The analysis of the cyclical behavior lets us understand the structural elements about economic volatility. Structural in the sense that the oscillations emerge from the own characteristics of these economies, from their specific conditions and their insertion into the international environment (Ocampo, Rada, \& Taylor, 2009). This recurrent oscillatory behavior is stable, and many authors set it as one of the main constraints to the process of long-run economic development in the region (Ocampo, 2017). The growth pattern in Latin America is known for producing short periods of growth followed by constraints that result in adjustments that lead the economy to interrupt its economic development process (Bertola \& Ocampo, 2012). As highlighted by Hausmann \& Gavin (2011), while the average depth of crisis in industrial countries is on average $-2 \%$, for Latin America it reaches $-8 \%$, which results in deeper average crisis even when compared to Asia (-3.5\%) and Africa (-6\%).

From the need to discuss these stylized facts for Latin America we start the chapter 1 of this thesis. The economic literature discusses many types of economic cycles. They are classified in terms of their amplitudes, underlying causes, and time frames. Economists claimed the discovery of cyclical patterns for economic prices and growth since the economics discipline became a field of study (Korotayev \& Tsirel, 2010). Clement Juglar discovered the existence of short-run cycles (from months to a few years) related to inventory rotation. Short-run cycles were also observed, and arguably caused by the maturity of investments (Kaldor, 1954). Cyclical behavior in the medium term was discovered by Kuznets, who related cycles to the behavior of 
infrastructural investments - these cycles were discussed by Abramovitz (1961, 1969), who empirically analyzed the recurrence of growth-crises periods for a broad range of countries at similar intervals. In terms of long-run cycles, Kondratiev claimed the existence of long periods of volatility in the world economy. These long cycles are still the subject of debates in terms of their identification and causes (Korotayev et al, 2010), being the main arguments related to technology shocks and changes in technical paradigm (Perez, 2010). Schumpeter (1939) described how technological aspects are related to the cyclical behavior of an economy, proposing a typology according to time periodicity. An updated version of Schumpeter's typology (Jadevicius \& Huston, 2014) leads us to identify four types of cycles: the Kitchin cycle ( 3 to 5 years); the Juglar cycle ( 8 to 11 years); the Kuznets cycle (15 to 25 years) and the Kondratiev wave (45 to 60 years).

Concerning the distinct types of cycle just mentioned, in Chapter 1 we raise the question about the specificity of Latin American cycles. To answer that, we apply empirical time-series methodologies to real GDP data (Christiano \& Fitzgerald, 2003) to extract these cycles using filter analysis. We identify the types of cycles for each country/region by the length of the cycles, grouping them using cluster analysis. The questions about the causes behind this volatility, nonetheless, stay unanswered.

Many structuralist authors have tried to explain the causes of high economic oscillation in Latin America. They claimed that the structural causes of volatility in Latin America are related to its peripheral position in the international division of labor (Ffrench-Davis, 2005; Ocampo et al., 2009; Prebisch, 1950). This is caused by external fragilities related to these countries' specialized and low-technology intensive productive structure (Cimoli \& Porcile, 2014; Botta, 2010). The fragilities result in a lower resilience to external shocks, a main source of volatility. In this sense, authors from the Structuralist theory argue that the historical development of Latin American economies gave them an idiosyncratic aspect that makes these countries more fragile (Furtado, 1965). However, the explanation is still centered in the presence of exogenous shocks.

In order to create an interpretation to explain the endogenous mechanism that generate cycles in a structuralist way, in chapters 2 and 3 we bring some classic economic traditions that have proposed to explain the underlying causes behind these cycles. The literature review discusses authors that modelled economic cycles as dynamic systems in the growth theory tradition. The 
interpretation presented in this thesis is based on three main theoretical pillars: endogenous volatility represented by the Goodwin Cycles, external constraints represented by the Balance of Payments Constrained Model (Thirlwall model) and a decline in terms of trade that traps lowand middle-income countries represented by the Prebisch-Singer hypothesis. The main theoretical relations are presented in the figure below:

Figure A. Thesis' theoretical framework

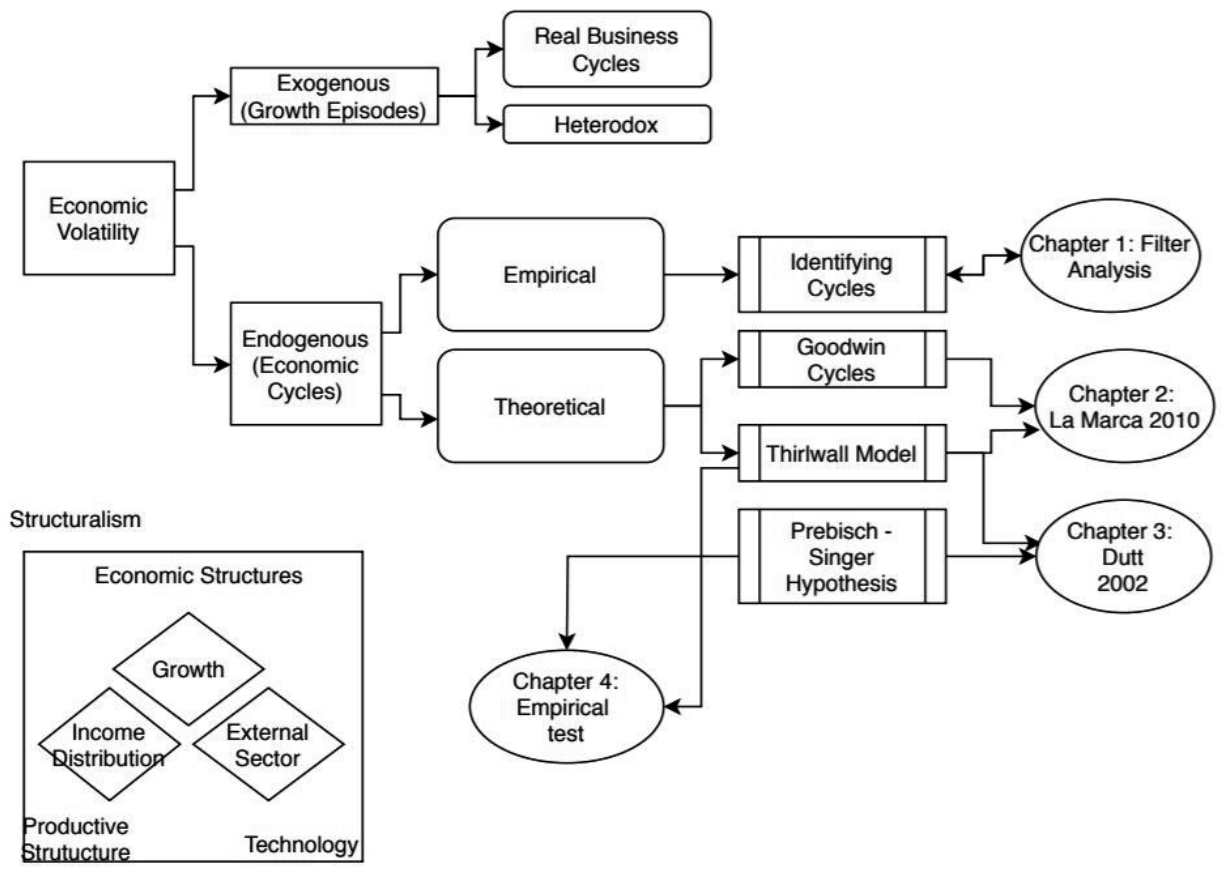

Source: Own elaboration

A pioneer work in growth theory that deals with endogenous oscillations is the Goodwin model (Goodwin, 1967) and its subsequent cycle theory tradition. Goodwin developed a model in which growth and distribution interact dynamically in a predator-prey pattern. Applying the biological Lotka-Volterra model to economics, he discovered the presence of stable cycles in the debate between functional income distribution and economic growth. This model opened the 
road to a whole tradition of models, such as its structuralist version (Barbosa-Filho \& Taylor, 2006) that takes into account elements from the productive structure.

The Structuralist tradition, accounting for the role of structural elements underlying the economic system, has made efforts to expand the Goodwin model (Barbosa-Filho \& Taylor, 2006). We then enter in the discussion of Chapter 2. The Structuralist tradition developed itself from Raul Prebisch, Celso Furtado and the whole Latin America tradition of thinkers that put in the center of the analysis the structural condition in a center-periphery framework. Since the 1980's, Lance Taylor has formalized many of the concepts in the Structuralist theory (Taylor, 1983). In an attempt to expand the Goodwin model adding structuralist features, Barbosa-Filho \& Taylor (2006) developed a dynamic system relationship between wage share and capacity utilization in a demand-driven economy. This model is based on the classical works of Kalecki (1971) and Steindl (1952) and puts the distributive conflict in the center of the analysis.

In order to further understand the causes of structural volatility, another relevant tradition is the Balance of Payments Constrained Model (BPCM). This framework, also known as the Thirlwall model (Thirlwall, 1979), offers an explanation to the endogenous repetitive patterns of oscillation. The model highlights that growth has its constraints caused in large part by its external conditions, especially in developing countries. The BPCM sustains that countries cannot grow in the long run at a higher rate than the growth rate compatible with the stability of its balance of payments (BP). If the actual growth rate has, in the long run, a higher rate than the BP compatible one, it results in imbalances in the current account, leading the economy to an external crisis. The BPCM consists in a demand-led theory that explains growth in a postKeynesian perspective for the long-run (Blecker, 2016).

More recently, La Marca (2010) develops a model that merges the Structuralist Goodwin system with the Foley \& Taylor (2004) model. The latter suggests that heterodox models should make use of social accounting matrices in order to derive its causal relations, being stock-flow consistent. Foley \& Taylor (2004) also works for an open economy, adding financial elements (equities) to the model. La Marca (2010) used the framework developed by Foley \& Taylor (2004) to developed an open economy version of the Goodwin model. Economic growth and fluctuations in output, capacity utilization, distribution and real exchange rate interact in an open 
economy generating damped cycles. La Marca (2010) extends the Structuralist Goodwin to an open economy, which results in a more complex structure of the Goodwin model, expanding it to a three dimensional system. The La Marca model is thoroughly studied in Chapter 2.

Entering Chapter 3 of the thesis, the third element in our discussion - beside volatility (Goodwin cycles) and the BPCM - concerns the old structuralist argument of the decline in terms of trade, also known as the Prebisch-Singer Hypothesis (PSH), empirically discussed by Ziesemer (2010). This theory defends the existence of a long-run tendency to a reduction in prices, in which countries in the periphery (South) are specialized in exporting products with smaller income elasticity of demand, which makes the price of their products grow at a relatively smaller rate than the one produced in developed countries. This condition generates a situation that traps economies in underdevelopment. This theory's main argument is related to the fragility of an economic structure, marked by the specialization in low-technology intensive sectors and commodities. In this sense, we relate (i) productive structure issues, (ii) external constraints, (iii) economic volatility (growth $\mathrm{x}$ distribution) and (iv) peripheral underdevelopment as a development trap - the four main structural aspects in the theoretical framework of this thesis. The relevance of the PSH is a matter of important academic debates, being challenged by authors such as Williamson (2011), who defends that the recent commodity boom is an example that the PSH is not the main development problem, but export price volatility. Our position in this thesis is in line with both ideas. We defend the PSH - decline in Terms of Trade - as a long-run endogenous phenomena, based on Bertola \& Ocampo (2012)'s perspective; and the relevance of export price volatility as an exogenous mechanism that creates oscillations and instability.

We also acknowledge the relevance of the debates around Dutch Disease posed by Williamson (2011), and how a large appreciation of the exchange rate generates incentives to invest in low technological intensive sectors.

In the New-Structuralist tradition (Cimoli \& Porcile, 2014), the theories by Raul Prebisch and Anthony Thirlwall are usually seen as complementary. However, there is a very important element usually neglected in the discussion, which is the central point of Chapter 3 . There is a big contradiction between the two main ideas of these authors: the long-run decline in terms of trade (Prebisch), and price-neutrality present in the BPCM (Thirlwall). When accepting both that 
Prebisch-Singer and that the Marshall-Lerner condition holds (price elasticity of imports is higher than 1), price effects are not neutral in the long-run, but declining in developing countries. This perspective contradicts the main assumption that leads to the Thirlwall Law, about price neutrality, in which prices to not affect long-run economic growth. Both theories are them proposing different statements to understand the development process.

With the validity of the Prebisch-Singer hypothesis ${ }^{1}$, adjustments to the equilibrium in the BPCM may not occur only in quantities, but also in prices (terms of trade), changing our perspective about the long-run economic growth rate. In this sense, price effects impact on longrun economic growth, which opens space to criticize and rethink elements of the Thirlwall Law. The seminal Dutt (2002) model offers a starting point to deal with this issue. The author criticizes the Thirlwall Law offering a theoretical proposal inside the BPCM framework to challenge the idea that prices are neutral in the long-run. This model allows us to approach the Prebisch-Singer hypothesis, in which prices decline in the long-run, while observing transition dynamics and uneven development.

Finally, in chapter 4 we come back to the theoretical debate about the role of price effects in economic growth and apply it to our region of interest, Latin America. An empirical analysis on how different changes in the economic variables impact in the economic system allow us to better understand the adjustment mechanisms and economic dynamics in Latin America. In order to observe this impact, we apply a Vector Error Correction Model (VECM) analysis to the BPCM-related macroeconomic variables for the four biggest Latin American countries, checking some model assumptions and some adjustment dynamics to the long-run (permanent shocks and some impulse-response analysis). We empirically test the BPCM assumption of price-neutrality, check if foreign income has positive effects on domestic income, and if (and how) other macroeconomic variables affect growth, real exchange rate, and the trade balance of the selected countries (Argentina, Brazil, Colombia, and Mexico).

\footnotetext{
${ }^{1}$ The relevance of the PSH is a matter of important academic debates, being challenged by authors such as Williamson (2011), who defends that the recent commodity boom is an example that the PSH is not the main development problem, but export price volatility. We defend the validity of the PSH, based on Bertola \& Ocampo (2012) that the PSH is a long-run endogenous phenomena with a relevant theoretical explanation, despite being recently empirically challenged (Szirmai, 2015).
} 


\section{Motivation and General Research Questions}

Despite the strong focus on quantitative methods and on the theoretical content, this thesis is centrally focused on discussing economic development, its challenges and possibilities, with a special focus on developing countries.

The thesis is led by the curiosity to further understand the main challenges and difficulties faced by some specific regions of the world in increasing social wealth, achieving inclusiveness and finding social empowerment. Most works in innovation studies are focused on the frontier of technological progress, looking at new inventions, and ways to improve life quality. However, in social terms, most of the world's population is still trapped in poverty, low- and middle-income situations, in which we observe the widespread existence of precarious work, difficult health conditions, and low educational levels. This massive number of poor people has a limited access to the benefits offered by the frontier of technological change. The urgent need to tackle development issues, thinking on ways to integrate this marginalized population in the economic system, is the motivation in this thesis.

A small number of rich countries managed since the aftermath of II world war to reach a virtuous development strategy (Marglin \& Schor, 1992), managing to distribute income and create a strong medium class, creating a virtuous and inclusive development process, overcoming the barriers raised by development traps. Most part of the world, however, struggle with basic development problems, such as the lack of sanitary conditions, low education, and inequality. In this thesis we look at one specific aspect of the middle-income development trap (Felipe, Abdon, \& Kumar, 2012; Lavopa \& Szirmai, 2014), economic volatility, and raise questions about the constraints that make development uneven and divergent.

Volatility is indeed a cause of development trap. As highlighted by Gavin \& Hausmann (1998, p.98): "Recent research suggests that a volatile macroeconomic environment leads to significantly lower rates of investment and economic growth, undermines educational attainment, harms the distribution of income, and increases poverty."

\section{Main objectives}


In this research we focus on economic volatility, which is one specific aspect that, when controlled, leads a small number of countries to achieve a virtuous development strategy. Developing regions, such as Latin America, still struggle on this regard. In this sense, we search to explain what are the main challenges and barriers for developing countries to overcome its development traps in the context of macroeconomic oscillations.

We focus on measuring the current pattern of economic volatility in Latin America, trying to explain its main causes. Is Latin America a special case in terms of economic volatility? And what is special about their cycles? Are there structural elements behind cycles? Which ones?

A central theoretical objective of this thesis is to advance the New-Structuralist theory (Cimoli \& Porcile, 2014; Cimoli, Porcile, \& Rovira, 2010; Botta, 2010; Ocampo et al., 2009), linking volatility to fragility (structural aspects), relating the external constraints of the economy to an endogenous cyclical behavior. In this sense, we put the Balance of Payments Constrained Model (BPCM) in the center of the discussion. By doing so, we also question the main assumptions behind the BPCM, which affect the way we propose new ideas to face the barriers to achieve a virtuous pattern of economic development.

\section{Methodologies}

This thesis is divided into four independent articles. Despite their independence, the topics are interrelated as different parts of a puzzle searching to answer the main research questions of this thesis: what are the conditions and causes of structural volatility in Latin America?

The methodological part consists in two different approaches: one empirical, and another theoretical. The empirical approach starts from the real data and shows some important stylized facts related to growth and GDP volatility in Latin America. In chapter 1, we bring GDP growth data from the Maddison Project Database and apply an asymmetric band-pass filter to extract cycles for 136 different countries. After extracting 4 different types of cycles and the residual, we classify countries in groups doing a cluster analysis. In this sense, we can observe the main cyclical characteristics of Latin American countries, in which we can mainly divide into two different main groups. 
In Chapter 4, the second empirical paper, we use data from the Penn World Tables (Feenstra et al., 2015) and apply a Vector Error Correction (VEC) model on the main BPCM-related macroeconomic variables for the 4 Largest Latin American Economies (Argentina, Brazil, Colombia, and Mexico). From the developed model, we apply impulse-response analysis on some selected variables, testing the main assumption of the BPCM, observing how changes in some selected variable affect all the others in the system.

On the theoretical part of the thesis we search for explanations on the causes of the cycles. In this part we have two theoretical model expansions that help us understand these cyclical causes. On chapter 2 we expand the La Marca (2010) model. This model consists in a dynamic system capable of reproducing dampened cycles in the relationship between growth and distribution (Goodwin, 1967) in an open economy. We study this complex model, adding the BPCM assumptions, and inserting a productivity dynamics and a technology catching-up element.

Finally, in Chapter 3, we expand the Dutt (2002) model. Based on the old structuralist centerperiphery framework, we discuss the topic of uneven development between countries in the center of the system (North) and countries in the periphery (South). From the Thirlwall model (BPCM) the author endogenizes the long-run behavior of terms of trade, bringing us the tools to discuss the presence of the Prebisch-Singer hypothesis in the BPCM. We expand the system by creating a Goodwin dynamics inside the Dutt model, modelling the labor market (Phillips curve) and applying a technological/productivity gap dynamics. The result is a dynamic system that is capable of reproducing cycles in the context of increases/decreases in the terms of trade. This chapter let us relate the Prebisch-Singer hypothesis to the BPCM.

Despite the similarities in Chapters 2 and 3, the expanded La Marca and the expanded Dutt model ask and answer to different research questions. The La Marca model let us understand the cyclical dynamics in the context of the Thirlwall Law (long-run), in an open economy that is capable of accumulating foreign assets/liabilities in the short-run. The model also focuses on the role of intermediate inputs. The Dutt Model, on the other hand, considers the short-run and the fundamental role of the terms of trade in the relationship between a developed industrialized North and a developing South, focusing on discussing the dynamics of the terms of trade, allowing us to add the technological catching-up discussion. 
This thesis raises different questions in each of its four chapters. The central element is present in all articles: understand what is behind the development traps that create structural barriers to the economic development of Latin America in the relationship between cyclical volatility, external constraints and economic structures. 


\title{
CHAPTER 1
}

Instability Constraints and Development Traps

An Empirical Analysis of Growth Cycles and Economic Volatility in Latin America

\begin{abstract}
Latin America and Caribbean (LAC) is a region marked by an endogenous pattern of volatility that halts its development process. This article consists of empirically testing its volatility characteristics in terms of cycles. This paper (1) uses a filter decomposition to isolate economic cycles of distinct natures on the GDP growth time series for 136 countries covering the period 1950-2018. (2) It calculates each country's cycle GDP volatility (standard deviation), and finally (3) applies clustering methods to classify the results into groups. The main conclusions are that the majority of Latin American countries are subject to the relative dominance of the long-run economic cycles explaining the overall volatility. Exceptions are Mexico, Colombia and Chile, where the short-run cycle shows a higher relative importance. Data shows that LAC is not the most volatile region of the world, but it has some characteristics as a region in terms of the origin of their volatility.
\end{abstract}

Keywords: Macroeconomic Volatility, Economic Cycles, Time Series, Filter Decomposition, Cluster Analysis

JEL: C21, C32, 047. 


\section{Chapter 1 - Introduction}

Historically, sustaining growth has been a central problem for a virtuous development strategy in many developing countries (Foster-McGregor et al., 2015). Short-term growth and high volatility in macroeconomic prices are constantly observed in developing countries, reducing their average period of stable growth. It results in an endogenous pattern of instability, reproduction of inequality, net outflows of financial capital, and halt in investments. Macroeconomic volatility creates major constraints to the process of economic development, affecting long-term decisions and imposing periodic crises (Stiglitz, 2000). This volatility has impacts on the economic structure, affecting in this way the long-run economic growth (Ocampo et al., 2009).

Macroeconomic volatility is not a new issue and it is a central problem currently affecting developing countries. Despite its importance, little effort has been made to understand the consequences of the type of instability that emerges from the productive structure, affecting the growth potential of economic systems. It is mostly treated in the literature as related to fluctuations in stock markets and government debt (Eichengreen \& Hausmann, 2010) and not linked to structural fragility and to the productive structure, which opens a gap in the literature.

Based on the Structuralist theory (Ocampo, 2002; Taylor, 1991), we plan to address the periodical phenomenon of volatility that we further argue as an element that emerges from the structural fragilities (defined as the weakness of an economy to absorb external economic shocks). In this chapter, we focus on understanding the aspects concerning GDP growth volatility. We empirically show distinct patterns of volatility that emerges from different countries and regions, which later in the thesis we discuss to be related to their structural conditions.

Many structuralist authors have claimed that the structural causes of volatility in Latin America are related to its peripheral position in the international division of labor (Ffrench-Davis, 2005; Ocampo et al., 2009; Prebisch, 1950). This position is defined by the external fragilities, which are related to these countries' productive structure. The fragilities result in a low resilience to external shocks, which is a main source of volatility. In this sense, authors from the Structuralist theory argue that the historical development of Latin American economies gave them an 
idiosyncratic aspect that makes these countries more fragile (Furtado, 1965). Nonetheless, there is a lack of empirical research to prove (or disprove) these claims. Leaving the structural discussion to chapters 2 and 3, this chapter tries to contribute to fill this gap in order to answer the following research question: Are Latin American economies different in terms of their volatility patterns than developed countries and other developing regions?

To answer the above question, we: (I) Show some stylized facts about GDP growth volatility for the available countries in our dataset. (II) Apply filtering techniques to decompose economic growth time series in distinct types of cycle and analyze the patterns that emerge from the data. (III) Build a typology using cluster analysis that groups countries by patterns of volatility. This methodology gives us an approach about the type of expansion-cycle processes followed by each specific country.

In Section 1.1 we offer a brief literature review relating (1) The main theories behind the idea of economic cycles, (2) The Structuralist perspective, and (3) Empirical evidence about the existence of cycles. In Section 1.2 we present the data used in this research. Section 1.3 focusses on the methodologies employed - the Christiano-Fitzgerald's Band Pass Filter, and the K-Means method of cluster analysis. In Section 1.4 we present evidences from the original data before applying the filtering analysis. Section 1.5 shows the results after applying the filters in the data, discussing them for the different types of cycle. Finally, Section 1.6 consists of a summary of the main results and the conclusion of the paper.

\subsection{Literature Review}

This section consists of a literature review about the classical and the current state of the discussion on economic cycles and volatility, raising three main aspects: (1) the relevance of cycles to economic theory. (2) How volatility is approached in the Structuralist theory. (3) Some methodological and empirical evidence on the presence of cycles in growth theory.

\subsubsection{Cycle Theory}

The study and development of cycle theories has enabled many analysts to understand the behavior of economic dynamics. Distinct theories approached the observance of economic cycles 
with its own explanations of the phenomenon (Korotayev \& Tsirel, 2010). The relevance on the study of these cycles lays in the fact that their occurrence for some key economic variables affects countries' short- and long-run economic behavior and their development strategies. Understanding the existence and causes of a cyclical behavior is a topic largely addressed by a whole tradition in cliometrics and cliodynamics.

Economists claimed the discovery of cyclical patterns for economic prices and growth. Since the beginning of the discipline, Clement Juglar (1889) had shown that the presence of cycles was related to business activities. The cycles ranged from 8 to 11 years and were caused by the maturity of investments. This behavior was later developed in the Business Cycle Theory, now in the mainstream of the economic discipline. In terms of long-run cycles, Kondratiev in 1935 discussed the existence of periods of volatility every 45 to 60 years in the world economy (Korotayev \& Tsirel, 2010). These long cycles are still the subject of debates in terms of their identification and causes as will be further discussed. Another type of cyclical behavior, for the medium-run, was discovered by Kuznets (1940), who related them to the behavior of infrastructure investments. This type of cycle was discussed by Abramovitz $(1961,1969)$, who empirically analyzed the recurrence of growth-crises periods for a broad range of countries at similar intervals. The very short-run cycles (Kitchin cycles) are usually related to changes in inventories (Korotayev \& Tsirel, 2010) and to international portfolio flows that create short-run oscillation.

Joseph Schumpeter wrote his classical book on business cycles (Schumpeter, 1939). He described how technological aspects are related to the cyclical behavior of an economy and proposed a typology for them according to their periodicity. An update of his typology (Jadevicius \& Huston, 2014) leads us to identify four types of cycles: the Kitchin cycle (3 to 5 years); the Juglar cycle ( 8 to 11 years); the Kuznets cycle (15 to 25 years) and the Kondratiev wave (45 to 60 years). In this research we base ourselves on this typology. We expanded the range of each cycle in order to have full time-frame coverage in the calibration for all the cycles, which ranges between 2 and 60 years. It is relevant to mention in terms of economic cycles that the fluctuations are not only related to a certain specific aspect of an economy, but cycles are present in every economy, each with its specific nature. These oscillations are not only a result of 
specific conditions, but volatility also diffuses through the whole economic system, having pervasive effects in the economic system.

The reasons behind the existence of cycles are a topic of great debate in the economic theory. Different authors try to understand the causes of these cycles. These arguments range from (a) the accumulation of inventories (Kitchin, 1923). (b) credit behavior. (c) The maturity of investments (Besomi, 2005; Fukuda, 2009). (d) investments in infrastructure (Abramovitz, 1969; Kuznets, 1940). (e) Technology development (Perez, 2010; Schumpeter, 1939). (f) International financial flows - it is also worth noting Fischer's Debt Deflation theory (Palley, 2008) and the Financial Instability Hypothesis (Minsky, 2016).

The Structuralist tradition is composed by theories that seek to explain the behavior of cycles in developing countries, looking for both supply and demand-side aspects of the macroeconomic system. The specificity of these theories is that they observe cycles as endogenous to the behavior of the system. In this sense, they differ from the traditional Real Business Cycle (RBC) framework that observes the main sources of cycles as exogenous (Kydland \& Prescott, 1990). In this RBC's perspective, well-functioning markets results in a stable equilibrium. Therefore, fluctuations are a result of bad policies or market failures, not a structural characteristic feature of some particular economic systems.

\subsubsection{Structuralism and volatility - Why are developing countries so volatile? What is the insertion of Latin America?}

The concept of center-periphery is at the center of the research performed by the Economic Commission of Latin America and the Caribbean (Eclac), historically linked to the Latin American Structuralist tradition. Latin America has always been seen as a region with a specific economic dynamic compared to other regions, since the works of Prebisch (1950), Furtado (1983), Sunkel (1972) and Fajnzylber (1990), and more recently with Caldentey \& Vernengo, (2010); Cimoli, Porcile, \& Rovira (2010); Botta (2010) and Ocampo (2002). Latin America is a region with a peculiar economic dynamic caused by its peripheral position in the international division of labor. Taylor (1991) models and summarizes the effects of the center-periphery dynamic to the constitution of a cyclical dynamic. This is caused by the idiosyncratic economic 
and institutional historical development of the region. This specificity has impacts on the growth dynamic in the short- and long-run.

Prebisch (1951) developed a theory explaining the emergence of a center-peripheral (or coreperipheral) dynamic in the international system. The position of each country in the system depends on to which types of products a country produces (depending on the product's technology intensity) and the country's insertion in the international division of labor. The center (north, central countries or core of the system) is the locus of technological change, producing new advanced products, with high technology intensiveness and high income elasticity of demand. On the other hand, the periphery (south) inserts itself in the international dynamic by producing and exporting raw goods and low technologic intensive products. This theory marks the beginning of the Latin American Structuralist tradition. Bielchowsky \& Torres (2018) track all the improvements in the Structuralist theory during the 70 years of the economic thought at ECLAC.

In this sense, and uneven international institutional arrangement emerges, in which the periphery has a distinct economic dynamic in its long run development when compared to the center. In this framework, the lack of development of the productive structure is seen as the main factor generating an increasing fragility into the developing countries (periphery). Following the longrun perspective, the theory argues for the presence of a long term decline of the terms of trade (Prebisch-Singer Hypothesis) that creates barriers to economic development.

Moving to the Post-Keynesian tradition, Thirlwall $(1979,2012)$ developed the Balance of Payments constrained model (BPCM). In this theory, countries are constrained in the long run by the income elasticity of demand from imports and exports of the products they trade. An increase in the growth rate should be compatible with the stability of the external sector, which depends on the productive structure, and defines the fragility pattern. More recently, Cimoli \& Porcile (2014) linked external constraints to the technological capabilities of peripheral countries, merging the Post-Keynesian, the Structuralist and the Evolutionary perspectives.

The lack of dynamism in the productive structure of developing countries and the aforementioned fragility result in a specific pattern of specialization in international trade. 
Developing countries concentrate their activities in low technological intensive products and highly standardized goods (commodities). This creates an additional issue to the Terms of Trade decline: the specialization in commodities results in higher volatility. Relevant works as Ziesemer (2010) observed the trends in these prices, measuring Terms of Trade. Commodity prices in international markets are more volatile than high-technology manufactured goods. This volatility affects the Balance of Payments conditions of developing countries not only in the long-run, as discussed by Thirlwall (2012) but also in the short-run. This results constraints the process of economic development. High volatility in developing countries may have its roots based on the increased fragility created by a specialized and low dynamic productive structure (Hausmann \& Gavin, 2011). This is the result of a specific peripheral insertion in the international division of labor.

The argument above defined can be explained through some specific channels. Higher volatility in international prices generates a mismatch in the Balance of Payments (exports, imports and capital flows). It affects economic growth through the following mechanisms:

(1) In a Keynesian perspective, it increases uncertainty, affecting economic agents' decisions in the short- and long-run. In this sense, investment projects with high capital immobilization are perceived as less profitable. It results in reduced marginal capital efficiency, as described by Keynes (1936). This results in a reduction in longrun projects, with smaller investment and less aggregate demand (reducing then economic growth).

(2) Instability in the external account reduces the possibilities to import capital goods. This is particularly relevant for developing countries in which a virtuous catching-up strategy demands access to capital goods (machinery) situated in the technologic frontier (Stiglitz, 2000).

(3) Volatility in external prices affects the real exchange rate of a country. Increasing oscillation in the exchange rate raises uncertainty, which may generate higher arbitration and speculation possibilities, but do not positively improve development possibilities. (Andrade \& Prates, 2013).

(4) Uncertainty affects not only investment but also consumption. Real wages are very sensitive to changes in the exchange rate. The price channel in an uncertain 
environment reduces consumption and aggregate demand. (Gabriel, Jayme, \& Oreiro, 2016).

(5) Increased uncertainty in investments and in the exchange rate affects agents' behavior through higher price volatility. Agents defend themselves by protecting their Mark-up (Steindl, 1979), increasing prices. In this sense, volatility is also seen as an inflationary mechanism.

(6) Reduction in investments, especially in the manufacturing sector, is also linked to a reduction in productivity. Following the classical Kaldor-Verdoorn (Kaldor, 1975) discussion, debated by McCombie \& Spreafico (2016), investment and growth boost not only the capital stock but as well as its quality, generating economies of scale and higher learning opportunities. In this sense, this is another mechanism that reinforces underdevelopment, through the specialization in low technological intensive activities.

In the mainstream economics, relevant economists argue that fragility is related to a higher resilience to shocks. This especially for external shocks that comes from abrupt price changes (Blanchard \& Gali, 2007) and also from institutional issues (Acemoglu \& Robinson, 2012). Countries with less diversified exports suffer mostly from external price volatility. Volatility in low technology intensive goods is historically much higher than for high technology intensive manufacturing goods. This boosts fragility in developing countries.

The import-export pattern is a central element in this discussion, either related to the short-run fluctuation, or to long-run waves. As discussed above, there is a whole tradition of literature that searched for the sources of volatility in the short- and long-run, but very few that have tried to measure and explain them. In this sense, this study aims to measure distinct aspect of volatility using economic cycle theories.

\subsubsection{Methodologies used for cycle analysis and empirical evidence for economic cycles}

Distinct methodologies in the field of time series have been developed to extract cycles from the original GDP growth time series data. There is a whole tradition in fields such as physics (oscillatory dynamics) in which frequencies as are essential to understand the behavior of certain 
volatile phenomena. This is similar in economics, in which we can observe empirically the existence of a cyclical behavior in many economic variables.

In terms of the main methodologies used to observe empirically extract the existence of cycles, we cite three: the Spectral Analysis (Bossier \& Huge, 1981; Korotayev \& Tsirel, 2010; Van Ewijk, 1981), the Filter design approach (Kriegel, Kröger, \& Zimek, 2009; Metz \& Stier, 1992), and the Wavelet analysis (Gallegati, Gallegati, Ramsey, \& Semmler, 2017). These methodologies focus on analyzing the distinct frequencies that emerge from real time series.

Spectral analysis applies Fourier transformations to time series and observes its spectrum in different frequencies. Using power accumulated frequencies it is then possible to identify the existence of periodic oscillations in the time series. This method initially removes the trend from the series as a requirement of stationarity. Fourier transformations uses combinations of sines and cosines to represent a non-local function - so changes affect the whole function. This restriction allows for using windowed transformation (use of bands). The wavelet analysis is analogous to the Spectral analysis but it uses a finite domain.

It is important to mention the literature on Structural Breaks, aimed at capturing shifts in growth regimes, based on Pritchett (2000); Papel \& Prodan (2014); and Bluhm et al (2019). In this literature, the time series is not seen as a cyclical component around one stable trend, as the breaks change the slope of the trend on time - as seen in the trend-cycle decomposition of Perron and Wada (2016). This is an extremely valid approach, and could help us understand further changes development strategies. Because of the focus on the historical cyclical components and the need for a higher number of observations, we opt to study the filter decomposition with structural breaks in a later development of the research. The high number of breaks reduces the number of observations used to observe the overall cycles, which potentially reduces the accuracy of the cyclical results. We opt to do not use structural breaks in this analysis, leaving for a future comparison between the results we have in this analysis with the one using breaks.

This paper uses a Filter Design approach, which is a development of the Spectral Analysis by defining a specific band filter. There are distinct possible filters, as described and enumerated by Pollock (2013). One commonly used filter is the low pass filter, also known as the Hodrick- 
Prescott's filter (Hodrick \& Prescott, 1997). Despite being one of the most used methods, this methodology was heavily criticized by Hamilton (2017) for its strong bias. Another important methodology is the Band-Pass (BP) filter, in which we observe the symmetric (Baxter-King) and asymmetric (Christiano-Fitzgerald) versions. This latter method is used to observe long waves and growth cycles. The procedure filters coefficients to isolate specific frequencies looking for the ideal filter band. We use the asymmetric BP filter of Christiano \& Fitzgerald (2003), also used by Erten \& Ocampo (2013).

We observe some empirical evidences on the existence of regular patterns of volatility (cycles) in GDP growth. There are many studies which test the existence of cycles at the global level. Korotayev et Tsirel (2010), using spectral analysis, claim that it is highly likely that Kitchin, Juglar and Kondratiev cycles exist at a global level. Kuznets' cycles are the third harmonic of the Kondratiev cycle, detected for the world level for each 17 years. In another relevant work, Diebol \& Doliger (2008) identified Kuznets swing for GDP growth arguing for it existence.

Despite the fact that these works pointed to the existence of cyclical behavior in the economic systems, it is important to point out that the results found in the literature are still open to debate, with contradictory results that is very sensitive to the methodology applied. There are still disagreements about the empirical existence of short and long waves (Bosserelle, 2015). This debate is not a topic raised in this work, and it does not aim to question the results of this research, but it is worthy to mention that the existence of GDP cycles is yet a controversial topic. The cyclical decomposition used for observing volatility is an important mathematical tool to let us investigate and classify groups according to specific elements, such as growth instability.

\subsection{Data}

This paper uses the Maddison Project Database (MPD), updated with data from the World Bank Database (WBD)'s World Bank Indicators (WBI). The MPD continues the works of Maddison (2001) and Maddison (2003). The database was most recently updated by Bolt and Van Zanden (2014). These authors calculated the long-run historical data of per capita GDP for a large number of countries and regions. The MPD has data since ancient times until 2010. We select from the MPD the period from 1950 to 2010 and update for 2010 to 2018 using the growth rates of per capita GDP from the World Bank Database (WBD). The updating procedure involved 
removing the population growth from the MPD in order to find GDP growth data (not percapita). Because of data problems, the former soviet republics and former Yugoslavia were excluded from the database.

The treated database consists of GDP growth data ${ }^{2}$ from 1951 to 2018 for 136 countries. For each country's time series, the Christiano and Fitzgerald (2003)'s Band Pass Filter was applied and the original data was decomposed in distinct cycles. After we extend the cycle data, these cycles cover very-short-run 2-8 years (Kitchin Cycle), short-run 8-15 years (Juglar cycle), medium-run 15-30 years (Kuznets cycle), and long-run 30-60 years (Kondratiev cycle) period. The results were grouped in clusters using the K-means methodology, dividing the instability patterns in different groups.

GDP growth data is used in this research for two main reasons: (1) There is a requirement of stationarity in order to apply the filtering methodology. (2) GDP growth focuses only on the dynamic aspect of volatility. The focus is not to observe how the stock of richness (GDP level) affects volatility, but how the flow (growth) is related to an oscillatory pattern.

\subsection{Methodology}

\subsubsection{Band-Pass filter}

Erten and Ocampo (2013) use the Asymmetric Band-Pass (ABP) to identify cycles for commodity prices. The same method is used here to filter the GDP growth time series. The ABP filter allows a time-series to be decomposed into different frequency components, which are then used to identify the cycles in the different time series. This approach is combined with the identification of medium-run cycles, following Comin and Gertler (2003) and Drehmann, Borio, $\&$ Tsatsaronis (2012). The adopted approach splits the per capita GDP growth $(y)$ into five components: (i) a long-run cycle $\left(y^{\mathrm{LR}}\right)$ - with periodicities of 30 to 60 years, corresponding to the Kondratiev cycle; (ii) a medium-run component $\left(y^{\mathrm{MR}}\right)$ - with periodicities between 15 and 30 years corresponding to the Kuznets cycle; (iii) a short-run cycle $\left(y^{\mathrm{SR}}\right)$ - with periodicities between 8 and 15 years corresponding to the Juglar cycle; (iv) a very short-run cyclical

\footnotetext{
${ }^{2}$ Growth data removes the problem of non-stationarity of the time series, which is a fundamental requisit to run the filter decomposition analysis.
} 
component $\left(y^{\mathrm{SSR}}\right)$ - with periodicities less than 8 years corresponding to the Kitchin cycle; and a residual component $(e)$, that will be later discussed as the structural component.

$$
y_{t} \equiv y_{t}^{L R}+y_{t}^{M R}+y_{t}^{S R}+y^{\mathrm{SSR}}+e
$$

The average length of a super-cycle reported by Erten and Ocampo (2013) in their analysis is 35.7 years, with a minimum of 24 years and just three (out of 18) super-cycles being more than 40 years in length. The Kuznets cycles is considered as having a periodicity between 15 and 30 years. The long-run trend therefore has a periodicity greater than 30 years, until 60 years, following the Kondratiev waves. A medium-run cycle Juglar wave is then defined as having a periodicity between 8 and 15 years, with the short term cyclical Kitchin cycle trend having a periodicity of less than 8 years.

The idea behind following this procedure is to find different types of cycle from the original time series for different countries. Then we observe the characteristics of each of these cycles. We group the countries with similar cyclical characteristics (for instance, higher oscillations in shortrun cycles) in similar categories. We then study the characteristics of each category. The asymmetric BP filter is useful in this sense, as it allow us to define bands for the periods in which we would like to extract the cycles. We can then remove the very short-run cycles from the other types. After defining the categories, we check if there is anything similar in terms of Latin American country cycles. If there are, then we observe what is behind that.

Table 1.1. Cycles in economic theory and their respective time periods

\begin{tabular}{llll} 
Cycle Name & Main origin & Period & Possible cause as discussed in the theory \\
\hline Kitchin & Market Cycle/Financial Flows & $0 \mathrm{y}-8 \mathrm{y}$ & Inventories (Consumption)/Portfolio Decisions \\
Juglar & Business Investment Cycle & $8 \mathrm{y}-15 \mathrm{y}$ & Medium-run Investments \\
Kuznets & Structural Investment Cycle & $15 \mathrm{y}-30 \mathrm{y}$ & Long-run Investments (Infra-Structure) \\
Kondratiev & Technological Cycle & $30 \mathrm{y}-60 \mathrm{y}$ & Technological paradigm change \\
Residual & Trend & - & Structural element, Human capital \\
\hline
\end{tabular}


Initially, we use the band-pass filter to remove the high frequency Kitchin cycle from the original time series. Then we readjust the band to extract the Juglar cycle from the residuals of the Kitchin cycle. From the residuals of the Juglar cycle, we extract the Kuznets cycle. The same procedure is used to extract the Kondratiev cycle from the residuals of the Kuznets cycle. The resulting data consists in a residual, which seems to be linked to the long-run economic growth. The sum of the five components results again in the original time series. The different patterns of cyclicality extracted for different countries can be grouped using cluster analysis. Those patterns are compared in terms of the average duration of the cycles and their standard deviation (amplitude).

\subsubsection{Cluster Analysis}

Cluster Analysis consists of organizing elements in similar groups according to some selected attributes. There is no standard way of clustering, but many distinct methodologies are used to group elements with similar aspects. In this paper, selected countries are divided into distinct groups based on their cycle standard deviations. The methodology used is the K-Means, a method of vector quantization that partition observations in clusters, partitioning the data space into regions.

The K-means is a method that minimizes distance in a graph in order to group elements with similar (selected) characteristics. We have to define the number of groups (clusters) we would like to find. The method selects which observations are similar according to their distance. The $\mathrm{K}$-means can use many variables, i.e. we could choose (for instance) eight interest characteristics to group people with similar interests from a selected population.

Technically, the K-Means is a randomized method that divides the data into $k$ distinct clusters. The $n$ objects are grouped according to the nearest mean to the clusters. The optimal number of clusters is not known and must be exogenously defined (however, there are tests to help us define that). The objective of this methodology is to minimize intra-cluster variance (the squared error function). This is done through the definition of an objective function $j$ that calculates a distance function that must be then minimized. The objective function can be written as: 


$$
j=\sum_{j=1}^{k} \sum_{i=1}^{n}\left\|x_{i}^{(j)}-c_{j}\right\|^{2}
$$

Where $x_{i}$ represents the case $i$ and $c_{j}$ represents the centroid for cluster $j$. The method firstly computes the clusters into the exogenously given $k$ groups. Then it randomly selects cluster centers and assigns observations to clusters, following the distance function, and calculates the mean of each object. This method repeats itself until it minimizes the distances. This method results in groups of clusters in which similar countries are divided from the non-similar ones in terms of the selected variables.

\subsection{Analysis by type of cycle}

In order to illustrate the methodology and the results obtained, we present below the filtering methodology applied to some selected Latin American and Caribbean (LAC) country data. In Figure 1.1 we can observe the four types of cycle filtered from the original GDP growth time series for selected countries. Each cycle has a detailed aspect and can be used to identify some historical turns in those countries' economies. This extraction shows the different degrees of stable volatility. An interesting aspect is the residual non-cyclical component. It shows the longrun aspects, which could be related to the countries' economic structures, a matter to be discussed in the following chapters. 
Figure 1.1. Volatility, cycles and residual in selected LAC countries

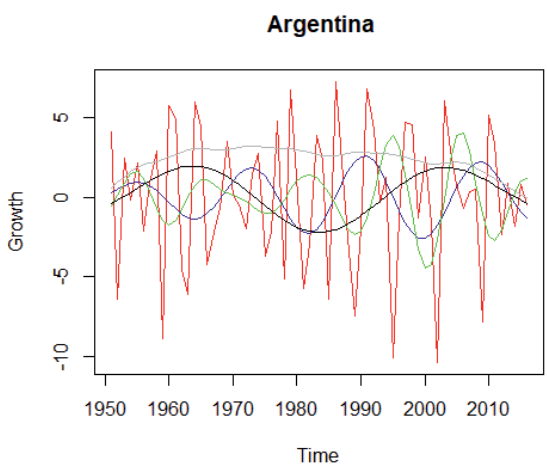

Brazil

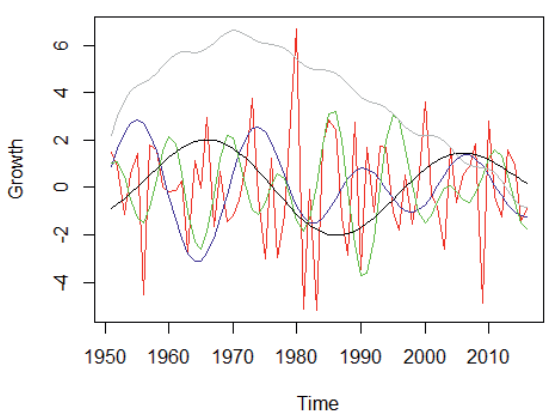

Chile

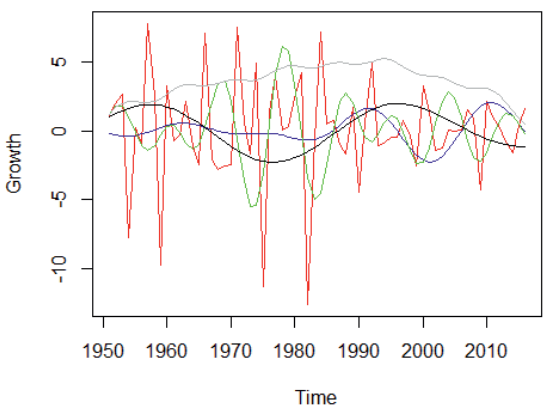

Mexico

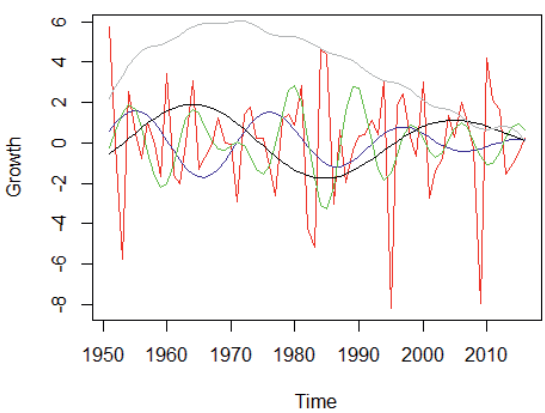

Source: Author's own. Data: Maddison Project Database

Figure 1.1 shows the decomposition of growth time series into cycles and trend for Argentina, Brazil, Chile and Mexico. The scales are different in each graph, which represents the difference in terms of volatility patterns for each country. The short-run Kitchin cycles, in red, have a higher frequency and variance. This cycle is marked by high amplitude and small duration. The presence of major economic crisis can be easily seen in the market Kitchin cycle. This is the case of the 1980's in many Latin Americas countries, as the example of the Mexican peso crisis of 1982. 
Each cycle can be linked to a major element, following the literature. The short-run Juglar cycles follows the investment cycles for each economy while the Kuznets cycle is related to longer investment cycles related to infrastructure. The Kondratiev cycle is approached by the theory of technological change (Perez, 2010). We can also observe the presence of the residual component. This latter does not follow a cyclical behavior but a trend. This residual can be (in a future work) used to explain changes in the productive structure - such as the reduction on the weight of the industrial sector in a specialization pattern that happened since the end of the 1970's in LAC.

\subsection{Results of the cluster analysis applied on Cycles}

The cluster analysis is applied on the different cycle components time series. Countries are grouped by their volatility patterns. We run the algorithm 1000 times, because of the randomized aspect of the K-mean, which resulted in monte-carlo frequencies to define the groups. The cluster analysis considered the Short-, Medium- and Long- run cycles as inputs. Isolating the very-short-run cycles was a decision based on the fact that this type of cycles capture all the noise related to not directly related economic aspects (mostly political). The number of cluster was selected using cluster optimization criteria, this defined 9 groups.

Table 1.2. Average growth GDP variance per cluster group

\begin{tabular}{|c|c|c|c|c|c|}
\hline G1 & 7.90 & G4 & 28.76 & G7 & 33.09 \\
\hline G2 & 15.93 & G5 & 22.17 & G8 & 69.97 \\
\hline G3 & 21.84 & G6 & 26.65 & G9 & 181.13 \\
\hline
\end{tabular}

Figure 1.2. Share of each cycle variance from total variance (average per cluster group) 


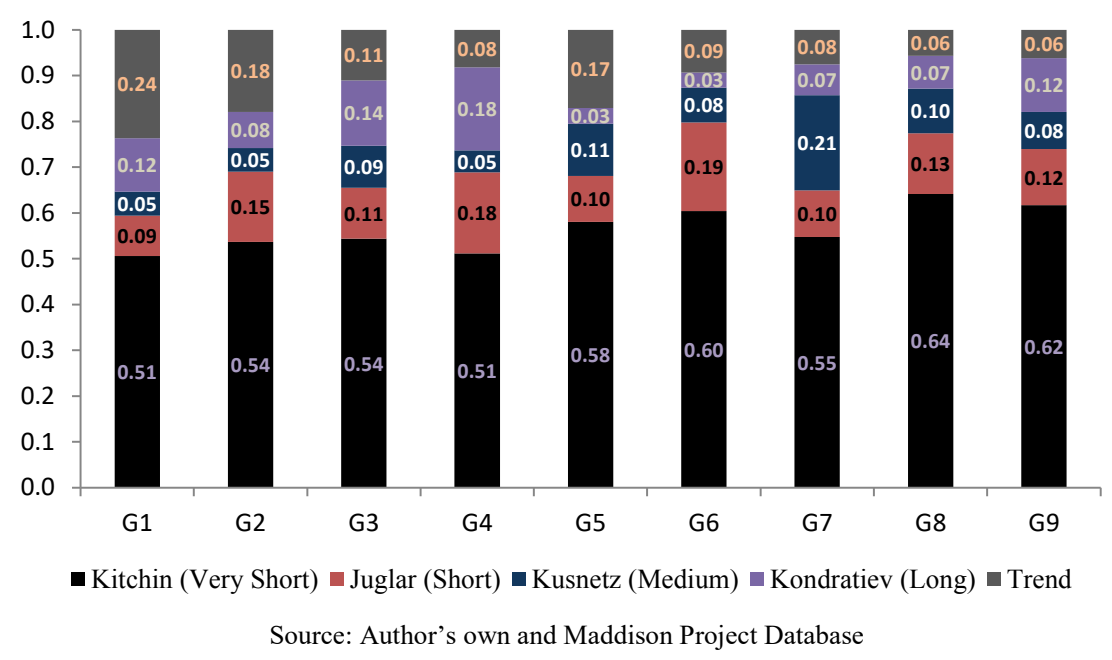

Group 1 (G1) represents the less volatile countries, in which most developed countries are included. This group is marked by low variance, high relative importance of the trend component and long run cycles explaining overall volatility. G1 has a smaller relative importance of the very-short- and short-run volatility. Group 2 (G2) has similar characteristics to G1, but a larger variance and higher relative relevance of the very short- and short-run volatilities. It is still composed by a mix of some developed countries with some emerging economies in Africa that show a similar volatility pattern.

Between Groups 3 and 6 (G3 - G6) the overall variance is almost equal, as seen in Table 1.2. The differences are related to the relative importance of each cycle to explain volatility. In G3 the Kondratiev cycles are more important relatively and the trend, the short- and very-short cycles are below the average. In G4 both the Juglar and the Kondratiev cycles are relatively more relevant, while G5 shows a pattern with higher relative importance of the trend, the medium-run and the very-short-run cycles. Finally, for G6 we see a very high relevance of the Kitchin and Juglar cycles (group that presents higher share of short-run oscillations explaining the overall volatility).

G7 shows an average variance a little higher than the first six groups and it is marked by the higher presence of the medium-run cycles. Finally, Groups 8 and 9 (G8 - G9) show a much 
higher variation in their overall volatility, both with a higher relative relevance of the very-short run cycles and small importance of the long-run cycle and the long-run trend.

Table 1.3. Summary of the relative characteristics per cluster group

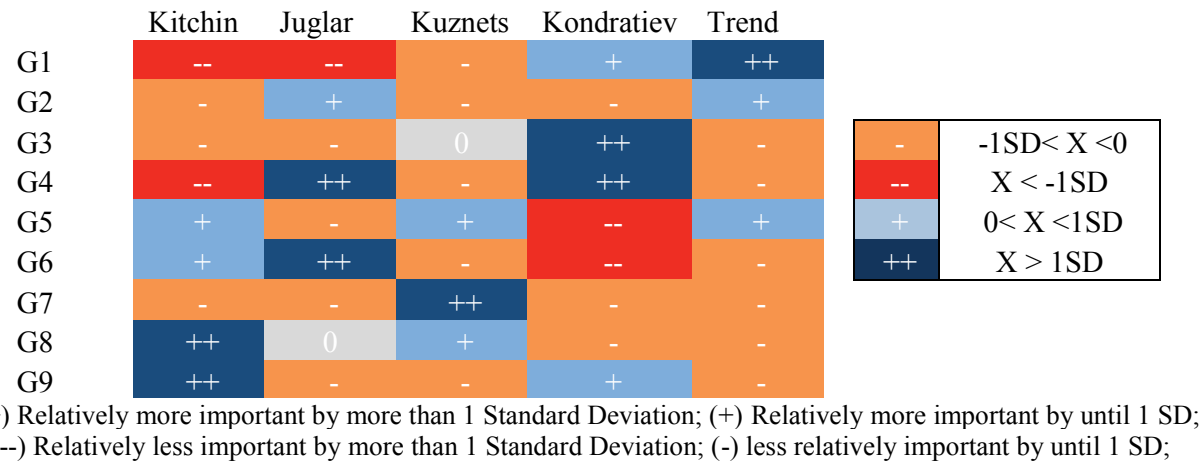

Table 1.3 shows the relative comparison between different groups by its cycle characteristics. Each group is compared with the average share, showing which cycle is relatively the most relevant to explain differences between the clusters. Each group shows a different behavior which poses some questions, in which not all can be properly answer in this research: Why is a country more affected by the long-run cycles? What determines that? Is it related to the structural conditions of the economies? Is it a matter of fragility? These questions open the door to a whole future research agenda. In chapters 2 and 3 we touch these topics.

Table 1.4 shows which countries are grouped in each of the clusters defined by the K-means methodology. In this table we observe some regional features. Developed countries are entirely situated in Groups 1 and 2. In these two first groups there are also the presence of many low and middle-income countries in Africa and Asia such as Benin, Bangladesh, Bahrain, Burkina Faso, India, Laos, etc. Most central Asian countries are in G8 and G9. Latin America finds itself between G2-G7 concentrated mostly in G3.

The measure is related to growth volatility, so a catch-up process right after WWII followed by long period of stagnation, as is the case of Japan, is measured in a certain specific way 
(Heteroscedasticity). On the other hand, countries with a profound stagnation are not volatile, which is the case of some of the developing countries observed in G1 and G2.

Table 1.4. Cluster Analysis applied on the Standard Deviation of the Juglar, Kuznets and Kondratiev cycles. LAC countries highlighted.

\begin{tabular}{|c|c|c|c|c|c|c|c|c|c|c|}
\hline \multicolumn{2}{|c|}{$\begin{array}{c}\text { GROUP } 1 \\
\text { (G1) }\end{array}$} & \multirow{2}{*}{$\begin{array}{l}\text { GROUP } 2 \\
(\mathrm{G} 2) \\
\text { BFA }\end{array}$} & \multicolumn{2}{|c|}{$\begin{array}{c}\text { GROUP } 3 \\
\text { (G3) }\end{array}$} & \multirow{2}{*}{$\begin{array}{l}\text { GROUP } 4 \\
(\mathrm{G} 4) \\
\text { ALB }\end{array}$} & \multirow{2}{*}{$\begin{array}{l}\text { GROUP 5 } \\
\text { (G5) } \\
\text { BDI }\end{array}$} & \multirow{2}{*}{$\begin{array}{l}\text { GROUP } 6 \\
(\mathrm{G} 6) \\
\text { CAF }\end{array}$} & \multirow{2}{*}{$\begin{array}{l}\text { GROUP } 7 \\
(\mathrm{G} 7)\end{array}$} & \multirow{2}{*}{$\begin{array}{l}\text { GROUP } 8 \\
\text { (G8) } \\
\text { GAB }\end{array}$} & \multirow{2}{*}{$\begin{array}{l}\text { GROUP } 9 \\
\text { (G9) } \\
\text { AGO }\end{array}$} \\
\hline AUS & LAO & & ARG & MNG & & & & & & \\
\hline AUT & LKA & CHE & BGR & MRT & POL & ECU & CHL & $\mathrm{COG}$ & IRN & GNQ \\
\hline BEL & MAR & $\mathrm{COL}$ & $\mathrm{BOL}$ & NAM & ROU & EGY & $\mathrm{CHN}$ & $\mathrm{COM}$ & KHM & IRQ \\
\hline BEN & NLD & ESP & BRA & PAN & PER & HKG & COD & CPV & LBN & KWT \\
\hline BGD & NOR & FIN & BWA & PHL & CUB & IDN & LSO & JOR & NGA & LBY \\
\hline BHR & NPL & GNB & CIV & PRY & NIC & KOR & MUS & SDN & PRK & OMN \\
\hline CAN & PAK & HND & CRI & SLV & AFG & LBR & NER & TTO & RWA & QAT \\
\hline DEU & PRI & IRL & DOM & STP & SAU & MWI & SYC & VEN & SLE & \\
\hline DNK & SEN & JPN & DZA & TZA & DJI & MYS & THA & YEM & SOM & \\
\hline FRA & SWE & KEN & GHA & UGA & ETH & SGP & URY & & SYR & \\
\hline GIN & UK & MDG & GMB & ZMB & $\mathrm{MOZ}$ & TUR & ZWE & & TCD & \\
\hline IND & USA & MEX & GRC & & SWZ & & & & UAE & \\
\hline & ZAF & MLI & GTM & & TGO & & & & & \\
\hline & & NZL & HTI & & & & & & & \\
\hline & & PRT & HUN & & & & & & & \\
\hline & & TUN & ISR & & & & & & & \\
\hline & & TWN & JAM & & & & & & & \\
\hline & & VNM & MMR & & & & & & & \\
\hline
\end{tabular}

Source: Author's own and Maddison Project Database

In Table 1.4, we see that the Latin American countries are colored in gray. It is possible to observe that half of them concentrate in G3 (11 countries out of 23). The continent is represented in every group with the exception of the two most volatile (G8 and G9). Puerto Rico follows a similar pattern of that of the Developed countries. Colombia, Mexico and Honduras have a volatility pattern also more closely similar to that of G2 developed countries. Chile and Uruguay differ from the majority of Latin American countries. This is not caused by differences of their overall volatility, but because in these countries we can observe that the very-short- and the short-run cycles are very relevant to explain the volatility. Peru, Cuba and Nicaragua are in G4. 
Ecuador is in G5. Venezuela and Trinidad \& Tobago are in a more volatile group (G7). In general we see that there are two main groups for LAC countries, the ones in which Short-Run (Juglar) cycles relatively dominate (G2, G4 and G6) and the majority in which Long-Run Cycles relatively dominate (G3 and G4). These two groups will be respectively called Juglar-dominated and Kondratiev-dominated.

We expect countries in the best situation to be in G1, followed by G2 - the less volatiles. The groups G8 and G9 have the countries that suffer the most about volatility. Nonetheless, between G3 and G7 there is no value judgement about which countries are in a "better condition". These groups just define countries in different situation, related to many aspects, such as their integration in the international environment, institutions, their economic structures, among other possible explanations.

Table 1.5. Latin American countries by cycle dominance

\begin{tabular}{|l|ll|l|l|}
\hline \multicolumn{1}{|c|}{ Juglar-dominated } & \multicolumn{2}{|c|}{ Kondratiev-dominated } & Juglar and Kondratiev & Others \\
\hline CHL & ARG & HTI & CUB & ECU \\
COL & BOL & JAM & NIC & PRI \\
HND & BRA & PAN & PER & TTO \\
MEX & CRI & PRY & & VEN \\
URY & DOM & SLV & \\
\multicolumn{5}{|l|}{ Source: Author's own and Maddison Project Database } \\
GTM & \\
\hline
\end{tabular}

Some results for the behavior of economic cycles in Latin America:

(1) Half of LAC countries are in Group 3, which is characterized by average standard deviation (neither small nor big compared to the world average). In G3 (and G4) there is a high relative importance of the long-run cycles (Kondratiev) despite a smaller relevance of the long-run trend.

(2) Latin American countries are not totally homogeneous as a group in terms of their volatility patterns. This poses a challenge when generalizing results to the whole continent. In this sense, finding a general theory to explain the causes of overall volatility in Latin American countries must take into account these specificities and discuss the 
causes of these differences. It is still relevant to highlight that we see one group (G3) that characterizes most of the Latin American countries.

(3) LAC countries, in terms of volatility, differ clearly from the pattern observed in developed countries. On the other hand, it shows a similar pattern to some other developing regions, especially with central Asia and parts of Sub-Saharian Africa.

(4) Considering only the big countries in the region, Mexico and Colombia have a different pattern than Brazil and Argentina, which are also different than Chile.

It is relevant to discuss the meaning of the Kondratiev-dominance. What does it mean to have a long-run cycle so relatively important in explaining growth volatility compared to the others?

Figure 1.3. Map of volatility patterns in Latin America by cluster group.

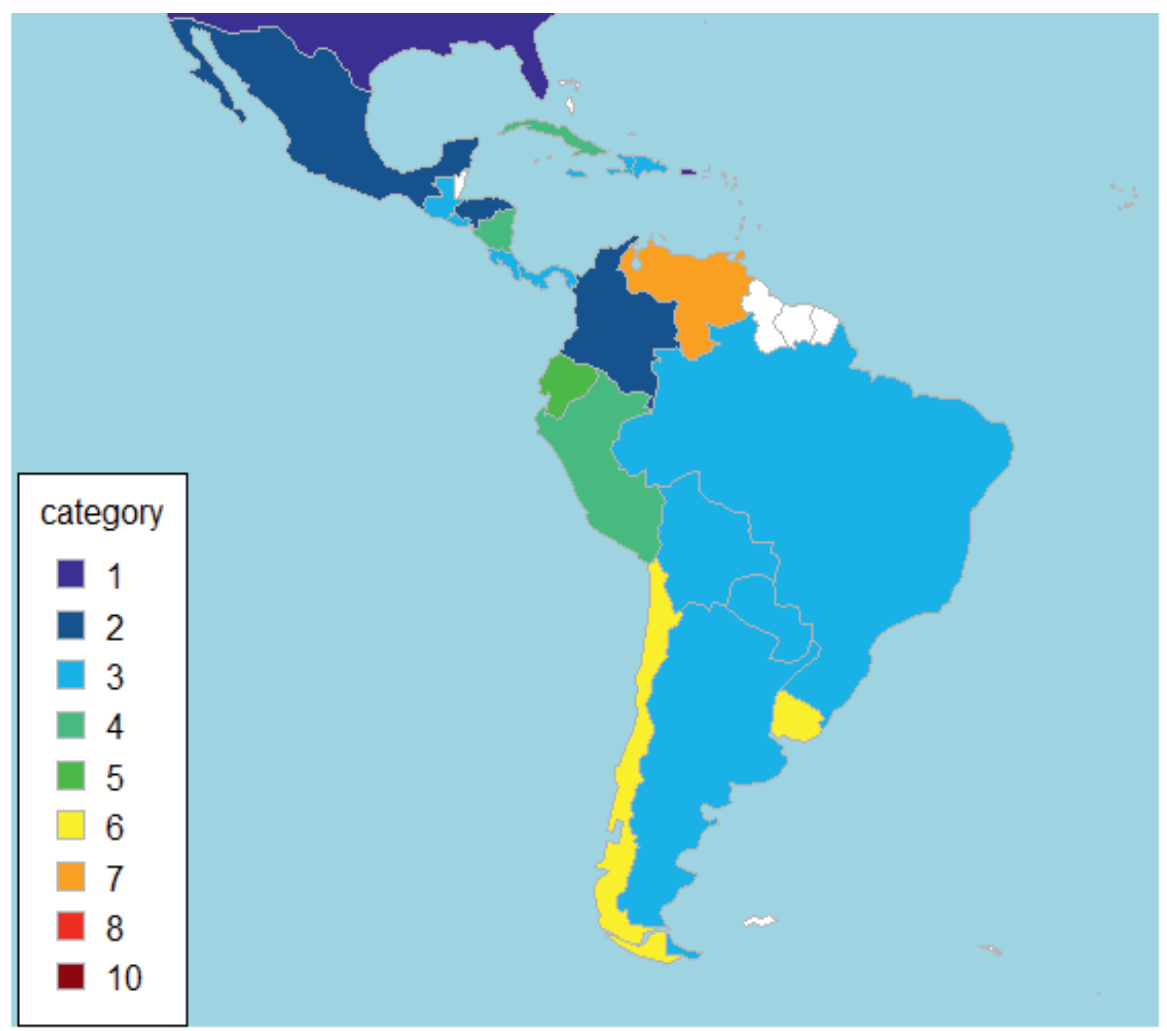


Legend: cluster group categories colors from 1 to 9 (top to bottom)

Source: Author's own and Maddison Project Database

Before stating a relationship between volatility and development, as it is the intent of this research, it is relevant to observe the aspects that lead to similar patterns in the world level. This occurs in groups of countries with many distinct volatility patterns. From the observance of the cluster analysis we may find the following results:

(1) Developed countries are the less volatile. They find themselves in G1 and G2. Oil rich countries are the more volatile in the world, being in G8 and G9.

(2) In addition to the more developed countries, there are many low- and medium-income countries in the G1 and G2. This aspect has to be further investigated, as the sources of their low volatility may not be related to their structural conditions.

(3) Developing countries with a similar overall volatility have very distinct patterns when examining the sources of this volatility. For some countries the volatility comes from shorter-run cycles, while, for others, it comes from longer-run cycles and the trend. 
Figure 1.4. Map of volatility patterns by cluster group, World Level. Groups 1 to 9.

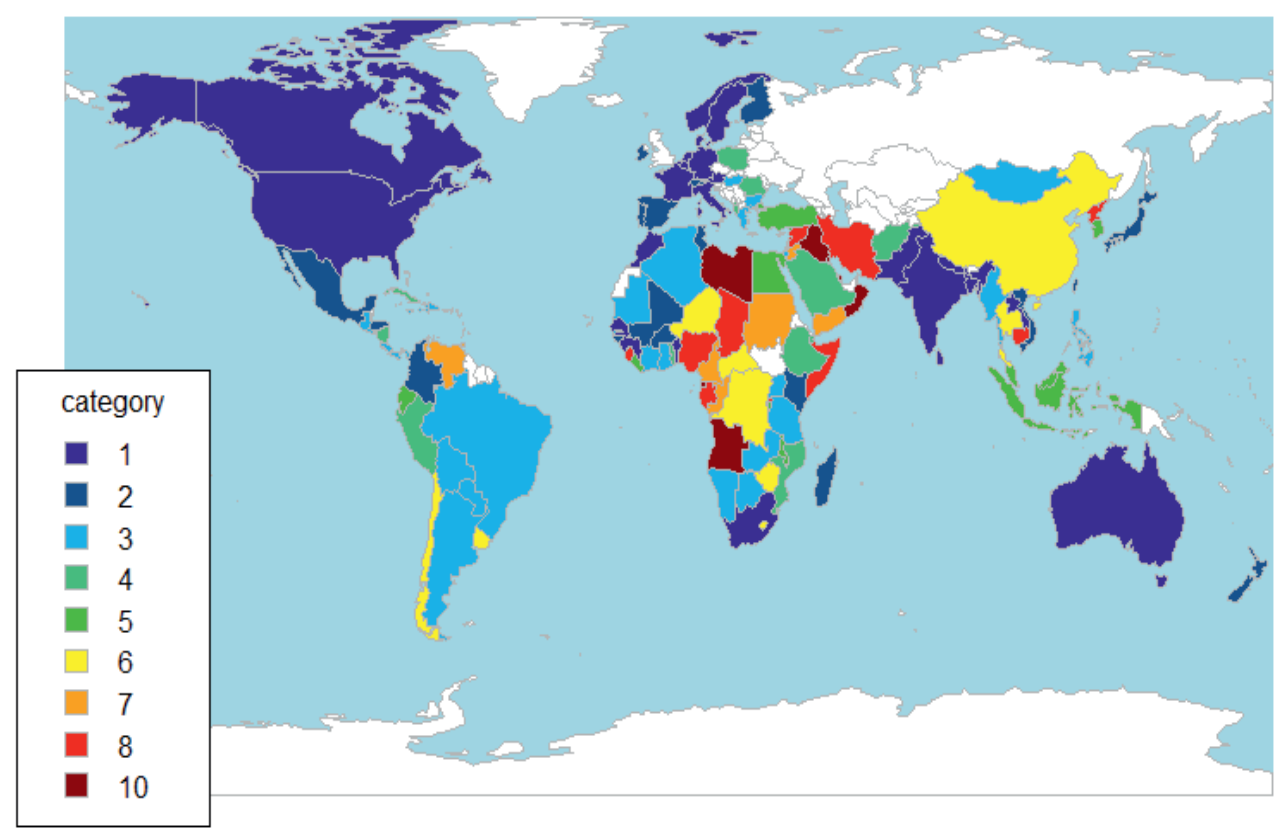

Legend: cluster group categories from 1 to 9 (top to bottom) Source: Author's own calculations and Maddison Project Database

\subsubsection{Kondratiev-dominance: the importance of the long-run cycles}

The evidence in this research shows that most of the Latin American countries are in a situation in which the Kondratiev long-run cycle is relatively dominant compared to the other groups defined in the previous session. The Kondratiev long-run growth is, as already mentioned, associated to technological changes in international patterns (Perez, 2010).

Latin America has a high dependency on commodity exports. Changes in technological paradigm result in long-run volatility in commodity prices. This is caused by a reduction in the dependency of the inputs of the previous industrial paradigm, with effects on the exchange rate (Guzman, Ocampo \& Stiglitz, 2017). The emergence of a new paradigm requires new inputs. Because of that, LA economies adjust to the cycle and change the products in which they will 
specialize if they have the possibility to do so. In Brazil, as an example, there have been historically distinct commodity cycles: the Rubber cycle, the Sugar Cane cycle, the Gold cycle, the Oil cycle. Each cycle was directly related to the industrial paradigm of the period.

Most developing countries have a high dependency on the production and exports of commodities, Latin America included. This region, though, seems to be integrated into the world economy in a different way. If we observe cycle synchronization (from the data observed in this research), we see that Latin America runs actually very coherently with the international pattern. This coherence is not that strong in Africa and Asia. The economic space of Latin America seems strongly linked with the developed countries, especially with regard to long-run changes. The short-run volatility is not as big as expected, but there is an element of dependency that generates high volatility in the long run.

A peripheral (strong) integration is the key to answer the specificity of Latin America. There is a low capacity for absorbing and generating technology, and a structure that favors specialization in low-technology intensive sectors. This is reinforced by the dependency situation (Cardoso, 1982) which argues that the political and economic elites control the natural resources, and concentrate income in order to maintain a modern high living standard. That happens in an environment marked by very high inequality. The region has an integrated but peripheral relationship with to the world markets.

\subsubsection{Juglar-dominance: the importance of the short-run cycles}

We argue based on (Korotayev \& Tsirel, 2010) that the Juglar cycles are related in the literature to investment cycles. A high volatility in this type of cycle is related to the fact that investments are done in blocks (immobilize a lot of capital). The uncertainty intrinsic in the economic systems is higher in developing countries. This uncertainty results in investments being made in periods in which there is a positive condition in the economic environment, commonly related to moments that coincide with commodity cycles. These cycles start maturing while the economic conditions of the system change. There is a period in which the investments are reduced, and that coincides with a worsening of the environmental economic conditions, increasing uncertainty and raising the (opportunity) costs to make new investments. This investment reduction results in a decline of the cycle. 
This cyclical component is then associated with the commodity cycles in developing countries. The dependence of the productive structure on the imports and exports of a few low-technology intensive commodity goods is a main component of the uncertainty. The Balance of Payments Constrained model (Thirlwall, 2012) states that investment in these economies tend to be endogenous to the foreign sector situation, which is also related to the structural conditions of the economy (Cimoli et al., 2010). The unstable effects of export and import prices as well as the price and income elasticity of imports and exports of traded goods result in the oscillation captured by the Juglar Cycles.

This is the case of countries such as Chile, Mexico and Colombia, in which the dependence of mining activities have been the main economic activity in terms of exports. Investments are responsive to price changes in the mining products these countries export, occurring when prices sustain themselves in high level for a certain period of time (Bertola \& Ocampo, 2012).

\subsection{Conclusion}

Macroeconomic volatility is a thermometer that measures the resilience that countries suffer from economic, political and institutional shocks. This chapter proposed itself to empirically study volatility at the country level. The specificity of this chapter resides in the effort to identify different types of regularities on GDP growth time series. The filter analysis extracted the regularities from the original series into different components (cycles). A cluster analysis applied on the cycle components allowed the identification of countries with similar volatility patterns.

The above procedure allowed the constitution of country groups that helped answering the research question initially defined in this research: Are Latin American economies different in terms of their volatility patterns than developed countries and other developing regions? The answer to this question is not simple and should take into account the following consideration:

LAC is at its most characterized by an average GDP growth standard deviation (compared to all 136 countries observed in the analysis). Half of its countries are marked by a high relative importance of the long-run cycles, despite a smaller relevance of the long-run trend (and of the short-run cycle). LAC countries are not homogeneous in terms of their volatility patterns but 
follow a similar characteristic, being the high relative relevance of the short-run Juglar cycle. These differences create a problem when generalizing results to the whole continent. In this sense, finding a general theory to explain the causes of overall volatility in LAC countries must take into account these specificities and discuss the causes of these differences.

Latin America has a high dependency in commodity exports. Changes in technological paradigm result in long run volatility in commodity prices. This is caused by a reduction in the dependency of the inputs of the previous industrial paradigm, with effects on the exchange rate (Guzman et al., 2017). The emergence of a new paradigm requires new inputs. LA economies adjust to the cycle and change the products in which they will specialize if they have the possibility to do so, generating high long-run Kondratiev cyclical oscillations.

A high volatility in the Juglar short-run type of cycle is related to the fact that investments are done in blocks. The uncertainty intrinsic in economic systems is higher in developing countries. This uncertainty results in investments being made in periods in which there is a positive condition in the economic environment, commonly related to periods that coincide with commodity cycles. These cycles start maturing while economic conditions of the system change. There is a period in which no new investments are made, that coincides with a reduction in the economic conditions, increasing uncertainty and raising the costs of making new investments.

On one hand, LAC in terms of volatility differs clearly from the pattern observed in developed countries. On the other hand, it shows a similar pattern to many other developing regions, especially in central Asia and parts of Sub-Saharian Africa. We see some evidence to suppose that LAC has a distinct behavior compared to developed countries, but there is no evidence to extend this conclusion to differentiate LAC from other developing countries.

In summary, the evidence from the Maddison's data shows that LAC is in average more volatile than developed countries. However, this is not necessarily true when comparing it to other developing countries. This is a common mistake presented in the Structuralist perspective, mainly because it frequently compares LAC with developed countries and not with other developing regions, which leads to these sometimes misleading strong statements. On the other hand, we see that LAC is a continent following a similar cyclical behavior, visible after applying 
the filtering methodology, which characterizes an idiosyncratic element - at least for the majority of LAC countries. 


\title{
CHAPTER 2
}

Volatility and External Crisis

Expansions of the structuralist La Marca model

\begin{abstract}
This research is aimed at investigating the causes of endogenous volatility by studying the La Marca (2010) model. Growth cycles have been broadly discussed in the literature since the times of Kondratiev and Schumpeter (Korotayev \& Tsirel, 2010). However, the literature modeling endogenous deterministic economic cycles is sparce. This article contributes to fill this gap by adding to the baseline model a macroeconomic demand-side Kaldor-Thirlwall perspective. In this model, economic activity, income distribution and accumulation of foreign assets dynamically interact, resulting in a pattern of dampened cycles. The study consists in analyzing the characteristics of the La Marca model by imposing the Balance of Payments Constrained Model (BPCM) main assumptions (Blecker, 2016): (I) Price-neutrality (the real exchange rate does not affect long-run economic growth), (II) stability of the external sector (exports and imports grow at the same rate), and (III) a fixed income distribution. We expand the original model by adding an evolutionary supply-side in which productivity is at the center of the economic dynamic through international technology transfer and the Kaldor-Verdoorn effect (economic activity leads to increases in productivity). The results show that (1) In all cases the model converges. (2) The price-neutrality assumption and external sector stability depend on specific parameter values to show either a cyclical or a monotonic convergence pattern. This reinforces the BPCM argument, implying a reduction in endogenous volatility. (3) Fixed income distribution leads to a monotonic trajectory, reducing oscillations. (4) The inclusion of the productivity dynamics generates new sources of volatility in the relationship between productivity, capacity utilization, and net external assets, in line with the structuralist argument of structural fragility (Cimoli \& Porcile, 2014).
\end{abstract}

Keywords: Economic Cycles, Evolutionary theory, Structuralism, Macroeconomic Dynamics.

JEL: E32; F44; O11; O30 


\section{Chapter 2 - Introduction}

The recurrence of a boom and bust dynamics in some key economic variables, such as GDP growth is a persistent problem for many economies, especially developing countries (Koren \& Tenreyro, 2007). This volatility has strong impacts on the economic structures, raising uncertainty, fostering productive specialization, and increasing the fragility of the economic system (Lavopa \& Szirmai, 2014). Stylized facts show that economic volatility has an important regular component, in which the literature explains using (I) concept of growth episodes (Szirmai \& Foster-McGregor, 2017) and (II) cycle theories (Korotayev \& Tsirel, 2010).

The study of Cliometrics is a classical one in the economic theory. Despite its long tradition, the existence and determinants of cycles, on many economic variables, is still a subject open to the academic debate. Econometric evidence is substantial and points to the existence of these cycles in key macroeconomic variables (Korotayev \& Tsirel, 2010). The debate surrounding growth cycles is especially important for the group of countries in which volatility is in overall higher, which includes most part of low- and medium- income countries. In poor countries, we observe the repetition of short periods of growth succeeded by strong crisis and followed by adjustment periods that weaken the structure of the economy (Foster-McGregor et al., 2015).

In chapter 1 we presented different types of cycles and discussed how countries relate to these cycles, doing an empirical analysis that managed to find some stylized facts. In this next part of the thesis, which includes chapters 2 and 3, we go deeper into the analysis about the types of cycle in which Latin America showed higher relevance, with a special attention to the long-run cycles. We look at the causes behind the emergence of these cycles and how their dynamics operate. In this research we are interested in understanding the structural elements that are the causes behind these longer, endogenous cycles. We do not focus on the very short ones, which are mainly caused by exogenous transitory shocks.

There are many economic traditions focused on discussing, modeling and explaining economic cycles. Business cycle theory has always been a hot topic in economics. Schumpeter (1939), with the technology cycle theory, and Goodwin (1967), with the growth and distribution cycle model, proposed to answer these questions using their own theoretical framework. Since the 1980's, real 
business cycle theorists have also been leading the discussion about cycles in a neoclassical perspective (Hodrick \& Prescott, 1997).

In the Structuralist theory, the role of economic structures is the main underlying aspect that defines the behavior of an economic system (Prebisch, 1950). Productive structure, labor markets, external sector, and institutions define the real economic and development possibilities of a country (Botta, 2010; Cimoli \& Porcile, 2014). The presence of weak economic structures is a central problem in the Latin American Structuralist tradition (Taylor, 1983). This weakness leads to the emergence of high amplitude short-growth cycles, and inherent instability. Latin America is a continent in which macroeconomic volatility has been a constant issue, but few efforts were made to model it endogenously. For this reason, there is still a, open gap to model the emergence of an endogenous ${ }^{3}$ cyclical dynamics for Latin America in a center-periphery framework.

This paper follows the growth model tradition started by Harrod and Goodwin. Goodwin (1967) designed a model in which the structure behind the economy defines a pattern in which growth and distribution interact in a cyclical predator-prey dynamics. This model was later developed in a structuralist version by Barbosa-Filho \& Taylor (2006). Finally, La Marca (2010) gave a further contribution to the model, combining the Structuralist Goodwin model with a stock-flow framework by Foley \& Taylor (2004). The La Marca model consists of a three dimensional dynamic system in which external sector dynamics is added to the growth and distributional interaction through accumulation of foreign assets/liabilities. This specification is able to produce dampened cycles in the trajectory to the steady state. The La Marca (2010) model is originally thought to address fast-growing export-led economies such as the ones in East Asia.

The La Marca model cares for its internal consistency. It merges the Goodwin cyclical dynamics with the Balance of Payments Constraints Model (BPCM), also known as Thirlwall model (Thirlwall, 1979), starting from a Stock-Flow consistent framework. It is an interesting and complex model despite the fact that no other work in the literature has until now proposed to

\footnotetext{
${ }^{3}$ The idea behind deterministic endogenous cycles is that the trajectory of the dynamic system oscillates indefinitely, neither converging to the steady state nor having an explosive trajectory. Cycles emerge as a central characteristic of the economic structure, and not by the presence of exogenous shocks (such as in the Real Business Cycle theory).
} 
explore it further, opening a methodological research gap. In this paper we propose to analyze and expand the La Marca model, observing the growth-cyclical pattern of countries who find themselves in the middle income trap (Lavopa \& Szirmai, 2014). The flexibility of this model, allowing us to relate economic cycles, external sector and structural elements in an oligopolistic economy - in which income distribution plays a central role - justifies our selection for this specific model. The La Marca (2010) model can be easily related to the structuralist framework, raising important insights to debate about the structural elements/failures behind developing countries' high economic volatility ${ }^{4}$.

In the La Marca (2010) model, economic actors interact in an open market economy. The dynamic behavior and interaction between capacity utilization, income distribution (wages/profits), external sector (current account), productivity and nominal exchange rate defines the trajectory and the equilibrium conditions of the system (La Marca, 2010). Under specific conditions, we test if the model can generate closed orbits, reproducing a Lotka-Volterra cyclical mechanism. The proposed model consists in a Structuralist Goodwin model with an evolutionary supply side and endogenous nominal exchange rate - with Balance of Payments constraints.

In order to further study this model, we impose some assumptions based on the main discussion of the Balance of Payments Constrained Model (BPCM), also known as Thirlwall Model. In this way we expand the La Marca (2010) model in the directions stated above. The study goes in the following direction:

I) Study the structure of the La Marca original system:

1) Impose the classic assumption of price-neutrality found on the BPCM (Thirlwall, 1979), defining the transition dynamics between short- to long-run. In this case the real exchange rate is considered constant in the long-run, growing at a zero rate.

2) Zero growth rate in the current account, avoiding the existence of structural deficits in the long run, another central assumption of the BPCM (Blecker, 2016).

\footnotetext{
${ }^{4}$ Ziesemer (1995) used the neoclassical model to get similar results, also adding the terms of trade to the discussion, as it will further developed in Chapter 3.
} 
3) Assume the case in which income distribution is constant. Profit share follows a fixed mark-up level, and the wage share is fixed. In this sense, we analyze the relationship between the evolution of the external account, and capacity utilization.

\section{II) Model a Supply Side structure}

4) Define a productivity dynamics by removing the assumption of constant technology, adding the Kaldor-Verdoorn effect (Kaldor, 1975). Through learning processes, investments lead to quantitative improvements in the productive structure, raising productivity.

5) Consider the world North-South technology gap dynamics in a center-periphery framework. The North is technologically dynamic while the south lags behind. Firms with external assets have more learning opportunities, adopting technology from abroad, which raises their domestic productivity.

In summary, our La Marca (2010) model expansions observes, in different ways, the dynamic interaction between exchange rate, wage share, output growth, capacity accumulation, net foreign asset accumulation, productivity, balance of payments constraints, and technology transfer.

In terms of the research gap, we raise the following question: how do cycles emerge from a dynamic endogenous pattern between productivity and foreign sector? This is a topic frequently discussed in the theory, and a matter of many econometric studies (Erten \& Ocampo, 2013). However, the literature does not offer well formalized models to address this specific topic. In this sense this paper aims at contributing to the Structuralist theory by studying and expanding a formal framework in search for deterministic cycles on the La Marca model, emerging from the external sector and the productive structure.

This chapter adds to the literature a better understanding on what is behind the regular boom-bust dynamics in developing countries. It is one of the biggest challenges for the low- and middleincome countries to sustain growth and overcome the medium-income trap (Foster-McGregor et al., 2015). The contribution goes through two main channels: (1) decomposing and understanding the La Marca model, observing how it behave under the Balance of Payments 
Constrained Model assumptions, under fixed income distribution, and under an exchange rate regime change; and (2) offering a solution to the inclusion of a supply side dynamics in the model, adding a productivity dynamics that takes into account a learning by doing KaldorVerdoorn element and a technology transfer/learning from domestic firms that have assets abroad (increasing the average productivity of the economy). In this way, the causes of endogenous cycles can be more deeply investigated.

\subsection{Literature Review:}

\subsubsection{Demand side cycles: Richard Goodwin and the Lotka Volterra Cycles}

The Lotka Volterra (LV) is a specific type of dynamic model in which its peculiar specification results in the formation of closed orbit solutions. In two dimension systems this model creates a Predator-Prey dynamics, commonly used in Biology and Ecological studies. It follows a specification in which one variable is the predator and the other is the prey. Both interact generating a cyclical dynamic. The LV model can be generalized for more than two dimensions (Kolgomorov model) (Gandolfo, 1971). In this case it is possible to have deterministic cycles that fluctuate around the long-run equilibria (steady state).

The use of the Lotka-Volterra system in economics can be traced back to the work of Goodwin (1967), who established a model in which economic activity and income distribution interact dynamically. The Goodwin model creates endogenous cycle in the relationship between wage share (predator) and employment (prey), reproducing a predator-prey dynamics in a closed saving-determined growing economy. This framework gave origin to a large amount of models in which economic activity (effective demand) and income distribution interact. The original model, thought for the US economy, finds profit squeeze cycles slightly damped and repetitive.

The Structuralist tradition, which accounts for the role of structural elements underlying the economic system, has made efforts to expand the Goodwin model. This tradition developed following Raul Prebisch, Celso Furtado and the whole Latin American tradition of thinkers that put structural elements, in a center-periphery framework, in the center of the analysis. Since the 1980's, Lance Taylor has formalized many of the concepts in the Structuralist theory (Taylor, 1983). In an attempt to expand the Goodwin Model with Structuralist features, Barbosa-Filho \& 
Taylor (2006) developed a dynamic system relationship between wage share and capacity utilization in a demand-driven economy. This model is based on the classical works of Kalecki (1971) and Steindl (1952) and puts the distributive conflict in the center of the analysis. The Structuralist Goodwin was also computed to the US economy, describing its profit led ${ }^{5}$ characteristics.

More recently, La Marca (2010) developed a model that merges the Structuralist Goodwin system with the Foley \& Taylor (2004) model. The latter suggests that heterodox models should use social account matrices in order to derive its causal relations, being stock-flow consistent. Foley \& Taylor (2004) also works for an open economy and also adds a financial elements (equities) to the model. La Marca (2010) used then the framework developed by Foley \& Taylor (2004) to developed an open economy version of the Goodwin model. Economic growth and fluctuations in output, capacity utilization, distribution and real exchange rate interact in an open economy generating damped cycles. La Marca (2010) extends the Structuralist Goodwin to an open economy, which results in a more complex structure than the Goodwin model, expanding it to three dimensions.

\subsubsection{Supply-side cycles: productivity, Schumpeterian cycles, structural change and catching up.}

Productivity and technological change are important aspects usually neglected in the Goodwin tradition. The Goodwin (1967) model traces back to the relationship between income distribution and economic activity, but there is a passive role for the supply-side. It assumes a Phillips curve to define the relationship between employment and real wages, and a Leontief production function, with fixed coefficients. Demand determines the adjustments on employment and economic activity through income distribution effects. The role of the supply side is secondary, if not ignored. Nonetheless, in the literature we find many supply side theories that address economic cycles. Some are presented here in this section, being part of the theoretical foundations of the La Marca (2010) model expansion.

\footnotetext{
${ }^{5}$ A pro-profit distribution has net positive effects on investment and growth.
} 
The motivation behind comparing and merging the demand- and supply-side theories of economic cycles goes hand in hand with the recent efforts to reconcile the demand-led Keynesian macroeconomic framework with the Schumpeterian evolutionary microeconomic supply-side theory. This research follows in this sense the "Keynes meets Schumpeter" tradition (Dosi, Fagiolo, \& Roventini, 2010) - focused on the use of Agent Based Models (ABM), which are not in the scope of this research.

In the mainstream growth theories, there is a central role for productivity (Total Factor Productivity) in a supply-side driven economic system. Total Factor Productivity is associated with technological change. This is the idea behind real business cycles that considers technological shocks as exogenous, in which the system itself reacts readjusting itself towards the equilibrium point (Plosser, 1989). Business cycles are created by stochastic shocks that converge monotonically (or with damped cycles) to a long run equilibrium trajectory. There are no endogenous deterministic persistent cycles in the model ${ }^{6}$. The system dynamics gets a cyclical behavior only from these stochastic shocks.

The evolutionary tradition offers a supply-side perspective focused on the presence of deterministic endogenous cycles. Schumpeter (1939) gave an implicit explanation for the existence of endogenous business cycles intrinsic to the economic structure. The central argument is focused on the role of technology. It changes the industrial paradigm through an endogenous innovative mechanism inherent of the capitalist system. This leads to a constant need of the economic structures to adjust to its new conditions because of its own competitive characteristics (Nelson \& Winter, 1977). The constant flow of innovation (some that are successful and others not) gives rise to a cyclical behavior (Silverberg \& Verspagen, 1995). This competitive process constantly changes the whole characteristics of the economic system, resulting in big productivity changes.

The evolutionary, Neo-Schumpeterian models, usually deal with individual or sectoral innovations and are currently using tools such as the ABM - eg. Ciarli et al (2010), Gaffeo et al (2008). The cyclical aggregate behavior in this framework results from the interaction of

\footnotetext{
${ }^{6}$ The absence of endogenous cycles is true for the canonical Real Business Cycle model. However, there is a tradition of mainstream models based on Shell (1967) that create endogenous cycles.
} 
individual heterogeneous agent's behavior - following a complex dynamic with many nonlinearities. This is an interesting way to deal with cycles, but the complexity involved in such simulation models turn these models into overly sensitive to the parameters, being not in the scope of this research.

Structural Change also plays a central role in terms of the supply side cyclical behavior. Krugman \& Venables (1995) show that multi-sector models in open economies define the specialization patterns and fragility of an economic structure, and Koren \& Tenreyro (2007) link this fragility to volatility. Each sector has a different productivity level and the reallocation of resources plays a central role in defining the productivity and competitiveness of an economy. In terms of the evolutionary theory, the discussion about the emergence of new sectors and reallocation between sectors is also a relevant source of volatility (Silverberg \& Verspagen, 1995). The Structuralist Theory has some important contributions in this regard. Botta (2009), and more recently Cimoli \& Porcile (2014) develop a toolbox linking a North-South framework, Structural Change, Balance of Payments Constraints and Technological Gap. The KaldorVerdoorn effect (Kaldor, 1975) is a central concept in this discussion, linking economic activity and productivity. The economy is externally constrained and has its fragility patter related to how it absorbs external shocks from terms of trade (Ziesemer, 2014).

Finally, we discuss the international technology transfer leading a catching up process (Verspagen, 1991; Lorentz et al, 2016). Countries lagged technologically have in principle more potential to catch-up to the technology frontier. Nevertheless the learning process is not natural. Lagging countries need to build a certain level of domestic capabilities that allow them to learn from abroad. In this way, they are only able to reach a virtuous catch-up process after creating some baseline conditions to learn and develop.

There are many reconciliation challenges to the academic research in defining an endogenous model for middle income countries. In this paper we address the following topics:

I. Integrate a productivity dynamics to the Goodwin model through (a) adding a Kaldor-Verdoorn effect, and (b) Modeling firms' learning in an international environment. 
II. Expand the open Structuralist Goodwin Model in a two-sector model following Krugman \& Venables (1995) (next chapter, based on the Dutt (2002) model).

These models focus on the role of the supply-side in generating the cyclical dynamics in an open economy in which growth and income distribution dynamically interact.

\subsubsection{Critiques to the Thirlwall model}

Another important source of volatility is related to the role of the external sector in the economic system. In this sense the nominal exchange rate is central. For this discussion we bring the Thirlwall framework of the Balance of Payments Constrained Model (BPCM).

The BPCM, which is also known as the Thirlwall model, reconciles the supply-side and the demand-side perspectives. The Thirlwall (1979) model is a demand-led one as it ultimately depends on the current account to define the long-run growth possibilities (Thirlwall Law). On the other hand, as the dynamic behavior of the current account depends on income and price elasticities of imports and exports, they are directly related to the condition of the productive structure and technology. The elasticities have been endogenized by authors such as Cimoli (1988), and Cimoli \& Porcile (2014).

The BPCM has two main underlying assumptions. First, it assumes that the growth rate of net foreign income is equal to zero in the long-run. In this sense, there cannot be structural explosive deficits in the external sector, and the current account is stable. Second, for the short-run, the model considers terms of trade and financial flows. In the long-run, those are assumed constant. This raises the price-neutrality assumption - the real exchange rate is constant and grows at zero rate. Considering these assumptions, the short-run model shows a stable exchange rate and a stable external position, which leads the BPCM to the Thirlwall Law (in which domestic growth adjust to the income elasticity ratio).

There is a more radical version of the BPCM called the Balance of Payments Dominance theory (Ocampo, 2011). In this version, LAC countries have their economic growth adjusted by the external sector conditions even in the short-run. The nominal exchange rate adjusts to the level that turns net exports equal to zero (so growth of exports and imports can be the same after that). 
From the Structuralist perspective, financial flows and terms of trade are important elements that create volatility. We aim to reconcile this with the La Marca (2010) model adding these elements to the system. We use a flexible nominal exchange rate that adjusts itself in order to guarantee that the growth of imports and exports grows at the same rate (zero growth in the current account in the long-run). In this way the real exchange rate would have a constant moving equation. This aspect is further explained when discussing the expansions of the model.

\subsection{The original $\operatorname{model}^{7}$}

The La Marca (2010) model is derived from a Social Accounting matrix with a stock-flow consistent set of accounts. The model implicitly starts from a Goodwin production function (Leontief). It is a demand-led model in which aggregate demand and income distribution plays a central role. The La Marca (2010) model has the following assumptions (mathematics in the annex):

1) There are four sectors: households, firms, government and external sector (ROW). Firms consist of a productive sector including industrial enterprises and the domestic financial sector. Firms can invest abroad with portfolio investments, loans, FDI or liquid assets (deposits and any kind of foreign currency reserves). Their net liabilities are denominated in foreign currency. These firms finance new investments through retained earnings and/or issuing new equities. They can pay back loans and equities. The central point is the transaction with the foreign sector, in which misalignments between national expenditure and income generate an increase or reduction in net foreign assets.

2) Government debt is negligible. The model abstracts from monetary policies.

3) There are three types of assets: productive capital, equities and net foreign assets (net foreign liabilities).

4) There are specific characteristics of the labor- and product- market equilibrium, the determinants of savings, investment and current account (explained in the annex).

5) Labor discipline defines the real wage setting (Bowles \& Boyer, 1988).

\footnotetext{
${ }^{7}$ It is important to mention that the notation in Chapter 2 is different from the one in Chapter 3. We opted to keep the expansions with the same algebraic notation as the original articles. In this sense we make our expansions compatible with the La Marca (2010) and the Dutt (2002) papers. However, it is very important to mention that these two articles have different notations among themselves. There is the variable list for each model in each of the respective chapters.
} 
6) There is a Keynesian Investment function that is autonomous from savings.

7) External sector is fundamental to define investment and demand expansion. There is a low substitutability between foreign and domestic investment.

8) There is a non-linear dynamics between real exchange rate and capacity utilization, and between distribution and net asset position.

9) Emerging economies have assets and liabilities denominated in foreign currency.

10) Consumers and investors do not borrow against future income. Retained earnings are a crucial source of finance for firms.

11) This is a pure demand-side model.

12) Distribution: interaction between workers, firms and government have traits of confliction. This conflictive nature leads to the emergence of cycles. Kaleckian and Kaldorian tradition in Wage/Profit led economies (Bhaduri \& Marglin, 1990). Real exchange rate here becomes a distributive variable.

13) Cycles emerge from: non-clearing labor market, distributional conflict, non-marginal productivity pricing.

The basic blocks of the model are described in the mathematical appendix and in the original La Marca (2010) paper. The next subsections present the dynamic aspects of the model, which consists in a relationship between a distribution wage share motion equation $(\dot{\psi})$, an economic activity capacity utilization motion equation $(\dot{u})$, and an external sector adjustment external asset accumulation equation $(\dot{b})$.

\subsubsection{Wage Share distributive equation}

Output $(X)$ in this model is divided in profit share $\pi$, wage share $\psi$, and the share of imported intermediate inputs $(a)$ in domestic currency - conversion done using the real exchange rate $(\xi)$. In this sense, the sum of the shares is equal to one. $\psi+\pi+\xi a=1$.

The motion equation of the Wage Share $(\dot{\psi})$ has the following simple specification (derivation in the annex): 


$$
\dot{\psi}=\tau\left(\psi^{*}-\psi\right)
$$

In eq. (1) $\tau$ represents the speed of adjustment between the equilibrium value of the wage share $\left(\psi^{*}\right)$ and the observed wage share $(\psi)$. The model assumes a linear adjustment process to the equilibrium point. The equilibrium value of the wage share is defined by a labor discipline real wage (Bowles \& Boyer, 1988), in which higher unemployment pressures workers to accept smaller wages (less bargaining power), reducing the wage share. The motion equation of the wage share result as (more information in the annex):

$$
\dot{\psi}=\tau[l \exp (1+u l k)-\psi]
$$

In which $l=L / X$, being $l$ the fixed amount of labor $(L)$ per unit of product $(X)$. $u=X / K, u$ is the output $(X)$ to capital $(K)$ ratio, used as an index of capacity utilization. $k=K / N$, being $k$ a constant for the relationship between capital $(K)$ and employable working population $(N)$.

The equilibrium value of the wage share follows a Phillips curve, in which employment rate $h$ has a positive relationship to wages. $h=\frac{u l k}{\varepsilon}$, in which $\varepsilon$ is the degree of effort exerted by workers. As mentioned, the equilibrium value comes from a labor discipline real wage Phillips curve theory (more in the appendix). It links the employment and the capacity utilization rate consistent with a labor market equilibrium wage share. The profit share and the share of intermediate inputs adjust to the wage share in the following way: $\xi=\frac{1-\psi}{a\left(1+\frac{1}{\eta}\right)}$ and $\pi=\frac{1-\psi}{\eta\left(1+\frac{1}{\eta}\right)}$ in which $\eta$ is the price elasticity of domestic output in world market.

\subsubsection{Capacity utilization equation}

The capacity utilization moving equation adjusts the goods market through the identity between domestic investment $(g)$, domestic savings $(\sigma)$ and net foreign investments $(z)$..

$$
\dot{u}=\lambda(g+z-\sigma)
$$

In this eq. (3), $\lambda$ is the speed of adjustment. $g$ is the domestic investment. It follows a Keynesian investment function in which $g=\alpha \pi u+\gamma, \alpha$ is the sensitivity of investment to profitability and 
$\gamma$ in the exogenous investment component that represent the "animal spirit" of the capitalists. The variable $z$ is the sum of all the components of the current account that depend on the exchange rate and $\sigma$ is the total national savings. The values of $z$ and $\sigma$ are the exchange rate sensitive elements of the external sector and the total savings, respectively ${ }^{8}$. A substitution of the variables that define the values of $g, z$ and $s$ in eq. (3), as originally in La Marca (2010) results in the following equation:

$$
\dot{u}=\lambda\left[\left(\alpha-s_{p}\right) \pi-s_{h} \psi-\xi a\right] u+\gamma+\xi^{\eta} x+\left(1-s_{p}\right) j \xi b
$$

In this equation $s_{h}$ is the propensity to save of households and $s_{p}$ is the aggregated propensity to save. $x$ is the export-capital ratio, $j$ is the interest rate and $b=B / K$ is the real value of foreign assets $(B)$ per unit of capital $(K)$. Capacity utilization evolves consistently with the level of savings, investment, interest payments and net exports. Capacity utilization then adjusts itself to the value that balances the product market. It is important to mention that he short-run equilibrium in the product market is determined by elastic imports which will be reflected in the variation of net foreign assets.

\subsubsection{External asset equation}

The third dynamic equation is related to the movements in the net external position $(b)$. It relates the internal and external changes in net asset accumulation. It comes from the relationship between current account surplus and an increase in the claims of the foreign sector. The relationship can be described as follows (more in the annex):

$$
\dot{b}=\frac{1}{\xi}(\sigma-g)-g b
$$

In this sense the growth (reduction) of net assets depends positively on internal savings but negatively on the internal and external investments. When substituting $\sigma$ and $g$ we end up with:

\footnotetext{
${ }^{8}$ We have $\sigma=s_{h}\left[\left(1-s_{b}\right)(\pi u+j \xi b)+\psi u\right]-v(\pi u+j \xi b)+s_{b}(\pi u+j \xi b)$ and $z=\xi^{\eta} x+j \xi b-\xi a u$. In which $v$ is the propensity to consume out of capital gains.
} 


$$
\dot{b}=\frac{\left(s_{p}-\alpha\right) \pi u+s_{h} \psi u-\gamma}{\xi}-\left(g-s_{p} j\right) b
$$

The three motion equations (2), (4) and (6) form a system of dynamic equations, the basis of the La Marca model. The trajectory and stability conditions of the system depend on the assumptions regarding the parameter values. La Marca extensively discuss each of the values one by one. The stability conditions are possible to observe through an analysis of the Jacobian $(J)$ of the system in its steady state.

$$
J=\left[\begin{array}{ccc}
\partial \dot{\psi} / \partial \psi & \partial \dot{\psi} / \partial u & 0 \\
\partial \dot{u} / \partial \psi & \partial \dot{u} / \partial u & \partial \dot{u} / \partial b \\
\partial \dot{b} / \partial \psi & \partial \dot{b} / \partial u & \partial \dot{b} / \partial b
\end{array}\right]
$$

The motion equation of the wage share does not depend of the net external assets, so $\partial \dot{\psi} / \partial b$ is equal to zero. A stable system must negative eigenvalues in their real part.

\subsubsection{Consolidated model, Steady State and Jacobian.}

As above discussed, the La Marca model consists in a system of three dynamic equations - eq. (2), (4) and (6). The model has the following system:

$$
\begin{gathered}
\dot{\psi}=\tau[(l \exp (1+u l k)-\psi)] \\
\dot{u}=\lambda\left\{\left[\left(\alpha-s_{p}\right) \pi-s_{h} \psi-\xi a\right] u+\gamma+\xi^{\eta} x+\left(1-s_{p}\right) j \xi b\right\} \\
\dot{b}=\frac{\left(s_{p}-\alpha\right) \pi u+s_{h} \psi u-\gamma}{\xi}-\left(g-s_{p} j\right) b
\end{gathered}
$$

We then calculate the steady state and the jacobian to understand the structural characteristics of the model.

In the steady state we have that $\dot{\psi}=\dot{u}=\dot{b}=0$. In this sense, the steady state conditions are:

$$
\psi^{*}=l \exp \left(1+u^{*} l k\right)
$$




$$
\begin{gathered}
u^{*}=-\frac{\left[\gamma+\xi^{* \eta} x+\left(1-s_{p}\right) j \xi^{*} b^{*}\right]}{\left[\left(\alpha-s_{p}\right) \pi^{*}-s_{h} \psi^{*}-\xi^{*} a\right]} \\
b^{*}=\frac{\xi^{* \eta} x-\xi^{*} a u^{*}}{g^{*}-j}
\end{gathered}
$$

Being $\xi^{*}=\frac{1-\psi^{*}}{a\left(1+\frac{1}{\eta}\right)}$ and $\pi^{*}=\frac{1-\psi^{*}}{\eta\left(1+\frac{1}{\eta}\right)}$.

In order to calculate the Jacobian matrix (eq.7) we take the partial derivatives of each of the motion equations in relation to another (annex for the math):

$$
J=\left[\begin{array}{ccc}
\lambda\left[\frac{\partial \xi}{\partial \psi}\left(\eta \xi^{\eta-1} x-a u\right)-\left(s_{p}-\alpha\right)\left(\frac{\partial \pi}{\partial \psi}\right) u+\frac{\partial \xi}{\partial \psi}\left(1-s_{p}\right) j b-s_{h} u\right] & -\lambda\left[\left(s_{p}-\alpha\right) \pi+s_{h} \psi+\xi a\right] & \lambda\left(1-s_{p}\right) j \xi \\
\frac{1}{\xi}\left(\frac{\partial \sigma}{\partial \psi}-\frac{\partial g}{\partial \psi}\right)-\frac{\partial \xi}{\partial \psi} \frac{(\sigma-g)}{\xi^{2}}-\frac{\partial g}{\partial \psi} b & \frac{1}{\xi}\left[\frac{\partial \sigma}{\partial u}-\frac{\partial g}{\partial u}(1+\xi b)\right] & -\left(g-s_{p} j\right)
\end{array}\right]
$$

From the study of the variable signs done in the La Marca (2010) model we end up with the jacobian results ${ }^{9}$, which would give us the following signs:

$$
\begin{gathered}
\psi^{*}=l \exp \left(1+u^{*} l k\right) \\
u^{*}=-\frac{\left[\gamma+\xi^{* \eta} x+\left(1-s_{p}\right) j \xi^{*} b^{*}\right]}{\left[\left(\alpha-s_{p}\right) \pi^{*}-s_{h} \psi^{*}-\xi^{*} a\right]} \\
J=\left[\begin{array}{lll}
- & + & 0 \\
- & - & + \\
+ & + & -
\end{array}\right]
\end{gathered}
$$

This type of jacobian gives a pair of conjugate complex numbers for two eigenvalues, and a third real negative eigenvalue, showing a cyclical dampened pattern around a stable point. The result

${ }^{9}$ In which $\frac{\partial \xi}{\partial \psi}=\left[-\frac{1}{a\left(1+\frac{1}{\eta}\right)}\right] ; \frac{\partial \pi}{\partial \psi}=\left[-\frac{1}{\eta\left(1+\frac{1}{\eta}\right)}\right] ; \frac{\partial \sigma}{\partial \psi}=\left[s_{h} u-s_{p} u \frac{1}{\eta\left(1+\frac{1}{\eta}\right)}-s_{p} j b \frac{1}{a\left(1+\frac{1}{\eta}\right)}\right] ; \frac{\partial \sigma}{\partial u}=\left[s_{p} \frac{1-\psi}{\eta\left(1+\frac{1}{\eta}\right)}+s_{h} \psi\right] ;$
$\frac{\partial g}{\partial \psi}=\left[\frac{-\alpha u}{\eta\left(1+\frac{1}{\eta}\right)}\right]$ 
is a dynamic adjustment in which there are dampened cycles between capacity utilization and income distribution, as we can see in the simulation in the next session.

\subsubsection{Calibrations of the La Marca (2010) model}

In this sub-section we see two distinct simulations taken from the original La Marca model. The first one shows the original results of the paper, in which the author calibrates the model using reasonable values for a growing Asian economy. The model shows the presence of dampened cycles, as observed analyzing the structure of the model. The second simulation reinforces the cyclical adjustment mechanism with higher cycles, in a calibration closer to represent a LAC economy. It shows an interesting pattern in which the variables oscillate many times before reaching its equilibrium value.

Figure 2.1. Reproduction of the La Marca (2010) original results.

Wage share $(\psi)$

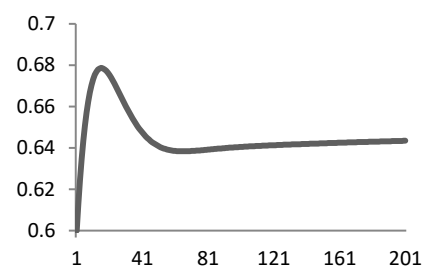

Real exchange rate $(\xi)$

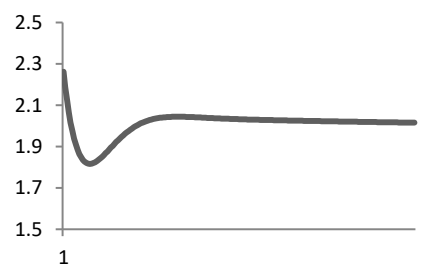

Capacity utilization $(u)$

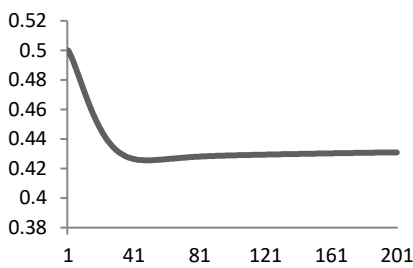

$\psi \times u$

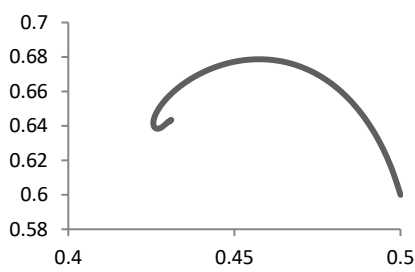

Net foreign assets $(b)$

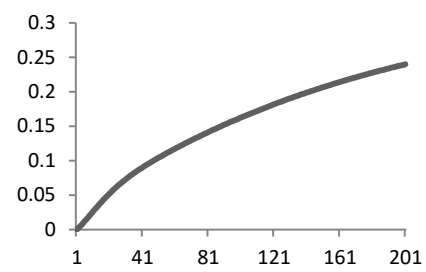

$\psi \times b$

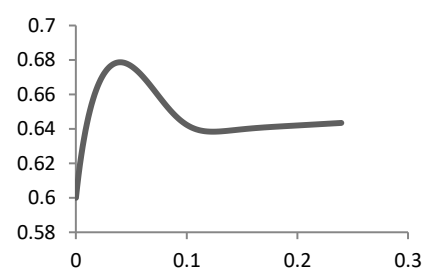

Parameter Values: $\tau=1, \lambda=1, k=20, l=0.1, \gamma=0.05, \alpha=0.5, \eta=1.3, a=0.1, x=0.05, j=0.03$, $s_{b}=0.5, s_{h}=0.3$.

Initial conditions: $\psi_{0}=0.6, u_{0}=0.5, b_{0}=0$.

Steady state: $\psi=0.65, u=0.43, b=0.34$. 
Eigenvalues: $\lambda_{1}=-0.71+0.59 i, \lambda_{2}=-0.7-0.59 i, \lambda_{3}=-0.06$.

$J=\left[\begin{array}{ccc}-1 & 1.29 & 0 \\ -0.33 & -0.41 & 0.02 \\ 0.14 & 0.08 & -0.06\end{array}\right]$

Figure 2.1 reproduces the Figure 5 results taken from the original La Marca (2010) paper. The upper left figure shows the evolution of wage share on time. On upper middle we have the capacity utilization. The top right graph shows the net external assets. Bottom left shows the real exchange rate dynamics. On bottom middle we see the cyclical relation between growth and distribution. Finally the bottom right figure shows the relation between wage share and net financial assets.

The original model results in a small oscillation dampened cycle configuration. The Jacobian of the dynamic model under these assumptions results in a negative trace and positive determinant which creates in a stable dynamics. Moreover, the eigenvalues of the Jacobian consists in a pair of conjugate complex numbers. As it is a $3 \times 3$ matrix, the determinants of the $2 \times 2$ sub-matrices should be observed according to the Routh-Hurwitz conditions. By looking at the sub-matrices (see original La Marca 2010), this ends up resulting in the generation of dampened cycles. The final result of the model is the emergence of a dampened cycle trajectory with a small number of oscillations.

The adjustment process can be understood in the following terms (La Marca, 2010):

Stagflationary phase: An initial shock shifts the variables away from their equilibrium values (eg. fiscal contraction). There is an excess supply which results in "forced exports". Output and capacity utilization fall to balance supply and demand (domestic plus foreign) at the current real exchange rate. Wage share grows, squeezing profits and appreciating the real exchange rate. The economy slows down and domestic prices increases relative to foreign prices. Competitive exports and net assets revenue reduces, which lead demand to reduce more than supply. Employment then reduces more than its equilibrium value - starting a reversal of the wage dynamics. 
Stagnationary phase: Prices slow down, the real exchange rate depreciates and profits and competitive exports start recovering. Output and wage contraction balances production and demand. Further wage reduction brings the economy to a recovery phase.

Recovery Phase: There is output and capacity utilization growth. There is "forced imports" which fill the gap between fast-growth demand and lagged supply. There is an inflationary boom (costs raising wages and prices) that leads to a reduction in profits. The role of the net assetcapital ratio $(b)$, as a response to the output-distribution dynamic, feeds back into the aggregate demand equilibrium.

This cyclical dynamics arise from the complex social relationship in the model. The growthdistribution dynamics feeds into the evolution of the real exchange rate, international competitiveness, and factor payments that combine to generate oscillations in the current account and trade balance.

Using the same model, it is possible to test different parameters to observe how that would affect the evolution of the distinct variables. As an exercise we impose changes in some specific variables to observe different adjustments, some with higher cyclical oscillations, as the case below, in which we change the values of $l, x, j$ and $s_{h}$

\section{Figure 2.2. Alternative calibration of the La Marca model}

Wage share $(\psi)$

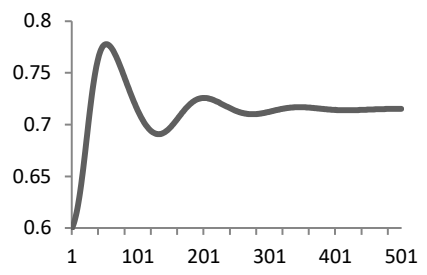

Real exchange rate $(\xi)$
Capacity utilization $(u)$

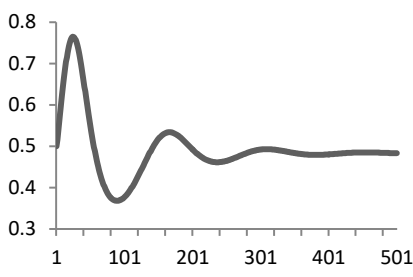

$\psi \times u$
Net external assets $(b)$

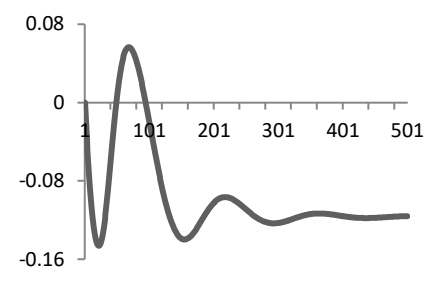

$\psi \times b$ 

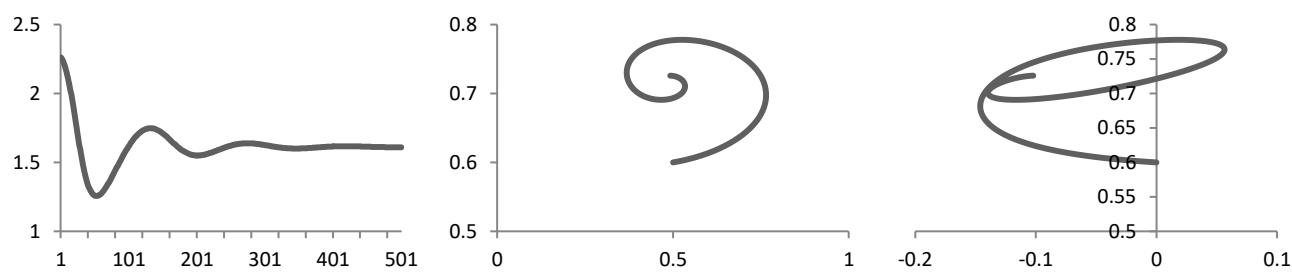

Parameter Values: $\tau=0.1, \lambda=1, k=20, l=0.01, \gamma=0.05, \alpha=5, \eta=1.3, a=0.1, x=0.01, j=0.1$, $s_{b}=0.5, s_{h}=0.6$.

Initial conditions: $\psi_{0}=0.6, u_{0}=0.5, b_{0}=0$.

Steady state: $\psi=0.71, u=0.48, b=-0.12$.

Eigenvalues: $\lambda_{1}=-0.12+0.44 i, \lambda_{2}=-0.12-0.44 i, \lambda_{3}=-0.34$

$J=\left[\begin{array}{ccc}-0.1 & 0.14 & 0 \\ -1.34 & -0.12 & 0.01 \\ 0.91 & 0.09 & -0.33\end{array}\right]$

In Figure 2.2 we have on the top left the behavior of the wage share over time. Top center is the capacity utilization rate over time, while top right is the net external assets over time. Bottom left is the dynamic behavior of the real exchange rate over time. In the bottom center we see the between wage share and capacity utilization. Finally in the bottom right is the relationship between net foreign assets and wage shares.

The results show a much stronger oscillation with dampened cycles in wage share and capacity utilization, as well as between the wage share and net external assets. The net assets show a peak in the first cycle but then smooth towards its steady state (negative one in this case), also showing a cyclical dynamics with the wage share. The real exchange rate follows the opposite of the wage share, with an interesting cyclical behavior. Considering the current specification of the model it is possible to define a dynamic pattern with dampened cycles.

The rationality behind this case is similar to the previous case (Southeast Asian growing country). The main difference is that the adjustment mechanism happens in many rounds, being every round weaker than the previous one. The economy under these conditions suffers higher volatility and has less capacity to adjust itself from shocks (e.g. external price changes), which is a much similar pattern of the behavior of a Latin American economy. It is relevant to mention that La Marca initially thought the model for a rapid developing Asian country such as Korea. 


\subsection{Model Analysis}

\subsubsection{Changing the clusure of the model: BPCM Assumptions - price neutrality and fixed RER}

The La Marca (2010) model assumes a constant nominal exchange rate (fixed $e$ ). The real exchange rate fluctuates according to the behavior of the terms of trade. In the La Marca model the economy can operate with chronic external deficit in the long-run. If we accept the Balance of Payments Constrained Model (BPCM), initially developed by Thirlwall (1979), an economy cannot have explosive deficits in the long run. Considering the price-neutrality assumption as well, the Thirlwall Law highlights that no economy can grow above the rate of growth compatible with the balance of payments - growth given in its simpler version by the ratio between income elasticities of exports and imports, times foreign growth.

In the original La Marca model, the real exchange rate is defined as $\xi=\frac{e \bar{P}}{P} . P$ is the price of domestic goods, $\bar{P}$ is the price of foreign goods and $e$ the nominal exchange rate, which is considered a constant. In the BPCM the long-run real exchange rate dynamics adjusts itself to stabilize the external sector. In the Balance of Payments dominance of Ocampo (2011), this is also valid for the short-run. In this way, the real exchange rate is constant, and the nominal rate fluctuates in order to create a trajectory in which the net external assets $(B)$ tend to a steady state equilibrium - growth of exports is equal to the growth of imports. This discussion can be summarized in the assumption that the real exchange rate is constant.

$$
\xi=\iota
$$

$\iota$ is a given constant. When considering the Balance of Payments Dominance of Ocampo (2011), in the case of middle-income trapped countries, the balance of payments needs to be balanced even in the short run. In order to do so, the nominal exchange rate must adjust itself to move towards this goal. In this case, the real exchange rate should have zero growth, being always in its steady state. This implies that $\dot{\xi}=0$.

This assumption goes in line with the first of the two main assumptions of the BPCM, in which prices are neutral in the long-run, do not affecting the growth rate compatible with balance of 
payments (equilibrium growth rate). This assumption has its roots in the very low price elasticity of imports and exports, in the stability of financial flows, and in the assumption that the terms of trade (real exchange rate) grows at zero rate in the long-run (Blecker, 2016).

The second main assumption of the BPCM concerns the fact that the growth of exports cannot de bigger or smaller than the growth of imports in the long-run (McCombie, 2012). This would result in an explosive behavior of the current account, creating major external imbalances that are not sustainable in the long-run. In order to follow this second assumption we set that the net foreign asset growth is constant, growing at zero rate $(\dot{B}=0)$, which implies that the net foreign asset growth per unit of capital is constant, also done by La Marca (2010). We assume $\dot{K}=0$, then $b$ also grows at zero rate $(\dot{b}=0)$.

When adding these BPCM assumption elements to the La Marca model, we reach a simpler 2dimensional system in which growth and distribution variates with a constant real exchange rate. We then have:

$$
\begin{aligned}
& \dot{\xi}=0 \Rightarrow \text { BPCM Assumption } 1 \\
& \dot{b}=0 \Rightarrow \text { BPCM Assumtpion } 2
\end{aligned}
$$

When applying these assumptions to the model, the system results the following:

$$
\begin{gathered}
\dot{\psi}=\tau[(l \exp (1+u l k)-\psi)] \\
\dot{u}=\lambda\left\{\left[\left(\alpha-s_{p}\right) \pi-s_{h} \psi-\iota a\right] u+\gamma+\iota^{\eta} x+\left(1-s_{p}\right) j \iota b\right\}
\end{gathered}
$$

In which $\dot{b}=0$. This completely changes the characteristics and the structure of the model and result in a relationship that is very similar to the one described by Goodwin (1967) between growth and distribution. We can analytically check the impacts on the trajectory by looking at the steady state and the Jacobian:

Steady State $(\dot{\psi}=0$ and $\dot{u}=0)$ :

$$
\psi^{*}=\tau\left[\left(l \exp \left(1+u^{*} l k\right)\right)\right]
$$




$$
u^{*}=\frac{-\left[\gamma+\iota^{\eta} x+\left(1-s_{p}\right) j \iota b\right]}{\lambda\left[\left(\alpha-s_{p}\right) \pi^{*}-s_{h} \psi^{*}-\iota a\right]}
$$

For the jacobian of partial derivatives, as $\frac{\partial \xi}{\partial \psi}=0$, we have:

$$
J=\left[\begin{array}{cc}
-\tau & \tau l^{2} k \psi \\
\lambda\left[-\left(s_{p}-\alpha\right)\left(\frac{\partial \pi}{\partial \psi}\right) u-s_{h} u\right] & -\lambda\left[\left(s_{p}-\alpha\right) \pi+s_{h} \psi+\iota a\right]
\end{array}\right]
$$

Considering, as La Marca does, the positive values of $\tau, l, k, \psi, \lambda, s_{p}, s_{h}, \alpha, u, \pi, a, \iota$, and $\frac{\partial \pi}{\partial \psi}$, we have the following jacobian:

$$
J=\left[\begin{array}{ll}
- & + \\
- & -
\end{array}\right]
$$

The matrix shows a negative trade and a positive determinant: $\operatorname{Tr}\left(J_{\bar{b}}\right)<0$ and $\operatorname{Det}\left(J_{\bar{b}}\right)>0$. This results in a pair of conjugate eigenvalues with positive real part and imaginary part. The result depends on the magnitude of the values, which could result in is a dampened cyclical adjustment between $\psi$ and $u$ (Goodwin dynamics), or in a monotonic convergence.

The results then show that the cyclical dynamics hold with the two assumptions of the BPCM, which opens the discussion about the real need of accepting these two strong assumptions to explain the cyclical economic adjustment in developing countries. There is a whole literature tradition that question the assumptions of the BPCM (Blecker, 2016; McCombie, 2012) later discussed in Chapter 4.

We can simulate the new system using similar values of the original La Marca model in order to show the differences in the adjustment dynamics when adopting both assumptions (priceneutrality and constant net asset accumulation), so the net foreign assets grow at zero rates in the long-run.

Figure 2.3. Modified La Marca model with $\dot{\xi}=0$ and $\dot{b}=0$ 
Wage share $(\psi)$

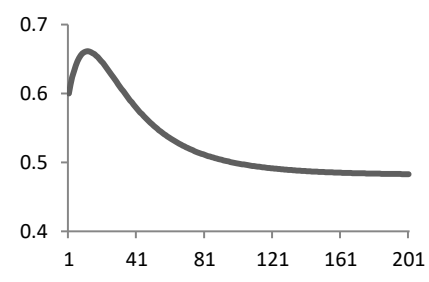

Net Foreign Assets (b)

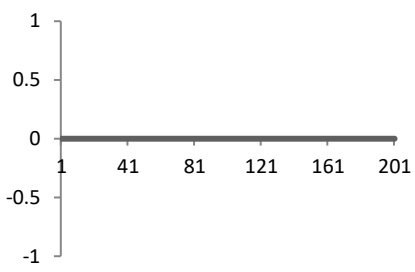

Capacity Utilization $(u)$

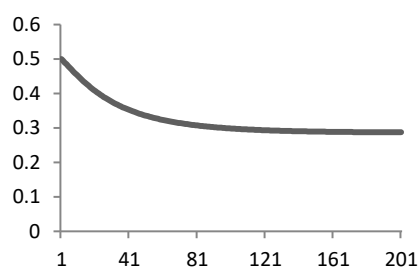

$\psi \times u$

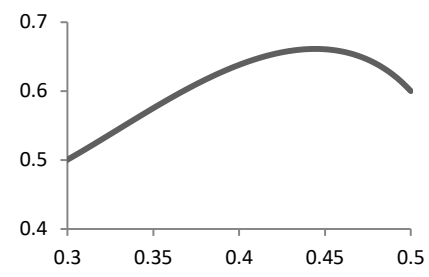

Parameter values: $\tau=1, \lambda=1, \mathrm{k}=20, \mathrm{l}=0.1, \gamma=0.05, \alpha=0.5, \eta=1.3, \mathrm{a}=0.1, \mathrm{x}=0.05, \mathrm{j}=0.03, \mathrm{~s}_{\mathrm{b}}=$ $0.5, \mathrm{~s}_{\mathrm{h}}=0.3$.

Initial conditions: $\psi_{0}=0.6, \mathrm{u}_{0}=0.5, \mathrm{~b}_{0}=0, \xi_{0}=0.01$.

Steady state: $\psi=0.47, \mathrm{u}=0.28, \mathrm{~b}=0, \xi=0.01$.

Eigenvalues: $\lambda_{1}=-0.91, \lambda_{2}=-0.26, \lambda_{3}=0$,

$J=\left[\begin{array}{cc}-1.00 & 0.96 \\ -0.06 & -0.18\end{array}\right]$

In Figure 2.3, the top figures represent the evolution of wage share (left), and capacity utilization (right), while the bottom left the net exports/capital respectively on time. The bottom right figure shows the relationship between capacity utilization and wage share.

This case followed the same calibration values of Figure 2.1. The system converges, showing a small oscillation, but it does not generate cycles (there are no complex eigenvalues). They follow a monotonic convergence to a stable equilibrium point. Variables such as the wage share and the net assets initially increase. Then they start converging to the steady state. The capacity utilization converges monotonically to the steady state. 


\subsubsection{Fixed income distribution.}

Income distribution is a central aspect in the harrodian tradition of growth models. Following a discussion in this sense, we test the case in which we fix the income distribution between profits and wages. That allows us to study the relationship between capacity utilization (economic activity) and external sector (net external assets). Considering a monopolistic economy, its profit share $(\pi)$ is a function of the mark-up $(z)$, being $\pi=\frac{z}{z+1}$. We fix the profit share as $\pi=\bar{\pi}$ and analyze the case in which the wage share is also constant $(\psi=\bar{\psi})$, growing at a zero rate $\dot{\psi}=0$.

That would imply that the equations for $\psi, \pi$, and $\xi$ would completely change, and the fixed income distribution would help us understand the relationship between capacity utilization $(u)$ and balance of payments $(b)$, a central debate on in the BPCM framework.

Considering fixed income distribution, the wage share is constant, therefore its growth rate is equal to zero: $\dot{\psi}=0$. That would also imply that $\pi=\bar{\pi}$ and $\xi=\bar{\xi}$. When applying these assumptions to the original system, we have that:

$$
\begin{gathered}
\dot{u}=\lambda\left\{\left[\left(\alpha-s_{p}\right) \pi-s_{h} \psi-\xi a\right] u+\gamma+\xi^{\eta} x+\left(1-s_{p}\right) j \xi b\right\} \\
\dot{b}=\frac{\left(s_{p}-\alpha\right) \pi u+s_{h} \psi u-\gamma}{\xi}-\left(g-s_{p} j\right) b
\end{gathered}
$$

The steady state can be computed when $\dot{u}=0$ and $\dot{b}=0$ :

$$
\begin{gathered}
u^{*}=-\frac{\left[\gamma+\xi^{\eta} x+\left(1-s_{p}\right) j \xi b^{*}\right]}{\left[\left(\alpha-s_{p}\right) \pi-s_{h} \psi-\xi a\right]} \\
b^{*}=\frac{\left(s_{p}-\alpha\right) \pi u+s_{h} \psi u^{*}-\gamma}{\xi\left(g-s_{p} j\right)}
\end{gathered}
$$

The Jacobian of partial derivatives of $\dot{u}$ and $\dot{b}$ in terms of $u$ and $b$ is the following:

$$
J=\left[\begin{array}{cc}
\lambda\left[\left(\alpha-s_{p}\right) \pi-s_{h} \psi-\xi a\right] & \lambda\left(1-s_{p}\right) j \xi \\
\frac{\left(s_{p}-\alpha\right) \pi+s_{h} \psi}{\xi}-b \alpha \pi & s_{p} j-\alpha \pi u-\gamma
\end{array}\right]
$$


Considering the sign value study of the La Marca original model, that would result in a Jacobian in which:

$$
J=\left[\begin{array}{ll}
- & - \\
+ & +
\end{array}\right]
$$

With this Jacobian we observe that the eigenvalues of this model would depend on value magnitude. The magnitude of the absolute values of the jacobian elements defines if the model converges or diverges from the steady state (possibility of divergence), as well as if there is a presence of cycles. In our simulation based on the original La Marca values we see that the model is likely to operate with real numbers, without an imaginary part.

Figure 2.4. Simulation for fixed income distribution $(\dot{\psi}=0)$

Wage share $(\psi)$

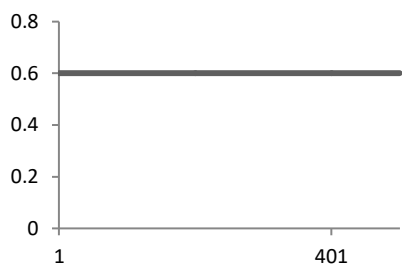

Net external assets $(b)$

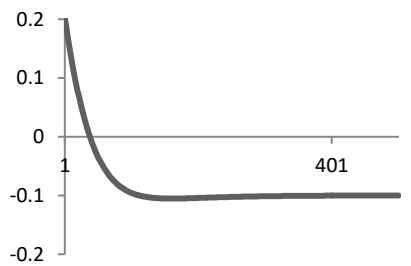

Capacity Utilization $(u)$

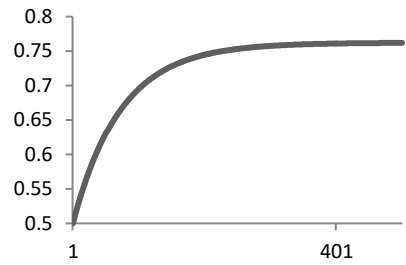

$u \times b$

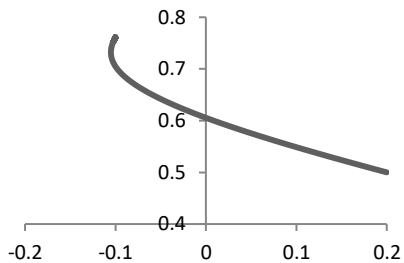

Parameter values: $\tau=1, \lambda=1, k=20, l=0.1, \gamma=0.05, \alpha=1.2, \eta=1.3, a=0.1, x=0.05, j=0.01$, $s_{b}=0.5, s_{h}=0.3$.

Initial conditions: $\psi_{0}=0.6, u_{0}=0.5, b_{0}=0.2, \xi_{0}=0.01$.

Steady state: $\psi=0.60, u=0.76, b=-0.1, \xi=0.01$.

Eigenvalues: $\lambda_{1}=-0.31, \lambda_{2}=-0.13, \lambda_{3}=0, \lambda_{4}=0$. $J=\left[\begin{array}{cc}-0.38 & -0.13 \\ 0.32 & 0.05\end{array}\right]$ 
The adjustment process converges to the equilibrium, but it loses the cyclical dynamics. The wage share is constant, keeping its initial value, and the growth of net external asset reduces initially, followed by increases when there are changes in the capacity utilization. We observe a monotonic convergence between growth and balance of payments, in which an increase in growth shows a negative correlation with accumulation of external assets. A rise in economic growth has negative effects in the Balance of Payments (BP), being a potential source of external constraints, maintaining the BP constraints.

The presence of fixed income distribution removes the cyclical component from the model. The source of endogenous oscillation disappears when we fix income distribution (strong assumption). Without any expansion to the system, changes in income distribution are shown as a central element in structural volatility.

\subsection{Model expansion:}

The scope of this model expansion is to change the focus to the behavior of economies trapped in the middle income. The middle-income trap (Lavopa \& Szirmai, 2014) is a concept that highlights how countries may not advance economically above certain level as their competitiveness in manufactured export goods is reduced by rising wages (Glawe \& Wagner, 2016). The idea of middle-income trap has been debated in the literature, with authors also strongly criticizing its existence (Felipe, Kumar, \& Galope, 2017). We understand this development trap in the context of Latin America, in which stagnation has been the norm in the last decades. In order to capture that, we understand that economic activity, captured by the capacity utilization rate, is a proxy to determine the growth possibilities in these economies.

In order to capture this development trap, we see that it is fundamental to reproduce endogenous cycles with neutral stability, as they reproduces a dynamic that may not monotonically converge to the steady state. The economics variables remain fluctuating in an endogenous mechanism that raises volatility and keep an economy trapped in its current development stage. Cycles with neutral stability $\left(R E\left(\lambda_{i}\right)=0\right.$ and $\left.I\left(\lambda_{i}\right) \neq 0\right)$ are only possible in the La Marca model when we see that competitiveness in terms of productivity is also affected by the distribution/output behavior in the exact value of a hopf bifurcation value. In this sense, we search to further develop the Structuralist literature, starting its central idea in which a chronic volatility is 
generated by structural failures, in terms of a weak and fragile productive structure, and a low capacity to innovate (Porcile \& Spinola, 2018). We briefly develop this idea in the next session.

\subsubsection{Productivity dynamics}

Following the theoretical debate, in this section we expand the La Marca (2010) model by adding a productivity dynamics that incorporates the role of the supply side as a central aspect of the model. We implement it using the idea of the Kaldor-Verdoorn effect (Kaldor, 1975). This effect incorporates learning by doing, which allows the occurrence of increasing returns to scale. In this sense, an increase in demand, either by a growth in output $(\dot{X})$ or in investment $(g)$, results in a rise in productivity. It is important to mention that the lack of investment in manufacturing tends to reduce innovation, technological progress, and diversification, with all the related consequences as to long-run development.

As can be observed in the Annex A3.3, Productivity is given by $\varepsilon / l$. We consider the work effort $(\varepsilon)$ as fixed, and endogenize the effective labor per unit of product $(l)$. The Kaldor-Verdoorn effect relates investment and productivity, so: $l=f(g), d l / d g<0$. In this sense, investment growth leads to a reduction of the effective labor per product $(L / X)$, increasing productivity.

In addition to that, we consider an additional assumption, that foreign investments in the form of foreign bonds are related to productive assets, to investments in foreign companies. The accumulation of external assets generates positive technological spillovers in terms of productivity to the domestic firms. Technology transfer is a fundamental aspect to understand the relationship between developed north and developing south, marked by the presence of a technology gap (Verspagen, 1991). The domestic firms become more competitive as they learn with the activities of their subsidiaries located abroad. Technology transfer to the domestic economy has the positive effect on domestic firms' productivity. This raises average country productivity. Using a linear equation, the effects of technology transfer in productivity $(\theta<0)$ are given by:

$$
i=\rho g+\theta b+\phi l
$$


$\rho$ represents the learning-by-doing Kaldor-Verdoorn effect, and $\theta$ captures the technological transfer from foreign firms to domestic firms. $\phi$ is the decreasing effect of the level of laboroutput. Because $l$ is seen as inverse of productivity, $\rho=d i / d g<0$. Increases in demand generate specialization in the sectors an economy produce, leading to learning by doing, and increases in labor productivity (reducing the labor-output ratio). Also, $\theta=d \dot{l} / d b<0$ and $\phi=d i / d l<0$. The option for a linear equation is a matter of simplification.

After implementing this addition, the new dynamic system can be presented as the following:

$$
\begin{gathered}
\dot{\psi}=\tau[(l \exp (1+u l k)-\psi)] \\
\dot{u}=\lambda\left\{\left[\left(\alpha-s_{p}\right) \pi-s_{h} \psi-\xi a\right] u+\gamma+\xi^{\eta} x+\left(1-s_{p}\right) j \xi b\right\} \\
\dot{b}=\frac{\left(s_{p}-\alpha\right) \pi u+s_{h} \psi u-\gamma}{\xi}-\left(g-s_{p} j\right) b \\
i=\rho g+\theta b+\phi l
\end{gathered}
$$

In the steady state $(\dot{\psi}=\dot{u}=\dot{b}=\dot{l}=0)$ :

$$
\begin{gathered}
l^{*}=-\frac{\theta b^{*}+\rho g^{*}}{\phi}= \\
b^{*}=\frac{\left(s_{p}-\alpha\right) \pi u^{*}+s_{h} \psi u^{*}-\gamma}{\xi^{*}\left(g^{*}-s_{p} j\right)} \\
\psi^{*}=l^{*} \exp \left(1+u^{*} l^{*} k\right) \\
u^{*}=-\frac{\left[\gamma+\xi^{* \eta} x+\left(1-s_{p}\right) j \xi^{*} b^{*}\right]}{\left[\left(\alpha-s_{p}\right) \pi^{*}-s_{h} \psi^{*}-\xi^{*} a\right]}=0
\end{gathered}
$$

Considering the derivatives in the original La Marca defining the first three rows and three columns, the expansion of the jacobian adds the partial derivatives for $l$ : 


$$
J=\left[\begin{array}{llll}
\partial \dot{\psi} / \partial \psi & \partial \dot{\psi} / \partial u & \partial \dot{\psi} / \partial b & \partial \dot{\psi} / \partial l \\
\partial \dot{u} / \partial \psi & \partial \dot{u} / \partial u & \partial \dot{u} / \partial b & \partial \dot{u} / \partial l \\
\partial \dot{b} / \partial \psi & \partial \dot{b} / \partial u & \partial \dot{b} / \partial b & \partial \dot{b} / \partial l \\
\partial \dot{l} / \partial \psi & \partial \dot{l} / \partial u & \partial \dot{l} / \partial b & \partial \dot{l} / \partial l
\end{array}\right]
$$

Based on the signs discussed by La Marca and in this session expansion, we have:

$$
J=\left[\begin{array}{llll}
- & + & 0 & + \\
- & - & + & 0 \\
+ & + & - & 0 \\
+ & + & - & -
\end{array}\right]
$$

From the Jacobian signs we study the stability conditions of the model for each pair of equations. Decomposing the system in pairwise effects results in the following structure:

$J_{\psi, u}=\left[\begin{array}{cc}- & + \\ - & -\end{array}\right]-$ Cyclical convergence

$J_{\psi b}=\left[\begin{array}{cc}- & 0 \\ + & -\end{array}\right]$ - Cyclical Convergence

$J_{\psi l}=\left[\begin{array}{cc}- & + \\ + & -\end{array}\right]$ - Monotonic Convergence

$$
\begin{aligned}
& J_{u, b}=\left[\begin{array}{ll}
- & + \\
+ & -
\end{array}\right]-\text { Monotonic convergence/divergence } \\
& J_{u, l}=\left[\begin{array}{ll}
- & 0 \\
+ & -
\end{array}\right] \text { - Conditional Cyclical convergence } \\
& J_{b, l}=\left[\begin{array}{ll}
- & 0 \\
- & -
\end{array}\right] \text { - Conditional Cyclical convergence }
\end{aligned}
$$

We observe the possibility of cycles emerging from the following relations: (1) wage share and capacity utilization (Goodwin). (2) Wage share and net foreign assets. (3) Capacity utilization and productivity. (4) Net foreign assets and productivity. The first two effects have been already discussed in the original model, so we focus on the latter two cyclical elements.

\section{Capacity utilization and productivity}

The relationship between capacity utilization and productivity is initially thought in terms of increasing returns brought by the Kaldor-Verdoorn law. Increases in economic activity have positive effects on productivity. What we observe in our dynamic system is that the relationship between capacity utilization and productivity has a cyclical aspect.

This is explained in the following terms: a higher productivity counter-balances the effects of increases in capacity utilization. The same output can be produced with a smaller rate of capacity, as there is higher productivity. The cyclical aspect emerges when we initially observe 
an increase in output, raising productivity. This rise in productivity pressures for a "virtuous" reduction in capacity utilization, as output increases given higher labor productivity. This behavior ends ups resulting in a cyclical adjustment towards the equilibrium value.

Net foreign assets and productivity

A second corollary in our model expansion concerns the cyclical relationship between the accumulation of net foreign assets and productivity. The accumulation of external assets let domestic firms learn from foreign activities, raising their productivity because of the bonus generated by firm internationalization. In dynamical terms, we see the cyclical aspect emerging because of two effects: First, more productive firms from developing countries become more attractive to be bought by big companies in the developed world (denationalization, a very common feature since the 1990's in Latin America). Second, Firms in developing countries find a barrier to their growth in productivity from technology transfer. As this transfer is not an automatic movement, these companies manage to catch-up until a certain point - after which they stagnate - as firms in the developed world continue with their innovative virtuous strategies. In this sense, this dynamically counterbalances the effects of increases in productivity, generating the oscillatory behavior.

Figure 2.5. Simulation 1 - Modified La Marca results with productivity dynamics, original calibration

Wage Share $(\psi)$

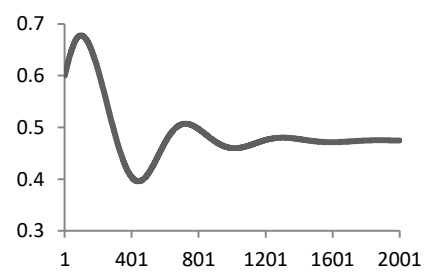

Real Exchange Rate $(\xi)$
Capacity Utilization $(u)$

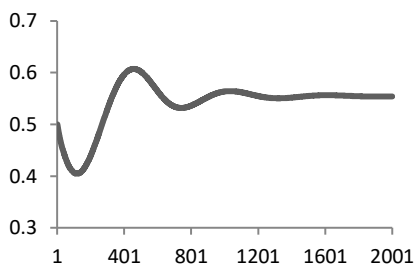

Labor-Output Ratio (l)
Net foreign Assets (b)

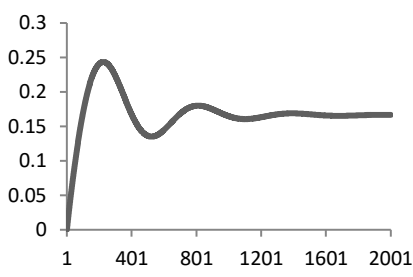

$\psi \times u$ 

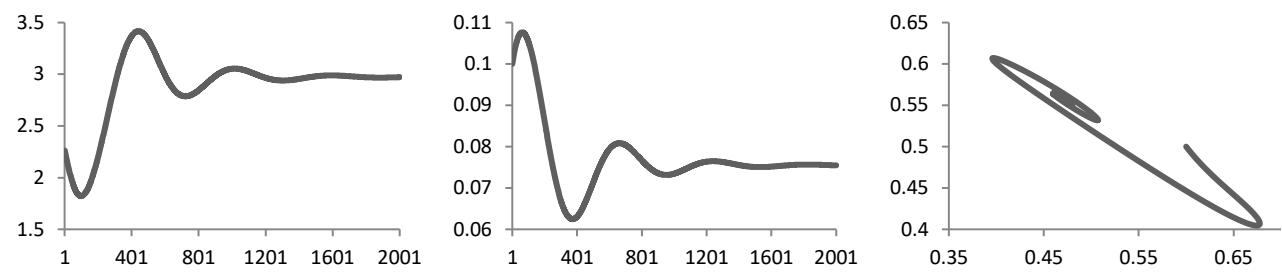

Parameter values: $\tau=0.1, \lambda=1, k=20, l=0.1, \gamma=0.05, \alpha=0.5, \eta=1.3, a=0.1, x=0.05, j=0.03$, $s_{b}=0.5, s_{h}=0.3, \rho=0.03, \theta=-0.02, \phi=-0.001$

Initial conditions: $\psi_{0}=0.6, u_{0}=0.5, b_{0}=0, l=0.1$.

Steady state: $\psi=0.47, u=0.55, b=0.16, l=0.09$

Eigenvalues: $\lambda_{1}=-0.029+0.108 i, \lambda_{2}=-0.029-0.108 i, \lambda_{3}=-0.413, \lambda_{4}=-0.029-0108 i$.

$J=\left[\begin{array}{cccc}-0.100 & 0.071 & 0 & 1.153 \\ -0.338 & -0.471 & 0.032 & 0 \\ 0.094 & 0.04 & -0.094 & 0 \\ -0.003 & 0.003 & -0.02 & -0.001\end{array}\right]$

The first five figures from top to bottom, and left to right, represent the evolution of the wage share, capacity utilization, net external asset/capital, real exchange rate and effective labor per unit of product in time. The last figure shows how growth and distribution evolve between themselves. We see that the oscillatory pattern with dampened cycles exists for all variables. All of them stabilize in an equilibrium point.

The addition of the productivity dynamics, which is a structural element of an economic system, results in the emergence of other sources of oscillatory behavior. All variables in the system have cycles, not only growth and distribution. This brings another element to discuss the role of foreign sector adjustments. Balance of payments adjustments now cyclically converge to a stable point. This expansion opens the floor debate how the cyclical aspects are related to economic structures, advancing the structural cycles that Taylor (1983) initially developed.

Figure 2.6. Simulation 2 - Modified La Marca results with productivity dynamics, Hopf calibration value 


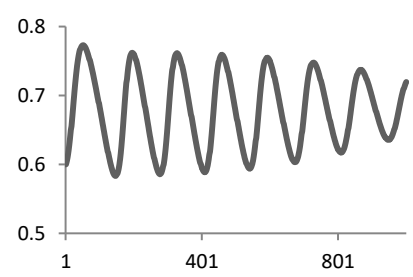

Real Exchange Rate $(\xi)$

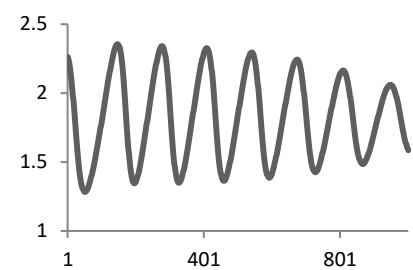

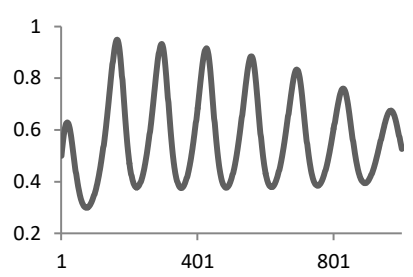

Labor-Output Ratio (l)

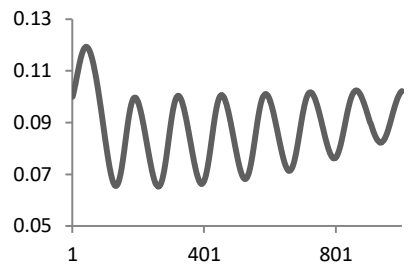

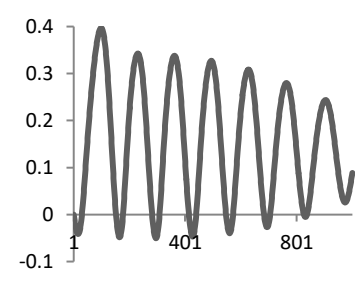

$\psi \times \mathrm{u}$

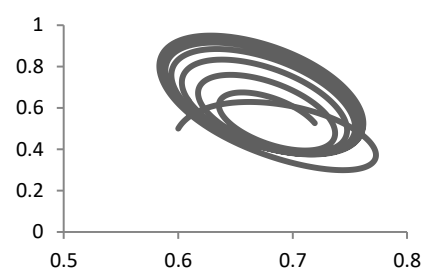

Parameter values: $\tau=0.1, \lambda=1, k=20, l=0.01, \gamma=0.05, \alpha=5, \eta=1.3, a=0.1, x=0.05, j=0.3$, $s_{b}=0.4, s_{h}=1 . \rho=0.01, \theta=-0.03$.

Initial conditions: $\psi_{0}=0.6, u_{0}=0.5, b_{0}=0, l=0.1$.

Steady state: $\psi=0.69, u=0.49, b=013, l=0.1$

Eigenvalues: $\lambda_{1}=-0.037+0.41 i, \lambda_{2}=-0.037-0.41 i, \lambda_{3}=-0.214+0.198 i, \lambda_{4}=-0.214-0.198 i$.

$J=\left[\begin{array}{cccc}-0.1 & 0.13 & 0 & 1.38 \\ -1.50 & -0.32 & 0.01 & 0 \\ 0.92 & -0.01 & -0.09 & 0 \\ -0.01 & 0.01 & -0.03 & 0\end{array}\right]$

When we change the parameters of the expanded model, we can reach a situation in which the cyclical dynamics repeats itself indefinitely. Using the variable $\theta$ as the adjustment variable, we calibrate it to a value that gets closer to a situation in which there is neither convergence nor divergence - so cycles can repeat themselves indefinitely (The hopf bifurcation point).

This specification generates a very interesting pattern. The initial value when in the hopf bifurcation value, converges to a limit cycle. However, it may not stay in the cycle indefinitely unless in the exact value that splits the convergence and the divergence areas. When observing the value of the eigenvalues, we see that the model is still stable, but it generates a chaotic behavior in which it keeps oscillating for a big number of runs and then stabilizes itself. The same pattern was observed under other initial values. We reinforce that the variable value $\theta=-0.03$ was simply calibrated to be closer to the hopf bifurcation point (Lorenz, 1989). Any 
small change in the system will result in a change in the trajectory, leading to either an explosive behavior or a regular cyclical stability. If we change the parameters of the system, then The hopf bifurcation parameter must then be adjusted to a different calibration.

What these results tell us is that the economy under these conditions may enter in a cyclical pattern in which it will never reach a stable equilibrium. The convergence pattern will always pull the economy to a volatility pattern, even with the absence of external shocks. In these sense, an endogenous pattern of volatility emerges in the economy that pushes to a trapped region. Important to mention that, as this result depends on the calibration, it is not a lotka-volterra system in which cycles show neutral stability, resulting from the characteristics of the model.

\subsection{Discussion of the results}

\section{a. Accepting the BPCM assumptions}

Figure 2.3 shows that when we change the exchange rate regime from fixed to flexible, this partially change the dynamics of the system. The cyclical dynamics can occasionally hold when accepting the two assumptions of the BPCM (depending on the parameter values), which opens the discussion about the real need of accepting these two strong assumptions to explain the cyclical economic adjustment in developing countries. There is a whole literature tradition that question the assumptions of the BPCM (Blecker, 2016; McCombie, 2012). This is further discussed in Chapter 4.

If we accept that these assumptions do not affect the convergence behavior, we have an additional argument to defend the BPCM and the Thirlwall Law (Blecker, 2016). This can be explained in the sense that an economy can possibly have non-price neutrality and an explosive behavior in its external accounts, but still reach an equilibrium point after an oscillatory period.

Depending on specific parameter values, the trajectory to equilibrium can also show a monotonic convergence, showing smaller volatility than the cyclical adjustment. In this sense, we can raise the argument behind the classic Dornbusch Latin Triangle (Dornbusch, 1992) discussion. Here, the exchange rate regime affects the endogenous pattern of volatility. The adoption of a fixed real exchange rate (fluctuating nominal rate) changes the model dynamic - this modifies the result from a dampened cyclical adjustment to a monotonic convergence. The fact that we do not 
observe explosive behavior in any of the cases indicates that the two assumptions may not be necessary to maintain the basic characteristics of the model.

The trajectory to the steady state changes from dampened cycles to a monotonic trajectory. This implies that changes in the exchange rate regime of the economy reduce endogenous oscillations. An external sector policy aimed at avoiding external debt reduces the endogenous pattern of volatility. This result is very much in line with the BPCM and the Balance of Payment Dominance theories. A middle-income economy, that cannot hold foreign debt in its own currency, has its growth directed constrained by the behavior of its external sector. A direct adjustment to the external sector reduces the endogenous volatility. However, the cost is high in terms of economic activity and distribution. As it can be seen in the model, a change in the currency regime reduces economic activity and the part of income that go to wages (wage share), when compared to the previous exchange rate regime.

This situation is similar to that of many Latin American countries in the 1990's decade. Taking the case of Brazil as an example, the transition to the fixed nominal exchange rate regime in 1994 resulted in increases in real wages, in the wage share and in the utilization capacity rate. However, the country started suffering from pressures in its Balance of Payments with the fixed nominal exchange rate. After the crisis of 1998, and return to the flexible nominal exchange rate, economic activity was strongly reduced as well as real wages (rise in internal prices and major nominal exchange rate devaluation). The exchange rate regime changes led to smaller volatility at the cost of higher inequality and smaller growth. This results indicates that the use of the exchange rate show not to be the best policy to aim at the reduction of endogenous volatility in the case of a development strategy.

\section{b. Fixed income distribution}

When we fix the income distribution fixed - constant wage- and profit-share - we can directly observe the relationship between capacity utilization and net external assets. The result in the simulation shows a monotonic convergence pattern to an equilibrium point. By looking at the jacobian, we see that we can also have dampened cycles if changing the parameters. 
From the original values, the adjustment still converges but it loses the cyclical dynamics it had before. Wage share is constant to its initial value, and the growth of net external asset initially reduces followed by an increase, as capacity utilization changes. We then see a monotonic convergence between growth and balance of payments, in which an increase in growth shows a negative correlation with accumulation of external assets. A rise in economic growth have negative effects in the Balance of Payments, showing a central source of external constraints, following then results that are similar to the BPCM framework ideas.

\section{c. Productivity dynamics}

In Figure 2.6, the inclusion of a productivity dynamics is part of a search to find deterministic stable cycles. This type of cycle happens when, in the presence of no shocks, the system inherently oscillates. We check if productivity interacts with income distribution and economic activity, generating stable cycles. With our current specification, which considers the effects of the Kaldor-Verdoorn effect and technology transfer, deterministic cycles only appear under very specific conditions. This leads us to the study of the hopf bifurcation parameters. The model itself, however, shows an interesting cyclical relationship between productivity and economic activity, and between productivity and the accumulation of net external assets.

These interesting relationships can be explained by (1) a higher productivity that counterbalances the effects of a rise in capacity utilization. The rise in productivity pressures for a virtuous reduction of capacity, as output increases given higher labor productivity. This behavior leads to a cyclical adjustment towards the equilibrium value. (2) The most productive firms from developing countries become attractive to be purchased by big international companies. Also, firms in developing countries find a barrier to their growth in productivity from technology transfer. These elements dynamically counterbalance the effects of Kaldor-Verdoorn increases in productivity, generating an oscillatory behavior.

The calibration we used was aimed test values for a middle-income economy. One in which the behavior of the real exchange rate is endogenously unstable. The endogeneity of productivity is central to explain this behavior. An increase in the wage share has negative effects on productivity itself, but in a wage-led economy it boosts growth, which through an increase in the 
capacity utilization affects investment. The rise in productivity occurs with the Kaldor-Verdoorn effect. This compensatory dynamics gives rise to the cycles.

The central contribution in this research resides in the fact that the economic cycles are explained as a pure endogenous mechanism in these developing economies. It is not a result of exogenous shocks, such as the policy shocks of the Real Business Cycle, technological shocks of the Schumpeterian theory or the Terms of Trade shocks as in the traditional Structuralist perspective. We argue that the cyclicality is a pattern generated by the own characteristics of these economies, related to their structural aspects.

\subsection{Conclusion}

This paper proposed to study and expand the La Marca (2010) model in 3 different fronts: (1) accepting the BPCM assumption of price-neutrality and stable behavior of the balance of payments; (2) considering a constant income distribution between wages and profits, and (3) adding a productivity dynamics and technology transfer to the model. This work offers a small contribution, adding a jigsaw, to a puzzle that is still open in the Structuralist literature: what is behind the "chicken flights" growth pattern, in which countries have their growth processes constantly interrupted after a small virtuous period of growth. This is one of the biggest challenges for the low- and middle- income countries to sustain growth and overcome the medium-income trap (Foster-McGregor et al., 2015). In other terms: how to think about endogenous deterministic cycles that are characteristic of middle-income countries in a CenterPeriphery framework?

The results show that (1) In all cases the model converges. (2) The price-neutrality assumption and external sector stability depend on parameters to have a cyclical or monotonic convergence. This reinforces the BPCM argument, and may imply a reduction in endogenous volatility. (3) Fixed income distribution lead to a monotonic trajectory, reducing volatility. (4) The inclusion of the productivity dynamics generates new sources of volatility in the relationship between productivity, capacity utilization, and net external assets, being in line with the Structuralist argument of structural fragility.

The inclusion of the BPCM assumptions does not change the convergence pattern of the model. This is relevant in the sense that the absence of an explosive divergent pattern guarantees that the 
BPCM leads to a stable equilibrium both in the short- and the long-run. The empirical critiques to the Thirlwall Law's heroic assumptions remain relevant, but without meaning that the BPCM do not hold in terms of its stability and brings another element to defended it in the debate about the critiques to the BPCM (Blecker, 2016; McCombie, 2012).

The currency regime $\grave{a}$ la Dornbusch (1992) Latin Triangle is briefly discussed. A flexible nominal exchange rate focused on balancing the external sector changes the dynamic properties of the model. The convergence trajectory to the steady state may not generate cycles depending on the parameters. This is an important finding. The Thirlwall model and the Balance of Payments Dominance of Ocampo (2011) state the relevance of the external constraints the longand short-run respectively. An exchange rate mechanism that is able to adjust the external sector automatically (no debt accumulation) results - in the La Marca (2010) model - in a pattern that reduces the endogenous instability in the adjustment mechanism. Despite the flexibility that the nominal exchange rate offers, when it keeps the real exchange rate constant, it reduces volatility. There are costs in terms of the steady state. It reduces the equilibrium values of the wage share and the capacity utilization. Achieving smaller volatility involves a trade-off, a reduction in the economic activity and income concentration on profits.

The perspective embedded in this paper clearly states that the answers to our research questions are partially related to the supply-side of the economy in the demand-led models. Schumpeter and the evolutionary school offer some central contributions to understand the complex dynamic that emerges in a world in which technological change is at the center of the development debate. The paper offer a simple solution to the inclusion of productivity in the model, taking into account a learning by doing Kaldor-Verdoorn element and a technology transfer/learning from domestic firms that have assets abroad (increasing the average productivity of the economy). The results indicate that even the simple inclusion of a productivity dynamics is able to, under very specific conditions, generate deterministic stable cycles. This is of fundamental importance, because it shows that even in the presence of no shocks, the system in inherently not stable, endogenously cyclical.

Finally, this paper offers an invitation to expand new contributions in the Structuralist KaldorThirlwall framework of La Marca (2010) exploring even further the Schumpeterian aspects of 
the economic cycles. The cyclical aspect of middle income trapped economies could be further analyzed with other model expansions: adding a multi-sector model, exploring further the technological dynamic, increasing the heterogeneity of agents (with the use of Agent based models). The Structuralist literature on cycles is still scarce on modeling techniques and the additions of new theoretical approaches and new models to observe specific aspects related to low- and middle- income countries offers an open space for a whole new road of research opportunities. 


\section{Annex 2.1. Chapter 2 variable list}

\begin{tabular}{|c|c|c|c|}
\hline$X$ & Aggregate Production & $r$ & Profit Rate \\
\hline$K_{i}$ & Capital Stock & $g$ & Domestic investment rate \\
\hline$x$ & Export-capital ratio & $\xi b$ & Foreign investments \\
\hline$L$ & Labor & $m$ & Mark-up over costs \\
\hline$l$ & Labor-output ratio & $P$ & Prices \\
\hline$B$ & Value of Foreign Assets & $p_{e}$ & Equities unit price \\
\hline$b$ & Net foreign assets rate & $\sigma$ & Domestic Savings \\
\hline$D_{i}$ & Dividends & $\gamma$ & Animal Spirit \\
\hline$N$ & Employable working population & $\alpha$ & Investment sensitivity to profitability \\
\hline$H$ & Amount of hours worked & $\xi$ & Real Exchange Rate \\
\hline$h$ & employment rate $(H / N)$ & $\kappa$ & Current Account $(\chi K)$ \\
\hline$k$ & Capital-population ratio & $\eta$ & $\begin{array}{l}\text { Price-elasticity of domestic output in } \\
\text { world market. }\end{array}$ \\
\hline$\varepsilon$ & effort exerted by workers & $z$ & $\begin{array}{l}\text { Non-exchange rate dependent current } \\
\text { account (Net foreign savings) }\end{array}$ \\
\hline$a$ & $\begin{array}{l}\text { Share of imported intermediate } \\
\text { inputs }\end{array}$ & $\tau$ & Wage Share speed of adjustment. \\
\hline$u$ & Capacity Utilization & $\lambda$ & speed of adjustment capital utilization \\
\hline$\psi$ & Wage Share & $s$ & Propensity to save \\
\hline$\pi$ & Profit Share & & SUBSCRIPTS: \\
\hline$j$ & Real return on net foreign assets & $b$ & firms \\
\hline$E$ & Equities & $h$ & Households \\
\hline$e$ & Nominal Exchange rate & $p$ & Weighted rate \\
\hline$\iota$ & Constant for RER & $g$ & Government \\
\hline$\rho$ & $\begin{array}{l}\text { Learning-by-doing Kaldor-Verdoorn } \\
\text { effect }\end{array}$ & $f$ & Foreign Sector \\
\hline$\theta$ & $\begin{array}{l}\text { Technological transfer from foreign } \\
\text { firms to domestic firms }\end{array}$ & * & Equilibrium value \\
\hline$\phi$ & $\begin{array}{l}\text { Decreasing effect of the level of } \\
\text { labor-output }\end{array}$ & $J$ & Jacobian \\
\hline$\Lambda$ & Balance of payments result & $\lambda_{i}$ & Eigenvalues \\
\hline$T_{i}$ & Taxes & $Y_{i}$ & Income per social class \\
\hline$t_{i}$ & Tax rate & $m$ & Mark-up \\
\hline$S$ & Savings & $\Omega$ & Liabilities \\
\hline$C_{o}$ & Costs & $w$ & Wage per worker \\
\hline
\end{tabular}




\section{Annex 2.2. Mathematical appendix (Chapter 2)}

Table 2.1. Balance Sheets

\begin{tabular}{|c|c|c|c|c|c|}
\hline \multicolumn{2}{|c|}{ Households } & \multicolumn{2}{c|}{ Firms } & \multicolumn{2}{c|}{ Foreign (RoW) } \\
\hline$p_{E} E$ & $\Omega_{h}$ & $K$ & $p_{E} E$ & $-\xi B$ & $\Omega_{f}$ \\
\hline & & $\xi B$ & $\Omega_{b}$ & & \\
\hline
\end{tabular}

Table 2.2. Social Accounts Matrix

\begin{tabular}{|c|c|c|c|c|c|c|c|c|c|}
\hline & $\begin{array}{c}\text { Output } \\
\text { Cost }\end{array}$ & $\mathrm{HH}$ & Firms & Gov & ROW & Cap & Equit & Bonds & Tot \\
\hline Output & & $C_{h}$ & & $G$ & $\chi K$ & $g K$ & & & $X$ \\
\hline \multicolumn{10}{|l|}{ Incomes } \\
\hline $\begin{array}{l}\text { Household } \\
(\mathrm{HH})\end{array}$ & $\psi X$ & & $D_{b}$ & & & & & & $Y_{h}$ \\
\hline Firms & $\pi X$ & & & & $j \xi B$ & & & & $Y_{b}$ \\
\hline Government & & $T_{h}$ & $T_{b}$ & & & & & & $Y_{g}$ \\
\hline RoW & $\xi a X$ & & & & & & & & $Y_{f}$ \\
\hline \multicolumn{10}{|l|}{ Funds } \\
\hline $\mathrm{HH}$ & & $S_{h}$ & & & & & $-p_{E} \dot{E}$ & & 0 \\
\hline Firms & & & $S_{b}$ & & & $-g K$ & $p_{E} \dot{E}$ & $-\xi \dot{B}$ & 0 \\
\hline Govvernment & & & & $\left(S_{g}\right)$ & & & & & 0 \\
\hline ROW & & & & & $\left(S_{f}\right)$ & & & $\xi \dot{B}$ & 0 \\
\hline Total & $X$ & $Y_{h}$ & $Y_{b}$ & $Y_{g}$ & $Y_{f}$ & 0 & 0 & 0 & \\
\hline
\end{tabular}

\section{Incomes:}

$$
\begin{gathered}
\text { Households: } Y_{h}=C_{h}+T_{h}+S_{h}=\psi X+D_{b} \\
\text { Firms: } D_{b}+T_{b}+S_{b}=\pi X+j \xi B=Y_{b} \\
\text { Government: } G+\left(S_{g}\right)=T_{h}+T_{b}=Y_{g} \\
\text { RoW: } \chi K+j \xi B+\left(S_{f}\right)=\xi a X=Y_{f}
\end{gathered}
$$

$\chi K-$ Current Account

$\xi a X$ - Share of intermediate import goods

$j \xi B-$ Revenue from foreign assets

$p_{E} \dot{E}-$ New Equities

$\xi \dot{B}-$ New Foregein Investment

\section{Flow of funds:}

$$
\text { Househoulds: } S_{h}=p_{E} \dot{E}
$$

Firms Savings: $S_{b}=g K+\xi \dot{B}-p_{E} \dot{E}$

Government: $S_{g}=0$

$$
\text { RoW: } S_{f}=\xi \dot{B}
$$

Adding Flows to Income:

Households Flows: $C_{h}+T_{h}+p_{E} \dot{E}=\psi X+D_{b}$

Firms Flows: $D_{b}+T_{b}+g K+\xi \dot{B}-p_{E} \dot{E}=\pi X+j \xi B$ 
Government Flows: $G=T_{h}+T_{b}$

RoW Flows: $\chi K+j \xi B-\xi \dot{B}=\xi a X$

External sector:

$$
-S_{f}=\xi \dot{B}
$$

As:

From (A2.13):

$$
\chi K+j \xi B-\xi \dot{B}=\xi a X \Rightarrow \xi \dot{B}=\chi K+j \xi B-\xi a X
$$

$$
\begin{gathered}
\xi \dot{B}=(\xi x+j \xi b-\xi a u) K-\Lambda \Rightarrow \xi \dot{B}=\xi x K+j \xi B-\xi a X-\Lambda \Rightarrow \\
\Rightarrow \xi a X=\xi x K-\Lambda+j \xi B-\xi \dot{B} \Rightarrow \chi K=\xi^{\eta} x K-\Lambda \\
\Lambda=\xi^{\eta} x K-\chi K
\end{gathered}
$$

Saving Propensity Rates: Household and firm net savings rate excluding taxes:

$$
\begin{aligned}
& s_{h}=s_{h}^{o}\left(1-t_{h}\right) \\
& s_{b}=s_{b}^{o}\left(1-t_{b}\right) \\
& v=v^{o}\left(1-t_{b}\right) \\
& s_{h}^{o}=\frac{S_{h}}{X} \\
& s_{b}^{o}=\frac{S_{b}}{X} \\
& s_{h}=\frac{S_{h}}{X}\left(1-t_{h}\right) \\
& \text { (A2.15) } s_{b}=\frac{S_{b}}{X}\left(1-t_{b}\right)
\end{aligned}
$$

Prices and Income Distribution:

$$
\begin{array}{ccc}
l=L / X & u & =X / K \\
h=H / N & \varepsilon=L / H & k=K / N \\
& h=\frac{H}{N}=\frac{H}{L} \frac{X}{K} \frac{L}{X} \frac{K}{N}=\frac{u l k}{\varepsilon}
\end{array}
$$

Wage share:

$$
\psi=\frac{w l}{P \varepsilon}
$$

Real Exchange Rate:

$$
\xi=\frac{e \bar{P}}{P}
$$

Profit Share:

Costs:

$$
\begin{gathered}
C_{o}=(w L+a P \xi)=\left(\frac{w l}{\varepsilon}+e \bar{P} a\right) \\
P=\text { Mark-up * Costs }=(1+m)(w L+a P \xi) \Rightarrow P=(1+m)\left(\frac{w l}{\varepsilon}+e \bar{P} a\right)
\end{gathered}
$$


Profit $=$ sales - costs $=P X-C_{o}=>$ Profit Rate $=$ Profit $/$ Capital Value $=>r=\frac{\left(P X-C_{o}\right)}{P K}$

$$
r=\frac{P X-\left(\frac{w l}{\varepsilon}+e \bar{P} a\right)}{P K}
$$

Real value of total profits :

$$
\begin{gathered}
r K=\pi X \text { or } r=\pi u \\
\psi X+\pi X+\xi a X=X \Rightarrow \pi+\psi+\xi a=1 \Rightarrow \pi=1-\psi-\xi a \Rightarrow \pi=1-\frac{w l}{P \varepsilon}-\frac{e \bar{P}}{P} a \Rightarrow \\
\Rightarrow \pi=\frac{1}{P}\left(P-\frac{e l}{\varepsilon}-e \bar{P} a\right) \Rightarrow \pi=\frac{1}{P}\left(P-C_{o}\right) \Rightarrow \\
\Rightarrow \pi=\frac{\left[(1+m)\left(\frac{w l}{\varepsilon}+e \bar{P} a\right)-\left(\frac{w l}{\varepsilon}+e \bar{P} a\right)\right]}{(1+m)\left(\frac{w l}{\varepsilon}+e \bar{P} a\right)} \Rightarrow \pi=\frac{m}{(1+m)} \\
\pi=\frac{m}{(1+m)}=m(\psi+\xi a)
\end{gathered}
$$

$\eta$ - elasticity of the price elasticity of domestic output in the world market

$$
\begin{gathered}
\pi=\frac{1-\psi}{\eta\left(1+\frac{1}{\eta}\right)} \\
\xi=\frac{1-\psi}{a\left(1+\frac{1}{\eta}\right)}
\end{gathered}
$$




\section{Annex 2.3. Labor Discipline Theory - From Bowles \& Boyer $(1988,1989)$}

$\omega_{f}-$ single firm's wage rate per hour worked, $\omega_{a}-$ wage offered by any other firm $h$ - employment rate as a proxy of the probability of reemployment.

Employment rent $-\omega_{f}-h \omega_{a}$

$$
\varepsilon=\ln \left(\omega_{f}-h \omega_{a}\right)
$$

$\omega^{o}$ - Labor cost-minimizing wage rate offered by a single competitive firm (optimal wage rate)

Firm's profit Maximization per effective work unit $(\omega / \varepsilon)$ at eq. wage:

$$
\begin{gathered}
\omega^{o}=\varepsilon\left(\frac{\partial \varepsilon}{\partial \omega_{f}}\right)^{-1} \\
\omega^{o}=\left(\omega_{f}-h \omega_{a}\right) \ln \left(\omega_{f}-h \omega_{a}\right)
\end{gathered}
$$

$\omega_{a}$ and $h$ are given for individual firm, but vary in the aggregate

Aggregate effect:

$$
\frac{d \omega^{o}}{d h}=\left(2-h \frac{\omega_{a}}{\omega^{o}}\right) \omega_{a}
$$

$$
\frac{d \omega}{d h}=\frac{d \omega^{o}}{d h}\left(1-\frac{h}{\omega_{a}} \frac{d \omega^{o}}{d h}\right)^{-1}=\frac{\left(2-h \frac{\omega_{a}}{\omega^{o}}\right) \omega_{a}}{1-h\left(2-h \frac{\omega_{a}}{\omega^{o}}\right)}
$$

Equilibrium as a uniform wage rate $\omega=\omega_{f}=\omega_{a}$

$$
\frac{d \omega}{d h}=\frac{(2-h) \omega}{(1-h)^{2}}
$$

Integrating, we have the market real wage as function of employment rate $\omega^{*}=\omega^{*}[h]$

$c$ - integration constant normalized to 1

$$
\omega^{*}=c \frac{\exp \left(\frac{1}{1-h}\right)}{1-h}
$$

The equilibrium wage share: $\psi^{*}=\omega^{*} / \varepsilon^{*}$

$$
\begin{gathered}
\omega^{*}=\frac{\exp \left(\frac{1}{1-h}\right)}{1-h}=(1+u l k) \exp (1+u l k) \\
\varepsilon^{*}=\frac{1}{1-h}=1+u l k \\
h=\frac{u l k}{\varepsilon}=\frac{u l k}{1+u l k}
\end{gathered}
$$

$$
\begin{gathered}
\psi^{*}=l \exp \left(\frac{1}{1-h}\right)=l \exp (1+u l k) \\
\dot{\psi}=\tau\left(\psi^{*}-\psi\right) \\
\dot{\psi}=\tau[(l \exp (1+u l k)-\psi)]
\end{gathered}
$$

Partial derivatives:

$$
\begin{array}{l|l}
\frac{\partial \dot{\psi}}{\partial u}=\tau l^{2} k \psi & \frac{\partial \dot{\psi}}{\partial \psi}=-\tau
\end{array}
$$




\section{Annex 2.4. Model derivation}

Effective demand:

Profit rate: $r$, Revenue from foreign investments: $j \xi b$

Net foreign asset rate $(b)$ :

$$
b=\frac{B}{K}
$$

The capitalized value of net profits gives the asset value of invested capital.

$$
q=\frac{\left(1-t_{b}\right)(\pi u+j \xi b)}{j}=\frac{p_{E} E}{K}
$$

$t_{b}-$ tax rate of profits. $g-$ Investment rate (capital accumulation).

$$
\begin{array}{r}
g=\alpha \pi u+\gamma \\
g=\frac{\dot{K}}{K}=\widehat{K} \\
\alpha=\alpha^{o}\left(1-t_{b}\right)
\end{array}
$$

Trade account:

$$
\chi K+j \xi B+\left(S_{f}\right)=\xi a X=Y_{f}
$$

$\xi a X$ - Technologically fixed component of imported inputs

$\xi^{\eta} x K$ - a component of "exchange rate-sensitive competitive net exports"

$\Lambda$ - Component of net imports that respondes elastically to excess supply

$$
\chi K=\xi^{\eta} x K-\Lambda
$$

Equilibrium between total aggregate demand and total supply:

$$
\begin{aligned}
C_{h}+G & +\chi K+g K=\psi X+\pi X+\xi a X \\
\chi K & =\psi X+\pi X+\xi a X-C_{h}-G-g K
\end{aligned}
$$

Or

$$
\begin{gathered}
\Lambda=\xi^{\eta} x K-\chi K \\
\Lambda=\xi^{\eta} x K-\left(\psi X+\pi X+\xi a X-C_{h}-G-g K\right) \\
\Lambda=\xi^{\eta} x K-\psi X-\pi X-\xi a X+C_{h}+G+g K \\
\Lambda=g K-\left(\psi X-C_{h}\right)-(\pi X)+\left(\xi^{\eta} x K-\xi a X\right)+G
\end{gathered}
$$


Being $G=T_{h}+T_{b}$

$$
\begin{aligned}
& \Lambda=g K-\left(\psi X-C_{h}\right)-(\pi X)+\left(\xi^{\eta} x K-\xi a X\right)+T_{h}+T_{b} \\
& \Lambda=g K-\left(\psi X-C_{h}-T_{h}\right)-\left(\pi X-T_{b}\right)+\left(\xi^{\eta} x K-\xi a X\right)
\end{aligned}
$$

Adding to both sides $j \xi B$ and $D_{b}$, then:

$$
\Lambda=g K-\left(\psi X+D_{b}-C_{h}-T_{h}\right)-\left(\pi X+j \xi B-D_{b}-T_{b}\right)+\left(\xi^{\eta} x K+j \xi B-\xi a X\right)
$$

Consumption demand depends on a fraction of their wealth $\left(p_{E} E\right)$. As:

$$
p_{E} E=q K \Rightarrow c P_{E} E=c q K
$$

Wealth Effect: $c q K$

$$
v^{o}=\frac{c}{j}
$$

$s_{h}^{o}$ - propensity to save of households out of net income

$s_{b}^{o}$ - propensity to save of firms our of net income

$$
\begin{aligned}
& s_{h}=s_{h}^{o}\left(1-t_{h}\right) \\
& s_{b}=s_{b}^{o}\left(1-t_{b}\right)
\end{aligned}
$$

$v$ - Propensity to save out of capital gains

$$
v=v^{o}\left(1-t_{b}\right)
$$

Household and firms's total savings in units of capital:

$$
\begin{gathered}
\sigma^{h}=\frac{\left(\psi X+D_{b}-C_{h}-T_{h}\right)}{K}=s_{h}\left[\left(1-s_{b}\right)(\pi u+j \xi b)+\psi u\right]-v(\pi u+j \xi b) \\
\sigma^{b}=\frac{\left(\pi X+j \xi B-D_{b}-T_{b}\right)}{K}=s_{b}(\pi u+j \xi b)
\end{gathered}
$$

Total Savings:

$$
\sigma=\sigma^{h}+\sigma^{b}=s_{h}\left[\left(1-s_{b}\right)(\pi u+j \xi b)+\psi u\right]-v(\pi u+j \xi b)+s_{b}(\pi u+j \xi b)
$$

Defining: $s_{p}=\left(1-t_{b}\right)\left[s_{h}^{o}\left(1-t_{h}\right)\left(1-s_{b}^{o}\right)-v^{o}+s_{b}^{o}\right]$

Then

$$
\sigma=s_{p}(\pi u+j \xi b)+s_{h} \psi u
$$

$z$ - sum of current account components that respond to the RER

$$
z=\xi^{\eta} x+j \xi b-\xi a u
$$




\section{Production adjustment}

$\lambda$ - fraction of excess demand that is filled by imports

$$
\begin{aligned}
\lambda \Lambda & =\dot{u} K \\
\dot{u} & =\frac{\lambda \Lambda}{K}
\end{aligned}
$$

From the excess demand function:

$$
\begin{gathered}
\Lambda=g K-\left(\psi X+D_{b}-C_{h}-T_{h}\right)-\left(\pi X+j \xi B-D_{b}-T_{b}\right)+\left(\xi^{\eta} x K+j \xi B-\xi a X\right) \\
\dot{u}=\frac{\lambda\left(g K-\left(\psi X+D_{b}-C_{h}-T_{h}\right)-\left(\pi X+j \xi B-D_{b}-T_{b}\right)+\left(\xi^{\eta} x K+j \xi B-\xi a X\right)\right)}{K} \\
\dot{u}=\frac{\lambda\left[g-\left(\psi u+D_{b}-C_{h}-T_{h}\right)-\left(\pi u+j \xi b-D_{b}-T_{b}\right)+\left(\xi^{\eta} x+j \xi b-\xi a u\right)\right]}{K} \\
\sigma=s_{p}(\pi u+j \xi b)+s_{h} \psi u \\
\sigma=\left(\psi u+\pi u+j \xi b-C_{h}-T_{h}-T_{b}\right) \\
z=\xi^{\eta} x+j \xi b-\xi a u
\end{gathered}
$$

Tough passage. Saving-investment condition becomes the law of motion of the capacity utilization change in the long-run:

$$
\dot{u}=\lambda(g+z-\sigma)
$$

Being:

$$
\begin{gathered}
z=\xi^{\eta} x+j \xi b-\xi a u \\
\sigma=s_{p}(\pi u+j \xi b)+s_{h} \psi u \\
g=\alpha \pi u+\gamma
\end{gathered}
$$

Then:

$$
\dot{u}=\lambda\left\{\left[\left(\alpha-s_{p}\right) \pi-s_{h} \psi-\xi a\right] u+\gamma+\xi^{\eta} x+\left(1-s_{p}\right) j \xi b\right\}
$$

Partial Derivatives:

$$
\begin{gathered}
\frac{\partial \dot{u}}{\partial u}=-\lambda\left[\left(s_{p}-\alpha\right) \pi+s_{h} \psi+\xi a\right] \\
\frac{\partial \dot{u}}{\partial \psi}=\lambda\left[\frac{\partial \xi}{\partial \psi}\left(\eta \xi^{\eta-1} x-a u\right)-\left(s_{p}-\alpha\right)\left(\frac{\partial \pi}{\partial \psi}\right) u+\frac{\partial \xi}{\partial \psi}\left(1-s_{p}\right) j b-s_{h} u\right] \\
\frac{\partial \dot{u}}{\partial b}=\lambda\left(1-s_{p}\right) j \xi
\end{gathered}
$$




\section{External Balance:}

Current account surplus is an increase of claims of the foreign sector:

$$
\begin{gathered}
-S_{f}=\xi \dot{B} \\
\xi \dot{B}=(\xi x+j \xi b-\xi a u) K-\Lambda
\end{gathered}
$$

Dynamic equation of the share of foreign good priced debt as a function of capacity utilization and growth rate:

$$
\dot{b}=x-a u-\dot{u}(\xi \lambda)^{-1}+(j-g) b
$$

Using $\dot{u}=\lambda(g+z-\sigma)$

$$
\begin{gathered}
\dot{b}=\frac{(\sigma-g)}{\xi}-g b \\
\dot{b}=\frac{\left(s_{p}-\alpha\right) \pi u+s_{h} \psi u-\gamma}{\xi}-\left(g-s_{p} j\right) b
\end{gathered}
$$

Partial derivatives:

$$
\frac{\partial \dot{b}}{\partial u}=\frac{1}{\xi}\left[\frac{\partial \sigma}{\partial u}-\frac{\partial g}{\partial u}(1+\xi b)\right]\left|\frac{\partial \dot{b}}{\partial \psi}=\frac{1}{\xi}\left(\frac{\partial \sigma}{\partial \psi}-\frac{\partial g}{\partial \psi}\right)-\frac{\partial \xi}{\partial \psi} \frac{(\sigma-g)}{\xi^{2}}-\frac{\partial g}{\partial \psi} b\right| \frac{\partial \dot{b}}{\partial b}=-\left(g-s_{p} j\right)
$$

Asset equilibrium:

$$
b=\frac{s_{p} \pi+s_{h} \psi u-g}{g-s_{p} j}
$$

Steady state $\dot{u}=\dot{\psi}=\dot{b}=0$

$$
b^{*}=\frac{\xi^{* \eta} x-\xi^{*} a u^{*}}{g^{*}-j}
$$




\section{Annex 2.5. Final original model:}

$$
\begin{gathered}
\dot{\psi}=\tau[(l \exp (1+u l k)-\psi)] \\
\dot{u}=\lambda\left\{\left[\left(\alpha-s_{p}\right) \pi-s_{h} \psi-\xi a\right] u+\gamma+\xi^{\eta} x+\left(1-s_{p}\right) j \xi b\right\} \\
\dot{b}=\frac{\left(s_{p}-\alpha\right) \pi u+s_{h} \psi u-\gamma}{\xi}-\left(g-s_{p} j\right) b
\end{gathered}
$$

Jacobian $(\psi, u, b)$ :

$$
\begin{aligned}
& J=\left[\begin{array}{ccc}
\lambda\left[\frac{\partial \xi}{\partial \psi}\left(\eta \xi^{\eta-1} x-a u\right)-\left(s_{p}-\alpha\right)\left(\frac{\partial \pi}{\partial \psi}\right) u+\frac{\partial \xi}{\partial \psi}\left(1-s_{p}\right) j b-s_{h} u\right] & -\lambda\left[\left(s_{p}-\alpha\right) \pi+s_{h} \psi+\xi a\right] & \lambda\left(1-s_{p}\right) j \xi \\
\frac{1}{\xi}\left(\frac{\partial \sigma}{\partial \psi}-\frac{\partial g}{\partial \psi}\right)-\frac{\partial \xi}{\partial \psi} \frac{(\sigma-g)}{\xi^{2}}-\frac{\partial g}{\partial \psi} b & \frac{1}{\xi}\left[\frac{\partial \sigma}{\partial u}-\frac{\partial g}{\partial u}(1+\xi b)\right] & -\left(g-s_{p} j\right)
\end{array}\right] \\
& \frac{\partial \dot{\psi}}{\partial \psi}=-\tau \quad \frac{\partial \dot{\psi}}{\partial u}=\tau l^{2} k \psi \\
& \frac{\partial \dot{u}}{\partial \psi}=\lambda\left[\frac{\partial \xi}{\partial \psi}\left(\eta \xi^{\eta-1} x-a u\right)-\left(s_{p}-\alpha\right)\left(\frac{\partial \pi}{\partial \psi}\right) u+\frac{\partial \xi}{\partial \psi}\left(1-s_{p}\right) j b-s_{h} u\right] \quad \frac{\partial \dot{u}}{\partial u}=-\lambda\left[\left(s_{p}-\alpha\right) \pi+s_{h} \psi+\xi a\right] \\
& \frac{\partial \dot{u}}{\partial b}=\lambda\left(1-s_{p}\right) j \xi \quad \frac{\partial \dot{b}}{\partial u}=\frac{1}{\xi}\left[\frac{\partial \sigma}{\partial u}-\frac{\partial g}{\partial u}(1+\xi b)\right] \\
& \frac{\partial \dot{b}}{\partial \psi}=\frac{1}{\xi}\left(\frac{\partial \sigma}{\partial \psi}-\frac{\partial g}{\partial \psi}\right)-\frac{\partial \xi}{\partial \psi} \frac{(\sigma-g)}{\xi^{2}}-\frac{\partial g}{\partial \psi} b \quad \frac{\partial \dot{b}}{\partial b}=-\left(g-s_{p} j\right)
\end{aligned}
$$

\section{Expanded Derivatives}

$$
\begin{gathered}
\dot{\psi}=\tau[(l \exp (1+u l k)-\psi)] \\
\dot{u}=\lambda\left\{\left[\left(\alpha-s_{p}\right) \pi-s_{h} \psi-\xi a\right] u+\gamma+\xi^{\eta} x+\left(1-s_{p}\right) j \xi b\right\} \\
\dot{b}=\frac{\left(s_{p}-\alpha\right) \pi u+s_{h} \psi u-\gamma}{\xi}-\left(g-s_{p} j\right) b \\
\xi=\frac{1-\psi}{a\left(1+\frac{1}{\eta}\right)} \\
\frac{\partial \xi}{\partial \psi}=\left[\begin{array}{c}
\left.\frac{1}{a\left(1+\frac{1}{\eta}\right)}\right] \\
\frac{\partial \sigma}{\partial \psi}=s_{p} u \frac{\partial \pi}{\partial \psi}+s_{p} j b \frac{\partial \xi}{\partial \psi}+s_{h} u \Rightarrow
\end{array} \quad \frac{\partial \pi}{\partial \psi}=\left[\begin{array}{c}
\eta\left(1+\frac{1}{\eta}\right) \\
\left.-\frac{1}{\eta}\right)
\end{array}\right]\right.
\end{gathered}
$$




$$
\begin{gathered}
\frac{\partial \sigma}{\partial \psi}=\left[\begin{array}{r}
\left.s_{h} u-s_{p} u \frac{1}{\eta\left(1+\frac{1}{\eta}\right)}-s_{p} j b \frac{1}{a\left(1+\frac{1}{\eta}\right)}\right] \mid \\
g=\alpha \pi u+\gamma=\alpha u \frac{1-\psi}{\eta\left(1+\frac{1}{\eta}\right)}+\gamma \\
\frac{\partial g}{\partial \psi}=\left[\frac{-\alpha u}{\eta\left(1+\frac{1}{\eta}\right)}\right]
\end{array} \quad \frac{\partial g}{\partial u}=\left[\alpha \frac{1-\psi}{\eta\left(1+\frac{1}{\eta}\right)}+s_{h} \psi\right]\right.
\end{gathered}
$$




\section{Annex 2.6. Structuralist La Marca expansion:}

$$
\begin{gathered}
\dot{\psi}=\tau[(l \exp (1+u l k)-\psi)] \\
\dot{u}=\lambda\left\{\left[\left(\alpha-s_{p}\right) \pi-s_{h} \psi-\xi a\right] u+\gamma+\xi^{\eta} x+\left(1-s_{p}\right) j \xi b\right\} \\
\dot{b}=\frac{\left(s_{p}-\alpha\right) \pi u+s_{h} \psi u-\gamma}{\xi}-\left(g-s_{p} j\right) b \\
\dot{l}=\rho g+\theta b+\phi l
\end{gathered}
$$

\section{Steady State}

$$
\begin{gathered}
\dot{l}=0 \Rightarrow \rho g+\theta b+\phi l=0 \Rightarrow l^{*}=-\frac{\theta b^{*}+\rho g^{*}}{\phi} \\
\dot{b}=0 \Rightarrow \frac{\left(s_{p}-\alpha\right) \pi u+s_{h} \psi u-\gamma}{\xi}-\left(g-s_{p} j\right) b=0 \Rightarrow b^{*}=\frac{\left(s_{p}-\alpha\right) \pi u^{*}+s_{h} \psi u^{*}-\gamma}{\xi^{*}\left(g^{*}-s_{p} j\right)} \\
\dot{\psi}=0 \Rightarrow \tau[(l \exp (1+u l k)-\psi)]=0 \Rightarrow \psi^{*}=l^{*} \exp \left(1+u^{*} l^{*} k\right) \\
\dot{u}=0 \Rightarrow \lambda\left\{\left[\left(\alpha-s_{p}\right) \pi-s_{h} \psi-\xi a\right] u+\gamma+\xi^{\eta} x+\left(1-s_{p}\right) j \xi b\right\}=0 \Rightarrow \\
u^{*}=-\frac{\left[\gamma+\xi^{* \eta} x+\left(1-s_{p}\right) j \xi^{*} b^{*}\right]}{\left[\left(\alpha-s_{p}\right) \pi^{*}-s_{h} \psi^{*}-\xi^{*} a\right]}=0
\end{gathered}
$$

Partial Derivatives and Jacobian (added to the original model):

$$
\begin{array}{cc}
\frac{\partial \dot{l}}{\partial \psi}=\rho\left[\frac{-\alpha u}{\eta\left(1+\frac{1}{\eta}\right)}\right]>0 & \frac{\partial \dot{\psi}}{\partial l}=\tau(k u l+1) \exp (k u l+1)>0 \\
\frac{\partial \dot{u}}{\partial l}=0 & \frac{\partial \dot{l}}{\partial u}=\alpha \pi>0 \\
\frac{\partial \dot{b}}{\partial l}=0 & \frac{\partial \dot{l}}{\partial b}=\theta<0 \\
& \frac{\partial \dot{l}}{\partial l}=\phi<0
\end{array}
$$




\title{
CHAPTER 3
}

Uneven Development and the Balance of Payments Constrained Model

Terms of Trade, Economic Cycles, and Productivity Catching-up.

\begin{abstract}
This paper expands the Dutt (2002) version of the Balance of Payments Constrained Model (BPCM) questioning its main assumption of price-neutrality and the incompatibility between the BPCM and the Prebisch-Singer hypothesis (PSH). We offer a Post-Keynesian/Structuralist alternative in which BPCM becomes compatible with the PSH. The research focuses on three main elements: (1) the long-run behavior of the terms of trade in a Structuralist framework. (2) The cyclical endogenous dynamics in the relationship between economic activity and income distribution à la Goodwin. (3) The productivity gap and catching-up between developing and developed countries. Dutt (2002) presents a north-south model that explicitly develops the transition between short- and long-run in the Thirlwall system. We modify the model by (a) adding a productivity gap dynamics in which the south has a catching-up element, (b) Modeling the labor market of the southern economy by including a Phillips Curve for the relationship between employment rate and economic activity, and (c) adding a labor supply dynamics that considers the Lewisian labor transfer issue between traditional and modern sectors. The inclusion of these elements changes the main structure of the model, resulting in a 4-dimensional dynamic system that captures uneven development and cyclical convergence patterns in the trajectory between the short and the long run. We find that the structuralist/evolutionary arguments hold in the BPCM framework even when the Thirlwall law is questioned. For the BPCM theorists, accepting price non-neutrality mean a return to the neoclassical world in which prices adjust the model to the equilibrium. We challenge this statement and offer a Structuralist alternative to question the price neutrality assumption, making the Thirlwall's BPCM compatible with the classical PSH.
\end{abstract}

Keywords: Balance of Payments constraints, Terms of Trade, Economic Cycles.

JEL: E2, E3, O4. 


\section{Chapter 3 - Introduction}

Thirlwall's framework, also known as the Balance of Payments Constrained Model (BPCM), is one of the most relevant contributions of the Post-Keynesian school of thought to economic theory (Davidson, 1990; Dutt, 2002). It states that the growth rate of an economic system must be compatible with the constraints imposed by the balance of payments. Assuming that terms of trade and financial flows are stable in the long run, Thirlwall derives a rule in which the growth rate of an economy depends directly on the income elasticity ratio between exports and imports. This became known in the literature as the Thirlwall Law (Mccombie, 1989).

There is a large literature tradition focused on estimating the parameter of the Thirlwall Law, measuring the income elasticity of imports and exports for different countries (Alonso \& Garcimartín, 1998). These measures show that the Thirlwall law offers a very good proxy to explain long-run growth rates, especially in developed countries. In developing economies, however, the correlation between observed growth rates and the ones predicted by the BPCM are not direct, as the short-term effects of terms of trade fluctuations and financial flows volatility systematically differentiates the actual growth rates from those predicted by the law (Thirlwall \& Hussain, 1982).

Despite the strong relevance of the Thirlwall law in the development economics literature, the strict focus on the law itself neglects some important aspects of the BPCM (Dutt, 2002) such as uneven development and the short- to long-run transition dynamics. This article tackle these two important aspects usually ignored in the broad debate about the Thirlwall framework.

A central assumption of the Thirlwall law is that price effects are stable in the long-run. This assumption, however, is subject to many critiques - as described by McCombie (2012). It contradicts the core of the Structuralist tradition, condensed in the Prebisch-Singer hypothesis, which defends the existence of a declining trend in the terms of trade for developing countries (Harvey, Kellard, Madsen, \& Wohar, 2010). This trend is caused by a specialization of the productive structure in products with smaller income elasticity of demand (primary commodities). As income grows, the relative prices of primary commodities increase at a smaller rate than manufactured goods, resulting in a decline in the terms of trade. This reinforces the uneven development conditions between north and south (Dutt, 2002).

From the long-run framework of the Thirlwall Law, to the short-run one described in the Thirlwall model, we discuss the problem of transition dynamics. In the short-run both price and 
quantity effects serve as adjustment mechanisms: price- and income-elasticity of imports and exports, the terms of trade (real exchange rate), and financial flows adjust the economy to its equilibrium. The transition between short- to long-run should be observed from the explicit imports and exports equations. In this research we follow the Dutt (2002) model, that offers a possible solution to the problem in the transition dynamics. The Dutt model endogenizes the evolution of the terms of trade towards the long-run adjustment. It consists in a model with a north-south dynamics in which the north follows a monopolistic Keynesian-Kaleckian framework while the south is modelled in perfect competition with a Marx-Lewis perspective (Lewis, 1954). Despite critiques to this model related to the way the south is modeled, we see it as an important contribution to start the discussion between uneven development and transition dynamics.

Economic volatility is another important element in discussing economic dynamics, a source of uneven development. Countries with bigger GDP oscillations, usually developing countries, face higher challenges in achieving a stable development process. Regular patterns of oscillation (cycles) may emerge in the transitory dynamics between short-run and long-run. A canonic contribution goes back to the Goodwin (1967) model, that discussed the emergence of endogenous cycles from the relationship between economic activity and income distribution. When considering the BPCM, the volatility sources come from terms of trade and financial flows, which are ignored in the Thirlwall law. This concept of volatility in the Thirlwall model is directly related to the concept of fragility, the resilience of an economic system to external shocks.

The role of the productive structure is brought to the model by the Structuralist theory. In Prebisch (1950), the behavior of the terms of trade is defined by the productive structure of a country in the context of an international division of labor. A specialized structure with lower labor productivity level has a higher productivity gap between laggard south and advanced north. This impacts in a decline in the terms of trade, as the southern economy is specialized in products with smaller income demand elasticity, which reduces the growth possibilities of the south. On the other hand, the productivity gap may follow its own virtuous dynamics. Laggard economies may have higher opportunities for learning, approaching the productivity levels of the north. The gap may create leapfrogging opportunities (Lee, 2013). 
The objective of this research is to observe the transition dynamics in the BPCM capturing economic cycles, the productivity gap, and the behavior of terms of trade. We initially follow the baseline model defined by Dutt (2002) and expand it by: (a) adding a productivity gap dynamics in which the south has a catching-up element; (b) modeling the labor market of the south economy by including a Phillips Curve to discuss the relationship between employment rate and economic activity; (3) adding a labor supply dynamics that considers the Lewisian problem of the labor transfer between traditional and modern sectors (Lewis, 1954). The inclusion of these elements changes the structure of the Dutt model, resulting in a 4-dimensional expanded dynamic system that is able to generate interesting patterns in the trajectory between the short and long run. We propose to study the model, presenting some scenario possibilities.

We raise the following points: In which way can we describe how price dynamics affect the results of the BPCM when we assume price non-neutrality. In this sense, we check if technology efforts and structural change are related or not to the price effects. In terms of fragility and volatility, what occurs to countries away from the technological frontier, and we study the causes that determine the magnitude of the cycles. Another discussion concerns the feedback loops caused by this higher volatility. Finally, under which conditions can we reach a virtuous development process in the context of non-neutrality of price effects, focused on the effects on economic growth.

After this introduction, in section 3.1 we develop a brief literature review discussing the BPCM. In section 3.2 we raise the research questions related to this research. In section 3.3 we show the development of the baseline model of this research, based on Dutt (2002). In section 3.4 we add the expansions to the model. In section 3.5 we discuss the properties of the expanded model. In section 3.6 we study the signs of the model to discuss stability and cycles. In section 3.7 we develop some simulations and analyze the results. In section 3.8 we discuss the main results. Finally, in section 3.9 we conclude this paper.

\subsection{Literature review}

\subsubsection{The Thirlwall Law and the Thirlwall Model}

The Thirlwall model (Thirlwall, 1979) is a long-run growth model that links the economic growth possibilities with the constraints imposed by the balance of payments. The system is 
derived from the behavior of the external sector. The model can be explicitly derived from export and import functions. Using the variables defined in Dutt (2002) we have:

$$
\begin{gathered}
M=\theta_{M}(1 / P)^{-\mu} Y^{\varepsilon} \\
X=\theta_{X}(P)^{-v} Y_{f}^{\delta}
\end{gathered}
$$

In which $M$ and $X$ represent total import and total export respectively. $\theta_{M}$ and $\theta_{X}$ are constants. $Y$ represents domestic income and $Y_{f}$ foreign income. The relative price $P$ represents the price ratio between domestic prices $\left(P_{d}\right)$ and foreign prices $\left(P_{f}\right)$, in domestic currency - multiplied by the real exchange rate $(E) . P=P_{d} / E P_{f} . \mu$ and $v$ are the price elasticities of imports and exports, respectively. Finally, $\varepsilon$ and $\delta$ are the income elasticity of imports and exports. Imports increase with higher domestic income while exports grow with higher foreign income. Import falls with increases in the relative price while exports rise. Price elasticities define the growth sensitivity to price changes, and income elasticities defines the growth sensitivity to output/income changes.

The variable $F$ represents the financial flows. The equilibrium of the balance-of-payments occurs when we have balance between net exports plus net financial flows and net imports:

$$
P X+F=M
$$

Writing eq.(3) in terms of growth rates we have:

$$
[1-(F / M)][\hat{P}+\hat{X}]+(F / M) \hat{F}=\widehat{M}
$$

In which the hat above the letters implies growth rates. When we replace $M, X$ and $P$ by eq. (1), (2) and (3), we end up with the Thirlwall growth equation, which is given by: 


$$
\widehat{Y}=(1 / \varepsilon)\left\{(1-\mu-v) \hat{P}+[1-(F / M)] \delta \widehat{Y}_{f}+\left(F / X_{N}\right)[\hat{F}-(1-v) \hat{P}]\right\}
$$

In the long run, Thirlwall assumes no changes in the Terms of Trade $(\hat{P}=0)$, and constant capital flows $(\hat{F}=0)$. These assumptions result in the Thirlwall Law. Net capital flows are stable in the long run, and the growth rate will depend on the ratio between income elasticities of exports and income elasticity of imports, multiplied by the rate of growth of foreign GDP.

$$
\hat{Y}=(\delta / \varepsilon) \widehat{Y}_{f}
$$

or

$$
\hat{Y}=(1 / \varepsilon) \hat{X}
$$

The income growth rate depends on the income elasticities, which is usually considered exogenous ${ }^{10}$. The usual simplification $(\hat{P}=\hat{F}=0)$ results in some theoretical and empirical problems. As pointed by Dutt (2002), (1) the simplification ignores the transitional dynamics. We cannot observe the trajectory between the short and the long run, which neglects some possible effects in the adjustment process that may affect the final outcome (steady state). (2) There is a large number of articles - discussed in Blecker (2016) and McCombie (2012) - that question the empirical validity of the Thirlwall law, especially for developing regions (effective rate diverging from the income elasticity ratio) (Thirlwall \& Hussain, 1982). (3) The BPCM assumes that terms of trade do not affect the long-run, contradicting the decline in the terms of trade theory $(\hat{P}<0)$ (Prebisch, 1950).

\subsubsection{Uneven Development and the Transitional Dynamics}

The questions posed in this research concern the relationship between the "short-run" version of the Thirlwall model and its "long-run" version (Thirlwall Law). Dutt (2002) proposes to discuss this problem offering a transition dynamics model in an open north-south framework. In this model he focus on uneven development, an important but usually neglected matter raised by the followers of the model Thirwall (2012).

\footnotetext{
${ }^{10}$ There are however articles focused on endogenizing the income elasticities in the structuralist theory, relating income elasticities to the behavior of the productive structure (Cimoli \& Porcile, 2014; Porcile \& Spinola, 2018).
} 
Uneven development is a central aspect in the study of developing economies behavior. This discussion contraposes itself to the Solow-type neoclassical growth models, and approaches itself to the old Structuralist ideas of Prebisch and Singer (Prebisch, 1950; Singer, 1950).

In the old structuralist tradition, the position of an economy in the international division of labor defines its role in the system and its development possibilities. A country specialized in the production and export of raw materials tends to progressively lag behind than those that produce and export manufactured goods. Products are heterogeneous in terms of their price and income elasticity of demand. Products with higher income elasticity of demands (manufactured goods) have a rise in their demand as international economy grows, resulting in higher relative prices than raw materials. This ends up in the emergence of an uneven development in which the core countries of the system advance in their productive structure while the periphery remains trapped in lower levels of economic development. According to the old Structuralist ideas, the way out of this vicious system is through increases in public intervention to foster the creation and development of modern manufacture sectors - through a process of import substitution industrialization (ISI).

The Thirlwall framework does not focus directly on product heterogeneity (as the old Structuralist ideas do), but on the role of changes in terms of trade (prices of exports divided by prices of imports) and financial flows, to define the growth rate considering the structural aspects of the economy (captured by price and income elasticity of imports and exports). There is no inherent declining trend of the terms of trade, as in the classical structuralism, but price behavior plays a role in stablishing the growth possibilities. It is important to say that in the Thirlwall model, autonomous demand ${ }^{11}$ is endogenous to the behavior of the external sector, and investments are endogenous to the balance of payments possibilities.

\subsubsection{Assumptions and Empirical validity of the Thirlwall Law.}

As observed, the Thirlwall model depends on two assumptions to keep its validity, (i) that the terms of trade and (ii) the financial flows grow at zero rate in the long-run. This can be condensed in what Blecker (2016) highlights as the main assumption in the Thirlwall model: price effects are neutral in the long-run. In order to have that, we must assume that either price-

\footnotetext{
${ }^{11}$ Consumption, Investment and Government Spending.
} 
elasticity is too low "Elasticity Pessimism" $(\mu+v \approx 1)$, or that the real exchange rate grows at zero rate in the long run $(\hat{P}=0)$, or that financial flows grows close to zero in the long-run $(\hat{F}=0)$. Accepting these three assumptions result that economic adjustments to the equilibrium occur in quantities rather than prices. As price effects are neutral, the domestic growth rate then adjusts the system to the conditions imposed by the balance of payments constraints.

These three assumptions, however, have been passive to critiques from the BPCM researchers (more on Chapter 4). Empirically we still have an open debate if actually price effects are neutral in the long-run.

\subsubsection{The role of price effects and the incompatibility between Prebisch and Thirlwall}

In the new structuralist ideas (Cimoli \& Porcile, 2014), the theories by Raul Prebisch and Anthony Thirlwall are usually seen as complementary. However, there is a very important element that is usually neglected in the discussion and that raises a big contradiction in the theory. In the theory of decline in the terms of trade (Prebisch-Singer hypothesis), there is a longrun tendency to a reduction in prices of the south compared to the north $(\hat{P}<0)$. When we accept the Prebisch-Singer and that the Marshall-Lerner condition holds (price elasticity imports is bigger than 1), price effects are not neutral in the long-run, but declining in developing countries. This perspective contradicts the main assumption that leads to the Thirlwall Law $(\hat{P}=0)$.

With the Prebisch-Singer hypothesis, adjustments to the equilibrium may not occur only in quantities, but also on prices (terms of trade), defining the long-run economic growth rate. In this sense, price effects impact on long-run economic growth, which opens space to discuss how this happens. A possible explanation discusses the long-term impacts of the real exchange rate, as defended by authors of the so called new developmentalist school (Bresser-Pereira, Oreiro, \& Marconi, 2014).

\subsubsection{Cycles: Labor market and the Goodwin dynamics}

Economic volatility is an important element that rises constraints to economic development. In this sense, merging the BPCM with the Goodwin system is a way to capture the relationship between economic constraints from the external sector, and economic constraints from 
oscillations in the economic system. We add this by incorporation the relationship between income distribution and unemployment rate (economic activity) through a modified version of the Phillips Curve.

\subsubsection{Catching-up and productivity dynamics}

On the other hand, the productivity gap may follow its own dynamics, following an evolutionary approach. Laggard economies may have greater opportunities for learning, getting closer to the productivity levels of the north. So the Gap may create opportunities for developing countries to approach the development levels of the developed ones.

\subsection{Research Considerations:}

This research proposes to relate (1) the behavior of the terms of trade with (2) cyclical endogenous volatility, and (3) the productive sector through the discussion of productivity gap. It consists in a Thirlwall-Goodwin model with elements of productivity gap.

Why are we using the Dutt (2002) model? The seminal Dutt (2002) model offers a starting point to answer the research questions posed in this research. It criticizes the Thirlwall Law offering a theoretical proposal inside the BPCM framework to challenge the idea that prices are neutral in the long-run. This model allows us to approach the Prebisch-Singer hypothesis, in which prices decline in the long-run, while observing transition dynamics and uneven development.

\section{Why do we want to expand the model?}

The original Dutt (2002) model restricts itself to the topic of the Terms of Trade, and how it evolves from capital accumulation. We add some elements that deal with the matter of volatility in developing countries to the original model, discussing its determinants and its effects. Following a Structuralist perspective, we associate the regular volatility (cycles) to the fragile structural conditions in the south. Another element of productivity and productivity gap, associated to the topics of structural change and technological dynamics closes the model. We then manage to link three Structural central issues of developing economies: Balance of payments constraints, high growth volatility, and a fragile productive structure.

In this research we raise some specific discussions - some theoretically-related and others development-related. The theoretical discussion focuses on the assumptions and derivations of 
the BPCM: the critique of the Thirlwall Law, the incorporation of Goodwin Cycles, and the theories of catching-up. The second group is related to development issues, trying to raise conditions for a virtuous development strategy.

An important discussion focuses on how price dynamics affect the results of the BPCM when assuming $\hat{P}$ endogenous and $\hat{P} \neq 0$. In this sense we may discuss under which conditions we can observe a Prebisch-Singer behavior $(\hat{P}<0)$. In terms of the structural elements, how can technology efforts and structural change be related to price effects. We debate the conditions that lead to a virtuous catching-up process, discussing how countries away from the technological frontier show themselves as more fragile and volatile.

Considering the effects of volatility in the process of economic development we discuss what determines the magnitude of the cycles and the impacts of a higher volatility on development. Under which conditions can we reach a virtuous development process in the context of nonneutrality of price effects and the effects on economic growth.

\subsection{The baseline Dutt (2002) model $^{12}$}

A basic North-South model based on the Thirlwall law states that the relationship between growth rates in North and South depends on the ration between their income elasticity of imports.

$$
\widehat{Y_{S}} / \widehat{Y_{N}}=\varepsilon_{N} / \varepsilon_{S}
$$

Dutt (2002) discusses two economies that interact through their external sector: (i) a Southern economy, marked by perfect competition with fixed real wage and unemployment labor (out of full employment - following a Marx-Lewis structure), and (ii) a Northern economy that has imperfect competition, in which firms practice mark-up pricing and excess capacity, with a Kalecki-Keynes structure.

The monopolistic north has its price level defined by a markup function over costs, with pricemaking firms:

\footnotetext{
${ }^{12}$ It is important to mention that the notation in Chapter 2 is different from the one in Chapter 3 . We opted to keep the expansions with the same algebraic notation as the original articles. In this sense we make our expansions compatible with the La Marca (2010) and the Dutt (2002) papers. However, it is very important to mention that these two articles have different notations among themselves. There is the variable list for each model in each of the respective chapters.
} 


$$
P_{N}=(1+z) W_{N} b_{N}
$$

In which $P_{N}$ is the price level in the north; $z$ consists in the mark-up $(z \geq 1) ; W_{N}$ is the wage level in the north and $b_{N}$ is the fixed unit labor requirement for the northern good (also understood as the inverse of labor productivity). An increase in markup and/or on costs (unitary wages) raises price levels, as well as a reduction in labor productivity (increases in productivity have a negative impact on prices).

The south follows a perfect competition specification. Southern GDP $\left(Y_{S}\right)$ operates at full utilization capacity. It follows a fixed the relationship between capital stock in the south $\left(K_{S}\right)$ and the fixed capital-output ratio in the south $\left(a_{S}\right)$.

$$
Y_{S}=K_{S} / a_{S}
$$

Real wages in the south $\left(V_{S}\right)$ are defined as the ratio between nominal wages $\left(W_{S}\right)$ and the price index in the south $\left(P_{S}\right)$ :

$$
V_{S}=W_{S} / P_{S}
$$

Consumers in the north consume all their income, while capitalists save a fraction $\left(s_{N}\right)$ of their income. The north spends a fraction $\alpha$ of its consumption expenditure on southern goods (and the rest on the northern goods). This fraction is equal to:

$$
\alpha=\alpha_{0} Y_{N}^{\varepsilon_{N}-1} P^{1-\mu_{N}}
$$

In which $\alpha_{0}$ is the autonomous part of the northern expenditure in southern goods; $Y_{N}$ is the GDP in the north. Considering $E=1$, the terms of trade $(P)$ is given by the ratio between prices in the south $\left(P_{S}\right)$ and prices in the north $\left(P_{N}\right)$ :

$$
P=P_{S} / P_{N}
$$


In the south, workers spend all their income on southern goods. Southern capitalists save a fraction $\left(s_{S}\right)$ and consume the rest. Part of the consumption $(\beta)$ is spent on the northern good. Analogous to $\alpha ; \beta$ can be described as:

$$
\beta=\beta_{0}\left(\sigma_{S} Y_{S}\right)^{\varepsilon_{S}-1}(1 / P)^{1-\mu_{S}}
$$

$\beta_{0}$ is the autonomous part of the southern expenditure in northern goods. $\sigma_{S}$ is the profit share of southern total income. This profit share is the residual from the wage share $\left(\omega_{S}\right)$ on total output: $\omega_{S}=b_{S} V_{S}$. The profit share can be specified as the part of total income that does not go to wages:

$$
\sigma_{S}=\left(1-b_{S} V_{S}\right)
$$

In which $b_{S}$ is the labor-output ratio in the south $\left(b_{S}=L_{S} / Y_{S}\right)$.

The investment function follows a Kaleckian specification based on Bhaduri \& Marglin (1990), in which capacity utilization affects the capitalists perception of economic activity. When capacity utilization increases, capitalists perceive it as an increase in effective demand, which stimulates them to increase total capacity by immobilizing capital in order to sustain the increases in the demand. Investments in the north are then given by:

$$
g_{n}=I_{N} / K_{N}=\gamma_{0}+\gamma_{1}(u)
$$

In which $I_{N}$ is total investment in the north, $\gamma_{0}$ and $\gamma_{1}$ are positive constants. $u$ consists on the rate of capacity utilization, which is given by $u=Y_{N} / K_{N}$. The next step is to find explicit equations for northern and southern exports. Considering the equations for $P_{S}$ and $X_{S}$, the total value of southern exports is given by:

$$
P_{S} X_{S}=\alpha\left\{\left[1+\left(1-s_{N}\right) z\right] /(1+z)\right\} P_{N} Y_{N}
$$


Applying eq.(3.12) on eq.(3.17), we end up with the equation for southern exports, which can be given in its reduced form as:

$$
X_{S}=\theta_{S} P^{-\mu_{N}} Y_{N}^{\varepsilon_{N}}
$$

In which $\theta_{S}=\alpha_{0}\left[1+\left(1-s_{N}\right) z\right] /(1+z) . \theta_{S}$ is a constant (more details in the annex).

The northern total exports to the south are equal to the southern imports from the north, being the southern total imports $M_{S}=\beta \sigma_{S} Y_{S}$ we have:

$$
P_{N} X_{N}=\beta \sigma_{S} P_{S} Y_{S}
$$

Using eq.(14) on eq.(19), the equation for northern exports is given by:

$$
X_{N}=\theta_{N}(1 / P)^{-\mu_{S}} Y_{S}^{\varepsilon_{S}}
$$

In which we have the constant $\theta_{N}=\beta_{0} \sigma_{S}^{\varepsilon_{S}}$.

This simple static model highlights the properties of the north-south interaction. Southern and Northern exports are explicitly addressed in order to reach equilibrium in current account, balancing the values of exports in north and south.

\subsubsection{Dynamics properties of the Thirlwall model}

The dynamic properties of the Dutt (2002) model are derived from the excess demand $(E D)$ functions in the north and south. In the south, excess demand $\left(E D_{S}\right)$ is given by:

$$
E D_{S}=C_{S S}+I_{S S}+X_{S}-Y_{S}
$$

And as $M_{S}=C_{S S}+I_{S S}-Y_{S}=$ and $M_{S}=\left(\frac{1}{P}\right) X_{N}$ : 


$$
E D_{S}=X_{S}-\left(\frac{1}{P}\right) X_{N}
$$

While, analogously, excess demand in the north $\left(E D_{N}\right)$ is given by:

$$
\begin{aligned}
& E D_{N}=C_{N N}+I_{N}+X_{N}-Y_{N} \\
& E D_{N}=I_{N}-S_{N}+X_{N}-P X_{S}
\end{aligned}
$$

Following a market clearing equilibrium, there is no excess demand in the long-run:

$$
E D_{i}=0
$$

The equilibrium condition can be used in eq. (3.22) and (3.24). When substituting all variables and applying the equilibrium in eq. (3.25), the results give us the following static equations for terms of trade and capacity utilization $E D_{S}=X_{S}-\left(\frac{1}{P}\right) X_{N}=0$ :

$$
X_{N}=P X_{S}
$$

Then substituting (3.18) and (3.20) in eq.(3.26), we have:

$$
P=\left[\left(\theta_{S} / \theta_{N}\right)\left(u K_{N}\right)^{\varepsilon_{N}}\left(a_{S} / K_{S}\right)^{\varepsilon_{S}}\right]^{1 /\left(\mu_{N}+\mu_{S}-1\right)}
$$

From the Saving-Investment balance condition in the north $\left(I_{N}=S_{N}\right)$ :

$$
u=\gamma_{0} /\left[s_{N} \sigma_{N}-\gamma_{1}\right]
$$

In the long-run the capital stock grows according to the rates of capital accumulation in the two regions $\left(g_{i}=I_{i} / K_{i}\right)$. The short-run conditions are always satisfied $\left(E D_{i}=0\right)$. In this sense accumulation in the north is given by:

$$
g_{N}=\gamma_{0}+\gamma_{0} \gamma_{1} /\left[s_{N} \sigma_{N}-\gamma_{1}\right]
$$


In the south, savings determine investments. Southern workers do not save, only southern capitalists save. The savings function is then given by the propensity to save times the profit share, times output:

$$
S_{S}=s_{S} \sigma_{S} K_{S} / a_{S}
$$

The investment function is then given by the value of total savings in domestic currency:

$$
I_{S}=P^{\xi} S_{S}
$$

$\xi$ is a constant with positive value. The next step is to define the savings - investment conditions for the south. Combining eq. (3.30) and (3.31) to the south we have the following equation for capital accumulation:

$$
g_{S}=s_{S} P^{\xi} \sigma_{S} / a_{S}
$$

When deriving eq.(3.27) we get the dynamic properties of the model. Terms of trade then fluctuate following the relationship between capital accumulation in the north and the south:

$$
\hat{P}=\left[1 /\left(\mu_{N}+\mu_{S}-1\right)\right]\left(\varepsilon_{N} g_{N}-\varepsilon_{S} g_{S}\right)
$$

Which means that terms of trade $(P)$ will fluctuate depending on the gap between investment in north and south weighted by their respective income elasticity of imports. So terms of trade here are not neutral in the long-run, changing an important assumption of the Thirlwall model.

The model just described is the canonical Dutt (2002) model. In the next session we expand this model by adding a productivity gap dynamics and modeling the labor market. These modifications completely change the characteristics of the dynamic model, resulting in the emergence of interesting new patterns.

\subsection{Expansion of the Dutt-Thirlwall Model}

The original Dutt model results in a one equation system for the dynamics of the terms of trade. This depends on the gap between capital accumulation in the north and in the south. In our expansion we focus on creating a productivity dynamics that is able to define other patterns, rather than a monotonic convergence and/or divergence. 


\subsubsection{Productivity Dynamics}

In eq.(9), northern price levels are defined as function of mark-up over costs $P_{N}=(1+$ $z) W_{N} b_{N}$. From this equation we introduce an initial productivity and wage rate dynamics to the north, which follows a constant rate of growth:

$$
\widehat{b_{N}}=-\beta_{N}
$$

$$
\widehat{W_{N}}=\beta_{N}
$$

$\beta_{N}$ is a constant. Labour productivity in the north $\left(\lambda_{N}=\frac{1}{N}\right)$ grows exogenously, and wages track productivity, growing both at the same rate. $Y_{S}=K_{S} / a_{S}$ remains for the south, considering that there is no idle capacity, and that the capital-output ratio is constant. $W_{S} / P_{S}=V_{S}$ defines the value of real wages. In this sense, productivity and real wages follow the same path, growing according to technological progress. Technological progress in the north is assumed constant and stable $^{13}$.

In Dutt (2002), the real wages in the south $\left(V_{S}\right)$ are fixed. Capitalist's income $\left(Y_{S, K}\right)$ in the south is equal to $Y_{S, K}=\left(1-b_{S} V_{S}\right) P_{S} Y_{S}$ and the share of that in total income is $\sigma_{S}=\left(1-b_{S} V_{S}\right)$. In this expansion we endogenize $b_{s}$ and $V_{s}$ developing a labor productivity dynamics. We need to specify $b_{s} V_{s}$, so they stay within bounds (wage share cannot be smaller than zero or higher than one).

Labor productivity $\left(\lambda_{i}\right)$ is the inverse of the unit labor requirement for the production of a good:

$$
\lambda_{i}=\frac{1}{b_{i}}
$$

Using this definition, the productivity gap ${ }^{14}(G)$ between north and south can be defined as:

$$
G=\ln \left(\frac{\lambda_{N}}{\lambda_{S}}\right)=\ln \left(\frac{b_{S}}{b_{N}}\right)
$$

\footnotetext{
${ }^{13}$ We understand, on the other hand, the central aspect of evolutionary major technological change happening in waves. (Schumpeter, 1939)

${ }^{14}$ Cimoli \& Porcile (2014b)
} 
In eq.(3.34), productivity grows in the north at a constant rate $\widehat{\lambda_{N}}=\beta_{N}$. We consider an extra dynamic gap effect in the south, which emerges from its laggard aspect. Labor productivity growth in the south can be written as a constant rate $\left(\beta_{S}\right)$ plus the effect of the productivity gap, which we put as a catching-up effect $(G)$ :

$$
\widehat{\lambda_{S}}=\beta_{S}+\rho G
$$

Being $\beta_{S}<\beta_{N}$, and considering the definition of productivity gap on eq.(37), we can work out the dynamics o the technology gap $(\widehat{G})$ as:

$$
\widehat{G}=\left(\beta_{N}-\beta_{S}\right)-\rho G
$$

\subsubsection{Labor market and the Phillips curve}

A second addition to the model consists in developing a labor market dynamics. We endogenize real wages using, for the southern economy, a modified version of the famous Phillips curve, relating real wages to the employment rate:

$$
\widehat{V_{S}}=-m+n\left(\frac{L_{S}}{\Lambda_{S}}\right)=-m+n l_{S}
$$

$m$ and $n$ are constants. $L_{S}$ consists on total employment, and $\Lambda_{S}$ the total workforce. The employment rate $\left(l_{S}\right)$ is defined as:

$$
l_{s}=\frac{L_{S}}{\Lambda_{S}}
$$

This addition changes the characteristics of the model. The profit share $\sigma=\left(1-b_{s} V_{s}\right)$ is no longer a constant. Defining the wage share in the south as $\omega_{S}=b_{S} V_{S}$, we have that its growth rate is given by:

$$
\widehat{\omega_{S}}=\widehat{b_{S}}+\widehat{V_{S}}=-\beta_{S}-\rho G-m+n l_{S}
$$

And the growth rate of the profit share in the south $\left(\sigma_{S}\right)$ follows then the opposite variation of the wage share $\left(\omega_{\mathrm{S}}\right)$, which results in the following equation:

$$
\widehat{\sigma}_{S}=-\widehat{\omega_{S}}=\beta_{S}+\rho G+m-n l_{S}
$$


Equation (3.29) does not change. But for equations (3.32) and (3.33) $\sigma_{S}$ becomes a variable, not a constant parameter. From equation (3.33) we then have that $\hat{P}=\frac{1}{\mu_{N}+\mu_{S}-1}\left(\varepsilon_{N} g_{N}-\varepsilon_{S} g_{S}\right)$. If we expand $g_{N}$ and $g_{S}$ from equations (3.29) and (3.32) respectively, we end up with the following equation for the evolution of the Terms of Trade:

$$
\hat{P}=\frac{1}{\mu_{N}+\mu_{S}-1}\left[\varepsilon_{N} \gamma_{0}\left(1+\frac{\gamma_{1}}{s_{N} \sigma_{N}-\gamma_{1}}\right)-\varepsilon_{S} \frac{s_{S} P^{\xi} \sigma_{S}}{a_{S}}\right]
$$

Equation (3.44) is a central result to the analysis. Terms of trade here evolve positively to the profit share in the north (exogenous) but negatively to the profit share in the south (now an endogenous variable). The evolution of the Terms of Trade is also negative to its value, stabilizing at a threshold value.

\subsubsection{Employment rate, population growth and the Lewis dynamics}

About labor market reallocation for workers, we may consider two situations. The first is in an economy divided by a traditional and a modern sector. When there is a higher percentage of income going to labor, this creates an incentive to workers move from informal to formal activities of the economy. The second situation is related to migration. A higher incentive may lead workers to move from one country to the other looking for better life conditions, increasing the labor supply in the receiver country.

Considering a linear specification relating the increases in wage share (and reduction in profit share) in the labor supply we have:

$$
\widehat{\Lambda_{S}}=\varphi-\psi \sigma_{S}
$$

$\varphi$ is the constant autonomous population growth and $\psi$ is a constant that measures the elasticity to move to from the traditional to the formal sector (or the migration cost). As we have defined that $l_{S}=L_{S} / \Lambda_{S}$, then in growth rates:

$$
\widehat{l_{s}}=\widehat{L_{S}}-\widehat{\Lambda_{S}}
$$


Total employment dynamics: $b_{S}=\frac{L_{S}}{Y_{S}} \Rightarrow L_{S}=b_{S} Y_{S} \Rightarrow \widehat{L_{S}}=\widehat{b_{S}}+\widehat{Y_{S}}$

Employment rate dynamics: $\widehat{l_{S}}=\widehat{L_{S}}-\widehat{\Lambda_{S}}=\widehat{b_{S}}+\widehat{Y_{S}}-\widehat{\Lambda_{S}}$

As we have the capital-output labor $b_{S}=L_{S} / Y_{S}$, the total labor growth in the south is $L_{S}=b_{S} Y_{S}$. In growth rates:

$$
\widehat{L_{S}}=\widehat{b_{S}}+\widehat{Y}_{S}
$$

From Eq. (10) $Y_{S}=K_{S} / a_{S}$. There is no depreciation, therefore $\widehat{K_{S}} K_{S}=I_{S}$. From the SavingsInvestment southern condition $\left(I_{S}=P^{\xi} S_{S}\right)$ and being $S_{S}=s_{S} \sigma_{S} Y_{S}$, we have that $I_{S}=P^{\xi} s_{S} \sigma_{S} \frac{K_{S}}{a_{S}}$. Then:

$$
\widehat{K_{S}}=\frac{I_{S}}{K_{S}}=P^{\xi} s_{S} \sigma_{S} \frac{1}{a_{S}}
$$

As $\widehat{a_{S}}=0, \widehat{K_{S}}=\widehat{Y_{S}}$ Which gives us finally the dynamic equation for the employment rate, from $\widehat{l_{S}}=\widehat{b_{S}}+\widehat{Y_{S}}-\widehat{\Lambda_{S}}$ :

$$
\widehat{l_{S}}=-\beta_{S}-\rho G+P^{\xi} S_{S} \sigma_{S} \frac{1}{a_{S}}-\varphi+\psi \sigma_{S}
$$

Finally, we end up with a system of four differential equations:

$$
\begin{gathered}
\widehat{P}=\frac{1}{\mu_{N}+\mu_{S}-1}\left[\varepsilon_{N} \gamma_{0}\left(1+\frac{\gamma_{1}}{s_{N} \sigma_{N}-\gamma_{1}}\right)-\varepsilon_{S} \frac{s_{S} P^{\xi} \sigma_{S}}{a_{S}}\right] \\
\widehat{\sigma_{S}}=\beta_{S}+\rho G+m-n l_{S} \\
\widehat{l_{S}}=-\beta_{S}-\rho G+P^{\xi} s_{S} \sigma_{S} \frac{1}{a_{S}}-\varphi+\psi \sigma_{S} \\
\widehat{G}=\left(\beta_{N}-\beta_{S}\right)-\rho G
\end{gathered}
$$

This system defines the north-south dynamics between terms of trade, distribution in the south, southern employment rate and the productivity gap. The trajectory defines the relationship between the short- and the long-run in the model. The next step is to analyze the dynamic properties of this system.

\subsection{Dynamic properties of the expanded model}

In this section we discuss the dynamic properties of the expanded model. We analytically calculate the steady state and the Jacobian, studying the trajectory and stability conditions. 
For the Steady State we set the dynamic variables equal to zero. $\widehat{P}=\widehat{\sigma}_{S}=\widehat{l_{S}}=\widehat{G}=0$. The Jacobian is a matrix of the partial derivatives of all pair of dynamic variables involved in the system. After computing the Jacobian we study the signs of all its elements one by one.

Setting the dynamic variables equal to zero we have the Steady State, which is (for the mathematical passages, see the annex):

$$
\begin{gathered}
P^{*}=\left[\frac{\gamma_{0} a_{S} \psi}{\left[\varphi+\beta_{N}-\frac{\varepsilon_{N} \gamma_{0}}{\varepsilon_{S}}\left(1+\frac{\gamma_{1}}{s_{N} \sigma_{N}-\gamma_{1}}\right)\right]} \frac{\varepsilon_{N}}{\varepsilon_{S} s_{S}}\left(1+\frac{\gamma_{1}}{s_{N} \sigma_{N}-\gamma_{1}}\right)\right]^{1 / \xi} \\
\sigma_{S}^{*}=\frac{1}{\psi}\left[\varphi+\beta_{N}-\frac{\varepsilon_{N} \gamma_{0}}{\varepsilon_{S}}\left(1+\frac{\gamma_{1}}{s_{N} \sigma_{N}-\gamma_{1}}\right)\right] \\
l_{S}^{*}=\frac{1}{n}\left(\beta_{N}+m\right) \\
G^{*}=\frac{\left(\beta_{N}-\beta_{S}\right)}{\rho}
\end{gathered}
$$

And after taking the partial derivatives of our system, we have the Jacobian of the model, which is, considering the row/column order as $P, \sigma_{S}, l_{S}$ and $G$ respectively:

$$
J=\left[\begin{array}{cccc}
-\frac{1}{\mu_{N}+\mu_{S}-1} \frac{\varepsilon_{S} s_{S} \sigma_{S}}{a_{S}} \xi P^{\xi-1} & -\frac{1}{\mu_{N}+\mu_{S}-1} \frac{\varepsilon_{S} s_{S} P^{\xi}}{a_{S}} & 0 & 0 \\
0 & 0 & -n & \rho \\
\xi P^{\xi-1} s_{S} \sigma_{S} \frac{1}{a_{S}} & P^{\xi} s_{S} \frac{1}{a_{S}}-\psi & 0 & -\rho \\
0 & 0 & 0 & -\rho
\end{array}\right]
$$

To observe the steady state conditions we check the signs of the Jacobian on the steady state.

\subsubsection{Values for the Lagrangean in the Steady State (Stability conditions)}

Considering our jacobian as:

$$
J=\left[\begin{array}{llll}
a_{11} & a_{12} & a_{13} & a_{14} \\
a_{21} & a_{22} & a_{23} & a_{24} \\
a_{31} & a_{32} & a_{33} & a_{34} \\
a_{41} & a_{42} & a_{43} & a_{44}
\end{array}\right]
$$

We have: 


$$
a_{11}=-\frac{1}{\mu_{N}+\mu_{S}-1} \frac{\varepsilon_{S} S_{S} \sigma_{S}}{a_{S}} \xi P^{* \xi-1}
$$

a. From the Marshall-Lerner condition, $\mu_{N}+\mu_{S}>1$. This implies $\frac{1}{\mu_{N}+\mu_{S}-1}>0$

b. The relationship $\frac{\varepsilon_{S} S_{S} \sigma_{S}}{a_{S}}$ has $0<s_{S} \sigma_{S}<1$. As it is possible that $a_{S}>\varepsilon_{S}$, and being both higher than 0 , we will will most likely have $0<\frac{\varepsilon_{S} S_{S} \sigma_{S}}{a_{S}}<1$.

c. $\xi>0$, so the sign of $\xi P^{* \xi-1}$ depends on the sign of $P$ on the Steady State.

d. $\operatorname{Sign}\left(a_{11}\right)=-\operatorname{Sign}\left(P^{*}\right)$. If we only consider the positive value of $P^{*}$, then $\operatorname{Sign}\left(a_{11}\right)<$ 0

$$
a_{12}=-\frac{1}{\mu_{N}+\mu_{S}-1} \frac{\varepsilon_{S} s_{S} P^{* \xi}}{a_{S}}
$$

e. Analogous to $a_{11}, \operatorname{Sign}\left(a_{12}\right)=-\operatorname{Sign}\left(P^{*}\right)$. Being $\operatorname{Sign}\left(P^{*}\right)>0$, then $\operatorname{Sign}\left(a_{12}\right)<0$.

f. Some values are equal to zero:

$$
a_{13}=a_{14}=a_{21}=a_{22}=0
$$

g. $a_{23}=-n . \mathrm{n}$ is always a positive number, so $\operatorname{Sign}\left(a_{23}\right)<0$

h. $a_{24}=\rho . \rho>0$, then $\operatorname{Sign}\left(a_{24}\right)>0$

i. $\quad a_{31}=\xi P^{* \xi-1} s_{S} \sigma_{S} \frac{1}{a_{S}}$. Analogously to the previous cases, $\operatorname{Sign}\left(a_{31}\right)=\operatorname{Sign}\left(P^{*}\right)$. Being $\operatorname{Sign}\left(P^{*}\right)>0$, then $\operatorname{Sign}\left(a_{31}\right)>0$.

j. $\quad a_{32}=P^{* \xi} s_{S} \frac{1}{a_{S}}-\psi$. The sign of $a_{32}$ depends on the relationship between $P^{* \xi} s_{S} \frac{1}{a_{S}}$ and $\psi$. If $P^{* \xi} s_{S} \frac{1}{a_{S}}>\psi$ then $\operatorname{Sign}\left(a_{32}\right)>0$

k. $\mathrm{a}_{34}=\mathrm{a}_{44}=-\rho$. As $\rho>0, \operatorname{Sign}\left(\mathrm{a}_{34}\right)=\operatorname{Sign}\left(\mathrm{a}_{44}\right)<0$

1. As $a_{33}=a_{41}=a_{42}=a_{43}=0$ :

$$
\operatorname{Sign}(J)=\left[\begin{array}{cccc}
-\operatorname{Sign}(P) & -\operatorname{Sign}(P) & 0 & 0 \\
0 & 0 & - & + \\
\operatorname{Sign}(P) & \operatorname{Sign}\left(P^{\xi} s_{S} \frac{1}{a_{S}}-\psi\right) & 0 & - \\
0 & 0 & 0 & -
\end{array}\right]
$$

We can then analyze the value of $P$ in the steady state $\left(P^{*}\right)$

$$
P^{*}=\left[\frac{\gamma_{0} a_{S} \psi}{\left[\varphi+\beta_{N}-\frac{\varepsilon_{N} \gamma_{0}}{\varepsilon_{S}}\left(1+\frac{\gamma_{1}}{s_{N} \sigma_{N}-\gamma_{1}}\right)\right]} \frac{\varepsilon_{N}}{\varepsilon_{S} s_{S}}\left(1+\frac{\gamma_{1}}{s_{N} \sigma_{N}-\gamma_{1}}\right)\right]^{1 / \xi}
$$


A. $\gamma_{0} a_{S} \psi$ is a product of three positive numbers, as well as $\frac{\varepsilon_{N}}{\varepsilon_{S} s_{S}}>0$

B. As defined by Dutt (2002), the relationship between $s_{N} \sigma_{N}-\gamma_{1}$ is a central condition that needs to be positive in order to have a converging trajectory dynamics, so $s_{N} \sigma_{N}>\gamma_{1}$.

Then: $\left(1+\frac{\gamma_{1}}{s_{N} \sigma_{N}-\gamma_{1}}\right)>0$.

C. The relationship between $\left(\varphi+\beta_{N}\right)$ and $\left[\frac{\varepsilon_{N} \gamma_{0}}{\varepsilon_{S}}\left(1+\frac{\gamma_{1}}{s_{N} \sigma_{N}-\gamma_{1}}\right)\right]$ defines the final value of the signs. If $\left(\varphi+\beta_{N}\right)>\left[\frac{\varepsilon_{N} \gamma_{0}}{\varepsilon_{S}}\left(1+\frac{\gamma_{1}}{s_{N} \sigma_{N}-\gamma_{1}}\right)\right]$ then $\operatorname{Sign}(P)>0$.

Considering $\operatorname{Sign}(P)>0$ and that usually, $P^{\xi} s_{S} \frac{1}{a_{S}}<\psi$, then we have as the complete signs of the Jacobian in the 4-dimensional system:

$$
\operatorname{Sign}(J)=\left[\begin{array}{cccc}
- & - & 0 & 0 \\
0 & 0 & - & + \\
+ & - & 0 & - \\
0 & 0 & 0 & -
\end{array}\right]
$$

The methodology describing Jacobian signs can be found on Gandolfo (1973).

The Jacobian sign pairwise decomposition indicates the stability conditions of the model:

$J_{P \sigma_{S}}=\left[\begin{array}{cc}- & - \\ 0 & 0\end{array}\right]-$ Convergence (curve) $\quad J_{\sigma_{S} l_{S}}=\left[\begin{array}{cc}0 & - \\ - & 0\end{array}\right]-$ Closed Orbit

$J_{P l_{S}}=\left[\begin{array}{cc}- & - \\ + & -\end{array}\right]$ - Cyclical Convergence $\quad J_{\sigma_{S} G}=\left[\begin{array}{cc}0 & + \\ 0 & -\end{array}\right]$ - Convergence (curve)

$J_{P G}=\left[\begin{array}{cc}- & 0 \\ 0 & -\end{array}\right]$ - Convergence (point) $\quad J_{l_{S} G}=\left[\begin{array}{ll}0 & - \\ 0 & -\end{array}\right]$ - Convergence (curve)

Following the specifications and the conditions imposed in our system we have a stable system. Cycles emerge from the relationship between $\sigma_{S}$ and $l_{S}$. The cyclical convergence aspect of $P$ comes from the relationship between $P$ and $l_{S}$.

\subsection{Defining values for each of the parameters for a Latin American and a developed country.}

In this section we discuss the expected values for each parameter. In this way we can define the possible values for the Jacobian and the stability conditions of the model imagining two economies, a developing south (Latin America) and a developed economy (US or Europe). 
Table 3.1. Variable list to observe signals

\begin{tabular}{|lc|cc|cc|} 
I. & $a_{s}$ & VIII. & $s_{s}$ & XV. & $\sigma_{N}$ \\
II. & $\xi$ & IX. & $b_{S}$ & XVI. & $\beta_{S}$ \\
III. & $\mu_{N}$ & X. & $b_{N}$ & XVII. & $\beta_{N}$ \\
IV. & $\mu_{S}$ & XI. & $\gamma_{0}$ & XVIII. & $\rho$ \\
V. & $\varepsilon_{S}$ & XII. & $\gamma_{1}$ & XIX. & $\psi$ \\
VI. & $\varepsilon_{N}$ & XIII. & $m$ & XX. & $\varphi$ \\
VII. & $s_{N}$ & XIV. & $n$ & &
\end{tabular}

I. Estimations for the Capital-Output ratio $\left(a_{s}\right)$. When estimating the values of $a_{s}$ using the Penn World Tables we observe that $a_{s}$ shows a value between 2 and 5 . The smaller the value, more similar it is to a developing economy.

Table 3.2. Capital-output estimation average for the period 2000-2014. Selected countries.

\begin{tabular}{llll}
\hline Argentina & 2.8 & Germany & 4.0 \\
Brazil & 3.7 & France & 4.0 \\
Colombia & 3.7 & UK & 3.7 \\
Mexico & 3.0 & Italy & 5.1 \\
Canada & 3.6 & China & 3.3 \\
USA & 3.3 & India & 3.0 \\
\multicolumn{3}{l}{ Source: Penn World Tables 9.0}
\end{tabular}

II. Dutt (2002) states that the variable $\xi$ is smaller than 1 and bigger than 0 .

III. Price elasticity of imports of the North and the South are usually considered small in the BPCM theory, what Blecker (2016) calls "elasticity pessimism". Considering them $n$ their absolute value $\mu_{N}>0$ and $\mu_{S}>0$. We follow the Marshall-Lerner condition, in which $\mu_{N}+\mu_{S}>1$, as argued by Dutt (2002).

IV. The same for point III. We also consider here $\mu_{N} \approx 1$ and $\mu_{S} \approx 1$

$\mathrm{V}$. As increases in southern income will result in a higher proportion of expenditure in the northern good, we consider $0<\varepsilon_{\mathrm{s}}<1$.

VI. The value of the northern income elasticity of import demand is always higher than zero $\left(\varepsilon_{N}>0\right)$. It is possible to consider two cases, the one in which a higher income results in higher expenditure in the northern good $\left(0<\varepsilon_{N}<1\right)$. And the case in which a higher income results in higher expenditure in the southern $\operatorname{good}\left(\varepsilon_{N}>1\right)$. 
VII. $s_{N}$ consists in the fraction of income saved by capitalists. As defined before $s_{N}=\frac{S_{N}}{\sigma_{S} Y_{S}}$. we consider $0<s_{N}<1$.

VIII. Idem VII. $0<s_{S}<1$.

IX. $b_{S}=L_{S} / Y_{S}$. Using the PWT we can calculate these values from many countries using as $L_{S}$ the number of persons engaged, and as $Y_{S}$ the output-sided real GDP at chained PPP.

Table 3.3. Number of persons engaged (in dozens) divided by the output-sided real GDP at chained PPP for 2017. Selected countries.

\begin{tabular}{llll}
\hline Argentina & 0.28 & Germany & 0.12 \\
Brazil & 0.34 & France & 0.11 \\
Colombia & 0.37 & UK & 0.13 \\
Mexico & 0.25 & Italy & 0.12 \\
Canada & 0.11 & China & 0.48 \\
USA & 0.09 & India & 0.73 \\
\hline \multicolumn{4}{l}{ Source: Penn World Tables }
\end{tabular}

X. As observed in point IX, developing countries have higher values for the labor-output ratio, so $0<b_{N}<b_{S}<1$.

XI. $\gamma_{0}$ and $\gamma_{1}$ are positive constants, which shows that the northern investment rate depends on the capacity utilization rate measured by $\frac{Y_{N}}{K_{N}}$. Higher capacity utilization implies more buoyant markets and higher profits. We consider $\gamma_{0}$ the animal spirit. It does not have an economic meaning on itself, but we consider its value between 0 (low capitalists confidence) and 1 (high capitalists confidence). $0<\gamma_{0}<1$.

XII. $\quad \gamma_{1}>0$ is the sensitivity of capacity utilization changes to investment-capital ratio. We consider this value close to 0 , but positive. $\gamma_{1} \approx 0$.

XIII. $m$ and $n$ are the effects on the southern real wage dynamics. $m$ is the constant rate of decrease in real wage growth. In this work we consider it has a small value (about $1 \%$ maximum decrease). Then: $0<m \leq 1$.

XIV. $n$ is the elasticity of real wage to changes in the employment rate. It also has a value between 0 and 1 .

$\mathrm{XV}$. The constant profit rate of the north follows the range between zero (all income goes to wages) and one (all income goes to profits). Then $0<\sigma_{N}<1$. 
XVI. $\beta_{S}$ and $\beta_{N}$ are the exogenous parameters in the growth rate of labor productivity. We consider that the exogenous rate of technical change improvements is higher in the North than in the South: $\beta_{N}>\beta_{S}$. Usually this value is very close to zero.

XVII. According to the previous $\beta_{N}-$ Exogenous growth of labor productivity - between 0 and 0.1 . So we have $0<\beta_{S}<\beta_{N}<0.1$.

XVIII. $\rho$ is the effect of changes in the gap on the evolution of labor productivity in the south. Increases in $G$ also increases the productivity gap and have negative effects on the southern productivity. We then consider $\rho$ having a positive value (so $-\rho$ is negative). We consider it has a value between 0 and $1.0<\rho<1$.

XIX. $\varphi$ is the autonomous population growth. In developed countries it is very often negative while still positive in many developing countries. We will consider it having a positive value, but very close to zero: $\varphi>0$ and $\varphi \approx 0$.

XX. $\quad \psi$ is the elasticity of the labor supply to increases in the wage share. It has a positive number between zero and 1 .

Table 3.4. Results for the parameter values

\begin{tabular}{|cc|cc|cc|} 
VII. & $3<a_{s}<5$ & VII. & $0<s_{n}<1$ & XIV. & $0<n<1$ \\
VIII & $0<\xi<1$ & VIII. & $0<s_{S}<1$ & XV. & $0<\sigma_{N}<1$ \\
IX. & $\mu_{N} \approx 1$ & IX. & $0<b_{N}<b_{S}<1$ & XVI. & $0<\beta_{S}<\beta_{N}<0.1$ \\
X. & $\mu_{N}+\mu_{S}>1$ & XI. & $0<\gamma_{0}<1$ & XVII. & $0<\rho<1$ \\
XI. & $0<\varepsilon_{\text {S }}<1$ & XII. & $\gamma_{1} \approx 0$ & XIX. & $\varphi \approx 0$ \\
XII. & $0<\varepsilon_{N}<1$ or $\varepsilon_{N}>1$ & XIII. & $0<m \leq 1$ & XX. & $0<\psi<1$
\end{tabular}

Based on these parameter values we construct a southern and a norther economy, building some scenarios for our model.

\subsubsection{Baseline}

The baseline model is part of an effort to select credible parameters values for a developing economy in the South (Latin America) and for a developed country in the North. The developing economy is marked by a low industrialization (capital-output ratio) close to 3 (levels close to 
Mexico and Argentina). It follows the Marshall-Lerner condition $\left(\mu_{N}+\mu_{S}>1\right)$. The income elasticities of imports are higher in the north than in the south. The savings rate in the north is around $35 \%$ while in the south it is around $18 \%$. The initial value for the profit rate in the south is $30 \%$, being $40 \%$ in the north. Exogenous increase in labor force is about $4 \%$ while the country shows higher labor force elasticity to increases in the wage share. The parameters used for our baseline are the following:

Table 3.5. Baseline Model: Parameter Values and initial values

\begin{tabular}{cccc}
\hline$a_{s}=3$ & $\varepsilon_{N}=1.05$ & $m=0.9$ & $\rho=0.3$ \\
$\xi=0.5$ & $s_{N}=0.35$ & $n=1$ & $\varphi=0.04$ \\
$\mu_{N}=1$ & $S_{S}=0.18$ & $\sigma_{N}=0.4$ & $\psi=0.2$ \\
$\mu_{S}=1$ & $\gamma_{0}=0.005$ & $\beta_{S}=0.005$ & \\
$\varepsilon_{S}=0.95$ & $\gamma_{1}=0.06$ & $\beta_{N}=0.03$ & \\
\hline \multicolumn{5}{c}{ Initial Values } \\
\hline$P_{0}=0.286$ & $\sigma_{S_{0}}=0.3$ & $l_{S_{0}}=0.92$ & $G_{0}=0.5$ \\
\hline
\end{tabular}

Figure 3.1. Baseline Results
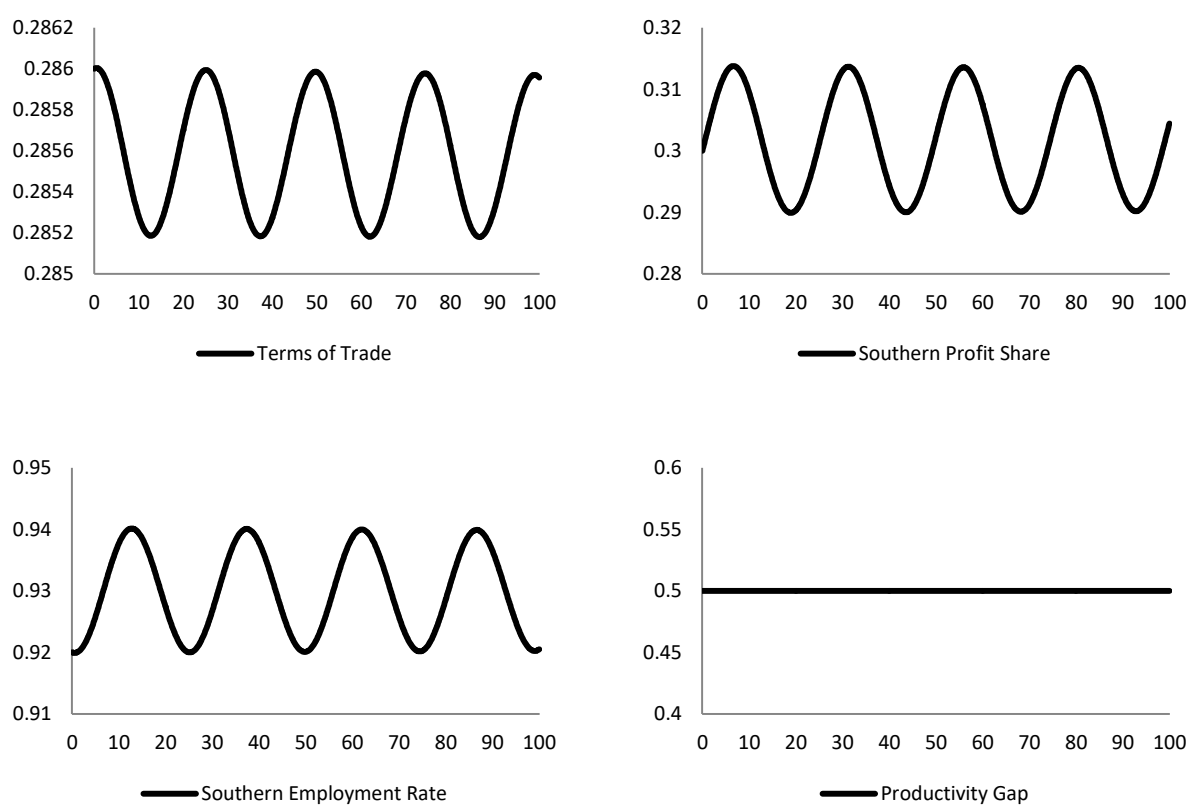
Table 3.6. Baseline: Steady state and Eigenvalues

\begin{tabular}{|c|c|c|}
\hline Steady State & $P^{*}=0.285$ & $l_{S}^{*}=0.929$ \\
\hline Eigenvalues & $\begin{array}{l}e_{1}=-0.0003+0.255 \mathrm{i} \\
e_{3}=-0.0250+0.000 \mathrm{i}\end{array}$ & $\begin{array}{l}e_{2}=-0.0003-0.255 \mathrm{i} \\
e_{4}=-0.0039+0.000 \mathrm{i}\end{array}$ \\
\hline
\end{tabular}

The baseline results show a situation in which the technology gap is constant at its initial level of 0.5. Terms of trade oscillate around a stable trend. The southern profit shares oscillate between the values of $29 \%$ and $31 \%$. And the Employment rate between $92 \%$ and $93.5 \%$. The baseline is marked by the presence of stable cycles that repeat themselves indefinitely (never reaching the equilibrium value).

\subsubsection{Scenario 1: Declining terms of trade and lagging behind}

From the baseline calibration we move to a case in which the economy is in a more fragile situation. We can compare this case with a more fragile Latin American country. It consists in a less industrialized economy (smaller $a_{s}$ ), in which the learning process occurs at a slower pace (reduced $\rho$ ) and the autonomous productivity growth is smaller (reduction in $\beta_{S}$ ). It is also an economy in which there is a smaller elasticity to move from the traditional to the modern sector - rigid labor market.

Table 3.7. Values for the lagging behind scenario

\begin{tabular}{cccc}
\multicolumn{4}{c}{ Initial Values } \\
\hline$P_{0}=0.286$ & $\sigma_{S_{0}}=0.3$ & $l_{S_{0}}=0.92$ & $G_{0}=0.5$ \\
\hline \multicolumn{4}{c}{ Modified Values } \\
\hline$a_{S}=2$ & $\beta_{S}=0.001$ & $\rho=0.05$ & $\varphi=0.03$ \\
\hline
\end{tabular}

Figure 3.2. Results for Scenario 1
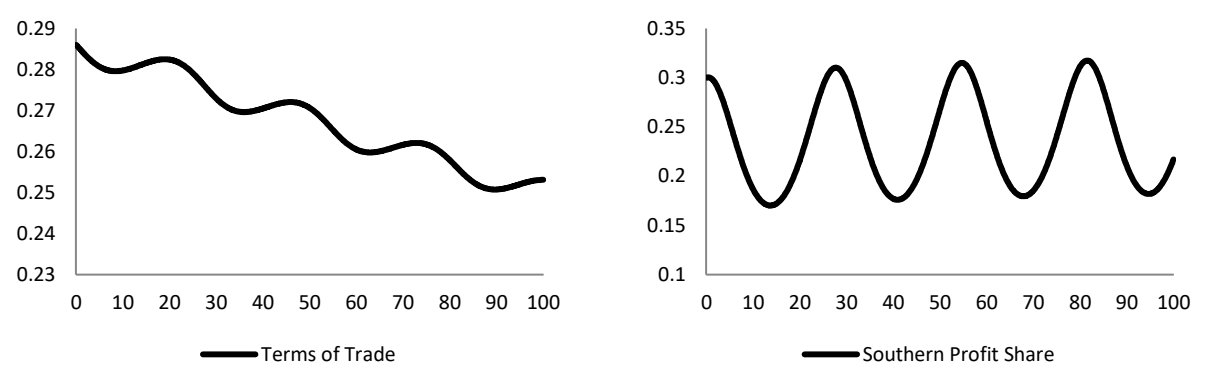



Table 3.8. Scenario 1: Steady State and Eigenvalues

\begin{tabular}{ccccc}
\hline Steady State & $P^{*}=0.182$ & $\sigma_{S}^{*}=0.251$ & $l_{S}^{*}=0.930$ & $G^{*}=0.58$ \\
\hline Eigenvalues & $e_{1}=-0.0003+0.236 \mathrm{i}$ & $e_{2}=-0.0003-0.236 \mathrm{i}$ \\
& $e_{3}=-0.0290+0.000 \mathrm{i}$ & & $e_{4}=-0.0038+0.000 \mathrm{i}$ \\
\hline
\end{tabular}

The structure of a less industrialized, more fragile economy, involves specialization in the exports of products with lower technology intensiveness. This economy has smaller learning efforts and the structural change goes towards less productive sectors. The results can be seen in Figure 3.2. This more fragile economy reaches an equilibrium value with a higher productivity gap than the baseline model.

The Prebish-Singer hypothesis is valid in this scenario. The southern, peripheral country, shows a decline in its terms of trade. This decline follows a cyclical adjustment toward a new equilibrium value $\left(P^{*}=0.182\right)$ that would be reached after many time periods. Capital accumulation and domestic growth would follow the same trajectory as the terms of trade $\left(\hat{Y}_{S}=g_{S}=\overline{s_{S}} P^{\xi} \sigma_{S} / \overline{a_{S}}\right)$, showing a reduction in the growth rate.

This more fragile economy also shows the presence of higher oscillations. When calculating the standard deviation in the baseline, $S D_{b}\left(l_{s}\right)=0.007$ and $S D_{b}\left(\sigma_{s}\right)=0.008$. For scenario 1 , $S D_{S 1}\left(l_{S}\right)=0.046$ and $S D_{S 1}\left(\sigma_{S}\right)=0.061$. There is a high increase in the oscillations amplitude. The steady state values are equal. However, a more specialized economy shows a higher endogenous pattern of volatility, increasing the amplitude of the oscillations.

\subsubsection{Scenario 2: Increases in the Terms of Trade and Catching-Up.}

In this scenario we simulate an economy in which, starting from the baseline, we focus on two main aspects: structural change and catching-up. In this scenario we increase the capital-output 
ratio, the exogenous productivity rate, the catching-up and the rate to which workers from the traditional sector can move to the modern sector.

Table 3.9. Values for the lagging behind scenario

\begin{tabular}{cccc}
\multicolumn{4}{c}{ Initial Values } \\
\hline$P_{0}=0.286$ & $\sigma_{S_{0}}=0.3$ & $l_{S_{0}}=0.92$ & $G_{0}=0.5$ \\
\hline \multicolumn{4}{c}{ Modified Values } \\
\hline$a_{S}=4$ & $\beta_{S}=0.01$ & $\rho=0.07$ & $\varphi=0.04$ \\
\hline
\end{tabular}

Figure 3.3. Results for Scenario 2
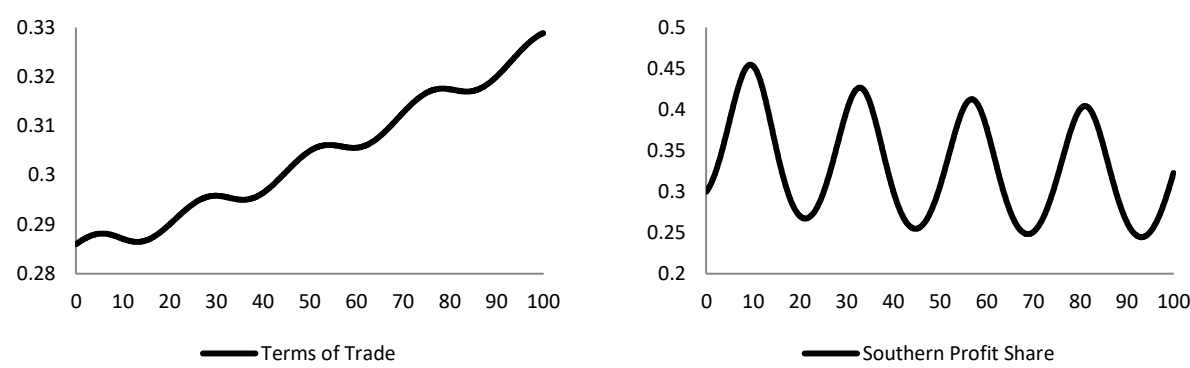

Southern Profit Share
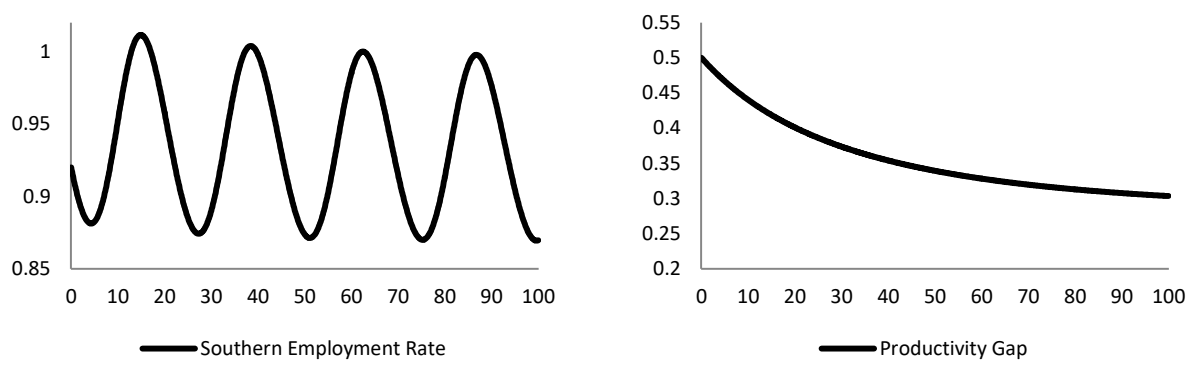

Table 3.10. Scenario 2: Steady State and Eigenvalues

\begin{tabular}{|c|c|c|c|c|}
\hline Steady State & $P^{*}=0.507$ & $\sigma_{S}^{*}=0.301$ & $l_{S}^{*}=0.930$ & $G^{*}=0.28$ \\
\hline Eigenvalues & $\begin{array}{l}e_{1}=-0.00 \\
e_{3}=-0.0\end{array}$ & $\begin{array}{l}.255 \mathrm{i} \\
.000 \mathrm{i}\end{array}$ & $\begin{array}{l}e_{2}=-c \\
e_{4}=-\end{array}$ & $\begin{array}{l}-0.255 \mathrm{i} \\
0.000 \mathrm{i}\end{array}$ \\
\hline
\end{tabular}

Scenario 2 has the opposite situation compared to the previous scenario 1 . The southern economy reduces the productivity gap with the north. There is economic diversification and 
structural change towards more productive sector. In this scenario, the country reverses the declining terms of trade tendency, and increase its growth rate.

This growth and structural change process create oscillations. However, increases in the amplitude of oscillations is milder when compared to the baseline, resulting in a much smaller volatility than the one compared with Scenario 1: $S D_{s 2}\left(\sigma_{S}\right)=0.048$ and $S D_{s 2}\left(l_{S}\right)=0.048$.

\subsection{Discussion of the results}

The price dynamics directly affect the behavior of the effective economic growth, as we have: $\hat{Y}_{S}=g_{S}=\overline{s_{S}} P^{\xi} \sigma_{S} / \overline{a_{S}}$. The effective growth rate will then depend on the dynamic behavior of prices $(P)$ (terms of trade/real exchange rate) and income distribution $\left(\sigma_{S}\right)$. This changes the structure of the BPCM, and long-run economic growth is dependent on price effects. Quantity effects also play a role, defined by the behavior of income distribution. The final result defining long-run growth is then much more complex than the more simple result highlighted in the Thirlwall model.

The Prebisch-Singer hypothesis can be observed under some specific conditions, when $\varepsilon_{S} \frac{s_{S} P^{\xi} \sigma_{S}}{a_{S}}>\varepsilon_{N} \gamma_{0}\left(1+\frac{\gamma_{1}}{s_{N} \sigma_{N}-\gamma_{1}}\right)$. Considering the northern characteristics as fixed, this means that a decrease in industrialization (reduction of $a_{S}$ ), a smaller wage share (rise in $\sigma_{S}$ ), a rise in the propensity to save $\left(s_{S}\right)$ and a rise in the income elasticity of imports $\left(\varepsilon_{S}\right)$ - reducing productive capacity and specialization - result in decreases in the terms of trade - and in economic growth.

A southern country that does not advance with structural change and learning opportunities, and does not absorb workers from the traditional into the modern sector, has the tendency to follow the cyclical decline in its terms of trade. Specialization in low technology intensive sectors and a lack of learning opportunities generates a decline in terms of trade (and economic growth).

In terms of technology efforts, we observe an indirect effect. The technology gap $(G)$ does not directly affect terms of trade $(P)$, but productivity $\left(l_{S}\right)$ and income distribution $\left(\sigma_{S}\right)$. Increases in the technology gap reduce the growth of employment rate, but increases the growth rate of the profit rate.

Following the ideas of the Goodwin model, cycles emerge from the relationship between economic activity and income distribution. Oscillations are endogenous to all economies (we can check the Jacobian of the model), as we can see from the baseline model. We observe that both a catching-up and a falling behind pattern raise volatility compared to the initial stable condition, 
however, the falling behind scenario is much more volatile and unstable than the catching-up one.

From the analysis of the model, an increase in volatility rises when the absolute values of $\frac{\partial \widehat{\sigma}_{S}}{\partial l_{S}}$ and $\frac{\partial \hat{l}_{S}}{\partial \sigma_{S}}$ increase without changing their sign. As $\frac{\partial \hat{l}_{S}}{\partial \sigma_{S}}=-n$ and $n>0$, when $n$ increases we observe more intense oscillations. The same for when $\frac{\partial \widehat{\sigma}_{S}}{\partial l_{S}}=P^{\xi} s_{S} \frac{1}{a_{S}}-\psi$ rises its value. In this sense, industrialization (structural change) reduces volatility (rise in $a_{S}$ ). Reduction in the elasticity between employment rate and wages (a more flexible labor market) also increases volatility. Increases in the autonomous propensity to save increases volatility and economic growth (rise in the terms of trade). In this sense, growth brings an increase in volatility, but it can be compensated by higher structural change.

Higher growth occurs when $P>0$, so the south can grow at a higher rate than the north. This happens in a scenario in which a virtuous structural change, learning opportunities and higher quality in the employment are a priority in the economic development of an economy, as we can see in Scenario 2.

The results of this research are aligned with the structuralist perspective, offering a perspective that deals with the critiques to the BPCM assumptions, and at the same time harmonize it with the Prebisch-Singer Hypothesis and the Center-Periphery framework. The model is able to capture macroeconomic mechanisms that trap developing economies in its underdeveloped condition, linking it to structural issues as a source of volatility, in the context of external constraints. This results in the creation of development traps.

\subsection{Conclusion}

This article expands the canonical Dutt (2002) model. Amitava Dutt, in a critique to an excessive focus of the literature on the Thirlwall law, highlights some neglected important aspects of the Thirlwall framework: uneven development and the transition dynamics between the short to long run. The author endogenizes, from a North-South model, the behavior of the terms of trade in a balance of payments constrained model (BPCM) framework.

Our paper adds to the Dutt (2002) model a Goodwin cyclical dynamics (using a Phillips curve), a Lewisian labor market transition between traditional and modern sectors, and a productivity (and technological) catching-up dynamics for the southern economy in relationship to the northern 
one. In this sense we expand the BPCM with a post-keynesian distributive dynamics and a structuralist-evolutionary structural change and technological catching-up element.

Part of the paper focuses on the development and the consistency of the expanded model, which results in a complex 4-dymensional dynamic system. The value range defined for the parameters show, based on the Jacobian of the system, a convergence pattern with cycles. Cycles initially emerge from the relationship between distribution (profit share) and employment rate (economic activity). This cyclical relationship affects the terms of trade dynamics, which adjusts cyclically to its equilibrium rate of growth. Rise in productivity and a virtuous technological catching-up occur when a southern country suffers a structural change towards more productive sectors, as well as when there are better conditions to benefit from learning opportunities. This virtuous catching-up pattern has the effect of reducing endogenous volatility.

The expanded model is able to reproduce cycles with neutral stability, showing a pair of conjugated eigenvalues from the Jacobian - cycles that repetitively oscillate around the steady state (never reaching it). This condition represents our central search for endogenous volatility. Industrialization and higher learning efforts generate a pattern with higher growth, increases in the terms of trade, reduction in the technology catching-up and smaller volatility when compared to the scenarios in which there is lagging behind. A virtuous catching-up strategy raises volatility when compared to a stagnated economy (baseline), however, this volatility increase is much smaller than the one observed in the case of a falling behind scenario (when a country specializes its productive structure in lesser technology intensive sectors).

Under the Thirlwall Law, price effects are neutral. We challenge this assumption, offering a solution to the transition dynamics. It is possible to have structuralist/evolutionary arguments emerging from the Thirlwall framework even when the Thirlwall law is under siege. For the BPCM theorists, accepting price non-neutrality is a return to the neoclassical world in which prices adjust the model to the equilibrium. We offer an alternative to question the price assumption without entering the neoclassical world.

From the model we see that economic growth can be reduced or increased in the long run depending on income distribution and on the terms of trade, both depending also on technology catching-up and on the employment rate. This relationship results in endogenous oscillatory cycles, which are in the "DNA" of these developing economies. In this sense, from the Thirlwall 
framework, we develop a system that relates a southern country to its dependency on terms of trade - which is directly related to the quality of the productive structure.

Finally, in the Thirlwall law, learning and structural change are brought to the model by endogenizing income elasticities of imports and exports (Cimoli \& Porcile, 2014). In our expanded version of the BPCM, we do not endogenize them to get the same result. The behavior of the productive structure comes from the evolution of productivity catching-up and of the terms of trade. The Prebisch-Singer hypothesis appears in the expanded Thirlwall framework, reconciling the theory of decline in the terms of trade with the balance of payments constrained model even when prices are not neutral. 
Annex 3.1. Chapter 3 - Variable List

\begin{tabular}{|c|c|c|c|}
\hline$Y_{i}$ & Total income ( $f$ - foreign $)$ & $\gamma_{0}$ & Autonomous Investment parameter \\
\hline$K_{i}$ & Capital Stock & $\gamma_{1}$ & $\begin{array}{l}\text { Sensitivity of Investment to Capacity } \\
\text { Utilization }\end{array}$ \\
\hline$C_{i}$ & Total Consumption & $\alpha$ & $\begin{array}{l}\text { Share of northern expenditure on } \\
\text { southern goods }\end{array}$ \\
\hline$S_{i}$ & Total Savings & $\alpha_{0}$ & $\begin{array}{l}\text { Autonomous part of the share of northern } \\
\text { expenditure on southern goods }\end{array}$ \\
\hline$I_{i}$ & Total Investment & $\beta$ & $\begin{array}{l}\text { Share of southern expenditure on } \\
\text { northern goods }\end{array}$ \\
\hline$M_{i}$ & Total Imports & $\beta_{0}$ & $\begin{array}{l}\text { Autonomous part of the share of southern } \\
\text { expenditure on northern goods }\end{array}$ \\
\hline$X_{i}$ & Total Exports & $g_{i}$ & Capital accumulation rate \\
\hline$P_{i}$ & Prices & $\theta_{i}$ & Constants to the import/export functions \\
\hline$P$ & Terms of Trade & $\lambda_{i}$ & Labor Productivity \\
\hline$L_{i}$ & Total Employment & G & Productivity Gap \\
\hline$V_{i}$ & Real Wages & $l_{i}$ & Employment rate \\
\hline$W_{i}$ & Nominal Wages & $\rho$ & $\begin{array}{l}\text { Sensitivity of Gap growth to Gap Level } \\
\text { (Catching-Up) }\end{array}$ \\
\hline$F$ & Financial Flows & $\beta_{i}$ & Autonomous productivity growth \\
\hline$\Lambda_{i}$ & Total Workforce & $m$ & Constant growth of real wages \\
\hline$b_{i}$ & Fixed unit labor requirement & $n$ & Real wage sensitivity to South labor \\
\hline$\varepsilon_{i}$ & Income Elasticity of Imports & $\xi$ & Exponential to the Terms of Trade \\
\hline$\mu_{i}$ & Price Elasticity of Imports & $\delta$ & Income Elasticity Exports \\
\hline$a_{i}$ & Capital-Output Ratio & $v$ & Price Elasticity Exports \\
\hline$s_{i}$ & Propensity to Save & $\varphi$ & intercept of the Lewis part \\
\hline$\omega_{i}$ & Wage Share & $\psi$ & slope of the Lewis part \\
\hline$\sigma_{i}$ & Profit Share & $E D$ & Excess Demand \\
\hline$u$ & Capacity Utilization & $N$ & Northern country \\
\hline$Z$ & Markup & $S$ & Southern country \\
\hline
\end{tabular}




\section{Annex 3.2. Mathematical Appendix (Chapter 3)}

\begin{tabular}{cc|cl|cc}
$\hat{Y}_{S} / \hat{Y}_{N}=\varepsilon_{N} / \varepsilon_{S}$ & $\mathrm{~A} 3.1$. & $u=Y_{N} / K_{N}$ & $\mathrm{~A} 3.2$. & $b_{S}=L_{S} / Y_{S}$ & A3.3. \\
$b_{N}=L_{N} / Y_{N}$ & $\mathrm{~A} 3.4$. & $a_{N}=K_{N} / Y_{N}$ & $\mathrm{~A} 3.5$. & $Y_{S}=K_{S} / a_{S}$ & A3.6. \\
$V_{S}=W_{S} / P_{S}$ & $\mathrm{~A} 3.7$. & $P=P_{S} / P_{N}$ & $\mathrm{~A} 3.8$. & $\omega_{S}=b_{S} V_{S}$ & A3.9. \\
$\sigma_{S}=\left(1-b_{S} V_{S}\right)$ & $\mathrm{A} 3.10$. & $S_{S} \sigma_{S}=\frac{S_{S}}{Y_{S}}$ & $\mathrm{~A} 3.11$. & & \\
& & & & & \\
\hline
\end{tabular}

Wage Share (South): $\omega_{S}=\frac{W_{S} L_{S}}{P_{S} Y_{S}} \Rightarrow \omega_{S}=b_{S} V_{S}$

Profit Share (South): $\sigma_{S}=1-\omega_{S} \Rightarrow \sigma_{S}=1-b_{S} V_{S}$

Prices (North): $P_{N}=(1+z) \frac{W_{N} L_{N}}{Y_{N}} \Rightarrow P_{N}=(1+z) W_{N} b_{N}$

Wage Share (North): $\omega_{N}=\frac{W_{N} L_{N}}{P_{N} Y_{N}} \Rightarrow \omega_{N}=\frac{W_{N} L_{N}}{(1+z) \frac{W_{N} L_{N}}{Y_{N}} Y_{N}} \Rightarrow \omega_{N}=\frac{1}{(1+z)}$

Profit Share (North): $\sigma_{N}=1-\omega_{N}$

Investment rate (North): $g_{N}=I_{N} / K_{N}=\gamma_{0}+\gamma_{1}(u)$

North expenditure in Southern goods: $\alpha=\alpha_{0} Y_{N}^{\varepsilon_{N}-1} P^{1-\mu_{N}}$

South expenditure in Northern $\operatorname{goods}^{15}: \beta=\beta_{0}\left(\sigma_{S} Y_{S}\right)^{\varepsilon_{S}-1}(1 / P)^{1-\mu_{S}}$

Total exports of the South: $P_{S} X_{S}=\alpha\left[\omega_{N}+\left(1-s_{N}\right) \sigma_{N}\right] P_{N} Y_{N} \Rightarrow$

$$
\begin{gathered}
\Rightarrow P_{S} X_{S}=\alpha\left\{\frac{\left[1+\left(1-s_{N}\right) z\right]}{(1+z)}\right\} P_{N} Y_{N} \Rightarrow P_{S} X_{S}=\alpha_{0} Y_{N}^{\varepsilon_{N}-1} P^{1-\mu_{N}}\left\{\frac{\left[1+\left(1-s_{N}\right) z\right]}{(1+z)}\right\} P_{N} Y_{N} \Rightarrow \\
\Rightarrow P_{S} X_{S}=\alpha_{0} Y_{N}^{\varepsilon_{N}-1}\left(P_{S} / P_{N}\right)^{1-\mu_{N}}\left\{\frac{\left[1+\left(1-s_{N}\right) z\right]}{(1+z)}\right\} P_{N} Y_{N} \\
\Rightarrow P_{S} X_{S}=\alpha_{0} Y_{N}^{\varepsilon_{N}-1}\left(P_{N} / P_{S}\right)^{\mu_{N}-1}\left\{\frac{\left[1+\left(1-s_{N}\right) z\right]}{(1+z)}\right\} P_{N} Y_{N} \Rightarrow
\end{gathered}
$$

\footnotetext{
${ }^{15}$ We corrected the notation error of the Dutt (2002) paper (P is actually $\left.1 / \mathrm{P}\right)$.
} 


$$
\begin{gathered}
\Rightarrow X_{S}=\alpha_{0} Y_{N}^{\varepsilon_{N}-1}\left(P_{N} / P_{S}\right)^{\mu_{N}-1}\left\{\frac{\left[1+\left(1-s_{N}\right) z\right]}{(1+z)}\right\}\left(P_{N} / P_{S}\right) Y_{N} \Rightarrow \\
\Rightarrow X_{S}=Y_{N}^{\varepsilon_{N}}\left(P_{N} / P_{S}\right)^{\mu_{N}} \alpha_{0}\left\{\frac{\left[1+\left(1-s_{N}\right) z\right]}{(1+z)}\right\} \Rightarrow \text { given } \theta_{S}=\alpha_{0}\left[1+\left(1-s_{N}\right) z\right] /(1+z) \Rightarrow \\
X_{S}=\theta_{S} P^{-\mu_{N}} Y_{N}^{\varepsilon_{N}}
\end{gathered}
$$

Total exports of the North: $P_{N} X_{N}=\beta \sigma_{S} P_{S} Y_{S} \Rightarrow$

$$
\begin{gathered}
\Rightarrow P_{N} X_{N}=\beta_{0}\left(\sigma_{S} Y_{S}\right)^{\varepsilon_{S}-1}(1 / P)^{1-\mu_{S}} \sigma_{S} P_{S} Y_{S} \Rightarrow X_{N}=\beta_{0}\left(\sigma_{S} Y_{S}\right)^{\varepsilon_{S}-1}(P)^{\mu_{S}-1} \sigma_{S}\left(P_{S} / P_{N}\right) Y_{S} \Rightarrow \\
\Rightarrow X_{N}=\beta_{0}\left(\sigma_{S} Y_{S}\right)^{\varepsilon_{S}}(P)^{\mu_{S}} \Rightarrow \text { given } \theta_{N}=\beta_{0} \sigma_{S}^{\varepsilon_{S}} \Rightarrow \\
X_{N}=\theta_{N}(1 / P)^{-\mu_{S}} Y_{S}^{\varepsilon_{S}}
\end{gathered}
$$

Excess Demand in the South: $E D_{S}=C_{S S}+I_{S S}+X_{S}-Y_{S} \Rightarrow$

$$
\Rightarrow \text { Considering } Y_{S}=C_{S S}+I_{S S}+M_{S} \text { and } M_{S}=\frac{X_{N}}{P} \Rightarrow E D_{S}=X_{S}-\left(\frac{1}{P}\right) X_{N}
$$

Excess Demand in the North: $E D_{N}=C_{N N}+I_{N}+X_{N}-Y_{N} \Rightarrow$

$$
\Rightarrow \text { Considering } Y_{N}=C_{N N}+S_{N}+M_{S} \text { and } M_{N}=P X_{N} \Rightarrow E D_{N}=I_{N}-S_{N}+X_{N}-P X_{S}
$$

Short-run equilibrium: $E D_{i}=0$

Equilibrium Value: $E D_{S}=X_{S}-\left(\frac{1}{P}\right) X_{N}=0 \Rightarrow X_{N}=P X_{S}$

$$
\begin{gathered}
\Rightarrow \text { as } X_{S}=\theta_{S} P^{-\mu_{N}} Y_{N}^{\varepsilon_{N}} \text { and } X_{N}=\theta_{N}(1 / P)^{-\mu_{S}} Y_{S}^{\varepsilon_{S}} \Rightarrow \theta_{N}(1 / P)^{-\mu_{S}} Y_{S}^{\varepsilon_{S}}=P \theta_{S} P^{-\mu_{N}} Y_{N}^{\varepsilon_{N}} \Rightarrow \\
\Rightarrow(1 / P)^{-\mu_{S}}(1 / P)^{-\mu_{N}}(1 / P)=\frac{\theta_{S} Y_{N}^{\varepsilon_{N}}}{\theta_{N} Y_{S}^{\varepsilon_{S}}} \Rightarrow P^{\mu_{N}+\mu_{S}-1}=\frac{\theta_{S} Y_{N}^{\varepsilon_{N}}}{\theta_{N} Y_{S}^{\varepsilon_{S}}} \Rightarrow \\
\Rightarrow \text { as } Y_{S}=K_{S} / a_{S} \text { and } u=Y_{N} / K_{N} \Rightarrow Y_{N}=u K_{N} \Rightarrow \\
\Rightarrow P^{\mu_{N}+\mu_{S}-1}=\frac{\theta_{S} u K_{N}^{\varepsilon_{N}}}{\theta_{N}\left(K_{S} / a_{S}\right)^{\varepsilon_{S}}} \Rightarrow P^{\mu_{N}+\mu_{S}-1}=\frac{\theta_{S}}{\theta_{N}} u K_{N}^{\varepsilon_{N}}\left(\frac{a_{S}}{K_{S}}\right)^{\varepsilon_{S}} \Rightarrow
\end{gathered}
$$




$$
P=\left[\left(\theta_{S} / \theta_{N}\right)\left(u K_{N}\right)^{\varepsilon_{N}}\left(a_{S} / K_{S}\right)^{\varepsilon_{S}}\right]^{1 /\left(\mu_{N}+\mu_{S}-1\right)}
$$

$$
{ }^{16} P=\left[\left(\theta_{S} / \theta_{N}\right)\left(u K_{N}\right)^{\varepsilon_{S}}\left(K_{S} / a_{S}\right)^{\varepsilon_{N}}\right]^{1 /\left(\mu_{N}+\mu_{S}-1\right)}(\text { Dutt, error })
$$

Capacity Utilization from Investment function (North): $I_{N} / K_{N}=\gamma_{0}+\gamma_{1}(u) \Rightarrow$

$$
\begin{gathered}
\Rightarrow \text { as } u=Y_{N} / K_{N} \Rightarrow K_{N}=Y_{N} / u \Rightarrow u I_{N} / Y_{N}=\gamma_{0}+\gamma_{1}(u) \Rightarrow u\left(\frac{I_{N}}{Y_{N}}-\gamma_{1}\right)=\gamma_{0} \Rightarrow \\
\Rightarrow u=\frac{\gamma_{0}}{\left(\frac{I_{N}}{Y_{N}}-\gamma_{1}\right)} \Rightarrow \text { assuming } \frac{I_{N}}{Y_{N}}=s_{N} \sigma_{N} \Rightarrow I_{N}=S_{N} \sigma_{N} \Rightarrow \\
u=\frac{\gamma_{0}}{\left(s_{N} \sigma_{N}-\gamma_{1}\right)}
\end{gathered}
$$

Capital accumulation rate (North): $g_{N}=\gamma_{0}+\gamma_{1}(u) \Rightarrow g_{N}=\gamma_{0}+\gamma_{1} \frac{\gamma_{0}}{\left(s_{N} \sigma_{N}-\gamma_{1}\right)} \Rightarrow$

$$
g_{N}=\gamma_{0}+\frac{\gamma_{1} \gamma_{0}}{\left(s_{N} \sigma_{N}-\gamma_{1}\right)}
$$

Total Savings (South): $s_{S} \sigma_{s}=\frac{s_{S}}{Y_{S}} \Rightarrow S_{S}=s_{S} Y_{S} \Rightarrow$

$$
\begin{aligned}
& S_{S}=s_{S} \sigma_{s} K_{S} / a_{S} \\
& S_{S}=s_{S} \sigma_{S} K_{S} / a_{S}(\mathrm{Dutt})
\end{aligned}
$$

Investment (South): $I_{s}=P^{\xi} S_{S}$

Capital accumulation rate (South): $g_{S}=I_{S} / K_{S} \Rightarrow g_{S}=\frac{P^{\xi} S_{S}}{K_{S}} \Rightarrow g_{S}=\frac{P^{\xi} S_{S} \sigma_{S} K_{S} / a_{S}}{K_{S}} \Rightarrow$

$$
\Rightarrow g_{S}=\frac{P^{\xi} s_{S} \sigma_{S}}{a_{S}} \Rightarrow
$$

\footnotetext{
${ }^{16}$ Solving the error of the Dutt (2002) paper.
} 


$$
g_{S}=s_{S} P^{\xi} \sigma_{s} / a_{S}
$$

Terms of trade variation: $p=\frac{d \ln P}{d t} \Rightarrow P=\left[\left(\theta_{S} / \theta_{N}\right)\left(u K_{N}\right)^{\varepsilon_{N}}\left(a_{S} / K_{S}\right)^{\varepsilon_{S}}\right]^{1 /\left(\mu_{N}+\mu_{S}-1\right)} \Rightarrow$

$$
\begin{gathered}
P=\left[\left(\theta_{S} / \theta_{N}\right)\left(Y_{N}\right)^{\varepsilon_{N}}\left(Y_{S}\right)^{-\varepsilon_{S}}\right]^{1 /\left(\mu_{N}+\mu_{S}-1\right)} \Rightarrow \\
\ln P=\frac{1}{\left(\mu_{N}+\mu_{S}-1\right)}\left[\ln \left(\frac{\theta_{S}}{\theta_{N}}\right)+\varepsilon_{N} \ln Y_{N}-\varepsilon_{S} \ln Y_{S}\right] \Rightarrow \frac{d \ln P}{d t}=\frac{1}{\left(\mu_{N}+\mu_{S}-1\right)}\left[\varepsilon_{N} g_{N}-\varepsilon_{S} g_{S}\right] \\
p=\left[1 /\left(\mu_{N}+\mu_{S}-1\right)\right]\left(\varepsilon_{N} g_{N}-\varepsilon_{S} g_{S}\right)
\end{gathered}
$$

Add a productivity dynamics by endogenizing labor productivity.

Labor Productivity (North): $\lambda_{N}=\frac{1}{b_{N}}$

Dynamics in the north: $\widehat{b_{N}}=-\beta_{N}, \widehat{\lambda_{N}}=\beta_{N}$ and $\widehat{W_{N}}=\beta_{N} \Rightarrow P_{N}=(1+z) W_{N} b_{N} \Rightarrow$

$$
\Rightarrow \widehat{P_{N}}=(\widehat{1+z})+\widehat{W_{N}}+\widehat{b_{N}} \Rightarrow \text { as }(\widehat{1+z})=0 \Rightarrow \widehat{P_{N}}=-\beta_{N}+\beta_{N} \Rightarrow \widehat{P_{N}}=0
$$

Labor Productivity (South): $\lambda_{S}=\frac{1}{b_{S}} \Rightarrow \widehat{\lambda_{S}}=-\widehat{b_{S}}$

Dynamics in the South: $\widehat{b_{S}}=-\beta_{S}-\rho G$ and $\widehat{\lambda_{S}}=\beta_{S}+\rho G$

Productivity Gap: $G=\ln \left(\frac{\lambda_{N}}{\lambda_{S}}\right) \Rightarrow G=\ln \left(\frac{b_{S}}{b_{N}}\right)$

Dynamics of the productivity Gap: $\Rightarrow \widehat{G}=\widehat{b_{S}}-\widehat{b_{N}} \Rightarrow \widehat{G}=-\beta_{S}-\rho G+\beta_{N} \Rightarrow$

$\widehat{G}=\left(\beta_{N}-\beta_{S}\right)-\rho G$ with $\widehat{\lambda_{N}}=\beta_{N}$ and $\widehat{\lambda_{S}}=\beta_{S}+\rho G$

$$
\widehat{G}=\left(\beta_{N}-\beta_{S}\right)-\rho G
$$

Add a labor market dynamics by endogenizing real wages.

Employment rate (South): $l_{s}=\frac{L_{S}}{\Lambda_{S}}$ 
Add Phillips curve to the real wage dynamics (South): $\widehat{V}_{S}=-m+n l_{s} \Rightarrow$

$$
\widehat{V}_{S}=-m+n\left(\frac{L_{S}}{\Lambda_{S}}\right)
$$

Wage Share dynamics: $\omega_{S}=b_{S} V_{S} \Rightarrow \widehat{\omega_{S}}=\widehat{b_{S}}+\widehat{V_{S}} \Rightarrow \widehat{\omega_{S}}=-\beta_{S}-\rho G-m+n l_{S}$

Profit Share Dynamics: $\widehat{\sigma_{S}}=-\widehat{\omega_{S}} \Rightarrow$

$$
\widehat{\sigma_{S}}=\beta_{S}+\rho G+m-n l_{S}
$$

\section{$\underline{\text { Terms of trade dynamics }}$}

As $\sigma_{s}$ is now endogenous, we have a new terms of trade dynamics:

$$
\begin{gathered}
p=\hat{P}=\frac{1}{\mu_{N}+\mu_{S}-1}\left(\varepsilon_{N} g_{N}-\varepsilon_{S} g_{S}\right) \Rightarrow \text { as } g_{N}=\gamma_{0}+\frac{\gamma_{1} \gamma_{0}}{\left(s_{N} \sigma_{N}-\gamma_{1}\right)} \text { and } g_{S}=s_{S} P^{\xi} \sigma_{S} / a_{S} \Rightarrow \\
\Rightarrow \hat{P}=\frac{1}{\mu_{N}+\mu_{S}-1}\left[\varepsilon_{N}\left(\gamma_{0}+\frac{\gamma_{1} \gamma_{0}}{\left(s_{N} \sigma_{N}-\gamma_{1}\right)}\right)-\varepsilon_{S} s_{S} P^{\xi} \frac{\sigma_{S}}{a_{S}}\right] \Rightarrow \\
\hat{P}=\frac{1}{\mu_{N}+\mu_{S}-1}\left[\varepsilon_{N} \gamma_{0}\left(1+\frac{\gamma_{1}}{s_{N} \sigma_{N}-\gamma_{1}}\right)-\varepsilon_{S} \frac{s_{S} P^{\xi} \sigma_{S}}{a_{S}}\right] \\
P=P_{S} / P_{N} \Rightarrow \widehat{P}=\widehat{P_{S}}-\widehat{P_{N}} \Rightarrow a s \widehat{P_{N}}=0 \Rightarrow \widehat{P}=\widehat{P_{S}}
\end{gathered}
$$

Employment rate Dynamics: $l_{S}=\frac{L_{S}}{\Lambda_{S}} \Rightarrow$ Let us consider $\widehat{\Lambda_{S}}=\varphi-\psi \sigma_{S} \Rightarrow \widehat{l_{S}}=\widehat{L_{S}}-\widehat{\Lambda_{S}} \Rightarrow$ Total employment dynamics: $b_{S}=\frac{L_{S}}{Y_{S}} \Rightarrow L_{S}=b_{S} Y_{S} \Rightarrow \widehat{L_{S}}=\widehat{b}_{S}+\widehat{Y}_{S} \Rightarrow$ Employment rate dynamics: $\widehat{l_{S}}=\widehat{L_{S}}+\widehat{\Lambda_{S}}=\widehat{b_{S}}+\widehat{Y_{S}}-\widehat{\Lambda_{S}}$

Growth dynamics (South): $Y_{S}=K_{S} / a_{S} \Rightarrow \widehat{Y_{S}}=\widehat{K_{S}}-\widehat{a_{S}} \Rightarrow$ as $a_{S}$ is constant, $\widehat{a_{S}}=0 \Rightarrow$

$$
\widehat{Y_{S}}=\widehat{K_{S}}
$$

Capital Acummulation (South): $I_{S}=P^{\xi} S_{S} \Rightarrow$ 


$$
\begin{gathered}
\Rightarrow \text { as } S_{S}=s_{S} \sigma_{S} K_{S} / a_{S} \Rightarrow I_{S}=P^{\xi} s_{S} \sigma_{S} \frac{K_{S}}{a_{S}} \Rightarrow \text { as } I_{S}=\widehat{K_{S}} K_{S} \Rightarrow \widehat{K_{S}} K_{S}=P^{\xi} s_{S} \sigma_{S} \frac{K_{S}}{a_{S}} \Rightarrow \\
\widehat{K_{S}}=P^{\xi} s_{S} \sigma_{S} \frac{1}{a_{S}}
\end{gathered}
$$

Employment dynamics (South): $\widehat{l_{S}}=\widehat{b_{S}}+\widehat{Y_{S}}+\widehat{\Lambda_{S}} \Rightarrow$ as $\widehat{Y_{S}}=\widehat{K_{S}} \Rightarrow \widehat{L_{S}}=\widehat{b_{S}}+\widehat{K_{S}}-\widehat{\Lambda_{S}} \Rightarrow$

$$
\widehat{l_{S}}=-\beta_{S}-\rho G+P^{\xi} s_{S} \sigma_{S} \frac{1}{a_{S}}-\varphi+\psi \sigma_{S}
$$

Dynamic system:

$$
\begin{gathered}
\widehat{P}=\frac{1}{\mu_{N}+\mu_{S}-1}\left[\varepsilon_{N} \gamma_{0}\left(1+\frac{\gamma_{1}}{s_{N} \sigma_{N}-\gamma_{1}}\right)-\varepsilon_{S} \frac{s_{S} P^{\xi} \sigma_{S}}{a_{S}}\right] \\
\widehat{\sigma_{S}}=\beta_{S}+\rho G+m-n l_{S} \\
\widehat{l_{S}}=-\beta_{S}-\rho G+P^{\xi} s_{S} \sigma_{S} \frac{1}{a_{S}}-\varphi+\psi \sigma_{S} \\
\widehat{G}=\left(\beta_{N}-\beta_{S}\right)-\rho G
\end{gathered}
$$

\section{$\underline{\text { Steady State }}$}

Productivity Gap: $\widehat{G}=0 \Rightarrow\left(\beta_{N}-\beta_{S}\right)-\rho G=0 \Rightarrow G^{*}=\frac{\left(\beta_{N}-\beta_{S}\right)}{\rho}$

Profit Share: $\widehat{\sigma_{S}}=0 \Rightarrow \beta_{S}+\rho G+m-n l_{S}=0 \Rightarrow \beta_{S}+\rho \frac{\left(\beta_{N}-\beta_{S}\right)}{\rho}+m-n l_{S}=0 \Rightarrow$

$$
n l_{S}=\beta_{S}+\rho \frac{\left(\beta_{N}-\beta_{S}\right)}{\rho}+m \Rightarrow l_{S} \Rightarrow \frac{1}{n}\left[\beta_{S}+\left(\beta_{N}-\beta_{S}\right)+m\right] \Rightarrow l_{S}^{*}=\frac{1}{n}\left(\beta_{N}+m\right)
$$

Total prices: $\hat{P}=0 \Rightarrow \frac{1}{\mu_{N}+\mu_{S}-1}\left(\varepsilon_{N} \gamma_{0}\left(1+\frac{\gamma_{1}}{s_{N} \sigma_{N}-\gamma_{1}}\right)-\varepsilon_{S} \frac{s_{S} P^{\xi} \sigma_{S}}{a_{S}}\right)=0 \Rightarrow \varepsilon_{N} \gamma_{0}\left(1+\frac{\gamma_{1}}{s_{N} \sigma_{N}-\gamma_{1}}\right)-$ $\varepsilon_{S} \frac{s_{S} P^{\xi} \sigma_{S}}{a_{S}}=0 \Rightarrow \varepsilon_{N} \gamma_{0}\left(1+\frac{\gamma_{1}}{s_{N} \sigma_{N}-\gamma_{1}}\right)=\varepsilon_{S} \frac{s_{S} P^{\xi} \sigma_{S}}{a_{S}} \Rightarrow P^{*}=\left[\frac{1}{\sigma_{S}} \frac{a_{S} \varepsilon_{N} \gamma_{0}}{\varepsilon_{S} s_{S}}\left(1+\frac{\gamma_{1}}{s_{N} \sigma_{N}-\gamma_{1}}\right)\right]^{1 / \xi}$

Total labor: $\widehat{l_{S}}=0 \Rightarrow-\beta_{S}-\rho G+P^{\xi} s_{S} \sigma_{S} \frac{1}{a_{S}}-\varphi+\psi \sigma_{S}=0 \Rightarrow$ 


$$
\begin{gathered}
\Rightarrow-\beta_{S}-\rho \frac{\left(\beta_{N}-\beta_{S}\right)}{\rho}+\frac{1}{\sigma_{S}} \frac{a_{S} \varepsilon_{N} \gamma_{0}}{\varepsilon_{S} s_{S}}\left(1+\frac{\gamma_{1}}{s_{N} \sigma_{N}-\gamma_{1}}\right) s_{S} \sigma_{S} \frac{1}{a_{S}}-\varphi+\psi \sigma_{S}=0 \Rightarrow \\
\Rightarrow-\beta_{N}+\frac{\varepsilon_{N} \gamma_{0}}{\varepsilon_{S}}\left(1+\frac{\gamma_{1}}{s_{N} \sigma_{N}-\gamma_{1}}\right)-\varphi+\psi \sigma_{S}=0 \Rightarrow-\beta_{N}+\frac{\varepsilon_{N} \gamma_{0}}{\varepsilon_{S}}\left(1+\frac{\gamma_{1}}{s_{N} \sigma_{N}-\gamma_{1}}\right)-\varphi=-\psi \sigma_{S} \Rightarrow \\
\Rightarrow \sigma_{S}=\frac{1}{\psi}\left[\beta_{N}-\frac{\varepsilon_{N} \gamma_{0}}{\varepsilon_{S}}\left(1+\frac{\gamma_{1}}{s_{N} \sigma_{N}-\gamma_{1}}\right)+\varphi\right] \Rightarrow \Rightarrow \sigma_{S}^{*}=\frac{1}{\psi}\left[\varphi+\beta_{N}-\frac{\varepsilon_{N} \gamma_{0}}{\varepsilon_{S}}\left(1+\frac{\gamma_{1}}{s_{N} \sigma_{N}-\gamma_{1}}\right)\right] \\
\text { ToT: } P^{*}=\left[\frac{\gamma_{0} a_{S} \psi}{\left[\varphi+\beta_{N}-\frac{\varepsilon_{N} \gamma_{0}}{\varepsilon_{S}}\left(1+\frac{\gamma_{1}}{s_{N} \sigma_{N}-\gamma_{1}}\right)\right.} \frac{\varepsilon_{N}}{\varepsilon_{S} S_{S}}\left(1+\frac{\gamma_{1}}{s_{N} \sigma_{N}-\gamma_{1}}\right)\right]^{1 / \xi}
\end{gathered}
$$

Steady State

$$
\begin{gathered}
P^{*}=\left[\frac{1}{\sigma_{S}} \frac{a_{S} \varepsilon_{N} \gamma_{0}}{\varepsilon_{S} s_{S}}\left(1+\frac{\gamma_{1}}{s_{N} \sigma_{N}-\gamma_{1}}\right)\right]^{1 / \xi} \\
l_{S}{ }^{*}=\frac{1}{n}\left(\beta_{N}+m\right) \\
\sigma_{S}^{*}=\frac{1}{\psi}\left[\varphi+\beta_{N}-\frac{\varepsilon_{N} \gamma_{0}}{\varepsilon_{S}}\left(1+\frac{\gamma_{1}}{s_{N} \sigma_{N}-\gamma_{1}}\right)\right] \\
G^{*}=\frac{\left(\beta_{N}-\beta_{S}\right)}{\rho}
\end{gathered}
$$

Calculating the partial derivatives:

$$
\begin{gathered}
\frac{\partial \hat{P}}{\partial P}=\left\{\frac{1}{\mu_{N}+\mu_{S}-1}\left[\varepsilon_{N} \gamma_{0}\left(1+\frac{\gamma_{1}}{s_{N} \sigma_{N}-\gamma_{1}}\right)-\varepsilon_{S} \frac{s_{S} P^{\xi} \sigma_{S}}{a_{S}}\right]\right\}^{\prime}=-\frac{1}{\mu_{N}+\mu_{S}-1} \frac{\varepsilon_{S} s_{S} \sigma_{S}}{a_{S}} \xi P^{\xi-1} \\
\frac{\partial \hat{P}}{\partial \sigma_{S}}=-\frac{1}{\mu_{N}+\mu_{S}-1}\left(\varepsilon_{S} \frac{s_{S} P^{\xi}}{a_{S}}\right) \\
\frac{\partial \hat{P}}{\partial l_{S}}=0 ; \frac{\partial \hat{P}}{\partial G}=0 ; \frac{\partial \widehat{\sigma_{S}}}{\partial P}=0 ; \frac{\partial \widehat{\sigma_{S}}}{\partial \sigma_{S}}=0 ; \frac{\partial \widehat{\sigma_{S}}}{\partial l_{S}}=-n ; \frac{\partial \widehat{\sigma_{S}}}{\partial G}=\rho \\
\frac{\partial \widehat{\sigma_{S}}}{\partial P}=\xi P^{\xi-1} s_{S} \sigma_{S} \frac{1}{a_{S}}
\end{gathered}
$$




$$
\frac{\partial \widehat{\sigma_{S}}}{\partial \sigma_{S}}=P^{\xi} S_{S} \frac{1}{a_{S}}-\psi ; \frac{\partial \widehat{\sigma_{S}}}{\partial l_{S}}=0 ; \frac{\partial \widehat{\sigma_{S}}}{\partial G}=-\rho ; \frac{\partial \widehat{\sigma_{S}}}{\partial P}=0 ; \frac{\partial \widehat{\sigma_{S}}}{\partial \sigma_{S}}=0 ; \frac{\partial \widehat{\sigma_{S}}}{\partial l_{S}}=0 ; \frac{\partial \widehat{\sigma_{S}}}{\partial G}=-\rho
$$

Partial derivatives

\begin{tabular}{|c|c|c|c|c|}
\hline & $\partial P$ & $\partial \sigma_{S}$ & $\partial L_{S}$ & $\partial G$ \\
\hline \multirow[t]{2}{*}{$\partial \widehat{P}$} & $1 \quad \varepsilon_{S} S_{S} \sigma_{S} \xi P \xi-1$ & $1 \quad \varepsilon_{S} s_{S} P^{\xi}$ & 0 & 0 \\
\hline & $\mu_{N}+\mu_{S}-1 \quad a_{S}$ & $\overline{\mu_{N}+\mu_{S}-1} \quad a_{S}$ & & \\
\hline$\partial \widehat{\sigma}_{S}$ & 0 & 0 & $-n$ & $\rho$ \\
\hline$\partial \widehat{l_{S}}$ & $\xi P^{\xi-1} s_{S} \sigma_{S} \frac{1}{a_{S}}$ & $P^{\xi} s_{S} \frac{1}{a_{S}}-\psi$ & 0 & $-\rho$ \\
\hline$\partial \hat{G}$ & 0 & 0 & 0 & $-\rho$ \\
\hline
\end{tabular}

Signs of the Main equations of the model

$$
\text { (1) } \widehat{\boldsymbol{P}}=\frac{1}{\mu_{N}+\mu_{S^{-1}}}\left[\varepsilon_{N} \gamma_{0}\left(1+\frac{\gamma_{1}}{s_{N} \sigma_{N}-\gamma_{1}}\right)-\varepsilon_{S} \frac{s_{S}}{a_{S}} P^{\xi} \sigma_{S}\right]
$$

1) Sign of Price Elasticity: $\frac{1}{\mu_{N}+\mu_{S}-1}$

As $\mu_{N}+\mu_{S}<1$, we have that the price elasticity sign is higher than zero $(+)$

2) Sign: Capital Accumulation (North): $g_{N}=\gamma_{0}\left(1+\frac{\gamma_{1}}{s_{N} \sigma_{N}-\gamma_{1}}\right)$

According to Dutt, $s_{N} \sigma_{N}>\gamma_{1}$ should have a positive

For a meaningful equilibrium value of $u$ we require $s_{N} \sigma_{N}>\gamma_{1}$ which is the standard condition in quantity adjustment models requiring that the responsiveness of saving to changes in output exceeds the responsiveness of investment for stability of output adjustment

$$
0<\gamma_{0}<1 \quad \gamma_{1} \approx 1 \quad 0<\sigma_{N}<1 \quad 0<s_{n}<1
$$

3) Sign: Income Elasticy of Exports (North): $\varepsilon_{N}$

$$
0<\varepsilon_{N}<1 \text { or } \varepsilon_{N}>1
$$

Positive Sign 
4) Sign: Product $\varepsilon_{N} g_{N}$

$$
\begin{gathered}
0<\varepsilon_{N}<1 \text { or } \varepsilon_{N}>1 \\
\text { Positive Sign }
\end{gathered}
$$

$g_{N}$ depends on point 2

5) Sign: Income Elasticy of Exports (South): $\varepsilon_{S}$

$$
0<\varepsilon_{\mathrm{s}}<1
$$

6) Sign: ratio $\frac{s_{S}}{a_{S}}$

$$
0<s_{S}<1 \quad 3<a_{s}<5
$$

7) Sign: Difference $\varepsilon_{N} \gamma_{0}\left(1+\frac{\gamma_{1}}{s_{N} \sigma_{N}-\gamma_{1}}\right)-\varepsilon_{S} \frac{s_{S}}{a_{S}} P^{\xi} \sigma_{S}$

8) Sign: $\frac{1}{\mu_{N}+\mu_{S}-1}\left[\varepsilon_{N} \gamma_{0}\left(1+\frac{\gamma_{1}}{s_{N} \sigma_{N}-\gamma_{1}}\right)-\varepsilon_{S} \frac{s_{S}}{a_{S}} P^{\xi} \sigma_{S}\right]$

Income Elasticy of Exports (South): $\varepsilon_{S}$

$$
\text { (2) } \widehat{\sigma_{S}}=\beta_{S}+\rho G+m-n \frac{L_{S}}{\Lambda_{S}}=\beta_{S}+m+\rho G-n \frac{L_{S}}{\Lambda_{S}}
$$

9) Sign: $\beta_{S}+m$

$$
0<\beta_{S}<\beta_{N}<0.1 \quad 0<m \leq 0.1
$$

10) Sign: $\rho$

$$
0<\rho<1
$$

11) Sign: $-\frac{n}{\Lambda_{S}}$

$$
0<n<0.1
$$$$
0<\Lambda_{S}<3
$$

12) Sign: $\beta_{S}+m+\rho G-n \frac{L_{S}}{\Lambda_{S}}$

Points 9, 10 and 11 


$$
\text { (3) } \widehat{L_{S}}=-\beta_{S}-\rho G+P^{\xi} \sigma_{S} \frac{s_{S}}{a_{S}}
$$

13) Sign: $-\beta_{S}$

$$
0<\beta_{S}<\beta_{N}<0.1
$$

14) Sign: $-\rho$

$$
0<\rho<1
$$

15) Sign: $\frac{s_{S}}{a_{S}}$

$$
0<s_{S}<1
$$$$
3<a_{s}<5
$$

16) Sign: $-\beta_{S}-\rho G+P^{\xi} \sigma_{S} \frac{s_{S}}{a_{S}}$

$$
\text { (4) } \widehat{G}=\left(\beta_{N}-\beta_{S}\right)-\rho G
$$

17) Sign: $\left(\beta_{N}-\beta_{S}\right)$

$$
0<\beta_{S}<\beta_{N}<0.1
$$

18) Sign: $-\rho$

$$
0<\rho<1
$$

19) Sign: $\left(\beta_{N}-\beta_{S}\right)-\rho G$. The sign depends on points 17) and 18). 


\title{
CHAPTER 4
}

Debating the assumptions of the Thirlwall Model

A VECM analysis of the Balance of Payments for Argentina, Brazil, Colombia, and Mexico.

\begin{abstract}
This article has at its main objective to empirically challenge the main assumptions of the Balance of Payments Constrained Model (BPCM, also known as Thirlwall model). The BPCM has its main assumptions related to the long-run: (1) equilibrium of the trade balance $(\widehat{X}=\widehat{M})$; (2) Stability of price-effects; (3) Foreign income growth positively affecting domestic income. The literature shows the existence of stylized facts that question these assumptions. Some authors raise the argument that the BP is rarely observed in equilibrium (Alonso \& Garcimartín, 1998); price effects, through the real exchange rate, do affect the long run (Rodrik, 2008); and foreign income has no effect (or negative) on domestic income (Razmi, 2016). The BPCM is based on these assumptions to defend the existence of a long-run growth rate compatible with a stable growth of the balance of payments, in which the effective growth rate converges to avoid external constraints (McCombie \& Thirlwall, 1994; Thirlwall, 1979). In order to challenge the assumptions of the BPCM, we apply a time series co-integration Vector Error Correction Model (VECM) using the BPCM related variables to Argentina, Brazil, Colombia, and Mexico, the largest countries in Latin America. The data source is the Penn World Tables (PWT) for 19502014. After estimating baselines for our models, we apply impulse-response and permanent shocks in selected variables, observing their effects on Real Exchange Rate, GDP, and Trade Balance. The results are compared to the assumptions raised in this research, adding more elements to the empirical debate behind the BPCM. We empirically find that the BPCM assumptions are not empirically robust for the selected countries. However, the results are far from invalidating the model, but offer an invitation to more empirical work that can strength the arguments of this important model to discuss economic growth and development.
\end{abstract}

Keywords: Balance of Payments Constraints, Latin America, Economic Development JEL: O11, F41, E12 


\section{Chapter 4 - Introduction}

In the history of the macroeconomic theory, there has been since the times of Keynes a special place to discuss the long-run properties of economic adjustments. Following a standard mainstream perspective (Samuelson, 1948), the theoretical relationship between short-run and long-run are linked to the idea of equilibrium, in which deviations are seen as short-run noises that do not affect the direction of the system. The system adjusts itself towards a fixed long-run gravitational point (or trend). This rationality also applies to cycles, which regularly oscillate around a long-run point/trend.

The Balance of Payments Constrained Model (BPCM) model, developed in the 1970's by Anthony Thirlwall (1979), follows a similar general idea about long-run adjustments. It links economic growth with the Balance of Payments (BP) behavior. In the short run, noises (changes in the real exchange rate/terms of trade or financial flows) do not affect the equilibrium long-run growth rate, which is given by the Thirlwall Law - long-run growth is define by the income elasticity ratio between exports and imports times foreign growth. As described by McCombie \& Thirlwall (1994), the Thirlwall law can be described as:

$$
\widehat{Y}=\frac{\delta}{\varepsilon} \widehat{Y}
$$

$\hat{Y}$ is the GDP growth rate compatible with BP constraints, $\delta$ is the income elasticity of exports, $\varepsilon$ the income elasticity of imports, and $\widehat{Y}_{f}$ is the international GDP growth rate. The derivation of the law can be observed in the annex.

There have been many efforts in the literature to empirically calculate the income elasticity ratio and the long-run growth rate for many countries (more in Table 4.3). The BP compatible growth rate $(\hat{Y})$ shows itself as a good predictor for developed countries' growth rate. However, the theory does not have the same success in predicting growth rates for developing countries (Alonso \& Garcimartín, 1998). In these countries, the behavior of terms of trade and financial flows are marked by high volatility, potentially affecting the long-run equilibrium rate, which puts into question the validity of the Thirlwall Law for these countries. 
One important critique to the BPCM (see the literature review raised by Blecker (2016)) concerns the observation that the growth of the current account does not converge to stability. Chronic deficit and surplus are the norm, not the exception. This can be observed in Figure 4.1 and Table 4.1, below.

Figure 4.1. Current account as \% of GDP. Selected Countries (1979-2017)

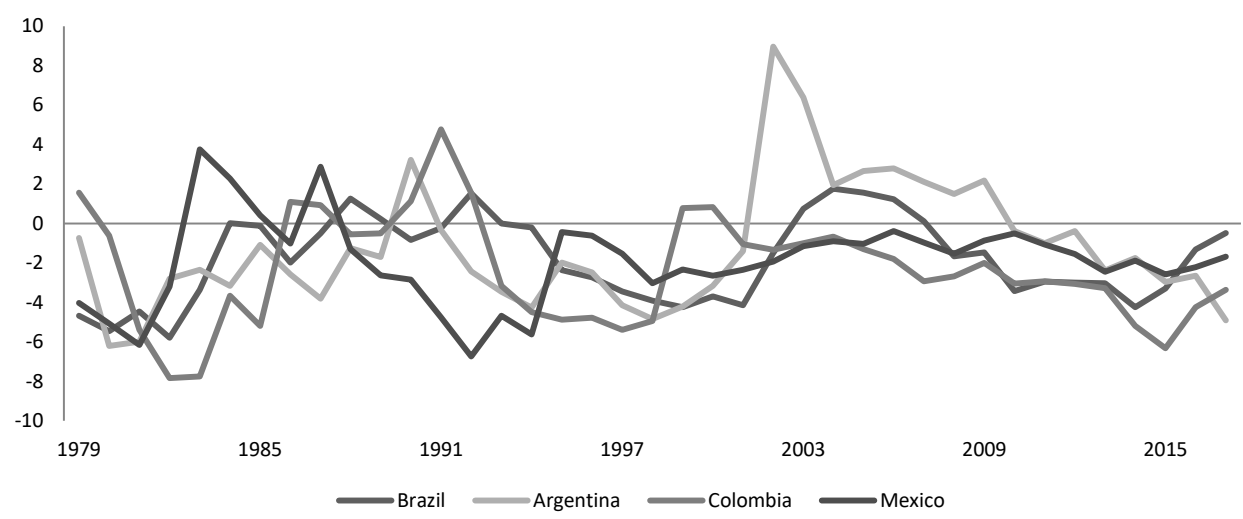

Source: World Bank Database

Table 4.1. Years in current account surplus or deficit. Selected countries. 1979-2017

\begin{tabular}{lcc} 
& $\begin{array}{c}\text { Years in } \\
\text { Surplus }\end{array}$ & Years in Deficit \\
\hline Argentina & 9 & 30 \\
Brazil & 10 & 29 \\
Colombia & 8 & 31 \\
Mexico & 4 & 35 \\
\hline \multicolumn{2}{c}{ Source: World Bank Database }
\end{tabular}

Latin America has been historically a region in which external constraints played a major role in halting the economic development process of the region (Bertola \& Ocampo, 2012). The trade balance has been a major source of economic constraints throughout its historical development generating a pattern of strong volatility in the region (López \& Thirlwall, 2006; Ocampo et al., 2009). 
An emblematic example is the debt-crisis of the 1980's. Most Latin American countries, indebted during the 1970 's, faced a halt in credit supply and a big rise in international interest rates in the beginning of the 1980's (Ocampo, 2004). This resulted in a shortage of foreign currency and high foreign debt services, forcing a strong domestic recessive adjustment and the need for external agreements, such as the ones with the IMF (Ffrench-Davis, 2005). In this case, the short-run situation defined the adjustment characteristics, and economies were dominated by their balance of payments (Ocampo, 2017). There were no margins for foreign deficits.

The recurrence of this problem in Latin American countries partially explains why so many Latin American scholars are working on this topic (see Table 4.2), and why the Thirlwall model has such high acceptance in Latin American economic debates.

The Latin American region rarely showed a long period of stability in its external accounts oscillating between large periods of deficit and short periods of surplus. This has been the core of the major interpretations of the Structuralist tradition (Cimoli, Porcile, \& Rovira, 2010). This stylized fact let us to raise some questions to qualify this discussion: can we observe that the long-run growth rate of the Thirlwall model is a good predictor of domestic effective growth rates in Latin America? Does the long-run growth rate make any empirical sense? Or are these economies actually just guided by short-run adjustments? If yes, what are the variables that affect long-run equilibrium growth?

To answer the above questions, we first search for the definition of the long-run, so frequently used in the economic literature, and usually with different meanings, which plays a central role in this discussion. Based on Carvalho (1984) we can resume three distinct perspectives about the long-run (LR) usually observed in the literature:

(1) The LR is a process of noise removal, where full equilibrium is attained when variables move to their natural value (Samuelson, 1948). Equilibrium here follows an abstract condition, and the equilibrium point reflects the conditions in which the variables "really" represent, based on their fundaments.

(2) LR as a stable point/trend to which countries converge to, following a gravity center approach. The long-run is then an attractor, a gravitational point, describing actual growth paths (Kaldor, 1957; Pasinetti, 1983). Following this perspective in our 
analysis, countries seem to converge, despite the presence of noise, to a long-run value.

(3) The LR seen as a conjunction of a succession of short-runs without any tendency to a stable equilibrium (Davidson, 1980; Minsky, 2016). As stated by Robinson (1971), the long-run does not exist separately from the short-run. In this perspective, the longrun is composed by persistent imbalances in the current account, which poses an empirical challenge to justify the Balance of Payments Constrained Model assumptions.

The BPCM has important assumptions related to the long-run (LR). These assumptions support the idea that adjustments to the equilibrium path occur on the GDP growth rates of these countries: (1) Trade balance is in equilibrium in the LR. (2) Price-effects are negligible and do not affect the equilibrium LR growth rate. (3) Foreign income growth positively affects domestic income. The literature, however, shows the existence of stylized facts that question these assumptions. Some authors raise the argument that the BP is rarely observed in equilibrium (Alonso \& Garcimartín, 1998); price effects, through the real exchange rate, do affect the longrun (Rodrik, 2008); and foreign income has no effect (or negative) on long-run domestic income growth (Razmi, 2016), despite a literature that shows the opposite using simultaneous equation systems- Mutz \& Ziesemer (2008) for Brazil; Hallonsten \& Ziesemer (2019) for Trinidad \& Tobago; Habiyaremye \& Ziesemer (2010) for Mauritius; and Ziesemer (2018) for Croatia. The BPCM is based on these assumptions to defend the existence of a LR growth rate compatible with a stable growth of the balance of payments, in which the effective growth rate converges to avoid external constraints (McCombie \& Thirlwall, 1994; Thirlwall, 1979). From the above definitions of the LR, we raise and discuss the main critiques and assumptions of the BPCM, and test these empirically, capturing the short- and long-run relationship between the BPCM variables.

For the empirical work, we reverse the often used research logic of the BPCM literature tradition. Instead of imposing a specification to estimate the model parameters, we select the BPCM variables and "allow the data to speak for itself". Using time-series Vector Error Correction Models (VECM), we let the model (based on the data) decide which and how variables associated with the BP (trade balance, real exchange rate, and domestic income) are 
related between themselves. Our dataset comes from the Penn World Tables (PWT) for the largest economies in Latin America (Argentina, Brazil, Colombia, and Mexico). The VECM method defines the short- and long-run relationships of the model.

Our research procedure firstly raises assumptions, critiques and research questions related to the Thirlwall Model. We then start our empirical analysis creating the baselines for our models applying the Johansen estimation method (Johansen, 1991). From the baselines we apply an impulse-response analysis to the data. Using the 1980's crisis example for Latin America, we add some permanent shock scenarios on the baseline, analyzing the behavior of the model. From our results - baselines, impulse-response and scenarios shocks - we discuss and test the BPCM assumptions, and this article's research questions.

After this introduction, in section 4.1 we present a literature review and raise the main assumptions and critiques related to the BPCM. We define our main research questions in section 4.2, which are further analyzed in the discussion section (section 4.6). In section 4.3 we present the data from the PWT. In section 4.4 we present the VECM methodology and explain how we estimated the models. In section 4.5 we show the overall results. In section 4.6 we discuss the results in the light of the literature review and the research questions presented respectively in sections 4.1 and 4.2. Finally, we conclude this paper in section 4.7.

\subsection{Literature Review}

The Balance of Payments Constrained Model (BPCM) and its consequent strong version, the Thirlwall Law, became the most relevant contribution from the Post-Keynesian school to economic theory (Davidson, 1997). The BPCM discusses the long-run economic growth for individual countries and aim to answer the following central question: "why nations differ in terms of their growth and development patterns?" offering an alternative (demand-sided) perspective to the neoclassical tradition. It is one of the most used alternative theories among non-mainstream economists to explain growth differences and the long-run economic growth. The BPCM has its success based on being a theoretically frugal model with a strong empirical support.

As discussed by Thirlwall (2011) himself, the BPCM model is inspired (I) in the Harrod's foreign trade multiplier, (II) in Hicks supermultiplier, (III) in Chenery's dual-gap model and (IV) 
in Prebisch's centre-periphery model (Prebisch, 1950). Prebisch's inspiration highlights the Latin American Structuralist flavor of the model ${ }^{17}$. This last theoretical inspiration puts the international dynamics as a fundamental aspect to define a country's development possibilities.

The brief literature review in this section has the following objectives: (1) raise and discuss the main assumptions behind the BPCM; (2) highlight the main critiques to the BPCM, both theoretically and empirically; and (3) identify the research gaps on the literature and introduce our own critique, opening the ground to raise some research questions to be further discussed in this research.

\subsubsection{Assumptions of the BPCM}

The core of the BPCM theory is focused on countries' external sector behavior and their relationship to the international environment. Based on the discussion of the BPCM debates and critiques raised by McCombie \& Thirlwall (1994), McCombie (2012) and Blecker (2016), we bring to this section the main assumptions behind this model. These assumptions here addressed are supposed to be later challenged and discussed, based on our empirical results.

\section{Assumption 1. A country cannot have persistent trade (current account) imbalances in the long-run}

There are two perspectives associated to assumption 1. The first concerns imbalances in levels of the trade balance. The second concerns its rate of change. The first perspective is related to the empirical observation of persistent current account deficits for many developing countries (Alonso \& Garcimartín, 1998). Those persistent imbalances are easily observed from a descriptive analysis of the data, and the assumption can be easily challenged - as we can see in the introduction of this chapter.

The second reading concerns the argument that the rate of growth of exports should balance the rate of growth of imports in the long run. In this way, countries can have persistent but not increasing deficits in their current account. In the first view, the short-run argument is that

\footnotetext{
${ }^{17}$ The initial formulation of the balance of payments constraints, later know as Thirlwall Law, is identical to the one before stated by the Structuralist author Rodríguez (1977).
} 
$X=M$ in the long run. In the second one the condition is that $\widehat{X}=\widehat{M}$, so we should not see an explosive path in the current account behavior.

\section{Assumption 2. Relative prices (RER) are constant in the long-run.}

This second and central assumption takes the BPCM out of the neoclassical world, as put by Blecker (2016). In the neoclassical world, adjustments to equilibrium come from changes in relative prices. In the Thirlwall model, however, we have quantity closures. The domestic growth rate fills the role of adjustment variable as price effects are negligible. The argument is based on the low price elasticity of imports and exports, and price in the long-run growing at zero rate, which guarantees price-effect neutrality in long-run economic adjustment (McCombie, 2012). Considering the constant value of the income elasticities of imports and exports, adjustments in the growth rates (assumption 2) make the growth of imports equal to the growth of exports in the long-run (assumption 1).

\section{Assumption 3. Foreign growth has a direct relationship to domestic growth.}

Returning to the Thirlwall Law equation $\widehat{Y}=\frac{\delta}{\varepsilon} \widehat{Y}$, we observe that domestic growth depends on the income elasticity ratio times foreign growth. In the canonic BPCM (Thirlwall, 1979), it is expected that both income elasticities of demand for exports and imports have positive values. An income increase raises the demand for foreign products. In this sense, growth in foreign income leads to increase in international demand, rising exports, domestic GDP growth (income), and then imports.

When accepting these assumptions, we enter in a Keynesian demand-led framework. Here, the BPCM states what we saw in eq.(4.1) (Thirlwall Law), in which the long-run growth rate of domestic income is equal to the growth rate of foreign income times the ratio of income elasticities. 


\subsubsection{Main critiques to the BPCM}

The critiques to the canonic BPCM refer to Thirlwall (1979)'s seminal paper, not to any of its expansions. Most of the critiques come from a theoretical basis, being always responded to by defenders of the BPCM tradition. Some other critiques, in which we include ours, start from an empirical basis, and the evidence is still in dispute. The main arguments in this section were taken from the broad literature review developed by McCombie (2012) and Blecker (2016).

Table 4.2. Literature review on the main critiques to the BPCM

\begin{tabular}{|c|c|c|}
\hline THEORETICAL & AUTHORS & MAIN ARGUMENT \\
\hline One price law & McGregor \& Swales $(1985,1991)$ & $\begin{array}{l}\text { Thirlwall Law fails to account for non-price } \\
\text { competition. }\end{array}$ \\
\hline 45-degree rule & Krugman (1989) & $\begin{array}{l}\text { Inverse causality on the Thirlwall model. It is a } \\
\text { supply-side dominated model. }\end{array}$ \\
\hline $\begin{array}{l}\text { Palley Pitfalls } \\
\text { Critique }\end{array}$ & $\begin{array}{l}\text { Palley (2002). Palley-Setterfield } \\
\text { controversy (Setterfield, 2006) }\end{array}$ & $\begin{array}{l}\text { The income elasticity of exports adjusts, but to the } \\
\text { cap of the natural rate of growth. Long-run } \\
\text { growth is supply-side dominated. }\end{array}$ \\
\hline Country Size & $\begin{array}{l}\text { McGregor \& Swales (1985), Ros } \\
\text { (2013), Clavijo \& Ros (2015) and } \\
\text { Razmi (2016) }\end{array}$ & $\begin{array}{l}\text { BPCM has problems for small countries. The } \\
\text { model is valid for large countries, but only under } \\
\text { certain conditions. }\end{array}$ \\
\hline \multicolumn{3}{|l|}{ EMPIRICAL } \\
\hline Near Identity & $\begin{array}{l}\text { Mccombie (1981), Clavijo \& Ros } \\
\text { (2015), Razmi (2016) }\end{array}$ & $\begin{array}{l}\text { The empirical works measure a tautology if } \\
\text { exports and imports grow at similar rate in the } \\
\text { long-run. }\end{array}$ \\
\hline $\begin{array}{l}\text { Foreign income } \\
\text { critique }\end{array}$ & Razmi (2016) & $\begin{array}{l}\text { Critique to the argument of a strong positive } \\
\text { correlation between individual country growth } \\
\text { rate and foreign growth. }\end{array}$ \\
\hline $\begin{array}{l}\text { Level and Rate } \\
\text { debate in relative } \\
\text { prices }\end{array}$ & $\begin{array}{l}\text { Rodrik (2008), (Rapetti, Skott, \& Razmi } \\
\text { (2012), Berg, Ostry, \& Zettelmeyer } \\
\text { (2012), Razmi (2016) Oreiro (2016) }\end{array}$ & $\begin{array}{l}\text { Evidence that RER levels have significant effects } \\
\text { on income growth in many countries. }\end{array}$ \\
\hline $\begin{array}{l}\text { Inconsistency of } \\
\text { the basic }\end{array}$ & Research gap found in this research. & $\begin{array}{l}\text { Question the empirical robustness of assumptions } \\
1 \text { and } 2 \text {. }\end{array}$ \\
\hline $\begin{array}{l}\text { assumptions of the } \\
\text { model }\end{array}$ & & \\
\hline
\end{tabular}

Sources: Author's own. Based on McCombie (2012) and Blecker (2016). 
In Table 4.2 there are some very interesting critiques to the Thirlwall Law such as the 45-degree rule by Krugman (1989) and the Palley-Setterfield controversy (Palley, 2002; Setterfield, 2006). Although interesting critiques, this article does not focus on them, but on the empirical part of the critique: (1) the near identity critique, (2) the foreign income critique, (3) the level and rate debate in relative prices, (4) the country size critique, and (5) the lack of empirical support on the basic assumptions of the model.

\section{Critique 1. Near Identity Critique: empirical works measure a tautology if exports and} imports grow at a similar rate in the Long-Run.

Mccombie (1981) criticizes the Thirlwall law for having a circular reasoning. When calculating the GDP rate of growth, if we divided it by its level, we end up with the Thirlwall law. This is the same as estimating the values of the income elasticities of demand for imports and exports when the terms of trade do not change. If exports and imports grow at similar rate in the longrun, then this leads to a circular argument in which the law is only measuring a tautology. This critique eventually comes back to the debate, and it has been debated by many critics and defenders such as Thirlwall (1981), and more recently McCombie (2012) himself.

\section{Critique 2. The role of foreign income against domestic capital accumulation}

The foreign income argument, stated mainly by Razmi (2016), questions the BPCM argument of a strong positive correlation between individual country growth rate and foreign growth. The author, using a Generalized Mixed Model (GMM) and growth data for 167 countries shows two interesting results to question some elements of the BPCM: (I) that there is a negative, or no$\underline{\text { correlation at all, between foreign and domestic growth, and (II) Currency undervaluation has }}$ positive effects on growth that is statistically significant in some estimates.

\section{Critique 3. The level of relative prices playing a role in the long-run}

One of the main aspects of the BPCM is related to assumption 2, in which price effects (real exchange rate changes) have no effect on the BP compatible growth rate, seem as a neoclassical assumption. This critique comes from two sources: 
1) The argument of price-elasticity pessimism, in which the sum of the price elasticities of imports $(\mu)$ and exports $(v)$ are close to $1(\mu+v=1)$. The literature shows mixed evidences about that.

2) The relative prices are rather stable in the long-run. It is not credible to believe the real exchange rate keeps continuously rising in the long-run, which would require constant structural devaluations (McCombie, 2012).

As Rapetti et al. (2012) point out, the price effects pointed above do not imply that the level of the real exchange rate does not affect growth, only its appreciation/depreciation rate. Razmi (2016) finds out that the RER levels have significant effects on income growth in many countries (especially developing countries). Low levels of RER for substantial periods of time can result in long-term benefits for the productive structure (competitivity gains). This argument follows the same line of the new developmentalist tradition (Bresser-Pereira, Oreiro \& Marconi, 2014), defending the central role of the exchange rate level in the development process.

\section{Critique 4. The country size argument}

The standard BPCM assumes an economy in which the price elastic supplies of exports and imports are infinite. Nonetheless, this is considered an unrealistic assumption for most countries. Empirically, price elasticity in the supply of exports are measured as finite (small countries are price takers in the export market) (Ros, 2013). Small economies have infinitely elastic supply of imports and infinitely elastic demand for exports, not supply. Based on this information, the external constrain comes from terms of trade, rather than the growth rate of foreign income. The critics suggest that the BPCG model is more appropriate for large countries (Cortes \& Bosch, 2015) with productive capacity to export larger amount of goods. On the other hand, the equilibrium can only happen when the Real Exchange Rate is not constant in the long-run, raising a theoretical conundrum.

\section{Critique 5. Questioning the main assumptions of the BPCM}

Since the seminal work of Houthakker \& Magee (1969), cited by Thirlwall (1979), there has been a large number of empirical works estimating the parameters associated to the BPCM. Most of the empirical works focus on making good estimations of the income elasticities of imports and exports. This results in the calculation of the long-run growth rate through the Thirlwall 
Law. There has been many works focusing on empirically measuring the Thirlwall model for Latin America, our region of interest in this research.

Despite the many empirical efforts, those works do not question the assumptions of the BPCM model (See Table 4.2). They just accept what is behind the model and go straight to compute its parameters using many different techniques, being the most common the use of cointegration analysis.

Table 4.3. Estimations of the Thirlwall Law for Latin America

\begin{tabular}{|c|c|c|c|c|}
\hline Authors & Journal & Year & Country Studied & Period \\
\hline Alvarez-Ude and Gomez & Applied Economics Letter & $(2008)$ & Argentina & $1968-2003$ \\
\hline Bertola, Higachi \& Porcile & $\begin{array}{l}\text { Journal of Post Keynesian Economics } \\
\text { (JPKE) }\end{array}$ & $(2002)$ & Brazil & $1890-1973$ \\
\hline Britto \& Mccombie & JPKE & $(2013)$ & Brazil & $1951-2006$ \\
\hline Mutz \& Ziesemer & Applied Economics & $(2008)$ & Brazil & $1972-2004$ \\
\hline Moreno-Brid & PSL Quarterly Review & (1998) & Mexico & $1950-1987$ \\
\hline Moreno-Brid & $\begin{array}{l}\text { International Review of Applied } \\
\text { Economics }\end{array}$ & (1999) & Mexico & 1950-1996 \\
\hline Hallonsten \& Ziesemer & Journal of Applied Economics & (2019) & Trinidad \& Tobago & $1990-2007$ \\
\hline Alonso \& Garcimartín & JPKE & (1998) & OECD Countries & 1965-1994 \\
\hline Holland, Vieira \& Canuto & Investigación Económica & (2004) & $\begin{array}{l}\text { Latin America (10 } \\
\text { countries) }\end{array}$ & $1950-2000$ \\
\hline Lopez \& Cruz & JPKE & $(2000)$ & $\begin{array}{l}\text { Latin America ( } 4 \\
\text { countries) }\end{array}$ & 1965-1996 \\
\hline Moreno-Brid \& Perez & JPKE & (1999) & Central America & $1950-1996$ \\
\hline $\begin{array}{l}\text { Pacheco-Lopez \& } \\
\text { Thirlwall }\end{array}$ & JPKE & (2006) & $\begin{array}{l}\text { Latin America ( } 17 \\
\text { Countries) }\end{array}$ & $1977-2002$ \\
\hline Perraton & $\begin{array}{l}\text { International Review of Applied } \\
\text { Economics }\end{array}$ & $(2003)$ & Developing Countries (34) & 1973-1995 \\
\hline
\end{tabular}

Source: Own elaboration, based on McCombie (2012)

In Table 4.3 we list a number of works that focused on estimating and empirically testing the BPCM for Latin America. The empirical works mainly support the BPCM in two aspects: (a) price changes do not show itself as an efficient BP adjustment mechanism. This is caused by the low value of price elasticities, so income has to adjust to reach the equilibrium of the system, rejecting critique 3. (b) Even in the presence of BP disequilibrium, capital inflows make no substantial difference in the long-run growth results. Thirlwall (2011) highlights that income adjustments to the long run is how economies behavior, defending the Thirlwall law. 
The main critique in this sub-section aims to challenge assumption 1 of the BPCM. Is it empirically observed that a country cannot have persistent trade balances? What about Latin America, a region in which the balance of payments problems have been so central? This also impacts on assumption 2, in which exports and imports should grow at the same rate in the long run.

It is fundamental to find a good methodological approach to these topics in order to discuss the critiques, which we do from the next session based on the works cited in Table 4.3.

\subsubsection{Empirical works, cointegration and Error Correction Models}

The BPCM has been a widely tested model, for many countries. As time-series econometrics advanced, authors begun to apply Vector Error Correction Models (VECM) to estimate the BPCM parameters. This method has the advantage of avoiding the issue of non-stationarity of many macroeconomic time series (Britto \& McCombie, 2013). This issue highlights the problem of non-constant variance generating spurious results and biased forecasts when using OLS and Maximum Likelihood estimation methods. The Johansen (1991) method gives a very thorough and careful procedure to estimate these cointegration models.

Cointegration techniques allow us work with the notion of long-run equilibrium. Alonso (1999) was one of the main authors proposing the use of this approach to estimate the parameters of the BPCM. This type of estimations focuses on predicting the BP constrained rate of growth, testing if it is cointegrated (has the same intergration order) with the effective growth rate (Mccombie, 1989).

Many empirical works focus on testing the cointegration between the model variables. As an example: Razmi (2005) tests if price variables are significant in cointegrating vectors for India. Lima \& Carvalho (2008) observe the cointegration between national income and exports in Brazil. Inspired in this tradition, this research applies the cointegration analysis to the BPCM to test some of the critiques raised in this brief literature review. Holland et al (2004) estimate the parameters for 17 Latin American countries, covering a large part of the region.

Britto \& McCombie (2013) use a Johansen (1991) cointegration model to merge variables in a VAR framework. They follow the standard procedure: calculate unit root test on the variables, 
check the lag order of the VAR, rank it to estimate cointegration vectors, and estimate them and the error correction terms. When estimating the variables associated to the BPCM using a VECM framework, we avoid imposing theoretical specifications, and are able to not only calculate the parameters of the model, but also assess the critiques raised in this review, testing them in the form of research questions.

In this research we follow the same procedure as the one used by Britto \& McCombie (2013). The Johansen method is a very robust procedure we use to estimate baseline functions for the main variables related to the Thirlwall model. From the baseline we apply an impulse-response analysis, with similar procedure to the one used by Elish (2018) for Egypt. We then apply permanent shocks creating distinct scenarios. Finally, we analyze the results in light of the research questions presented in the following sections.

\subsubsection{Estimations of the BPCM for Latin American countries}

The estimations start from explicit import and export functions. Using the usual representation of these functions, following López \& Thirlwall (2006) - changing the notation to the one used in Dutt (2002), and chapter 3 - we have:

$$
\begin{gathered}
M=\theta_{M_{t}}\left(P_{t}^{-1}\right)^{-\mu} Y_{t}^{\varepsilon} \\
X=\theta_{X_{t}}\left(P_{t}\right)^{-v} Y_{f}^{\delta}
\end{gathered}
$$

$M$ represents total imports, $\theta$ is a constant, $P$ is the Terms of Trade (Real Exchange Rate), and $Y$ is the total domestic income. $\mu$ is the price elasticity of the demand for imports and $\varepsilon$ is the income elasticity of the demand for imports. The subscript $t$ represents time. When applying logs and taking the first difference, we have the equation in growth rates:

$$
\begin{gathered}
\widehat{M}=\hat{\theta}_{M_{t}}-\mu\left(\widehat{P_{t}^{-1}}\right)+\varepsilon \hat{Y}_{t}+e_{t} \\
\hat{X}=\hat{\theta}_{X_{t}}-v\left(\hat{P}_{t}\right)+\delta \hat{Y}_{f_{t}}+u_{t}
\end{gathered}
$$

The circumflex sign represents growth rates. From eq.(4.1) we have the Thirlwall Law, in which $\hat{Y}=\frac{\delta}{\varepsilon} \widehat{Y}_{f}$, that can be represented as $\hat{Y}=\hat{X} / \varepsilon$, being $\hat{X}$ the growth of export volume. From the 
estimation of the parameters in eq. (4.4), López \& Thirlwall (2006) use a pooled regression to get the following estimates for Latin American Countries ( $b$ for estimates):

Table 4.4. Latin America: Actual versus predicted growth rates (1977-2002)

\begin{tabular}{l|rrrrrrr} 
& $\hat{\theta}_{M}$ & $-\mu$ & $\varepsilon$ & $\hat{X}$ & $\widehat{Y}_{b}$ & $\hat{Y}$ & $\hat{Y}-\widehat{Y}_{b}$ \\
\hline Argentina & 4.66 & -0.13 & 3.66 & 6.07 & 1.66 & 1.33 & -0.33 \\
Brazil & -0.26 & -0.31 & 1.59 & 8.07 & 5.08 & 2.7 & -2.38 \\
Chile $^{18}$ & 0.04 & -0.54 & 2.03 & 8.62 & 4.24 & 5.5 & 1.26 \\
Mexico & 0.06 & -0.18 & 3.17 & 11.38 & 3.59 & 3.3 & -0.29 \\
\hline \multicolumn{7}{c}{ Source: López \& Thirlwall (2006) }
\end{tabular}

The authors calculate the parameters associated to the Thirlwall law and the difference between predicted value (by the model) and the observed GDP values. This is the usual procedure in the literature to estimate the BPCM parameters. This approach has been applied for many distinct countries and expansions. Gouveia and Lima (2003) estimated also the export function using cross-country panels for multi-sectoral approach.

Because of the high number of stationary series, some authors use a different time-series approach way to estimate the income elasticities, from eqs. (4.4) and (4.5). More recently, there have been many estimations using model of cointegration methods, as discussed above. Authors such as Britto \& Mccombie (2013) (for a multi-sectoral approach), use cointegration to estimate income elasticity of demand for imports for Latin American countries. Holland, Vieira \& Canuto (2004) also estimate the income elasticities using VAR methods. The use of these approaches has the advantage of working with the notion of long-run equilibrium. For more details, McCombie (1997) reviews the Thirlwall model in the light of cointegration techniques.

Following the same approach as ours, Lopez \& Cruz (2000) estimate some Vector AutoRegression (VAR) models for selected Latin American countries (Argentina, Brazil, Colombia and Mexico). The authors observe the relationship between selected variables for the period 1965-96. They run three different specifications, following the Johansen Cointegration Method after testing through Augmented Dickey Fulley (ADF) the stationarity of the series. First in specification I they run a VAR for domestic income $Y_{d}$ and Real Exchange Rate $(P)$. In

\footnotetext{
${ }^{18}$ There are no data for Colombia, so we used Chile to illustrate
} 
specification II they run it for domestic income $\left(Y_{d}\right)$ and exports $(X)$. Finally in specification III they run it for the trade balance $(T B)$, domestic income $\left(Y_{d}\right)$, real exchange rate $(P)$ and foreign income $\left(Y_{f}\right)$. This third specification is similar to the one we propose in our specification 2.

Table 4.5. VAR estimations in López \& Cruz (2000), normalized cointegration vector for Latin America countries

\begin{tabular}{|l|cc|cc|ccc|}
\hline \multirow{2}{*}{ Countries } & \multicolumn{2}{|c|}{ Specification I* } & Specification II* & \multicolumn{3}{|c|}{ Specification III** } \\
\cline { 2 - 7 } & $\begin{array}{c}\text { Export } \\
\text { coefficient }\end{array}$ & $\begin{array}{c}\text { Import } \\
\text { coefficient }\end{array}$ & RER & coefficient & $\begin{array}{c}\text { Foreign } \\
\text { GDP } \\
\text { coefficient }\end{array}$ & $\begin{array}{c}\text { GDP } \\
\text { coefficient }\end{array}$ & $\begin{array}{c}\text { RER } \\
\text { coefficient }\end{array}$ \\
\hline Argentina (1965-96) & 0.41 & 2.8 & -1.7 & 76.7 & -118 & 1.05 \\
Brazil(1965-95) & 0.59 & 1.03 & -0.05 & 52.7 & -42 & -38.7 \\
Colombia (1968-96) & 1.7 & 1.8 & 0.16 & 493 & -856 & 135 \\
Mexico (1965-96) & 2.2 & 1.3 & 0.5 & 351 & -230 & -114 \\
\hline
\end{tabular}

Note: *Vector normalized for domestic GDP. ** Vector normalized by the Terms of Trade. Source: López \& Cruz (2000)

Using the cointegration estimation method (VECM) we check how each variable affects others looking at their elasticities. The VECM allows observing the long-run relations and see some interesting effects: how price changes (RER) affect the long-run domestic growth - showing if one of the most important assumptions of the Thirlwall model (zero price effects on the longrun) hold or not.

As pointed out by Romero \& McCombie (2016), the VECM suffers from one main limitation. The estimation results are usually very sensitive to the model specifications, both in terms of the type of deterministic trend and the number of lags used. In this sense, we are very careful to select the optimum number of lags, trend type, and number of cointegration equations, following all the appropriate tests and standardizing the decision on the best model to select.

\subsection{Research Questions}

The research questions are developed from the critiques presented in the previous sub-section. In this section we present the main question, briefly explaining the motives and ideas behind them. We discuss our expectations for the results and their implications for the BPCM theory. 
(1) Research Question 1 (RQ1): Do countries show a trade balance equilibrium (TB) in the long-run? How to re-balance the TB to equilibrium?

This question concerns one of the main critiques to the BPCM: the BP has to be stable in the long-run, so countries do not present structural deficits in their current account. In the literature there are confusions when looking at levels and/or rates. As reinforced by McCombie (2012), the confusion may reside in the idea that in the BPCM model the argument is not about $X=M$, but $\widehat{X}=\widehat{M}$. The author claims that the Thirlwall model is about growth rates, not levels. So in the long-run it is not the BP that needs to stabilize, but the foreign deficit growth rate. In this sense, there can be persistent deficits, but they cannot consistently grow in the long-run. Otherwise, the growth rate of imports would be higher than the growth rate of exports, generating an explosive growing imbalance in the external sector. We can check that by looking at the baselines of our models. In the case of an imbalance, how to re-balance the model? Could we use an export shock which counterbalance these effects? In order to answer that we raise the following question: what would be the impacts of a rise in export and investment shocks on growth?

(2) Research Question 2 (RQ2): Do price effects affect the long-run equilibrium rate of GDP growth?

This is the main aspect of the Thirlwall model that differentiates it from the neoclassical world, in which price effects are the main adjustment mechanism. In Thirlwall (1979), the adjustment to the equilibrium occurs in quantities rather than prices. Domestic growth adjusts to the external constraints, not to the terms of trade or the real exchange rate. We expect the result in our test to be not as strong as theoretically defined in the BPCM, in which we see the presence of both adjustments in prices and quantities. The empirical implications maintain the existence of balance of payments constraints, although with a smaller role in defining the long-run growth. We analyze the effects of RER shocks (terms of trade) on domestic income. The presence of a Marshall-Lerner effect guarantees that an exchange rate undervaluation increases trade balance (after a short $J$-curve period of adjustment). We expect this improved trade balance to increases domestic demand, resulting in higher domestic growth.

(3) Research Question 3 (RQ3): Do increases in foreign income result in higher economic growth? 
The positive foreign income effects on domestic growth argument have been historically accepted by the BPCM literature without questions. When the world grows, does that also imply in higher growth in the domestic economy? Do we observe this positive pass-through?

Following the traditional literature (Thirlwall \& Hussain, 1982) we expect increases in foreign income to generate higher international demand, resulting in higher domestic exports and higher domestic growth. Empirically this idea has been challenged by Razmi (2016) who found that increases in foreign growth may lead to either no effect on domestic income, or even in some cases a reduction. To test this, we apply shocks in the foreign demand variable (lnusa_q) observing its effects on domestic income, and on other variables of the model.

Based on the Thirlwall law, when we have a negative elasticity of foreign growth on domestic income, the ratio between income elasticity of exports and imports has a negative value. This is a result that poses a challenge to be explained economically, as this would imply that increases in income foreign would reduce domestic exports, generating smaller income.

It is important to mention that this research does not aim to answer the reasons behind differences in the results between the selected countries. Countries may present distinct responses to economic shocks. We are interested in observing the general effects in order to answer our research questions. The causes generating country differences are a very relevant topic, however they will not be discussed in this analysis.

\subsection{Data}

The data source for the empirical work comes from the Penn World Tables' (PWT) National Accounts dataset. Due to availability, the data was selected for the period 1950-2014. Based on the critique 4 (section 2), we only select large economies. The focus of this research is on Latin American big countries: Argentina, Brazil, Colombia, and Mexico.

The selected variables from the PWT are: GDP $(q)$, total consumption $(c)$, total investment ( $i$ ), total exports $(x)$, total imports $(m)$, and price levels $(p l)$. We have a total of 65 observations for each variable. 
For the GDP $(q)$, we use the output-side real GDP at current PPPs ( $g d p o$ ) and the real GDP at constant 2011 national prices (in mil. 2011US\$) (rgdp_na). Following the PWT methodological notes (Feenstra et al., 2015), this measure is often used to compare relative productive capacity across countries at a single point in time.

In order to calculate the main macroeconomic variables $(c, i, x$, and $m$ ) we use the shares of each variable $\left(c s h \_c, c s h \_i, c s h \_x\right.$, and $\left.c s h \_m\right)$ applied to the measures of GDP.

The Real Exchange Rate (RER) is computed as the ratio between price levels of the output-side real GDP (country_pl_gdpo) of the selected country divided by the same variable for the reference country (USA) ( $u s a_{-} p l_{-} g d p o$ ). For our estimations, we take the log of the


ln_country_m).

We use the USA as reference country. US data is used in two occasions: to measure foreign income (lnusa_q), which is used as an exogenous variable in the estimation, and to calculate the Real Exchange Rate (from price levels).

Finally, In order to avoid any incompatibility issue with units, we calculate the trade balance as :

$$
T B=\ln \left(x_{t}\right)-\ln \left(m_{t}\right)
$$

All the data is in mil. 2011 US\$.

Table 4.6. List of variables applied to the VECM analysis

\begin{tabular}{cc|cc}
\hline Variable & Meaning & Variable & Meaning \\
$g d p o, r g d p_{-} n a^{19}$ & output-side real GDP at current PPPs & country_c \\
country_q & Country's ${ }^{20} g d p$ & Country's total consumption \\
country_ $i$ & Country's total Investment \\
country_g & US GDP (reference country) & Country's total government \\
country_pl_gdpo & Country's price levels of $g d p o$ & expenditure \\
usa_pl_gdpo & US price levels of $g d p o$ & country_x & Country's total exports
\end{tabular}

\footnotetext{
${ }^{19}$ The use of the variable $g d p o$ resulted in many specifications to reject the stability condition test, so we decided to use $r g d p \_n a$ as the base of domestic income for our analysis, keeping the $g d p o$ shares.

${ }^{20}$ As country we have Argentina (arg), Brazil (bra), Colombia (col), and Mexico (mex).
} 
Debating the assumptions of the Thirlwall Model

\begin{tabular}{|c|c|c|c|}
\hline country_rer_dir & Direct measure of RER & country_tb & Country's total trade balance \\
\hline country_rer_ind & $\begin{array}{c}\text { country_pl_gdpo/usa_pl_gdpo } \\
\text { Indirect Measure of RER } \\
\text { usa_pl_gdpo/country_pl_gdpo }\end{array}$ & lncountry_c & Log of country_c \\
\hline lncountry_rer & log of country_rer_ind & lncountry_i & Log of country_i \\
\hline lncountry_q & Log of country_q & lncountry_g & Log of country_g \\
\hline \multirow[t]{3}{*}{ lnusa_q } & Log of $u s a_{-} q$ & lncountry_x & Log of country_x \\
\hline & & lncountry_m & Log of country_m \\
\hline & & lncountry_tb & Log of country_tb \\
\hline
\end{tabular}

\subsection{Methodology}

This research aims to observe the relationship between the macroeconomic variables that adjust the economic system to its equilibrium. For this reason, we focus on the system's short- and long-run properties using the time-series analysis of the Vector Error Correction Model (VECM) (Johansen, 1991). We challenge the BPCM theory and its assumptions, comparing the actual empirical results with what was theoretically expected in the research questions.

The VECM is a method that can be applied to many time series, working with long-run stochastic trends (cointegrations). This model let us observe the short- and long-term effects of one series on another. The VECM consists on a restricted Vector Auto-Regression (VAR) with variables known to be non-stationary (but stationary in their lag differences) and cointegrated. The VECM does not impose any specification to the model - in the sense that all the variables affect each other. The variable order defined in the VECM does not affect the final result, but selects which variable is the reference in the standardization process. The research procedure is the following (using the software Eviews):

I. Select which variables are used for the estimations and the analysis. Following the terminology in the Eviews software, we call the real data actuals.

II. Initially estimate an unrestricted VAR, then check the lag-length criteria (observing under which lag difference is series stationary) and apply a stability test to define the model. If the VAR model is stable, we apply the Johansen cointegration test, checking the number of cointegrated equations in the selected series given the lag criteria. 
III. Build the VECM using the previously defined number of lags (minus one) and the number of cointegration equations, picking always the trend linear case as first option when suggested by the test.

IV. Estimate the VECM results (baseline). The model is run as a stochastic simulation, being repeated many times (monte-carlo simulation). We then check the significance of each parameter. There we see the short- and long-run relations. It is possible to graph the baseline against the actuals to check how the model fits the data.

V. Apply impulse-response analysis and permanent shocks, creating distinct scenarios. This allows us to observe how the system behaves when shocked and test the research questions.

VI. Observe the overall results and compare them with the expected results, discussing all of them in the light of the research questions previously defined in this article.

\section{Step I. Model Specification}

The first step in the VECM process is to select our variables. This selection was based on choosing the BPCM variables that allow us to answer our research questions. We focus on the variables that affect the external sector, as well as the three fundamental elements in the short- to long-run aspect of the Thirlwall model: domestic income, current account, and the real exchange rate. For specification 1 we add consumption and investment as interest variables, as well as using exports and imports separately, not the trade balance. These two modifications result in some interesting changes in the outcome of our results. For specification 2 we use the same variables as in the literature (trade balance, domestic income, real exchange rate and foreign income), based on López \& Cruz (2000).

An important aspect of the specification process concerns the use of exogenous variables. In our case, it is hard to conceive that the international growth can be affected by the behavior of developing countries' domestic variables. The GDP of the reference country (the US) is then considered an exogenous variable in our specifications and taken in its first lag $(\operatorname{lnusa} q(-1))^{21}$.

\footnotetext{
${ }^{21}$ This variable enters in an equation for the first difference of your endogenous variables. For example, D(LNARG_Q) is one of your dependent variables, and this is the first different of LNARG_Q, or, in other words, the growth rate of GDP of Argentina. We must have also the first different of lnusa_q in this equation $\left(L N U S A_{-} Q(-1)\right)$.
} 
Table 4.7. VECM specification models, endogenous and exogenous variables

\begin{tabular}{lcc} 
& Endogenous variables & Exogenous variables \\
\hline$\underline{\text { Specification 1 }}$ & country_rer_ind & Constant \\
RER, Domestic GDP, Exports, & lncountry_q & Trend \\
Imports, Investment, Consumption & lncountry_x & lnusa_q(-1) \\
and Foreign GDP. & lncountry_m & \\
& lncountry_i & \\
& lncountry_c & Constant \\
\hline Specification 2 & lncountry_tb & Trend \\
RER, Trade Balance, Domestic & country_rer_ind & lnusa_q(-1) \\
GDP, and Foreign GDP. & lncountry_q & \\
\hline
\end{tabular}

Source: Own elaboration

Specification 1 is a broader one, in the sense that it considers not only the foreign variables, but also the domestic absorption variables. It is focused on the macroeconomic adjustment in a Keynesian sense. For this reason, we select the main demand-side macroeconomic variables: GDP, Consumption, Investment, Exports and Imports. Government consumption was left out because of its autonomous exogenous behavior. Specification 2 mainly focuses on the foreign sector aspects. It reduces the number of variables to the ones that affect the balance of payments (López \& Cruz, 2000). We use the computed trade balance as reference, adding the real exchange rate and economic growth (domestic and foreign) to the model.

Considering the four selected countries, we estimate 8 models: Argentina 1, Argentina 2, Brazil 1, Brazil 2, Colombia 1, Colombia 2, Mexico 1, and Mexico 2. The numbers represent which specification we are currently using.

\section{Step 2. Model characteristics}

Following the Johansen estimation method (Johansen, 1991), we initially run stability tests for our estimations. In our tests all of the eight specifications are stable, passing the unit root test. Then we compute the lag length criteria (5 lags option as default). After defining the number of optimum lags, we run a Johansen cointegration test to define the optimum number of cointegration equations (CE) for each case, and the optimum type of VEC (linear types were in all cases selected as best options). Our result estimations are the following: 
Table 4.8. Models attributes: Lag Numbers, Number of Cointegration Equations, Type of VEC

\begin{tabular}{lcccl} 
Model & Stability & Lag number & Cointegration Equations & Type of the VEC \\
\hline Argentina 1 & Yes & 1 & 1 & Linear with trend \\
Argentina 2 & Yes & 1 & 1 & Linear with trend \\
Brazil 1 & Yes & 2 & 2 & Linear with trend \\
Brazil 2 & Yes & 1 & 1 & Linear with trend \\
Colombia 1 & Yes & 1 & 1 & Linear with trend \\
Colombia 2 & Yes & 2 & 1 & Linear with trend \\
Mexico 1 & Yes & 1 & 2 & Linear with trend \\
Mexico 2 & Yes & 1 & 2 & Linear with trend \\
\hline
\end{tabular}

From Table 4.8 we see that most countries have one CE with the exception of Mexico (for both specifications) and Brazil (specification 1). All models point to the linear specification with trend as the best options. Most tests point to 1 lag specification, with the exception of 2 specifications for 2 lags (Brazil 1 and Colombia 2).

\section{Step 5. Scenarios}

After creating baselines, we apply (1) an impulse-response analysis and (2) some permanent shocks to selected variables to observe the behavior of the system. Scenarios are created from shocks in the following variables:

Table 4.9. Scenarios shocks applied on the baseline of the VECM.

\begin{tabular}{lclc}
\hline Specification 1 & Shocked variable & Specification 2 & Shocked variable \\
Scenario 1 - RER & country_rer_ind & Scenario 6 - RER & country_rer_ind \\
Scenario 2 - Exports & lncountry_x & Scenario 7 - Trade Balance & lncountry_tb \\
Scenario 3 - GDP & lncountry_q & Scenario 8 - GDP & lncountry_q \\
Scenario 4 - Investment & lncountry_ $i$ & Scenario 9- Foreign GDP & lnusa_q \\
Scenario 5 - Foreign GDP & lnusa_q & & \\
\hline
\end{tabular}

In order to create some consistent scenarios for the analysis, we apply the impulse-responses in some selected variables (real exchange rate, exports/trade balance, GDP, investment, and foreign income). For the permanent shocks we shock the intercept of the selected variables (an equation 
intercept shift) with 0.05 magnitude (or 5\%) from 1979 until 2014. The selected period covers the 1980 crisis, period which we analyze, as discussed in the introduction of this research.

Using Scenarios 1 and 6 we can discuss the Research Question 2, observing the effects of price shocks on domestic income and on trade balance. We can check if those affect or not the longrun equilibrium rate of growth. When using Scenarios 2 and 7, we test Research Question 1, if exports can be used as an adjustment mechanism back to a stable equilibrium point (in which $\hat{X}=\widehat{M}$ ). We also observe if investment can be used as an adjustment mechanism (Scenario 4). Finally, we use Scenarios 5 and 9 to discuss Research Question 3 - if higher foreign income growth has positive effects on domestic income.

\subsection{Overall Results}

In this section we present an overview of the results. We analyze the baseline models (computed using a VECM), and the scenarios by applying temporary shocks (impulse-response analysis) and permanent shocks in the selected variables. We focus on the effects on the three main variables that allow us answer the research questions: trade balance, real exchange rate, and domestic income.

The overall results consist on 1 baseline and 5 scenarios in specification 1 (for each of the 4 countries), and 1 baseline and 4 scenarios in specification 2 (by country). Our final result has a total of 36 scenarios ( 9 scenarios for each of the 4 countries). These scenarios are briefly presented in the next section.

We condense our shock results observing the sign of three different effects. The first effect (E1) concerns the immediate initial effects of a shock. The second effect (E2) observes, from the initial effects, if the trajectory increased or decreased on time when reaching the stability point. The third effect (E3) is related to the net final effects. These measured effects are illustrated in the following figure: 
Figure 4.2. Example: Shock effects decomposition

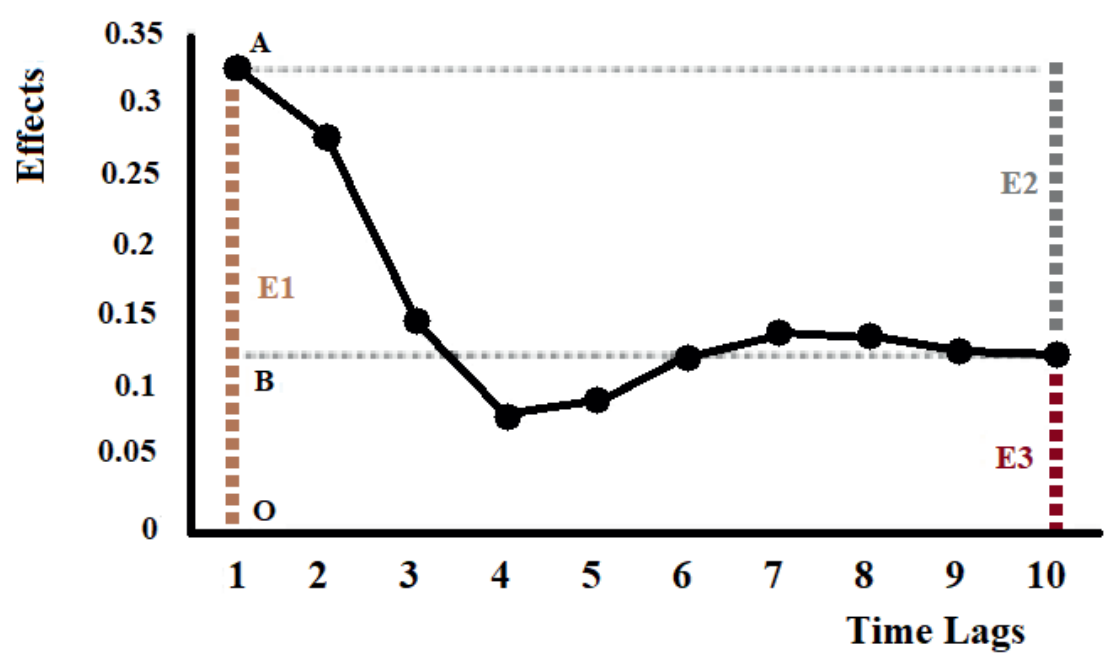

This graph illustrates the impact of a shock in a baseline. Axis $\mathrm{Y}$ is the percentage effects of changes between shock and baseline considering a one standard deviation residual impulse (decomposition method). Axis $\mathrm{X}$ is time, representing the number of periods after an initial shock. In this example, point $\mathrm{O}$ is on the origin (the value before the shock). We observe that the initial effect $\mathrm{E} 1$ (the segment $\overline{O A}$ ) is positive $(E 1>0)$. The second effect (E2) is the difference between initial and final effects $(\overline{A B})$ is negative $(E 2<0)$. The final net effect (E3) given by the segment $(\overline{O B})$ is positive $(E 3>0)$. This representation is used in the next section to interpret our results.

\subsubsection{Baselines, Impulse-Response Analysis and Permanent Shocks}

\subsubsection{Baselines}

The baselines, computed from the VECM, consist in our main representation of the actual model. We compute baselines for each of our endogenous variables: Real Exchange Rate (country_rer_ind), domestic income (lncountry_q), total exports (lncountry_x), total imports $($ lncountry_m $)$, total investments $($ lncountry_ $i)$, and total consumption (lncountry_c $)$ in specification 1, and trade balance (lncountry_tb), RER (country_rer_ind), and domestic 
income (lncountry_q) in specification 2. In specification 1, the trade balance is computed from the baseline results for exports and imports. Baselines are not scenarios, but a model that fits to the data (Actuals) using the characterizations defined in the Johansen Method (Number of Lags, type of VEC, and number of Cointegration Equations).

From the baselines we observe the dynamic evolution of the system, checking if it converges or diverges from a long-run equilibrium point/trend. We later discuss, based on our baselines, the assumptions of the BPCM, the evolution of its variables, and implications to the Thirlwall model.

\subsubsection{Impulse-response analysis}

The impulse-response analysis measures the response of our interest variable to a shock on another variable of the system (which is called innovation). It deals with non-permanent temporary shocks. We are interested in knowing the response of a one-time shock in the system adjustment process. This impact affects not only the selected variable but other variables in the system as well.

With the impulse-response analysis we observe not only if a shock has positive or negative effects, but also some convergence properties, if the system returns to an equilibrium point or not. We assess the stability of many variables of the system, checking some of the research questions raised on this article. In our analysis we shock the variables with a one standard deviation residual impulse (decomposition method).

\subsubsection{Permanent Shocks}

Permanent shocks are the ones repeated for a long period of time. We observe the effects of these impacts in some key variables of the system, checking where these consistent movements lead. Shocks are applied from 1979 in some selected key variables (scenarios), covering from the "lost decade" period in Latin American history (1979) until the end of the commodity boom in 2014. The shocks consist in a $0.05(5 \%)$ consistent increases in the intercept of the selected variables.

The next session shows the actuals, baseline, and scenarios (impulse-response and permanent shocks) for each country of the analysis. Countries may show an individual different dynamics than others, which makes it eventually hard to generalize some effects. In the following analysis we present the overall results and discuss each of the research questions. 


\subsubsection{Trade Balance: baseline and scenarios}

Initially, we observe the outputs of the estimated models by looking at their baselines and how they fit the actuals. Then we analyze the temporary and permanent effects of the BPCM related main variables on the trade balance current account (variable measured from exports and imports). Finally, we discuss the implication of these results to the research question posed in section 3 and to the BPCM theory.

Figure 4.3. Trade balance baseline Argentina

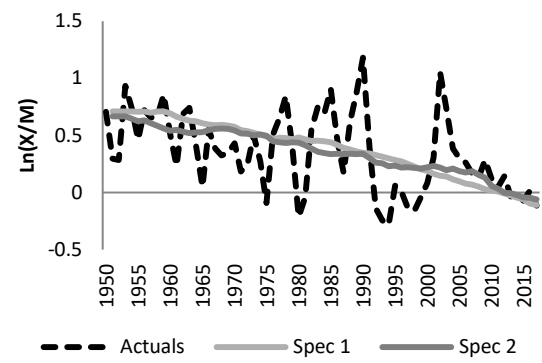

Figure 4.5. Trade balance baseline Colombia

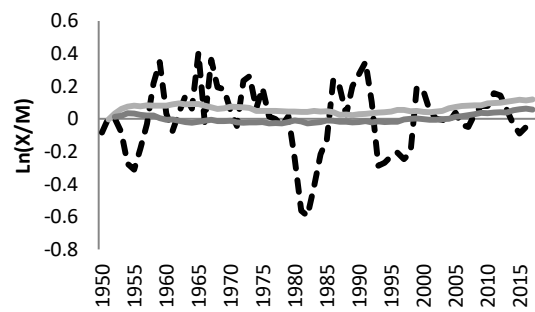

- $\operatorname{spec} 1$

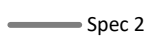

Figure 4.4. Trade balance baseline Brazil

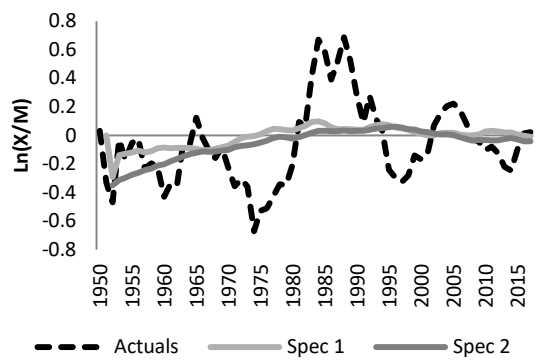

Figure 4.6. Trade balance baseline Mexico

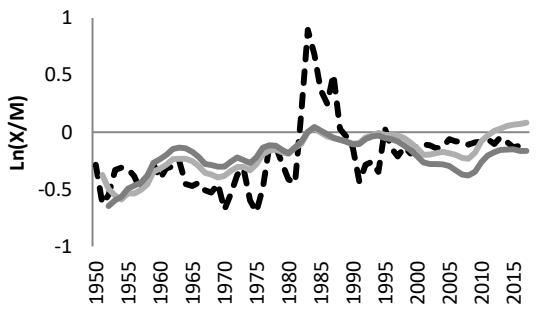

- - Actuals $\operatorname{Spec} 1 \longrightarrow \operatorname{Spec} 2$

Data source: Penn World Tables

The baselines ${ }^{22}$ show some of the structures of the system, and the directions in which the system goes. They also illustrate the stability conditions. We see that Argentina shows an initial

\footnotetext{
${ }^{22}$ Specification 1 does not have a baseline for the Trade Balance, only for Exports. What we do from here is to calculate the effects on the Trade Balance deriving it from its effects on exports and imports.
} 
behavior that converges to a value around zero. Argentinean trade balance keeps decreasing on time since 1955 until 2014. However, the rate of reduction decreases in both specifications. That might indicate either a continuity of the decrease, or a future reversion of this trend.

In this research we avoid trying to predict the future behavior of the variables, focusing only on the current data. What we observe in Argentina is a steady reduction of the trade balance towards zero. On the other hand, Mexico shows a cyclical behavior around a positive trend, converging towards a trade balance equal to zero. Brazil and Colombia show a much smaller oscillation in their trade accounts, especially compared to Mexico. Both countries (Brazil and Colombia) seem to converge to the trade balance equilibrium (with a small positive trend). In this specification, Brazil is in a far position from the trade balance equilibrium, but it starts moving towards it, until reaching it around the 1980 's, stabilizing since them.

Argentina shows a steady long-run behavior with negative trend in the trade balance. Mexico shows a cyclical behavior with positive trend. Brazil and Colombia shows a mild cyclical behavior. All of these countries seem to converge to an equilibrium value, where the trade account is equal to zero.

Table 4.10. Impulse Response Analysis - Effects on Trade Balance 


\begin{tabular}{|c|c|c|c|c|c|c|c|c|c|c|c|}
\hline \multicolumn{12}{|c|}{ E1 - Initial Effects on the Trade Balance } \\
\hline \multicolumn{6}{|c|}{ Specification 1} & \multicolumn{6}{|c|}{ Specification 2} \\
\hline & Sc & Arg & Bra & Col & Mex & & Sc & Arg & Bra & Col & Mex \\
\hline RER (Devaluation) & 1 & 0 & $\uparrow$ & $\uparrow$ & $\uparrow$ & RER (Devaluation) & 6 & 0 & 0 & 0 & 0 \\
\hline Exports & 2 & $\uparrow$ & $\uparrow$ & $\uparrow$ & $\uparrow$ & Trade Balance & 7 & $\uparrow$ & $\uparrow$ & $\uparrow$ & $\uparrow$ \\
\hline GDP & 3 & 0 & 0 & 0 & 0 & GDP & 8 & 0 & 0 & 0 & 0 \\
\hline Investments & 4 & 0 & 0 & 0 & 0 & & & 0 & 0 & 0 & 0 \\
\hline Foreign Income & 5 & $\downarrow$ & $\uparrow$ & $\downarrow$ & $\downarrow$ & Foreign Income & 9 & $\uparrow$ & 0 & $\uparrow$ & 0 \\
\hline \multicolumn{12}{|c|}{ E2 - Effects on time on Trade Balance } \\
\hline \multicolumn{6}{|c|}{ Specification 1} & \multicolumn{6}{|c|}{ Specification 2} \\
\hline & Sc & Arg & Bra & Col & Mex & & Sc & Arg & Bra & Col & Mex \\
\hline RER (Devaluation) & 1 & $\uparrow$ & $\uparrow$ & $\uparrow$ & $\downarrow$ & RER (Devaluation) & 6 & $\uparrow$ & $\uparrow$ & $\uparrow$ & $\downarrow$ \\
\hline Exports & 2 & $\downarrow$ & $\downarrow$ & $\downarrow$ & $\downarrow$ & Trade Balance & 7 & $\downarrow$ & $\downarrow$ & $\downarrow$ & $\downarrow$ \\
\hline GDP & 3 & $\uparrow$ & $\downarrow$ & $\downarrow$ & $\uparrow$ & GDP & 8 & $\downarrow$ & $\uparrow$ & $\downarrow$ & $\uparrow$ \\
\hline Investments & 4 & $\downarrow$ & $\uparrow$ & $\downarrow$ & $\uparrow$ & & & & & & \\
\hline Foreign Income & 5 & $\uparrow$ & $\downarrow$ & $\uparrow$ & $\uparrow$ & Foreign Income & 9 & $\downarrow$ & $\uparrow$ & $\downarrow$ & $\uparrow$ \\
\hline \multicolumn{12}{|c|}{ E3 - Net Effects on Trade Balance } \\
\hline \multicolumn{6}{|c|}{ Specification 1} & \multicolumn{6}{|c|}{ Specification 2} \\
\hline & Sc & Arg & Bra & Col & Mex & & Sc & Arg & Bra & Col & Mex \\
\hline RER (Devaluation) & 1 & $\uparrow$ & $\uparrow$ & $\uparrow$ & $\downarrow$ & RER (Devaluation) & 6 & $\uparrow$ & $\uparrow$ & $\uparrow$ & $\downarrow$ \\
\hline Exports & 2 & $\uparrow$ & $\uparrow$ & $\uparrow$ & $\uparrow$ & Trade Balance & 7 & $\uparrow$ & $\uparrow$ & $\downarrow$ & $\uparrow$ \\
\hline GDP & 3 & $\uparrow$ & $\downarrow$ & $\downarrow$ & $\uparrow$ & GDP & 8 & $\downarrow$ & $\uparrow$ & $\downarrow$ & $\uparrow$ \\
\hline Investments & 4 & $\downarrow$ & $\uparrow$ & $\downarrow$ & $\uparrow$ & & & & & & \\
\hline Foreign Income & 5 & $\downarrow$ & $\uparrow$ & $\uparrow$ & $\downarrow$ & Foreign Income & 9 & $\uparrow$ & $\downarrow$ & $\uparrow$ & $\downarrow$ \\
\hline
\end{tabular}

We look at some impulse-response analysis from the baseline data observing the three decomposed effects. We are able to check whether temporary effects can change the equilibrium values, as well as if they show a convergent or divergent pattern.

Table 4.10 consists in three types of effects. The initial effect (E1) measures the initial innovation (shock in the variable of interest) impacts on the variables that receive the shock (short-run effect). The second effect (E2) is the effect on time, in which direction the effect diverges or converges to a higher or smaller value than the initial shock (trajectory). Finally, the third effect (E3) shows the trajectory and whether the new equilibrium value is higher or smaller than the initial value (long-run effect).

Figure 4.7. Impulse-response: effects of depreciation on the trade balance (spec 1)
Figure 4.8. Impulse-response: effects of depreciation on trade balance $(\operatorname{spec} 2)$ 


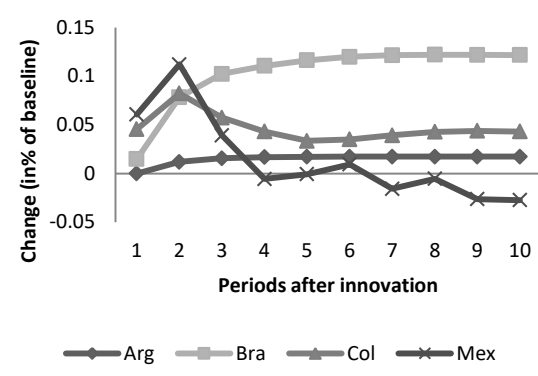

Data source: Penn World Tables

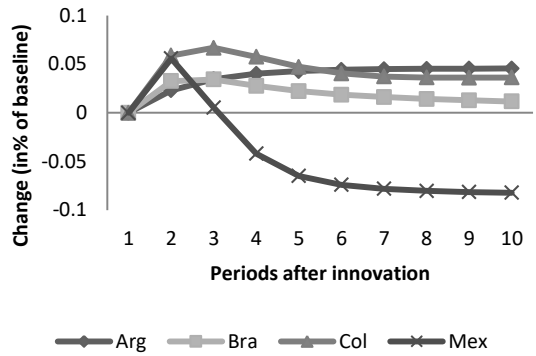

Data source: Penn World Tables

The RER shocks represent a temporary depreciation (impulse) in the domestic currency (scenarios 1 and 6). This shock has a positive effect on Trade Balance (TB) in specification 1 for Brazil, Colombia, and Mexico $(E 1>0)$, but no initial effect in Argentina. The RER has no initial trade balance effect in any of the four countries for specification $2(E 1=0)$. The effects on time are positive in both scenarios for Brazil and Argentina $(E 2>0)$. For Colombia, RER depreciation effect is positive in specification 2, but neutral in specification 1 . The net effect is positive $(E 3>0)$ for all countries but Mexico, which shows a negative LR effect in both specifications.

Figure 4.9. Impulse response: effects of a rise in exports on the trade balance (specification 1)

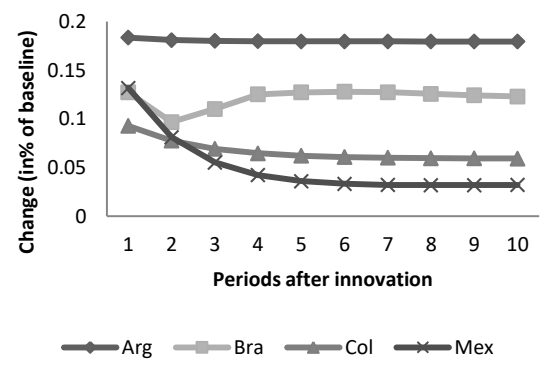

Data source: Penn World Tables
Figure 4.10. Impulse response: effects of a rise in TB on the TB (specification 2)

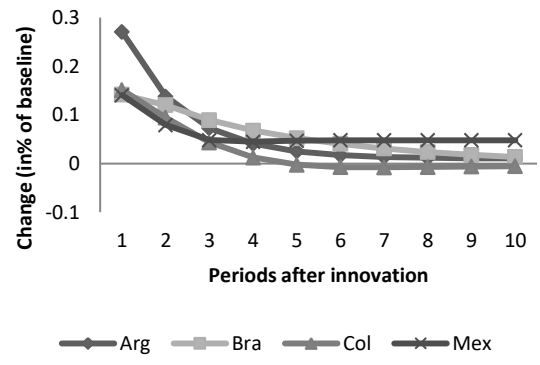

Data source: Penn World Tables 
We have two different ways to see the foreign effects on the trade depending on how we specified the models. In specification 1 we are able to observe the effect of export shocks on the trade balance. In specification 2, as there is no exports variable, we check how trade balance shocks affect itself in the long-run.

In specification 1, export effects on the trade balance are initially positive in all models $(E 1>$ $0)$. In a second moment the trade balance reduces itself from the initial shock $(E 2<0)$ in all cases but Brazil. The new equilibrium values are nonetheless in a higher magnitude than they were before the shocks $(E 3>0)$ for all countries.

In specification 2 we see the effects of trade balance on the trade balance. As a tautology, the initial effect is always positive in every case $(E 1>0)$. All countries show a decrease from the initial shock $(E 2<0)$ but a small positive long-run effect $(E 3>0)$, returning to a point that is very close to zero (no LR effect), so we observe a convergence pattern here.

Figure 4.11. Impulse-Response: rise in GDP effects on the trade balance (specification 1)

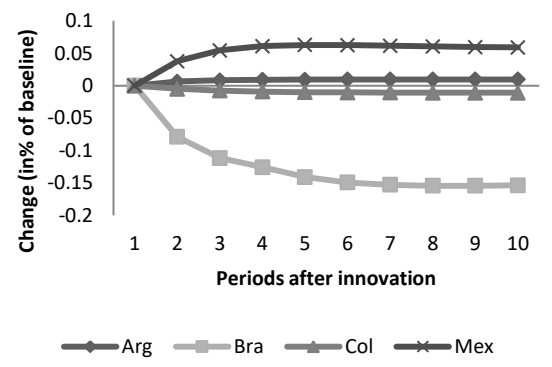

Data source: Penn World Tables
Figure 4.12. Impulse-Response: rise in GDP effects on the trade balance (specification 2)



Data source: Penn World Tables 
For both specifications, a positive GDP growth shock results in no changes in the TB initial value $(E 1=0)$. In both cases, Mexico has a positive time effect and net value $(E 2>0$ and $E 3>0)$, while Colombia has a negative effect $(E 2<0$ and $E 3<0)$. Brazil shows a negative trajectory on specification 1, while it starts negative but turns positive on specification 2 . Argentina, on the contrary, has a positive E2 and E3 effect in specification 1, but negative on specification 2.

Figure 4.13. Impulse-response: Investment effects on the trade balance (Specification 1)

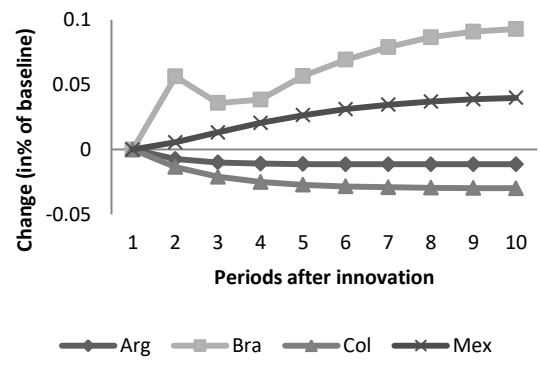

Data source: Penn World Tables

The effects of investments on trade balance are available only for specification 1 . There is no investment in specification 2. An initial investment increase has no effect in all cases $(E 1=0)$. The continuous effects of economic shocks in investments are positive in the long-run only for Brazil and Mexico $(E 2>0$ and $E 3>0)$. Investment has negative impacts on Trade Balance for Argentina and Colombia $(E 2<0$ and $E 3<0)$.

Figure 4.14. Impulse-Response: rise in foreign growth impacts on trade balance (spec. 1)
Figure 4.15. Impulse-Response: rise in foreign growth impacts on trade balance (spec. 1) 


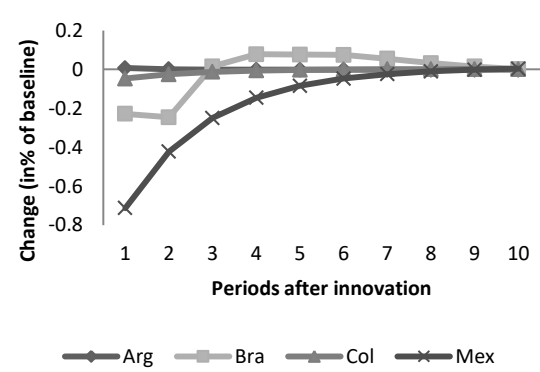

Data source: Penn World Tables

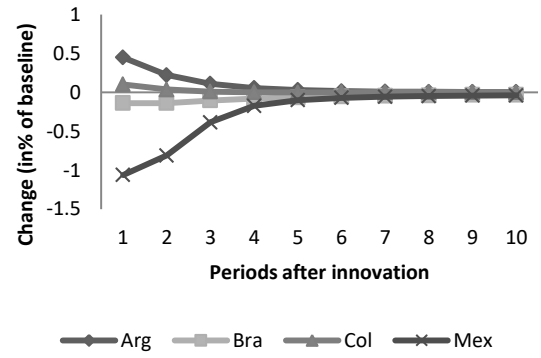

Data source: Penn World Tables

In terms of the impulse-response of the foreign income effects on trade balance, we see interesting results. On average the effects on the long-run (E3) all converge to values which are close to zero in both bases. In specification 2, The initial effects are positive for Argentina and Colombia $(E 1>0)$ but negative for Brazil and Mexico $(E 1<0)$, but the ones with smaller initial effects are the ones with biggest growth until reaching a steady state very close to zero. Foreign growth is absorbed and shows no long-run impacts on the trade balance. 
Debating the assumptions of the Thirlwall Model

Table 4.11 - Permanent Effects on Trade Balance

\section{PERMANENT EFFECT}

\begin{tabular}{|c|c|c|c|c|c|c|c|c|c|c|c|}
\hline \multicolumn{12}{|c|}{ E1 - Initial Effects on Trade Balance } \\
\hline \multicolumn{6}{|c|}{ Specification 1} & \multicolumn{6}{|c|}{ Specification 2} \\
\hline & Sc & $\operatorname{Arg}$ & Bra & Col & Mex & & $\mathrm{Sc}$ & Arg & Bra & Col & Mex \\
\hline RER (Devaluation) & 1 & $\uparrow$ & $\uparrow$ & $\downarrow$ & $\uparrow$ & RER (Devaluation) & 6 & $\uparrow$ & $\uparrow$ & $\uparrow$ & $\uparrow$ \\
\hline Exports & 2 & $\uparrow$ & $\uparrow$ & $\uparrow$ & $\uparrow$ & Trade Balance & 7 & $\uparrow$ & $\uparrow$ & $\uparrow$ & $\uparrow$ \\
\hline GDP & 3 & $\uparrow$ & $\downarrow$ & $\downarrow$ & $\uparrow$ & GDP & 8 & $\downarrow$ & $\downarrow$ & $\uparrow$ & $\downarrow$ \\
\hline Investments & 4 & $\downarrow$ & $\uparrow$ & $\downarrow$ & $\uparrow$ & & & & & & \\
\hline Foreign Income & 5 & $\uparrow$ & $\downarrow$ & $\downarrow$ & $\downarrow$ & Foreign Income & 9 & $\uparrow$ & $\downarrow$ & $\uparrow$ & $\downarrow$ \\
\hline \multicolumn{12}{|c|}{ E2 - Effects on time on Trade Balance } \\
\hline \multicolumn{6}{|c|}{ Specification 1} & \multicolumn{6}{|c|}{ Specification 2} \\
\hline & Sc & $\operatorname{Arg}$ & Bra & Col & Mex & & $\mathrm{Sc}$ & Arg & Bra & Col & Mex \\
\hline RER (Devaluation) & 1 & $\uparrow$ & $\uparrow$ & $\downarrow$ & $\uparrow$ & RER (Devaluation) & 6 & $\uparrow$ & $\uparrow$ & $\uparrow$ & $\downarrow$ \\
\hline Exports & 2 & $\uparrow$ & $\uparrow$ & $\uparrow$ & $\uparrow$ & Trade Balance & 7 & $\downarrow$ & $\uparrow$ & $\uparrow$ & $\uparrow$ \\
\hline GDP & 3 & $\uparrow$ & $\downarrow$ & $\downarrow$ & $\uparrow$ & GDP & 8 & $\downarrow$ & $\downarrow$ & $\downarrow$ & $\uparrow$ \\
\hline Investments & 4 & $\downarrow$ & $\uparrow$ & $\downarrow$ & $\uparrow$ & & & & & & \\
\hline Foreign Income & 5 & $\downarrow$ & $\uparrow$ & $\downarrow$ & $\downarrow$ & Foreign Income & 9 & $\uparrow$ & $\downarrow$ & $\uparrow$ & $\downarrow$ \\
\hline \multicolumn{12}{|c|}{ E3 - Net Effects on Trade Balance } \\
\hline \multicolumn{6}{|c|}{ Specification 1} & \multicolumn{6}{|c|}{ Specification 2} \\
\hline & Sc & Arg & Bra & Col & Mex & & Sc & Arg & Bra & Col & Mex \\
\hline RER (Devaluation) & 1 & $\uparrow$ & $\uparrow$ & $\downarrow$ & $\uparrow$ & RER (Devaluation) & 6 & $\uparrow$ & $\uparrow$ & $\uparrow$ & $\downarrow$ \\
\hline Exports & 2 & $\uparrow$ & $\uparrow$ & $\uparrow$ & $\uparrow$ & Trade Balance & 7 & $\uparrow$ & $\uparrow$ & $\uparrow$ & $\uparrow$ \\
\hline GDP & 3 & $\uparrow$ & $\downarrow$ & $\downarrow$ & $\uparrow$ & GDP & 8 & $\downarrow$ & $\downarrow$ & $\downarrow$ & $\uparrow$ \\
\hline Investments & 4 & $\downarrow$ & $\uparrow$ & $\downarrow$ & $\uparrow$ & & & & & & \\
\hline Foreign Income & 5 & $\downarrow$ & $\downarrow$ & $\downarrow$ & $\downarrow$ & Foreign Income & 9 & $\uparrow$ & $\downarrow$ & $\uparrow$ & $\downarrow$ \\
\hline
\end{tabular}

The permanent effects occur after a specific selected period and consist on continually shocking one specific variable to observe its continuous effects on others. In this case we apply a shock of $5 \%$ magnitude for every year after 1979 . Here we observe the shock effects on the trade balance (Table 4.11).

Scenarios 1 and 6 (RER) show how the real exchange rate affects trade balance. In scenario 1 (specification 1), constant depreciations have a positive impact on the trade balance in Brazil, Argentina and Mexico, while it has a negative effect in Colombia. In specification 2 (scenario 5), the RER effects turn positive to Colombia and negative to Mexico. In scenario 2 (export effects), export have a positive effect on the trade balance in all cases. This was initially expected, considering that an initial growth effect on exports does not result in higher growth of imports, the same positive result is seen for scenario 7, which shows the trade balance effects in specification 2 . 
For scenario 3 (GDP effects) domestic growth affects positively TB in Argentina and Mexico, but negatively Brazil and Colombia. In specification 2 (scenario 8), GDP has a negative net effect (E3) in the TB of all countries but Mexico. Shocks increasing investment (scenario 4) result in mixed effects. For Brazil and Mexico, investment has a positive net effect on the trade balance, while it results in negative net effects for Argentina and Colombia.

Foreign income effects (scenarios 5 and 9) have a negative impact on the trade balance of all countries in specification 1. In specification 2, It has a positive impact for Argentina and Colombia, but negative for Brazil and Mexico.

\subsubsection{Real exchange rate effects}

The real exchange rate changes are part of the price effects discussed on the BPCM. It is expected from the standard BPCM theory that this value should show zero growth in the longrun.

Figure 4.16. RER Baseline Argentina

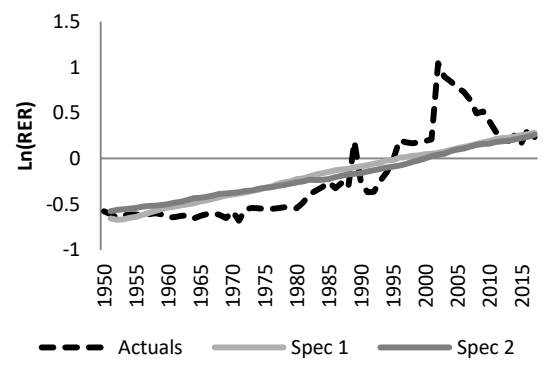

Data source: Penn World Tables
Figure 4.17. RER Baseline Brazil

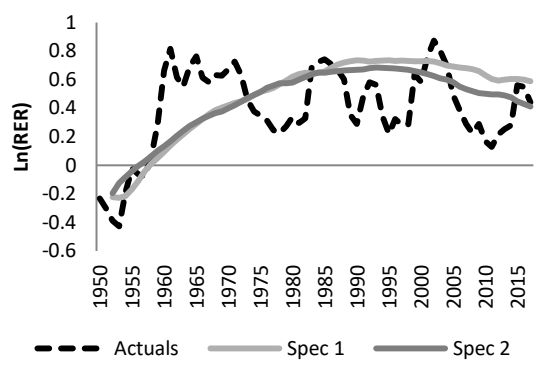

Data source: Penn World Tables 
Figure 4.18. RER Baseline Colombia

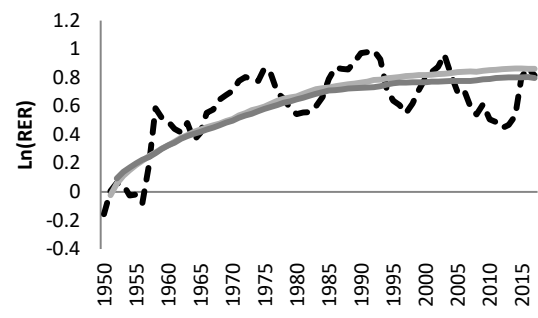

Actuals

Spec 1

$\longrightarrow$ Spec 2

Data source: Penn World Tables
Figure 4.19. RER Baseline Mexico

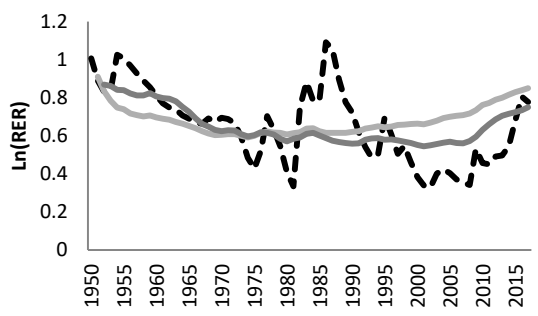

- - Actuals Spec $1 \longrightarrow$ Spec 2

Data source: Penn World Tables

Table 4.12. Impulse Response Analysis - Effects on the Real Exchange Rate

\begin{tabular}{|c|c|c|c|c|c|c|c|c|c|c|c|}
\hline \multicolumn{12}{|c|}{ E1 - Initial effects on Real Exchange Rate } \\
\hline \multicolumn{6}{|c|}{ Specification 1} & \multicolumn{6}{|c|}{ Specification 2} \\
\hline & Sc & Arg & Bra & Col & Mex & & Sc & Arg & Bra & Col & Mex \\
\hline RER (Devaluation) & 1 & $\uparrow$ & $\uparrow$ & $\uparrow$ & $\uparrow$ & RER (Devaluation) & 6 & $\uparrow$ & $\uparrow$ & $\uparrow$ & 个 \\
\hline Exports & 2 & 0 & 0 & 0 & 0 & Trade Balance & 7 & $\uparrow$ & 0 & 0 & 0 \\
\hline GDP & 3 & 0 & 0 & 0 & 0 & GDP & 8 & 0 & 0 & 0 & 0 \\
\hline Investments & 4 & 0 & 0 & 0 & 0 & & & & & & \\
\hline Foreign Income & 5 & $\downarrow$ & $\uparrow$ & $\downarrow$ & $\downarrow$ & Foreign Income & 9 & $\downarrow$ & $\downarrow$ & $\downarrow$ & $\uparrow$ \\
\hline \multicolumn{12}{|c|}{ E2 - Effects on time on Real Exchange Rate } \\
\hline \multicolumn{6}{|c|}{ Specification 1} & \multicolumn{6}{|c|}{ Specification 2} \\
\hline & Sc & $\operatorname{Arg}$ & Bra & Col & Mex & & Sc & Arg & Bra & Col & Mex \\
\hline RER (Devaluation) & 1 & $\downarrow$ & $\downarrow$ & $\downarrow$ & $\uparrow$ & RER (Devaluation) & 6 & $\uparrow$ & $\uparrow$ & $\uparrow$ & $\downarrow$ \\
\hline Exports & 2 & $\uparrow$ & $\downarrow$ & $\downarrow$ & $\uparrow$ & Trade Balance & 7 & $\downarrow$ & $\downarrow$ & $\uparrow$ & $\downarrow$ \\
\hline GDP & 3 & $\downarrow$ & $\downarrow$ & $\downarrow$ & $\downarrow$ & GDP & 8 & $\downarrow$ & $\downarrow$ & $\downarrow$ & $\uparrow$ \\
\hline Investments & 4 & $\uparrow$ & $\downarrow$ & $\downarrow$ & $\uparrow$ & & & & & & \\
\hline Foreign Income & 5 & $\uparrow$ & $\downarrow$ & $\uparrow$ & $\uparrow$ & Foreign Income & 9 & $\uparrow$ & $\downarrow$ & $\downarrow$ & $\downarrow$ \\
\hline \multicolumn{12}{|c|}{ E3 - Net Effects on Real Exchange Rate } \\
\hline \multicolumn{6}{|c|}{ Specification 1} & \multicolumn{6}{|c|}{ Specification 2} \\
\hline & Sc & Arg & Bra & Col & Mex & & Sc & Arg & Bra & Col & Mex \\
\hline RER (Devaluation) & 1 & $\uparrow$ & $\uparrow$ & $\uparrow$ & $\uparrow$ & RER (Devaluation) & 6 & $\uparrow$ & $\uparrow$ & $\uparrow$ & $\uparrow$ \\
\hline Exports & 2 & $\uparrow$ & $\downarrow$ & $\downarrow$ & $\uparrow$ & Trade Balance & 7 & $\downarrow$ & $\downarrow$ & $\uparrow$ & $\downarrow$ \\
\hline GDP & 3 & $\downarrow$ & $\downarrow$ & $\downarrow$ & $\downarrow$ & GDP & 8 & $\downarrow$ & $\downarrow$ & $\downarrow$ & $\uparrow$ \\
\hline Investments & 4 & $\uparrow$ & $\downarrow$ & $\downarrow$ & $\uparrow$ & & & & & & \\
\hline Foreign Income & 5 & $\downarrow$ & $\downarrow$ & $\downarrow$ & $\uparrow$ & Foreign Income & 9 & $\downarrow$ & $\downarrow$ & $\downarrow$ & $\downarrow$ \\
\hline
\end{tabular}


Observing the impulse-response of some selected variables on the RER, we can see which variables affect the price adjustments of the system.

Figure 4.20. Impulse response: effects of a depreciation on the RER (Specification 1)

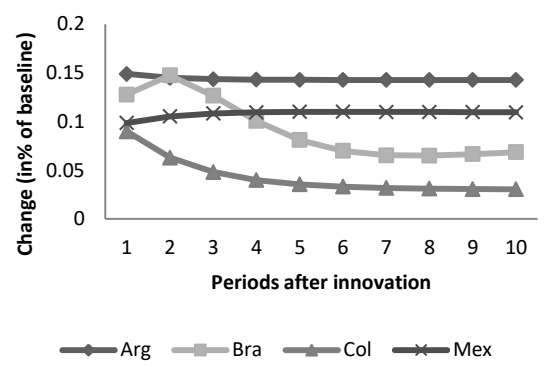

Data source: Penn World Tables
Figure 4.21. Impulse-response: effects of a depreciation on RER (Specification 2)

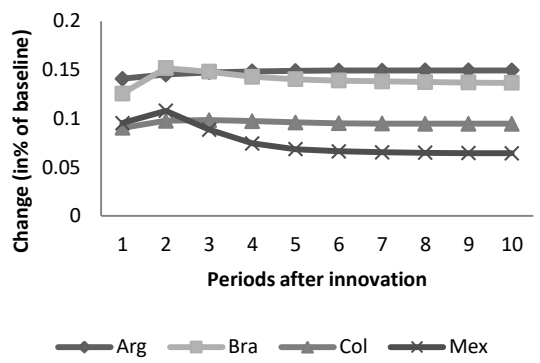

Data source: Penn World Tables

As a tautology, the effect of a real exchange rate shock on itself has a positive initial effect on the RER $(E 1>0)$. In time it evolves a little bit different depending on each country. For Argentina, Brazil and Colombia, depreciation results in a new equilibrium smaller than the initial shock $(E 2<0)$. In all cases though, currency depreciation results in increase in the RER in the long$\operatorname{run}(E 3>0)$.

Figure 4.22. Impulse-response: rise in exports effects on the RER (specification 1)

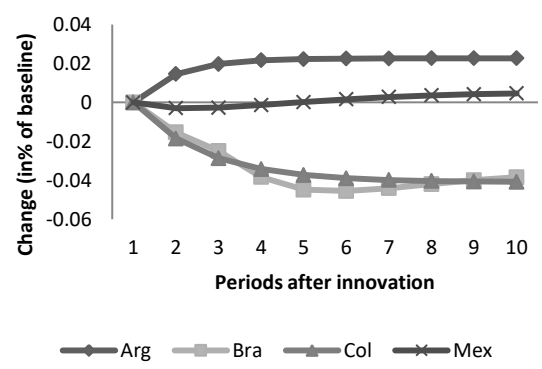

Data source: Penn World Tables
Figure 4.23. Impulse-response: rise in trade balance effects on the RER (specification 2)

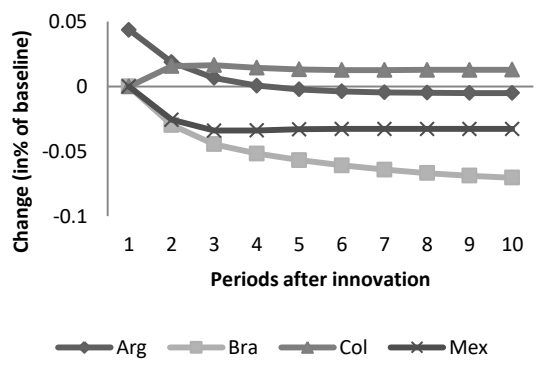

Data source: Penn World Tables 
In terms of the export effects on the RER in specification 1, we see no initial effect $(E 1=0)$, but on time we see that Argentina and Mexico reach a higher value than the one in the initial condition $(E 2>0$ and $E 3>0)$. Brazil and Colombia, however, reach a long-run equilibrium in a smaller value $(E 2<0$ and $E 3<0)$ than the original value. Mexico oscillates, having its net effects coming to a value close to zero. In specification 2 we see the effects trade balance change on the Real Exchange Rate. The effects are initially positive for Argentina $(E 1>0)$ but zero for all other countries $(E 1=0)$. The new equilibrium value for Colombia is positive $(E 3>0)$ but the net effect is negative for Argentina, Brazil and Mexico.

Figure 4.24. Impulse-response: rise of GDP effects on the RER (Specification 1)

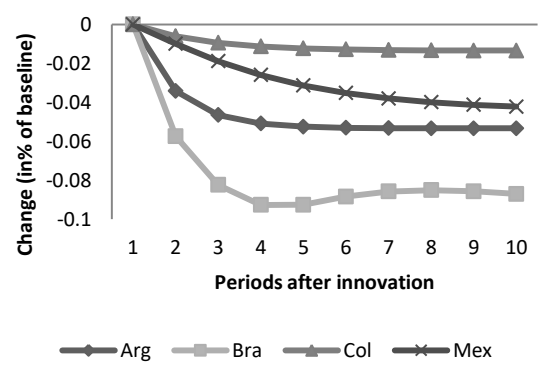

Data source: Penn World Tables
Figure 4.25. Impulse-response: rise of GDP effects on the RER (Specification 2)

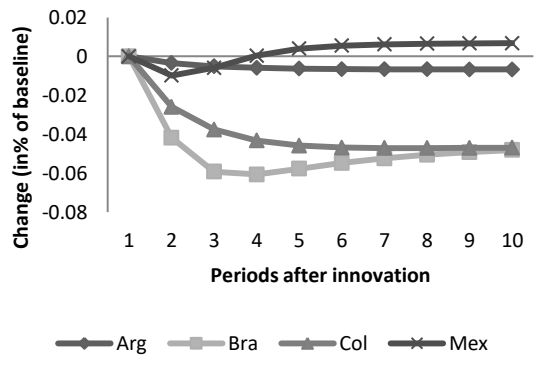

Data source: Penn World Tables

In terms of GDP effects on the RER we see no initial effect in both specifications $(E 1<0)$, meaning that the time effects are always equal to the net effects $(E 2=E 3)$. The time and net effects are negative for all countries in specification 1 and $2(E 2<0$ and $E 3<0)$, the only exception is being positive for Mexico in specification 2. This means that GDP growth for almost all cases results in a real appreciation of domestic currency. 
Figure 4.26. Impulse-Response: rise of investment effects on the RER (specification 1)

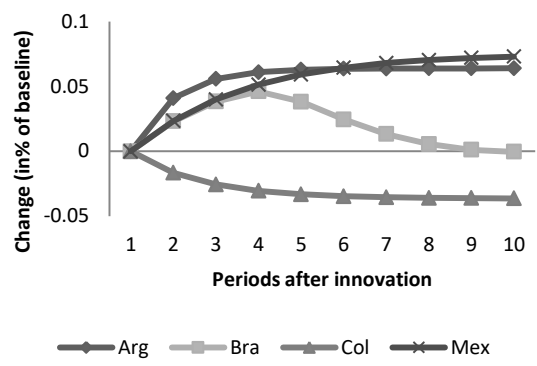

Data source: Penn World Tables

The investment effects on the RER show a distinct behavior than GDP. Investment can be only discussed for specification 1. Initially, it has no effect $(E 1=0)$ for all cases. A rise in investments results in a higher RER value (depreciation) in Argentina, Brazil and Mexico ( $E 2>0$ and $E 3>0$ ), with Brazil oscillating back to the origin. For Colombia we see a negative impact of investment in the RER (appreciating it) (negative $E 2$ and E3).

Figure 4.27. Impulse-response: rise of foreign income in RER (spec. 1)

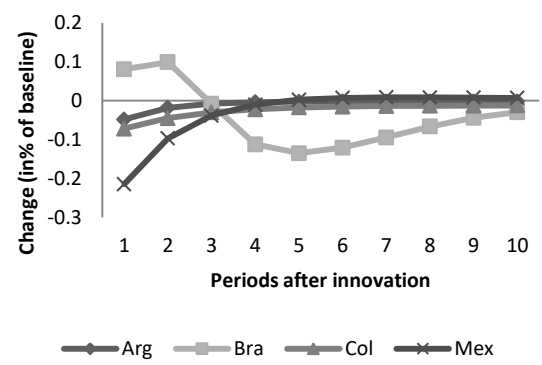

Data source: Penn World Tables
Figure 4.28. Impulse-response: rise of foreign income in RER (spec. 2)

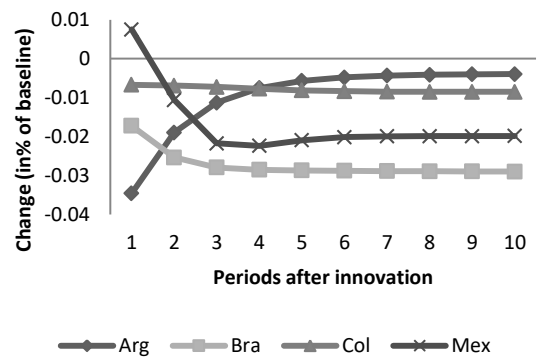

Data source: Penn World Tables

The effects of foreign income on the RER are mixed. The initial effect depreciates currency in Brazil $(E 1>0)$, but appreciates the domestic currency for Argentina, Colombia and especially 
Mexico in specification $1(E 1<0)$. For all countries in specification 1 the values converge to zero (which shows stability on that). For specification 2, the initial effect in Argentina, Brazil and Colombia is negative $(E 1<0)$, while for Mexico it is positive. The time effects is only positive in Argentina $(E 2>0)$, being negative for the other countries. The final effect is negative in all countries $(E 3<0)$.

Table 4.13. Permanent effects on the Real Exchange Rate

\begin{tabular}{|c|c|c|c|c|c|c|c|c|c|c|c|}
\hline \multicolumn{12}{|c|}{ E1 - Initial effects on Real Exchange Rate } \\
\hline \multicolumn{6}{|c|}{ Specification 1} & \multicolumn{6}{|c|}{ Specification 2} \\
\hline & Sc & Arg & Bra & Col & Mex & & Sc & Arg & Bra & Col & Mex \\
\hline RER (Devaluation) & 1 & $\downarrow$ & $\uparrow$ & $\uparrow$ & $\downarrow$ & RER (Devaluation) & 6 & $\downarrow$ & $\uparrow$ & $\uparrow$ & $\downarrow$ \\
\hline Exports & 2 & $\uparrow$ & $\uparrow$ & 个 & $\uparrow$ & Trade Balance & 7 & $\uparrow$ & $\uparrow$ & $\uparrow$ & $\uparrow$ \\
\hline GDP & 3 & $\uparrow$ & $\uparrow$ & $\uparrow$ & $\uparrow$ & GDP & 8 & $\uparrow$ & $\uparrow$ & $\uparrow$ & $\uparrow$ \\
\hline Investments & 4 & $\uparrow$ & $\downarrow$ & $\uparrow$ & $\uparrow$ & & & & & & \\
\hline Foreign Income & 5 & $\downarrow$ & $\uparrow$ & $\uparrow$ & $\uparrow$ & Foreign Income & 9 & $\downarrow$ & $\downarrow$ & $\downarrow$ & $\uparrow$ \\
\hline \multicolumn{12}{|c|}{ E2 - Effects on time on Real Exchange Rate } \\
\hline \multicolumn{6}{|c|}{ Specification 1} & \multicolumn{6}{|c|}{ Specification 2} \\
\hline & Sc & Arg & $\mathrm{Bra}$ & Col & Mex & & Sc & Arg & Bra & Col & Mex \\
\hline RER (Devaluation) & 1 & $\downarrow$ & $\uparrow$ & $\uparrow$ & $\downarrow$ & RER (Devaluation) & 6 & $\downarrow$ & $\uparrow$ & $\uparrow$ & $\downarrow$ \\
\hline Exports & 2 & $\uparrow$ & $\downarrow$ & $\uparrow$ & $\uparrow$ & Trade Balance & 7 & $\uparrow$ & $\uparrow$ & $\uparrow$ & $\uparrow$ \\
\hline GDP & 3 & $\uparrow$ & $\uparrow$ & $\uparrow$ & $\uparrow$ & GDP & 8 & $\uparrow$ & $\uparrow$ & $\uparrow$ & $\uparrow$ \\
\hline Investments & 4 & $\uparrow$ & $\uparrow$ & $\uparrow$ & $\uparrow$ & & & & & & \\
\hline Foreign Income & 5 & $\downarrow$ & $\downarrow$ & $\downarrow$ & $\downarrow$ & Foreign Income & 9 & $\downarrow$ & $\downarrow$ & $\downarrow$ & $\downarrow$ \\
\hline \multicolumn{12}{|c|}{ E3 - Net Effects on Real Exchange Rate } \\
\hline \multicolumn{6}{|c|}{ Specification 1} & \multicolumn{6}{|c|}{ Specification 2} \\
\hline & Sc & Arg & Bra & Col & Mex & & Sc & Arg & Bra & Col & Mex \\
\hline RER (Devaluation) & 1 & $\downarrow$ & $\uparrow$ & $\uparrow$ & $\downarrow$ & RER (Devaluation) & 6 & $\downarrow$ & $\uparrow$ & $\uparrow$ & $\downarrow$ \\
\hline Exports & 2 & $\uparrow$ & $\downarrow$ & $\uparrow$ & $\uparrow$ & Trade Balance & 7 & $\uparrow$ & $\uparrow$ & $\uparrow$ & $\uparrow$ \\
\hline GDP & 3 & $\uparrow$ & $\uparrow$ & 个 & $\uparrow$ & GDP & 8 & $\uparrow$ & $\uparrow$ & $\uparrow$ & $\uparrow$ \\
\hline Investments & 4 & $\uparrow$ & $\uparrow$ & $\uparrow$ & $\uparrow$ & & & & & & \\
\hline Foreign Income & 5 & $\downarrow$ & $\downarrow$ & $\downarrow$ & $\downarrow$ & Foreign Income & 9 & $\downarrow$ & $\downarrow$ & $\downarrow$ & $\downarrow$ \\
\hline
\end{tabular}

Table 4.13 shows the permanent effects of our selected shocked variables on relative prices (real exchange rate). Depreciations of the RER have positive long-run effects on the RER for Brazil and Colombia (final depreciation), and negative (appreciation) for Argentina and Mexico (scenarios 1 and 6). A rise in exports (scenario 2 - specification 1) has negative effects (appreciation) on the RER for Brazil, but positive effects (depreciation) for the other three countries. A trade balance increase (scenario 7 - specification 2) has positive effects in the RER for all countries. GDP increases have a positive effect on the RER in all countries and cases. Investments (scenario 4) also show a positive effect on the RER in all countries. On the other 
hand, foreign income increases has always negative effects on the RER, appreciating the currency.

\subsubsection{Domestic Income Effects}

This section presents the baselines for domestic income, as well as the impulse response, and the permanent effects of the selected economic shocks on domestic income. When looking at the effects of currency depreciation, income elasticity shocks (exports), and foreign income shocks in domestic GDP, it is possible to discuss important aspects of the BPCM.

Figure 4.29. Baseline: GDP - Argentina



Data source: Penn World Tables

Figure 4.31. Baseline GDP - Colombia

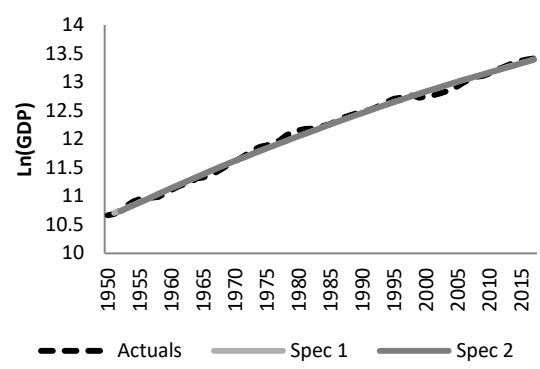

Data source: Penn World Tables
Figure 4.30. Baseline GDP - Brazil

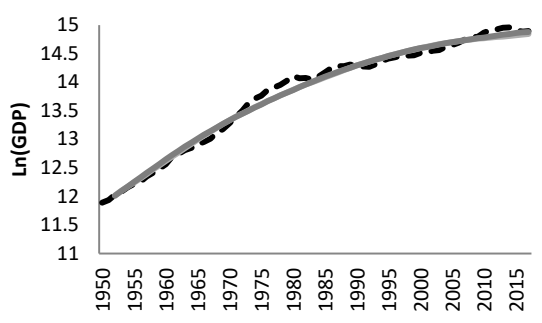

- - Actuals

Spec 1 Spec 2

Data source: Penn World Tables

Figure 4.32. Baseline GDP - Mexico

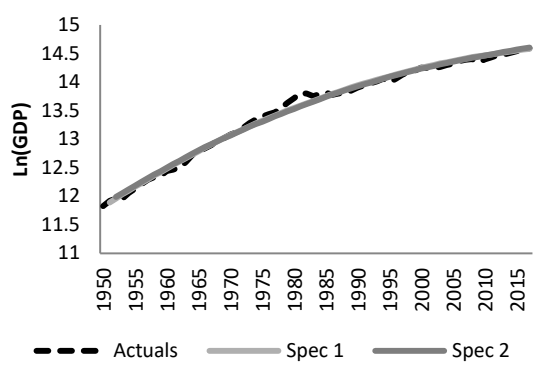

Data source: Penn World Tables 
Debating the assumptions of the Thirlwall Model

Table 4.14. Impulse Response Analysis - Effects on Domestic Income

\begin{tabular}{|c|c|c|c|c|c|c|c|c|c|c|c|}
\hline \multicolumn{12}{|c|}{ E1 - Initial Effects on Domestic Income } \\
\hline \multicolumn{6}{|c|}{ Specification 1} & \multicolumn{6}{|c|}{ Specification 2} \\
\hline & Sc & $\operatorname{Arg}$ & Bra & Col & Mex & & Sc & Arg & Bra & Col & Mex \\
\hline RER (Devaluation) & 1 & 0 & 0 & 0 & 0 & RER (Devaluation) & 6 & $\downarrow$ & 0 & 0 & 0 \\
\hline Exports & 2 & 0 & 0 & 0 & 0 & Trade Balance & 7 & $\downarrow$ & 0 & 0 & 0 \\
\hline GDP & 3 & $\uparrow$ & $\uparrow$ & $\uparrow$ & $\uparrow$ & GDP & 8 & $\uparrow$ & $\uparrow$ & $\uparrow$ & $\uparrow$ \\
\hline Investments & 4 & 0 & 0 & 0 & 0 & & & & & & \\
\hline Foreign Income & 5 & $\downarrow$ & $\uparrow$ & $\uparrow$ & $\uparrow$ & Foreign Income & 9 & 个 & $\downarrow$ & $\downarrow$ & $\downarrow$ \\
\hline \multicolumn{12}{|c|}{ E2 - Effects on time on Domestic Income } \\
\hline \multicolumn{6}{|c|}{ Specification 1} & \multicolumn{6}{|c|}{ Specification 2} \\
\hline & Sc & Arg & Bra & Col & Mex & & $\mathrm{Sc}$ & $\operatorname{Arg}$ & Bra & Col & Mex \\
\hline RER (Devaluation) & 1 & $\downarrow$ & $\uparrow$ & $\uparrow$ & $\downarrow$ & RER (Devaluation) & 6 & $\downarrow$ & $\uparrow$ & $\uparrow$ & $\downarrow$ \\
\hline Exports & 2 & $\uparrow$ & $\downarrow$ & $\uparrow$ & $\uparrow$ & Trade Balance & 7 & $\uparrow$ & $\uparrow$ & $\uparrow$ & $\uparrow$ \\
\hline GDP & 3 & $\downarrow$ & $\uparrow$ & $\uparrow$ & $\downarrow$ & GDP & 8 & $\uparrow$ & $\uparrow$ & $\uparrow$ & $\uparrow$ \\
\hline Investments & 4 & $\uparrow$ & $\uparrow$ & $\uparrow$ & $\uparrow$ & & & & & & \\
\hline Foreign Income & 5 & $\uparrow$ & $\downarrow$ & $\downarrow$ & $\downarrow$ & Foreign Income & 9 & $\downarrow$ & $\uparrow$ & $\uparrow$ & $\uparrow$ \\
\hline \multicolumn{12}{|c|}{ E3 - Net Effects on Domestic Income } \\
\hline \multicolumn{6}{|c|}{ Specification 1} & \multicolumn{6}{|c|}{ Specification 2} \\
\hline & Sc & Arg & Bra & Col & Mex & & $\mathrm{Sc}$ & Arg & Bra & Col & Mex \\
\hline RER (Devaluation) & 1 & $\downarrow$ & $\uparrow$ & $\uparrow$ & $\downarrow$ & RER (Devaluation) & 6 & $\downarrow$ & $\uparrow$ & $\uparrow$ & $\downarrow$ \\
\hline Exports & 2 & $\uparrow$ & $\downarrow$ & $\uparrow$ & $\uparrow$ & Trade Balance & 7 & $\downarrow$ & $\uparrow$ & $\uparrow$ & $\uparrow$ \\
\hline GDP & 3 & $\uparrow$ & $\uparrow$ & $\uparrow$ & $\uparrow$ & GDP & 8 & $\uparrow$ & $\uparrow$ & $\uparrow$ & $\uparrow$ \\
\hline Investments & 4 & $\uparrow$ & $\uparrow$ & $\uparrow$ & $\uparrow$ & & & & & & \\
\hline Foreign Income & 5 & $\downarrow$ & $\downarrow$ & $\downarrow$ & $\downarrow$ & Foreign Income & 9 & $\uparrow$ & $\downarrow$ & $\downarrow$ & $\uparrow$ \\
\hline
\end{tabular}

Figure 4.33. Impulse-response: effects of depreciation on domestic income (specification

1)

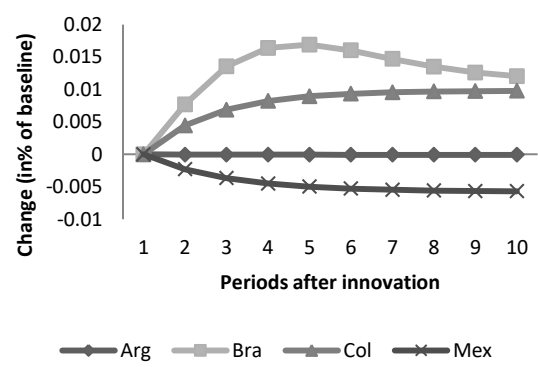

Data source: Penn World Tables
Figure 4.34. Impulse-response: effects of depreciation on domestic income (specification

2)

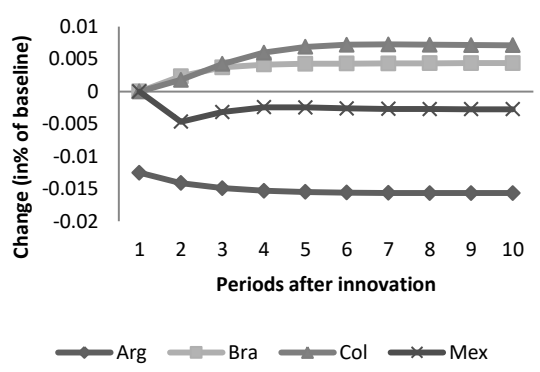

Data source: Penn World Tables 
The effects of RER on domestic income have zero initial effect for all countries $(E 1=0)$ for both specifications. The only exception is Argentina in specification 2 (negative effects). The net effects are positive for Brazil and Colombia and negative for Mexico for both specifications. In Argentina it is close to zero in specification 1, but negative in specification2.

Figure 4.35. Impulse-response: effects of exports on domestic income (specification 1)

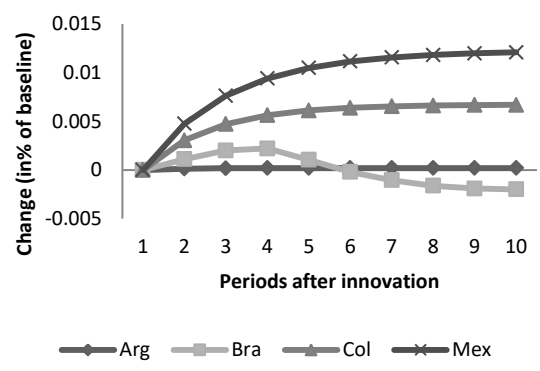

Data source: Penn World Tables
Figure 4.36. Impulse-response: effects of trade balance on domestic income (specification 2)

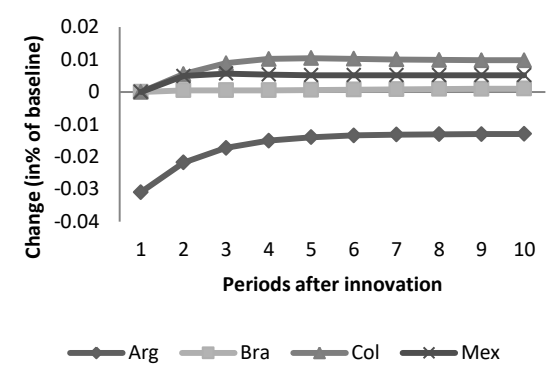

Data source: Penn World Tables

Export effects on domestic income (specification 1) show no initial effect $(E 1=0)$. In terms of long-run effects, Mexico and Colombia show that exports increase the equilibrium rate of domestic income ( $E 2$ and $E 3$ are positive), but it decreases in the case of Brazil (after an initial increase). In Argentina there is no effect $(E 1=E 2=E 3=0)$.

For specification 2, a positive shock on the trade balance has an initial negative impact on domestic income only in Argentina $(E 1<0)$, and no effect in the other countries $(E 1=0)$. It grows after the initial negative effect for all countries $(E 2>0)$. The net effective is positive for Brazil, Colombia and Mexico $(E 3>0)$, but negative for Argentina.

Figure 4.37. Impulse-response: effects of GDP on domestic Income (specification 1)
Figure 4.38. Impulse-response: effect of GDP on domestic income (specification 2) 


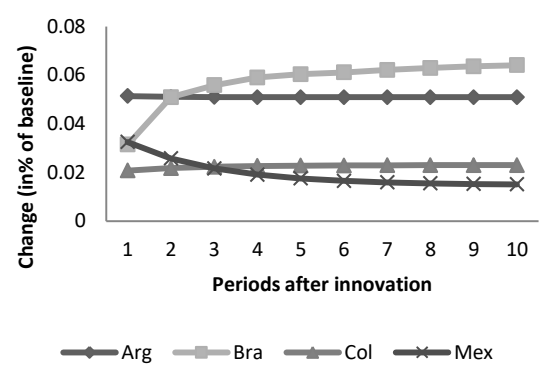

Data source: Penn World Tables



Data source: Penn World Tables

As a tautology, GDP increases result in a positive initial shock to domestic income $(E 1>0)$ in all countries for both specifications. In specification 1, the trajectory goes downward from the initial shock for Argentina (very small effect) and Mexico $(E 2<0)$, being positive for Brazil and Colombia $(E 2>0)$. The adjustment goes upward in all cases in specification $2(E 2>0)$. The net effects are positive for all countries in all cases $(E 3>0)$.

Figure 4.39. Impulse-response: effects of investment on domestic income (specification 1)

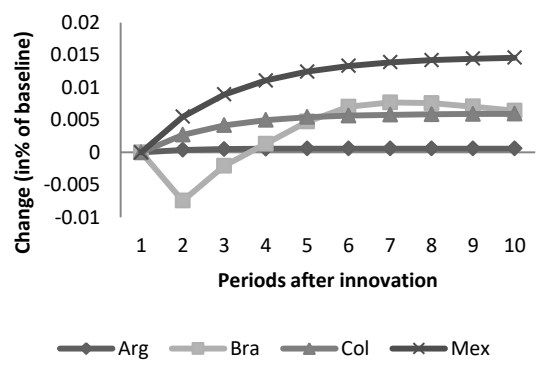

Data source: Penn World Tables

From our specification 1 results, the initial effects of investment in domestic income are zero $(E 1=0)$. Investment has a positive effect in time and a net positive effect for all countries $(E 2>0$ and $E 3>0)$. It has a small effect for Argentina. It also oscillates in the case of Brazil.

Figure 4.40. Impulse-Response: rise foreign growth impacts on domestic income (spec. 1)
Figure 4.41. Impulse-Response: rise foreign growth impacts on domestic income (spec. 2) 


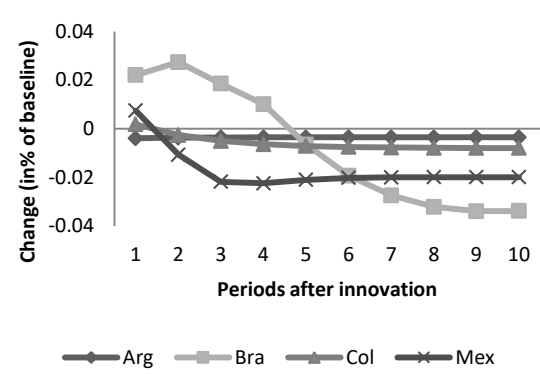

Data source: Penn World Tables

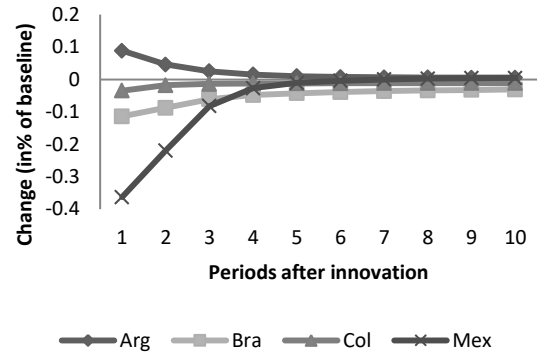

Data source: Penn World Tables

The impulse-response analysis of a positive foreign income shock on domestic income shows some interesting pattern. In specification 1, for all countries the final effects of a rise in foreign income is negative in the long-run $(E 3<0)$. The initial effects for Brazil, Colombia, and Mexico is positive in specification 1 but negative in specification 2, while for Argentina it is the opposite, negative in specification 1, but positive on specification 2. In specification 2 the model seems to converge, as the shocks for all countries move toward zero (condition after the initial shock) $(E 3 \approx 0)$. 
Debating the assumptions of the Thirlwall Model

Table 4.15. Permanent Effects in Domestic Income

\begin{tabular}{|c|c|c|c|c|c|c|c|c|c|c|c|}
\hline \multicolumn{12}{|c|}{ E1 - Initial Effects on Domestic Income } \\
\hline \multicolumn{6}{|c|}{ Specification 1} & \multicolumn{6}{|c|}{ Specification 2} \\
\hline & Sc & $\operatorname{Arg}$ & Bra & Col & Mex & & Sc & Arg & Bra & Col & Mex \\
\hline RER (Devaluation) & 1 & $\uparrow$ & $\uparrow$ & $\uparrow$ & $\uparrow$ & RER (Devaluation) & 6 & $\uparrow$ & $\uparrow$ & $\uparrow$ & $\uparrow$ \\
\hline Exports & 2 & $\uparrow$ & $\downarrow$ & $\downarrow$ & $\downarrow$ & Trade Balance & 7 & $\downarrow$ & $\downarrow$ & $\uparrow$ & $\downarrow$ \\
\hline GDP & 3 & $\downarrow$ & $\downarrow$ & $\downarrow$ & $\downarrow$ & GDP & 8 & $\downarrow$ & $\downarrow$ & $\downarrow$ & $\downarrow$ \\
\hline Investments & 4 & $\uparrow$ & $\uparrow$ & $\downarrow$ & $\uparrow$ & & & & & & \\
\hline Foreign Income & 5 & $\downarrow$ & $\uparrow$ & $\downarrow$ & $\downarrow$ & Foreign Income & 9 & $\uparrow$ & $\downarrow$ & $\downarrow$ & $\downarrow$ \\
\hline \multicolumn{12}{|c|}{ E2 - Effects on time on Domestic Income } \\
\hline \multicolumn{6}{|c|}{ Specification 1} & \multicolumn{6}{|c|}{ Specification 2} \\
\hline & Sc & $\operatorname{Arg}$ & Bra & Col & Mex & & $\mathrm{Sc}$ & Arg & Bra & Col & Mex \\
\hline RER (Devaluation) & 1 & $\uparrow$ & $\uparrow$ & $\uparrow$ & $\uparrow$ & RER (Devaluation) & 6 & $\uparrow$ & $\uparrow$ & $\uparrow$ & $\uparrow$ \\
\hline Exports & 2 & $\uparrow$ & $\downarrow$ & $\downarrow$ & $\uparrow$ & Trade Balance & 7 & $\downarrow$ & $\downarrow$ & $\uparrow$ & $\downarrow$ \\
\hline GDP & 3 & $\downarrow$ & $\downarrow$ & $\downarrow$ & $\downarrow$ & GDP & 8 & $\downarrow$ & $\downarrow$ & $\downarrow$ & $\uparrow$ \\
\hline Investments & 4 & $\uparrow$ & $\uparrow$ & $\downarrow$ & $\uparrow$ & & & & & & \\
\hline Foreign Income & 5 & $\downarrow$ & $\downarrow$ & $\downarrow$ & $\downarrow$ & Foreign Income & 9 & $\uparrow$ & $\downarrow$ & $\downarrow$ & $\downarrow$ \\
\hline \multicolumn{12}{|c|}{ E3 - Net Effects on Domestic Income } \\
\hline \multicolumn{6}{|c|}{ Specification 1} & \multicolumn{6}{|c|}{ Specification 2} \\
\hline & Sc & $\operatorname{Arg}$ & Bra & Col & Mex & & Sc & Arg & Bra & Col & Mex \\
\hline RER (Devaluation) & 1 & $\uparrow$ & $\uparrow$ & $\uparrow$ & $\uparrow$ & RER (Devaluation) & 6 & $\uparrow$ & $\uparrow$ & $\uparrow$ & $\uparrow$ \\
\hline Exports & 2 & $\uparrow$ & $\downarrow$ & $\downarrow$ & $\uparrow$ & Trade Balance & 7 & $\downarrow$ & $\downarrow$ & $\uparrow$ & $\downarrow$ \\
\hline GDP & 3 & $\downarrow$ & $\downarrow$ & $\downarrow$ & $\downarrow$ & GDP & 8 & $\downarrow$ & $\downarrow$ & $\downarrow$ & $\uparrow$ \\
\hline Investments & 4 & $\uparrow$ & $\uparrow$ & $\downarrow$ & $\uparrow$ & & & & & & \\
\hline Foreign Income & 5 & $\downarrow$ & $\downarrow$ & $\downarrow$ & $\downarrow$ & Foreign Income & 9 & $\uparrow$ & $\downarrow$ & $\downarrow$ & $\downarrow$ \\
\hline
\end{tabular}

The permanent shocks effects of selected variables on domestic income (economic growth) show some interesting results. First, an undervaluation (which is only temporarily possible) shows positive effects on growth for all four countries $(E 1>0, E 2>0$ and $E 3>0)$ in both specifications.

In terms of an increase in exports (scenario 2 - specification), it has an initial positive effect on growth in Argentina, but negative in the other countries for specification 1. The final effect however is also positive for Mexico (besides Argentina), being negative for Brazil and Colombia. For specification 2, increases in the trade balance show negative impacts on domestic growth for Argentina, Brazil and Mexico, being positive only for Colombia (for both initial and net effects). Investments have positive effects for Argentina, Brazil and Mexico $(E 3>0)$, but negative ones $(E 3<0)$ for Colombia.

In opposition to what we expected, foreign income increases (scenarios 5 and 9) have negative effects in all countries $(E 3<0)$. The only exception is Argentina for specification $2(E 3>0)$. 
This section presented the overall results for our model estimations, the impulse-response analysis and the permanent shocks. We focused on the impacts on our three interest variables trade balance, real exchange rate, and domestic income. As mentioned before, we are not focusing our analysis on the causes why the selected countries present different results, but on the research questions presented in the previous sections. The next session analyzes the results to discuss the research questions raised on section 3, challenging the empirical robustness of the BPCM assumptions.

\subsection{Discussion of the Research Questions}

Answer to Research Question 1. Do countries show a trade balance equilibrium in the longrun? How to re-balance the TB to equilibrium?

We analyze the baselines in Figures 4.3 - 4.6 to answer the first part of this research question. Interestingly, all the countries we observe are converging in levels towards a stable trade balance (convergence to a level close to zero). This goes in accordance to McCombie \& Thirlwall (1994)'s argument of stable equilibrium. This convergence may take periods to happen, so we observe a persistency of foreign deficit/surpluses for several years, which does not invalidate the Thirlwall model, as already defended by McCombie (2012).

Based on McCombie (2012), the equilibrium between import and export long-run growth rates is the main assumption of the Thirlwall model that should be tested. This can be empirically observed by looking at the slope of the trade balance baseline curve. The baseline model shows some mixed results in this regard. Taking the case of Argentina, its adjustment process follows a seemingly negative sloped curve. This means that imports are systematically growing more than exports to the direction in which the trade balance is equal to zero. Mexico, on the other hand, shows fluctuations around a positively sloped curve, which means that exports are, on average, systematically growing more than imports. Brazil and Colombia oscillate around the value to which trade balance is equal to zero.

Are these non-flat slopes part of a long-run adjustment process of convergence to a gravitational point? Or are they part of a structural imbalance in the current account? Depending on the answer we have different implications for the BPCM theory. In this sense we go back to the three concepts of the long run based on Carvalho (1984) raised in the introduction of this article. If the 
trajectory is part of an adjustment process, it does not create any problems to the BPCM theory. On the other hand, if there is enough evidence of a structural imbalance, this challenges one of the main assumptions of the Thirlwall model, which has the power to de-construct the procedure that leads to the Thirlwall Law. Our intention is not to argue against the model, neither to offer any alternative to it, but to challenge its robustness in empirical terms. The argument behind resides in the fact that the BPCM would benefit for more empirical studies testing its assumptions, which could strengthen its results, and open space for other types of expansions, especially regarding the different perspective on the idea of long-run.

In the case of a structural imbalance in the trade balance and on the LR equilibrium, a way to resolve it is by shocking exports. If a rise in exports or a reduction in imports changes the longrun growth rate, then it could be used as an adjustment mechanism to reestablish the trade balance equilibrium.

When looking at the effects of export shocks on trade balance, we see that exogenous positive export shock raises the trade balance in every case, but the result of the positive initial shock is reduced on time. Nevertheless, the net final effect is positive on the trade balance equilibrium. Considering the impacts of exports on GDP, there are no initial effects of a rise in exports on GDP growth for any of the observed countries using the impulse-response function. There are final positive effects in Argentina, Colombia and Mexico, but negative in Brazil. On the permanent effects, Argentina and Mexico show positive effects. While Brazil and Colombia show a negative effect.

The expected result of a positive relationship between exports and domestic growth is only valid for Argentina and Mexico. For these countries, exports shocks raise the long-run equilibrium rate - exports have positive effects on trade balance, creating demand. However for Brazil and Colombia (permanent effects) a rise in exports has negative effect on growth, which is probably caused by the also negative effect of a rise of exports in the RER, counterbalancing the demand increase with a reduction in the international purchasing power. The use of an increase in exports to restore the trade balance equilibrium then may result in negative effects on domestic GDP.

We can also observe if investments could work as a stabilization mechanism. Temporary increases in investments in all cases result in increases in domestic income, while permanent 
effects have only negative effects in Colombia. In terms of trade balance, temporary and permanent investment effects have negative effects in Argentina and Colombia, but positive in Brazil and Mexico. This states that investments can stabilize the trade balance when reduced in these last two countries. Investment growth can positively change the equilibrium growth in the LR, at the cost of generating deficits in the trade account.

An adjustment in the trade balance through a rise in exports or reduction in investments may reestablish the equilibrium in the long-run trade balance. In Brazil and Mexico, this adjustment comes at the cost of reduction in growth rates. In one hand, it goes against our expectations in which exports generate demand and raise growth. On the other hand, it goes in line to what has been empirically observed in these countries during the 80 's crisis - in which a structural trade imbalance resulted in the need for an export positive shock, at the cost a low economic growth recessive policy during the "lost decade" (Bertola \& Ocampo, 2012).

\section{Answer to the Research Question 2: Do price effects (RER shocks) affect the long-run equilibrium rate of GDP growth?}

All countries observed in the analysis converge to a RER level close to $0.5-0.7$ when looking at the baseline. However, in this convergence process the slopes of the RER curves differ by country. Mexico starts in a depreciated RER value and advances in appreciating the currency in a negatively sloped curve (specially for specification 2). Argentina, on the other hand, follows a completely opposite direction, starting from an overvalued RER, systematically depreciating it, showing a positively sloped curve. Brazil and Colombia show an approach towards a stable horizontal line (with Brazil showing a small decrease).

Are these Real Exchange Rate movements really part of a convergence process to the long-run, or are they part of a structural imbalance, in which price levels do not stabilize? If the latter is true, we enter in a theoretical conundrum in which quantity (GDP growth) is not the only possible adjustment to external sector imbalances in the long-run (Rodrik, 2008). This is a central aspect of the Thirlwall Law: because of the price stability assumption, the ratio between income elasticity of exports and imports define the limits to domestic economic growth. If price effects (RER, terms of trade) do play a role, we leave the Keynesian world of the BPCM (Blecker, 2016) and enter a gray area, in intersection with the neoclassical world. In the 
neoclassical world the short-run price adjustments are the main mechanisms for economies reach the equilibrium, and as in Krugman (1989), growth is supply-side dominated.

As above discussed, the central argument of the BPCM is that price effects are negligible in the long-run, do not affecting the growth rate compatible with stability in the balance of payments. This can be observed when looking at the effects of temporary and permanent RER shocks on domestic income's long-run growth.

When applying an impulse-response of RER (currency real depreciation) on GDP, it results in an income reduction for both short- and long-run for Argentina and Mexico. Following a Kaleckian wage-led interpretation (Bhaduri \& Marglin, 1990; Stockhammer \& Onaran, 2013), a real depreciation in the short-run reduces purchasing power, resulting in smaller domestic income. In terms of permanent shock effects, depreciations have positive effects which could be either (1) related to the fact that an exchange rate undervaluation increases exports and reduces imports, resulting in a demand increase, or (2) to the fact that a devaluated exchange rate raises competitiveness, and stimulates growth in an export-led growth model.

The results above affects two strands of literature related to the BPCM:

1) The traditional BPCM literature (McCombie \& Thirlwall, 1994). Based on the main assumptions of the Thirlwall model, price effects do not affect long-run economic growth. However, we can empirically observe this contractionary effect of RER devaluations by looking at the impulse-response analysis. We were expecting that the effects would affect only short-run. Nevertheless, these changes occur on both time scopes.

2) The New Developmentalist school (Bresser-Pereira et al., 2014; Oreiro, 2016), a tributary of the Thirlwall model. It defends that, in the long-run, a depreciated exchange rate leads to a situation in which, by distinct mechanisms, it is possible to reach higher growth rates. When looking at the permanent effects of RER on growth, we can observe these exact results. ${ }^{23}$

\footnotetext{
${ }^{23}$ Ribeiro, McCombie, \& Lima (2016) also discuss the case in which the real exchange rate can have negative impacts on GDP growth in the long-run inside a BPCM framework.
} 
This result lets us to questions the main assumption of the Thirlwall model. If prices effects can work as an adjustment mechanism, we cannot directly define the equilibrium GDP growth rate compatible to external sector constraints. In this scenario, a country can grow in the long run at any rate if there are price effect mechanisms that allow it. If we accept this stylized fact, we find two alternatives. The first is to accept the neoclassical critiques to the Thirlwall model (Krugman, 1989; Rodrik, 2008), in which growth is supply-side dominated and given by a natural growth rate. The second is to expand the model to capture the short-term effects of terms of trade and financial flows on the long-run economic growth, as tried by Moreno-Brid (1998), Dutt (2002), Setterfield (2011), and Cimoli, Lima \& Porcile (2016).

Again, our critique is directly related to how we conceptualize long-run. If we accept the longrun as an equilibrium point to which assumptions such as zero growth in RER are valid, we analyze it in one specific way. But we can also perceive the long run as a convergence gravitational point to which the variables move (or oscillate) around, or as a succession of shortruns during a long amount of time (Robinson, 1971).

The main point here does not only concern definitions but also the relationship between the theoretical idea and the empirics of the estimated model. In the VECM we observe the presence of short- and long- run relations. We assume that the long run in theoretical and in empirical terms coincide in the VECM. This can be theoretically challenged, which again opens a space to question whether the concepts of short- and long-run match in theoretical and empirical terms.

\section{Answer to Research Question 3: Do increases in foreign income result in higher economic growth?}

Foreign income shocks can affect the whole dynamics of the economic system. It is a central variable in the Thirlwall Law, defining the growth rate of domestic GDP compatible with BP constraints. We consider foreign income as an exogenous variable in our analysis. The US GDP would be rarely affected by trade balance changes in Argentina or Brazil, or by investments shocks in Colombia and Mexico. The opposite is not true, as the US GDP is expected to have a relevant impact in its neighboring Latin American countries. Initially, our expectation is that foreign shocks would result in increases in domestic growth, especially in the long-run. As stated by the Thirlwall law, domestic growth in the long-run depends on the relationship between 
income elasticities (both positive) times foreign income. If foreign income increases, long-run growth should increase.

However, when looking at the permanent shocks results, we get opposite outcomes as expected. We bring Figure 4.42 and Figure 4.43 to highlight this effect. Foreign income reduces domestic income all countries (it only increases the GDP). This is true for both specifications.

Figure 4.42. Effects of Permanent Foreign

Growth shocks on Domestic Growth. 1950-

2014 (Specification 1)

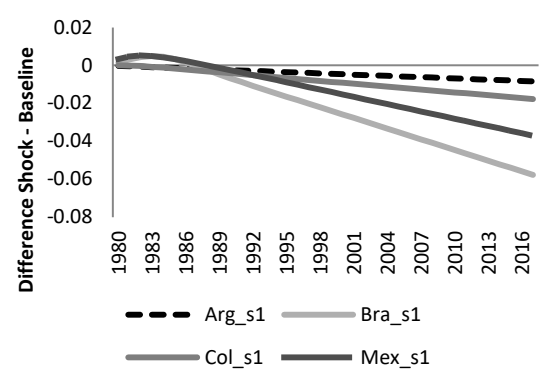

Data source: Penn World Tables
Figure 4.43. Effects of Permanent Foreign Growth shocks on Domestic Growth. 1950-

2014 (Specification 2)

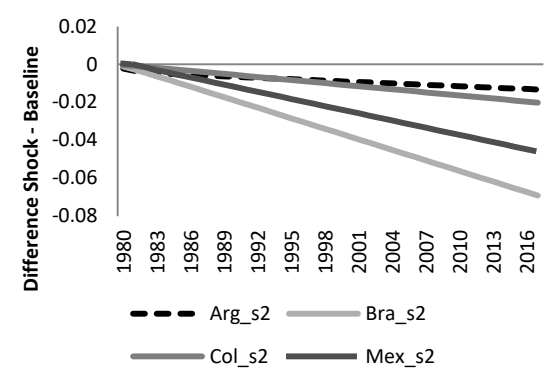

Data source: Penn World Tables

Initially, in specification 1, foreign growth has positive effects on domestic growth for all countries. However, it starts decreasing on time when shocks are permanent. The short-run effect can be positive, but the long-run are negative, and keep decreasing. For specification 2 it already starts decreasing since the first impact.

The implications of this outcome for the BPCM theory has already been discussed in the literature by Razmi (2016). The author showed that, when included domestic capital accumulation and controlled for endogeneity, foreign income has insignificant effects on domestic income. These results can be negative when looking at their correlation for some countries. 
Evidence around the role of foreign income on domestic GDP are still mixed, and the debate is still open, but our results clearly indicate that permanent increases in foreign income result in a decrease in domestic income for all countries. In terms of the impacts on the Thirlwall law, if we accept the law, these results indicate that the income elasticity ratio between exports and imports have a negative value, which does not make much sense in economic terms. An income increase will most certainly result in an increase in imports. In terms of exports, foreign growth may reduce domestic growth if income elasticity of exports shows a negative value, which can be caused by an exchange rate appreciation. However, this last case would affect the other assumption of the BPCM, in which prices would not be able to keep their long-run stability. This debate opens a large space to debate the causes of this negative relationship between foreign income and domestic income.

As already mentioned, these debates are not aimed at attacking or disproving the Thirlwall model, but to challenge it empirically in order to open the debate for new expansions that take into account these results, reinforcing the relevance of the model. The BPCM is a powerful and relevant framework to tackle the issue of uneven development, explaining why countries differ in terms of their growth rates in a demand-side perspective. We open the debate to other possible explanations, bringing elements related to the productive structure, mark-up, income distribution, among others. Topics modelled by authors from the Structuralist literature, such as Botta (2009); Blecker (2013), Cimoli \& Porcile (2010), (2014), Porcile \& Spinola (2018), among others.

\subsection{Conclusion}

In this research we discussed some of the main assumptions behind the BPCM. Our objective, far from challenging the model in order to question its validity, is to improve the debate behind this important growth model. The Thirlwall model focuses on the role of demand on growth, and explains through external constraints why countries differ in terms of their GDP growth patterns (uneven development).

We firstly raised the some main assumptions behind the Thirlwall model: (I) The trade balance is stable in the long-run; (II) Price effects do not affect long-run economic growth; (III) foreign growth has positive effects on domestic income. Secondly, we brought from the literature the 
most important critiques to the BPCM, deriving research questions, to empirically debate the assumptions of the BPCM model. From the literature review we enter into the methodological part. We gathered data from the PWT and searched for the best methodology to answer our research questions. From the literature we selected VECM methods, that are recently used in many empirical articles to measure income and price elasticities of imports and exports, such as Britto \& McCombie (2013), Moreno-Brid \& Pérez (1999), among other relevant works listed on Table 4.3. We create baselines using a Johansen Estimation framework (Johansen, 1991), with the use of VECM estimations. We check the short- and long-run relations of selected variables for Argentina, Brazil, Colombia, and Mexico. We applied temporary shocks using impulseresponse analysis, as well as permanent shocks. From the results we discussed the main research questions raised in this research.

Our results raise some important critiques on the assumptions of the model. There is mixed evidence for both of the two assumptions initially raised. In terms of the trade balance, we see that countries possibly converge to a long-run point (stability). However, during this convergence process we observe a systematic imbalance between the growth rate of imports and exports - which potentially invalidates the first assumptions. The way we interpret the concept of long run plays a central role: Is it the natural values of the variables (Samuelson, 1948) or is it related to a gravitational point to which the time series converge/divergence/oscillate (Kaldor, 1957; Pasinetti, 1983)? Does it concern the direction (slope) to which the time series are going? Or is it a systematic succession of short-run periods (Robinson, 1971)? We do not propose to state a final answer to these questions here in this article, but highlight that we need to discuss the concepts in the light of more elements, which are necessary to discuss the empirical evidence behind the BPCM assumptions. The idea of long-run present in empirical VECM models may differ from the theoretically raised in the BPCM.

Concerning the second assumption, about price effect neutrality in the long-run, we observe that (a) In all cases, there seems to be a convergence process of the real exchange rates to a specific long-run point (b) However, some countries systematically devaluate their currencies while others systematically appreciate them. If we consider that this structural behavior defines the long-run, we observe strong evidence against the second assumption. (c) real exchange rate devaluations affect long-run economic growth. We expected that long-run growth was not going 
to suffer any impact from short-run devaluations (impulse-response), but this is not what we see in the data. With these three observations we qualify the discussion about assumption 2, which defines the conditions behind the Thirlwall Law.

Prices not being stable in the long-run, the adjustments do not necessarily come from quantities, or growth rates. This would make the effective growth rate to be restricted not only by the growth rate compatible with balance of payments constraints, but also from price-effects. This results in a more complex environment for economic adjustment, in which price and quantities play a part in the adjustment process. These results strengthen the usual Structuralist argument of those that include terms of trade and financial flows as elements affecting the long-run economic growth rate (Cimoli et al., 2016; Dutt, 2002; Moreno-Brid, 1998; Setterfield, 2011).

For foreign income effects, we expected to observe that increases in foreign income would impact positively on domestic growth, as stated in the Thirlwall law. However, the results point in an opposite direction. In almost every permanent shocks scenario, an increase in foreign income initially results in domestic income growth, followed by a strong and permanent domestic GDP reduction. This result is in line to what Razmi (2016) had in his estimations. It is relevant to say that more empirical work is necessary on this regard. Razmi gives an initial contribution debating India, we enforce his argument with Latin American countries, however the effects of foreign demand shocks on the long-run equilibrium growth rate is matter that still needs further empirical research.

The three research questions in this empirical work successfully challenge the three assumptions of the BPCM. In one hand, this article is able to empirically reinforce some of the empirical critiques already stated in the literature, as well as offer new estimations of the BPCM for Latin America. On the other hand, the effects on the BPCM theory depend on other conceptual debates such as the concept of short- and long-run, as well as how the current empirical methods are suitable to question theoretical arguments. This work offers an invitation to expand this debate, both theoretically as empirically.

Finally, our estimation results aim to qualify the BPCM discussion and bring new elements to the debate. This paper is an effort to add elements to the empirical literature of the BPCM by testing its main assumptions. I emphasize again that our objective is not to challenge the validity of the 
model, but the robustness of some of its assumptions. In this sense, we would like to pose a challenge to further investigate the empirics of this model. Not only on estimating the income and price elasticities but also challenging what is behind the Thirlwall model. Our next steps aim to open the debate to find theoretical solutions to expand and reinvent the model, solving the empirical problems in an inductive way. We are very clear that we are limited by the data, by our methodology, and the choices in terms of countries. Nevertheless, the presence of this evidence lets us open the space for new propositions aimed at reinforcing the analysis in such a relevant model.

\section{Annex 4.1: The Thirlwall Model - Based on Thirlwall (1979)}

Exports: The quantity of exports demanded $(\mathrm{X})$ is a function of the price of exports (in foreign currency), the price of competitive exports goods, and the level of world income. We simplify the economy to one of homogeneous goods so we not consider the price of competitive goods. Thus:

(1) $X=\left(\frac{P_{f} E}{P_{d}}\right)^{v} Y_{f}^{\delta}$

Being $P=\frac{P_{f} E}{P_{d}}$, When converting to growth rates, the elasticities will play a central role defining the growth rate of exports:

(2) $\hat{X}=\delta \widehat{Y}_{f}+v \hat{P}$

Imports: The level of imports $(M)$ is a multiplicative function of the price of imports (measured in units of the home currency in order to incorporate the effect of exchange rate changes), the price of import substitutes, and domestic income $(Y)$. Not considering the price of import substitutes, the amount of exports is given by:

(3) $M=\left(\frac{P_{f} E}{P_{d}}\right)^{\mu} Y_{d}^{\varepsilon}$, in growth rates:

(4) $\widehat{M}=\varepsilon \widehat{Y_{d}}+\mu(\widehat{P})$

In equilibrium we have $\hat{X}=\widehat{M}$. The growth rate compatible with the equilibrium in the Balance of Payments then given as:

(5) ${\widehat{Y_{d}}}^{B P}=\frac{1}{\varepsilon}\left[\delta \widehat{Y}_{f}+\hat{P}(v-\mu)\right]$

As in the long-run $\widehat{P}=0$, we finally have:

(6) ${\widehat{Y_{d}}}^{B P}=\frac{\delta}{\varepsilon} \widehat{Y}_{f}$ 


\section{Conclusion}

This thesis contributes to the understanding of the causes behind endogenous volatility (cycles) in Latin America and the Caribbean (LAC). It is composed of four chapters, two empirical and two theoretical, in search for the elements that create a solid interpretation of the current economic oscillatory conditions that traps low- and middle- income countries in their current development situation.

The main debate surrounds macroeconomic volatility, a concept used in two senses: (1) as a thermometer that measures the resilience that countries suffer from economic, political and institutional shocks and (2) as a measurement of the endogenous debility and structural fragility that generate these oscillatory dynamics.

In this final section we bring the results for each chapter to answer the questions we posed in the introduction of this thesis and then present some final considerations. We proposed to measure and understand the pattern of economic endogenous volatility (cycles) in Latin America, trying to explain its main causes. Is LAC a special case in terms of economic volatility? And what is special about their cycles? Are there structural elements behind cycles? If yes what?

\section{Characteristics of the cyclical behavior of LAC}

In this research we observe the specificities of Latin America and the Caribbean (LAC) in terms of its cyclical components. The region can be sub-divided into two cyclical group categories the countries with dominance of long-run cycles and the ones in which the short-run cycles dominate the oscillatory movement. We present the main interpretation for the causes of each cycle discussed in chapter 1 .

In order to discuss the long-run cycles, we observe that LAC has a high presence in commodity exports. Changes in technological paradigm result in long-run cyclical oscillation in commodity prices. This is caused by a reduction in the dependence of previous industrial paradigm inputs, with effects on the exchange rate (Guzman et al., 2017). The emergence of a new technological paradigm requires new different inputs, resulting in a strong structural change. LAC economies 
adjust to the cycle and change the products in which they will specialize (if they have the possibility to do so), generating higher-amplitude long-run Kondratiev cyclical oscillation.

For the second group, a high volatility in the Juglar short-run type of cycle is related to investments, which are done in large blocks (big investments immobilize large quantities of capital). The uncertainty intrinsic in economic systems is higher in developing countries. This uncertain situation results in investments being made in periods in which there is a positive condition in the economic environment, commonly related to the ones that coincide with the rising part of commodity cycles. These cycles start maturing while environmental economic conditions of the system change. The reversal of investments coincides with a reduction in the environmental conditions, increasing uncertainty and raising the costs to make new investments. This is followed by a period with few demand pushes, resulting in a crisis.

These two groups cycle define the conditions of Latin American economies, and they are the ones we focus our analysis on in the rest of the analysis (chapters 2 and 3). We pay a special attention to the role of the long-run (LR) cycles, observing their main properties. As discussed above, the LR cycles are central in determining the overall volatility in Latin American countries (group 1). However, the characteristics we highlight in the models also apply for the short-run (SR). The transition dynamics between SR and LR are then a central aspect in the discussion - as observed in Chapter 2. In this sense, our analysis from now on applies for group 1, but also to the characteristics of Latin American countries in group 2, being consistent with a discussion about the whole region.

Another important feature about LAC economies appears when we calibrate the model parameters with values that represent a more fragile country. The economic system in this sense presents a much more intense cyclical adjustment (higher amplitude and more cycles), than the baseline calibrations presented in the original papers - La Marca (2010) and Dutt (2002) - which reinforces the argument about fragile structures leading to higher economic volatility.

\section{Theoretical Model and Empirics for Latin America}

In terms of the stylized facts, as we see in chapter 4, the results for LAC empirically challenge the assumptions of the BPCM: prices are not neutral in the long-run. In this sense, the economic 
adjustments do not necessarily come from quantities, or growth rates, which would make the effective growth rate to be restricted by the growth rate compatible with balance of payments constraints, but also from price-effects. This is a possible explanation of why LAC countries' growth rate have historically showed so many deviations between the predicted BP constrained growth rate and its actual growth rates (Thirlwall \& Hussain, 1982). This result means that there is a more complex environment for economic adjustment, in which price and quantities play a part in the adjustment process. We develop this part below in the final considerations.

These results strengthen the usual Structuralist argument of those that include structure, terms of trade and financial flows as important elements affecting the long-run economic growth rate of economic systems (Cimoli et al., 2016; Dutt, 2002; Moreno-Brid, 1998; Setterfield, 2011).

An interesting observation is that foreign income effects generate a strong and permanent reduction on domestic GDP. This contra-intuitive argument, which creates a theoretical conundrum in the Thirlwall Law, is in line to what Razmi (2016) had on his estimations. This is interesting as it contradicts most of the common sense about economic growth, as foreign demand shows a negative impact on domestic demand.

\section{Causes behind endogenous volatility}

We conclude from this study that structural elements are central to explain the causes of volatility. Endogenous volatility emerges not only (a) from the classic relationship between growth and distribution (Goodwin, 1967), but also from (b) the relationship between capacity utilization and economic structures à la Kaldor-Verdoorn, and (c) from the Structuralist-BPCM relationship between economic structures and external sector, as we can see in the development of the La Marca (2010) model. These relationships can be respectively explained by (I) A higher productivity that counter-balances the effects of a rise in capacity utilization (unemployment caused by improvements in technical progress). (II) The balance between external sector and economic structures, which has two main elements: first, the most productive firms from developing countries are attractive to large companies in the developed world aiming to acquire them; second, firms in developing countries find a barrier to their growth in productivity from technology transfer, as catching-up has its limits. 
From the expansion of the Dutt (2002) model, we see that the structural conditions also determine the pattern in which prices operate. There is a cyclical adjustment in which a country with specialized productive structure (commodity-based), with a low capacity to absorb foreign technology, presents a decline in its terms of trade, which reinforce a development trap (Lavopa $\&$ Szirmai, 2014) condition to this economy.

The expanded Dutt (2002) model has a pair of conjugate eigenvalues from its Jacobian matrix, showing the emergence of cycles with neutral stability. This means we have cycles that oscillate around the steady state without ever reaching it. This condition represents our central search for endogenous volatility in the relationship between economic activity, income distribution, terms of trade and productivity gap. In this sense, there is a mechanism that puts developing economies in a cyclical condition even in the absence of exogenous shocks, making volatility a structural characteristic of these economies.

The study, perspective, and arguments discussed in this thesis follow a New-Structuralist framework. This tradition is developed from the classic old structuralism of the Prebisch-Singer hypothesis, and from the center-periphery framework, associated to the Post-Keynesian Goodwin Cycles and the Balance of Payments Constraints tradition, as well as to the evolutionary Schumpeterian perspective. The choice for the New-Structuralist tradition is based on the understanding that this tradition allows us to interpret the peculiar challenges faced by developing (peripheral) countries, highlighting their peculiar characteristics in the context of the international division of labor. At the same time the tradition brings supply (Evolutionary) and demand-side (Post-Keynesian) elements to the macroeconomic debate.

After answering the more general research questions, we summarize below the main questions, methods and results for each chapter. 
Figure 5.1. Chapters, research questions and main conclusions.

\begin{tabular}{|c|c|c|c|c|}
\hline & Chapter 1 & Chapter 2 & Chapter 3 & Chapter 4 \\
\hline Type of analysis & Empirical & Theoretical & Theoretical & Empirical \\
\hline Data Source & $\begin{array}{l}\text { Maddison Project } \\
\text { Database }\end{array}$ & $\begin{array}{l}\text { Calibrations from the } \\
\text { La Marca (2010) } \\
\text { model }\end{array}$ & $\begin{array}{l}\text { Calibrations for an } \\
\text { industrial economy } \\
\text { versus a developing } \\
\text { one. }\end{array}$ & Penn World Tables \\
\hline Countries & $\begin{array}{l}136 \text { countries, } \\
\text { focus on Latin } \\
\text { America and } \\
\text { Caribbean (LAC) }\end{array}$ & $\begin{array}{l}\text { Middle income } \\
\text { countries }\end{array}$ & $\begin{array}{l}\text { Developed country } \mathrm{x} \\
\text { developing one }\end{array}$ & $\begin{array}{l}\text { Argentina, Brazil, } \\
\text { Mexico and } \\
\text { Colombia }\end{array}$ \\
\hline Methodology & $\begin{array}{l}\text { Filter analysis } \\
\text { (Asymmetric } \\
\text { Band-Pass Filter) } \\
\text { and Cluster } \\
\text { Analysis (K- } \\
\text { Means) } \\
\end{array}$ & $\begin{array}{l}\text { Multi-dimensional } \\
\text { Dynamical System }\end{array}$ & $\begin{array}{l}\text { Multi-dimensional } \\
\text { Dynamical System }\end{array}$ & $\begin{array}{l}\text { Vector Error } \\
\text { Correction Model } \\
\text { (VECM), Impulse- } \\
\text { Response Analysis. }\end{array}$ \\
\hline Theoretical basis & Cycle theory & $\begin{array}{l}\text { Structuralist } \\
\text { Goodwin model }\end{array}$ & $\begin{array}{l}\text { BPCM and the } \\
\text { Prebisch-Singer } \\
\text { hypothesis (PSH) }\end{array}$ & $\begin{array}{l}\text { BPCM assumptions, } \\
\text { impacts of shocks on } \\
\text { macro variables }\end{array}$ \\
\hline $\begin{array}{l}\text { Main research } \\
\text { Question }\end{array}$ & $\begin{array}{l}\text { LAC special in } \\
\text { terms of cycles? }\end{array}$ & $\begin{array}{l}\text { Endogenous } \\
\text { volatility: Goodwin } \\
\text { cycles reproducible } \\
\text { with productive } \\
\text { structure in an open } \\
\text { economy with BPC? }\end{array}$ & $\begin{array}{l}\text { PSH compatible with } \\
\text { the BPCM? }\end{array}$ & $\begin{array}{l}\text { Are the BPCM } \\
\text { assumptions } \\
\text { observed } \\
\text { empirically? }\end{array}$ \\
\hline Main Conclusion & $\begin{array}{l}\text { LAC has its } \\
\text { specificities. It can } \\
\text { be divided in two } \\
\text { groups (Juglar- } \\
\text { dominance and } \\
\text { Kondratiev- } \\
\text { dominance). } \\
\text { LAC not more } \\
\text { volatile than other } \\
\text { developing regions }\end{array}$ & $\begin{array}{l}\text { Structure matters } \\
\text { when related to } \\
\text { growth and external } \\
\text { sector. } \\
\text { We could not find } \\
\text { cycles with neutral } \\
\text { stability, only } \\
\text { dampened cycles. }\end{array}$ & $\begin{array}{l}\text { PSH and BPCM ate } \\
\text { compatible. We can } \\
\text { have the PS } \\
\text { hypothesis with } \\
\text { Balance of Payments } \\
\text { Constraints in } \\
\text { developing countries. } \\
\text { We find neutral } \\
\text { stability cycles. }\end{array}$ & $\begin{array}{l}\text { The BPCM can be } \\
\text { empirically } \\
\text { challenged. We see } \\
\text { that prices have a } \\
\text { tendency to stabilize } \\
\text { in the long run but at } \\
\text { values different than } \\
\text { zero. Exports and } \\
\text { imports do not grow } \\
\text { at the same rate. } \\
\text { Foreign growth with } \\
\text { negative impact on } \\
\text { domestic growth. }\end{array}$ \\
\hline
\end{tabular}




\section{Final Considerations}

In this thesis we presented results in both theoretical and empirical terms. First, we challenged the usual Structuralist argument in which Latin America and the Caribbean (LAC) are claimed to be the most volatile region in the world. That is not what our data shows. The LAC region is in the average of the distribution when observing the list from the least to the most volatile regions. The LAC region shows a different behavior than developed countries. However, when comparing it to other developing regions, the degree of volatility is not that different, despite LAC having some particular and specific characteristics. In terms of cycles, LAC shows the presence of a regional dynamics. However, the region is not entirely homogeneous in terms of its cyclical characteristics. As we observed, there are two main cycle groups in the LAC countries, one dominated by the short-run cycles, and other by the long-run cycles, both covered in the studies presented in Chapters 2 to 4 .

In terms of LAC volatility and fragility, when we simulated in Chapter 3 our models using calibrated values that could reproduce a more fragile (Latin American) economy, we saw an increase in the amplitude of the oscillations (when compared to the baselines). This indicated the role of structural fragilities in the region as a cause of this higher volatility. This fragility, further discussed in the rest of the thesis, is fundamentally linked to the conditions of the productive structure of these economies.

Another important finding: increases in fragility resulted in a steady decline in the terms of trade for developing countries (in comparison to the developed ones). The relationship between volatility and structures showed feedback effects that reinforce a situation of development trap. Weak structures generate higher volatility. That reinforces the specialization and makes the structure even more fragile. Then the terms of trade decline and growth is even more constrained in developing countries, reinforcing a vicious causation.

In terms of a Structuralist reading of the Thirlwall law, fragility is related to learning and structural change. Those aspects are usually brought into the BPCM by endogenizing income elasticities of imports and exports. We offered a different approach here, filling a research gap. In our expanded version of the BPCM, the Prebisch-Singer hypothesis was reproduced from the expanded Thirlwall framework by adding a dynamic system that shows the trajectory between 
the short and the long run. This distinct approach is central because it allows us to work with the important matters of transition dynamics and uneven development.

A central debate in the thesis concerns the concept of long-run. In summary, the long run can be explained as: (1) the natural values of the variables (Samuelson, 1948), by (2) a gravitational point to where the time series converge/divergence/oscillate (Kaldor, 1957; Pasinetti, 1983) or by (3) a systematic succession of short-run periods (Robinson, 1971). The way we dealt with the concept affected how we interpreted the results of our analysis and the theoretical critiques we posed in the thesis. We used the distinct concepts of long-run to defend the VECM analysis as an important way to challenge the assumptions of the BPCM.

Concerning the external conditions, we observed that the LAC region is directly affected by its position in the international division of labor. This is defined by the specialization pattern in the production and export of particular (commodity) products. The idea of a center-peripheral system, which is at the base of the Structuralist tradition, is fundamental in our perspective, as well as the presence of external constrains in the process of economic development presented by the Post-Keynesian dynamics of the BPCM. The particular peripheral condition is a problem related to the lack of proper strong and resilient economic structures in the country, in which we can observe by the looking at the productive structure and the degree of technological conditions - relevant elements of the Evolutionary (Neo-Schumpeterian) theory. In order to understand the causes of the endogenous volatility, we bring elements of these three theories, advancing the discussion helping the development of a New-Structuralist framework.

Concerning theoretical aspects, we advanced the theory by expanding two important Goodwintype models - the La Marca (2010) model and the Dutt (2002) model. The addition of a supply side structure in these demand-sided models generated interesting new patters of economic adjustment. The expansions showed that endogenous volatility and economic structures were directly interrelated, as the productive structure interacted with economic activity and income distribution through the addition of productivity and technological catching-up variables to the model. The presence of stable cycles, especially in the Dutt (2002) expansion, showed that volatility is not a matter of exogenous shocks, but it is a central element, an intrinsic part of developing economies. The discussion of endogenous volatility is fundamental in this regard, as volatility is not a matter of recurrent external shocks, but part of the dynamics of developing 
economies. It is part of their "DNA" - related to the economic history and the institutional aspects that are characteristic of these economies.

Concerning the endogenous cycles, they initially emerged from the relationship between distribution (profit share) and employment rate (economic activity) - taken from the Goodwin theory. This cyclical relationship affected the dynamics of the terms of trade, which cyclically adjusted to its equilibrium rate of growth. When we fixed the income distribution and the real exchange rate, cycles gave rise to a monotonic trajectory. In the case of the real exchange rate, there were costs in terms of the steady state, reducing the equilibrium values of the wage share and the capacity utilization. The final result was that the smaller volatility achieved when fixing the real exchange rate involves a trade-off with a reduction in the economic activity and income concentration on profits.

Concerning the productivity dynamics, its inclusion generated new sources of volatility in the relationship between capacity utilization, income distribution, net external assets, and economic structures. We observed the emergence of two new sources of cyclical volatility: (I) the relationship between economic activity (capacity utilization) and economic structures (productivity) - productivity has a counterbalancing effect on utilization capacity (the more productive firms are, the smaller the number of workers needed to be employed to maintain the same level of production). (II) the relationship between economic structures and external sector, in which internationalization brings productivity up, but offers some challenges to local firms maintaining their catching-up strategy and not to be taken-over developed countries' firms.

The results indicate that even the simple inclusion of a productivity dynamics is able to, even under very specific conditions, generate deterministic stable cycles. This is of fundamental importance, as it shows that in the absence of shocks, the system is still inherently and endogenously oscillatory. Increases in productivity and a virtuous technological catching-up occur when (i) a southern country presents a virtuous structural change towards more productive sectors and (ii) when there are better conditions to benefit from learning opportunities. A virtuous catching-up strategy reduces volatility. Increases in industrialization, and higher learning efforts, generate a higher growth pattern, with increases in the terms of trade, reduction in the technology catching-up, and smaller volatility when compared to the falling behind scenario. 
Concerning the problem of development traps and the terms of trade, the more fragile economy presents higher volatility. This leads to a decline in the terms of trade, reinforcing the problem of the development trap. In this sense, we can pose the question on how to reduce the structural fragility, advancing in the construction of a strong and resilient structure, overcoming the trap? There is no easy answer to that, considering that an economy is a complex element of the society, being the reflex of history, political economy, institutional, beside other social elements that are above a pure economist-based analysis. However it is a valid and important question to think about economic policy and political implications in this context - which we would argue should focus on the structural aspects of these economies, and not only on the short-run conditions, reducing these countries' external fragility and their growth volatility. There is a large scope to explore proper policy recommendations from the results of this thesis, which is in the agenda for future research.

Concerning the assumptions of the model, this thesis' results have some important implications to the theoretical literature. We questioned some fundamental elements that are in the basis of the BPCM, one of the most relevant demand-led growth models. The main debate concerned two elements: (a) the determinants of long-run economic growth, and (b) the transition between short- and long-run. The Thirlwall Law claims that only quantities impact the long-run adjustments (observed GDP growth rate have to adjust to the rate compatible with constraints in the Balance of Payments - the long-run economic growth rate). We empirically showed that price changes do show impacts in the long run. This result partially explains why the estimations for the BPCM long-run economic growth in developing countries are not that precise when compared to the real observed values.

As prices are not stable in the long-run, the adjustments do not necessarily come from quantities (growth rates), which would make the effective growth rate directly restricted by the growth rate compatible with the balance of payments equilibrium. Adjustment also comes from price-effects. This results in a more complex environment for economic adjustment, in which price and quantities play a part in the adjustment process. This strengthens the usual Structuralist argument, as real exchange rate and financial flows do play a role in adjusting and defining the long-run economic growth rate. 
We challenged the price-neutrality argument, empirically observing how it affected long-run economic growth in Latin American countries. We observed a convergence process of the real exchange rate. Some countries systematically devaluated their currencies while others systematically appreciated them. If this structural behavior defines the long-run, we have evidence against the price-neutrality assumption, and that the exchange rate does affect the economic system. Changes in the real exchange rate value affect the long-run economic growth, but the direction of the effect would differ from on country to the other. Traditions such as the new developmentalist theory would argue that the level (not only the rate of change) of the real exchange rate also affect the long-run economic growth and the economic structures - as devaluations raise the competitiveness, changing structures and raising the long-run economic growth rate.

For the BPCM theorists, accepting price non-neutrality is a return to the neoclassical world in which prices adjust the model to the equilibrium. This research offers an alternative to question the price assumption while remaining in the Post-Keynesian demand-side world.

It is important to mention about the nature of our empirical work. We were not particularly interested in the current value of our estimations for the income and price elasticity of imports and exports. We follow a distinct approach from the usual empirical BPCM tradition. Our concern was to challenge the assumptions of the model, checking if they hold or not. The answer to our theoretical questions impacts the interpretation of these models. In this way, we could better assess the causes of endogenous volatility in Latin America based on the BPCM, while questioning the theoretical aspects that are on the base of this interpretation.

There is a long path to move forward in the development of the emerging New-Structuralist tradition, in which we would like to offer a small contribution. It is relevant to debate, in a structural sense, the south-south conditions in the context of global value chains, understand the lack of capacity and capabilities in a knowledge-intensive productive structure, tackle the difficulties in developing mature National Systems of Innovation in developing countries, as well as their lack of institutional adequate conditions, among many other challenges which are in an agenda of future research.

The methodology here developed can be used as a baseline for posterior development. We offer an invitation to those interested in understanding the causes of endogenous volatility in Latin 
America to further expand and test the models developed in this thesis. We also presented and analyzed some theoretical problems in the transition dynamics of growth models that deserve a whole research agenda. In this sense, there is a large scope for methods and theory to be further developed.

Finally, we emphasize that, despite the strong focus on methodology, the main debate of this thesis is focused on economic development and how to overcome developing traps created by economic volatility. Besides the theoretical curiosity, our intent, above all, was to bring more debate to understand some specific challenges faced by developing economies in their development process, offering inputs to think of ways to overcome these development challenges.

\section{$\underline{\text { Reflexions on Tentative Policy Recommendations }}$}

We argue in this thesis that there are endogenous and exogenous causes why volatility persists, which is directly related to the laggard economic structures, lack of innovative capacity, and specialization in low tech sectors, that creates external constrains to the developing economies. The persistence of oscillations has a reinforcement mechanism, pushing the structures to further specialization, in a vicious causation mechanism.

This diagnostic open the door for policy recommendations, focused on breaking the vicious causation that traps Latin American economies into under development. In Chapters 2 and 3 we investigate the causes of endogenous volatility by expanding existing Structuralist models. The results point to the need of focusing policies in the supply and the demand side of the economy. In the supply side we propose policies to foster the absorptive and innovative capacity of the Latin American economies, as well as focusing macroeconomic management in the direction of balancing stability with developing a stronger industrial sector, competitive in international terms, such as the strategy followed by East Asian countries.

On the demand side, social policies that reduce income inequality are fundamental to reduce poverty, tackle volatility, and create the necessary effective demand to advance with the development strategy. This has been successfully done with policies such as the conditional cash transfers and real increases in minimum wages - however, there have been only short-term 
impacts on these policies. Our recommendation is to focus on a mix between short and long run effects, with social investments in public health and public education, housing, and employment strategies - such as the employer of last resort program (Wray, 2007).

In this sense, Latin American countries can reduce their external constrains, at the same time push towards more inclusive societies.

Those general recommendations can be addressed using recent frameworks such as the missionoriented innovation policies, addressing the structural failures on important sectors for the Latin American economies. This aims to strategic public sector investment to increase economic activity, spark innovation, solve public problems, and lay the foundations for future economic growth (Mazzucato, 2018). The choice of sectors can go to a strategy that focuses on natural resource industrialization, or on higher-technology intensive sectors. Based on the ideas of external constrains and volatility of commodity prices, we recommend to focus on sectors that demands higher technology intensive, but closer to the manufacturing sector, generating local spillovers and a more consistent productive structure.

Nonetheless, a central message of this thesis resides in the difficulties in establishing such policies in volatile countries. This is more dramatic considering the scarcity of resources needed for such strategies, which are only available during periods of boom, and that are commonly used to maintain an overvalued exchange rate, improving local living standards in the short run in lieu of the competitiveness of the productive structure in the long run, forcing strong adjustments in the recession period. We recommend focusing on strategies that avoid falling into this common pro-cyclical behavior, creating an anti-cyclical policy that smooth cycles, allowing developing countries to advance with long term strategies, as the ones discussed above.

Another difficulty is related to the role of the State in society, and what drives its behavior. Policy recommendations need to take into account the social forces that drive State decisions. Assuming an independent role of government decision, only based on technical recommendations can be understood as naïve, especially in the context of unequal societies, politically unstable, such as the Latin American ones, in which social groups and local elites have historically presented a narrow short term perspective. 


\section{References}

Abramovitz, M. (1961). The Nature and Significance of Kuznets Cycles. Economic Development and Cultural Change, 9, 225-248.

Abramovitz, M. (1969). The Passing of the Kuznets Cycle: A Correction. Economica, 36.

Acemoglu, D., \& Robinson, J. A. (2012). Why nations fail: The origins of power, prosperity, and poverty. Crown Books.

Alonso, J. A., \& Garcimartín, C. (1998). A New Approach to Balance-of-Payments Constraint: Some Empirical Evidence. Journal of Post Keynesian Economics, 21, 259-282.

Álvarez-Ude, G. F., \& Gómez, D. M. (2008). Long- and short-run balance of payments adjustment: Argentine economic growth constrained. Applied Economics Letters, 15, $815-820$.

Andrade, R. P., \& Prates, D. M. (2013). Exchange rate dynamics in a peripheral monetary economy. Journal of Post Keynesian Economics, 35, 399-416.

Barbosa-Filho, N. H., \& Taylor, L. (2006). Distributive and Demand Cycles in the US Economy—a Structuralist Goodwin Model. Metroeconomica, 57, 389-411.

Berg, A., Ostry, J., \& Zettelmeyer, J. (2012). What makes growth sustained? Journal of Development Economics, 98, 149-166.

Bertola, L., Higachi, H., \& Porcile, G. (2002). Balance-of-payments-constrained growth in Brazil: A test of Thirlwall's Law, 1890-1973. Journal of Post Keynesian Economics, 25, 123-140.

Bertola, L., \& Ocampo, J. A. (2012). The Economic Development of Latin America since Independence. Oxford University Press.

Bhaduri, A., \& Marglin, S. (1990). Unemployment and the real wage: The economic basis for contesting political ideologies. Cambridge Journal of Economics, 14, 375-393.

Bielschowsky, R., Torres, M (2018). Desarrollo e igualdad: El pensamiento de la CEPAL en su séptimo decenio. Textos seleccionados del periodo 2008-2018. CEPAL.

Blanchard, O. J., \& Gali, J. (2007). The Macroeconomic Effects of Oil Shocks: Why are the 2000s So Different from the 1970s? (Working Paper No. 13368). National Bureau of Economic Research. 
Blecker, R. (2013). Long-Run Growth in Open Economies: Export-Led Cumulative Causation or a Balance-of-Payments Constraint? In: Oxford Handbook of Post-Keynesian Economics. Oxford University Press.

Blecker, R. (2016). The debate over 'Thirlwall's law': Balance-of-payments-constrained growth reconsidered*. European Journal of Economics and Economic Policies: Intervention, 13, 275-290.

Bluhm, R., de Crombrugghe, D., \& Szirmai, A. (2019). Do Weak Institutions Prolong Crises? On the Identification, Characteristics, and Duration of Declines during Economic Slumps. The World Bank Economic Review.

Bolt, J., \& Zanden, J. L. van. (2014). The Maddison Project: Collaborative research on historical national accounts. The Economic History Review, 67, 627-651.

Bosserelle, É. (2015). Mouvements longs Kondratieff, transformations institutionnelles et performances du capitalisme, Kondratieff long-waves, institutional transformations and performances of capitalism. Revue Française de Socio-Économie, 283-298.

Bossier, F., \& Huge, P. (1981). Une vérification empirique de l'existence de cycles longs à partir de données belges. Brussels Economic Review, 90, 253-267.

Botta, A. (2009). A structuralist North-South model on structural change, economic growth and catching-up. Structural Change and Economic Dynamics, 20(1), 61-73.

Botta, A. (2010). Economic development, structural change and natural resource booms: a structuralist perspective. Metroeconomica, 61(3), pp.510-539.

Bowles, S., \& Boyer, R. (1988). Labor Discipline and Aggregate Demand: A Macroeconomic Model. The American Economic Review, 78, 395-400.

Bresser-Pereira, L. C., Oreiro, J. L., \& Marconi, N. (2014). Developmental Macroeconomics: New Developmentalism as a Growth Strategy. Routledge.

Britto, G., \& McCombie, J. S. L. (2013). Thirlwall's law and the long-term equilibrium growth rate: An application to Brazil. An addendum. Journal of Post Keynesian Economics, 35, 695-696.

Caldentey, E. P., \& Vernengo, M. (2010). Back to the future: Latin America's current development strategy. Journal of Post Keynesian Economics, 32, 623-644. 
Cardoso, F. H. (1982). Dependency and Development in Latin America. In Sociology of "Developing Societies." Introduction to the Sociology of "Developing Societies" (pp. 112-127). Palgrave, London.

Carvalho, F. (1984). Alternative Analyses of Short and Long Run in Post Keynesian Economics. Journal of Post Keynesian Economics, 7, 214-234.

Christiano, L. J., \& Fitzgerald, T. J. (2003). The Band Pass Filter*. International Economic Review, 44, 435-465.

Ciarli, T., Lorentz, A., Savona, M., \& Valente, M. (2010). The Effect of Consumption and Production Structure on Growth and Distribution. A Micro to Macro Model. Metroeconomica, 61, 180-218.

Cimoli, M. (1988). Technological Gaps and Institutional Asymmetries in a North-South Model with a Continuum of Goods. Metroeconomica, 39, 245-274.

Cimoli, M., Lima, G. T., \& Porcile, G. (2016). The production structure, exchange rate preferences and the short-run-Medium-run macrodynamics. Structural Change and Economic Dynamics, 37, 13-26.

Cimoli, M., \& Porcile, G. (2010). Specialization, Wage Bargaining and Technology in a Multigoods Growth Model. Metroeconomica, 61, 219-238.

Cimoli, M., \& Porcile, G. (2014). Technology, structural change and BOP-constrained growth: A structuralist toolbox. Cambridge Journal of Economics, 38, 215-237.

Cimoli, M., Porcile, G., \& Rovira, S. (2010). Structural change and the BOP-constraint: Why did Latin America fail to converge? Cambridge Journal of Economics, 34, 389-411.

Clavijo Cortes, P. H., \& Ros Bosch, J. (2015). La Ley de Thirlwall: Una lectura crítica. Investigación Económica, 74, 11-40.

Comin, D., \& Gertler, M. (2003). Medium Term Business Cycles. National Bureau of Economic Research.

Cortes, P. H. C., \& Bosch, J. R. (2015). La Ley de Thirlwall: Una lectura crítica. Investigación Económica, 74, 11-40.

Davidson, P. (1980). Causality in Economics: A Review. Journal of Post Keynesian Economics, $2,576-584$.

Davidson, P. (1990). A Post Keynesian Positive Contribution to "Theory." Journal of Post Keynesian Economics, 13, 298-303. 
Davidson, P. (1997). Minisymposium on Thirlwall's law and economic growth in an openeconomy context: Introduction. Journal of Post Keynesian Economics; Armonk, 19, 311.

Diebolt, C., \& Doliger, C. (2008). New international evidence on the cyclical behaviour of output: Kuznets swings reconsidered. Quality \& Quantity, 42, 719-737.

Dornbusch, R. (1992). The Case for Trade Liberalization in Developing Countries. Journal of Economic Perspectives, 6, 69-85.

Dosi, G., Fagiolo, G., \& Roventini, A. (2010). Schumpeter meeting Keynes: A policy-friendly model of endogenous growth and business cycles. Journal of Economic Dynamics and Control, 34, 1748-1767.

Drehmann, M., Borio, C. E. V., \& Tsatsaronis, K. (2012). Characterising the Financial Cycle: Don't Lose Sight of the Medium Term! (SSRN Scholarly Paper No. ID 2084835). Rochester, NY: Social Science Research Network.

Dutt, A. K. (2002). Thirlwall's Law and Uneven Development. Journal of Post Keynesian Economics, 24, 367-390.

Eichengreen, B., \& Hausmann, R. (2010). Other People's Money: Debt Denomination and Financial Instability in Emerging Market Economies. University of Chicago Press.

Elish, E. (2018). An Examination of the Empirical Validity of the Thirlwall 'Law': The Case of Egypt. International Journal of Business and Economics Research, 7, 203.

Erten, B., \& Ocampo, J. A. (2013). Super Cycles of Commodity Prices Since the Mid-Nineteenth Century. World Development, 44, 14-30.

Fajnzylber, F. (1990). Industrialización en América Latina: De la caja negra" al "casillero vacio": comparación de patrones contemporáneos de industrialización". CEPAL.

Feenstra, R. C., Inklaar, R., \& Timmer, M. P. (2015). The Next Generation of the Penn World Table. American Economic Review, 105, 3150-3182.

Felipe, J., Abdon, A., \& Kumar, U. (2012). Tracking the Middle-Income Trap: What is it, Who is in it, and Why? (SSRN Scholarly Paper No. ID 2049330). Rochester, NY: Social Science Research Network.

Felipe, J., Kumar, U., \& Galope, R. (2017). Middle-income transitions: Trap or myth? Journal of the Asia Pacific Economy, 22, 429-453.

Ffrench-Davis, R., \& CEPAL, N. (2005). Macroeconomía, comercio y finanzas para reformar las reformas en América Latina. CEPAL. 
Foley, D., \& Taylor, L. (2004). A Heterodox Growth and Distribution Model. Economic growth and distribution: on the nature and causes of the wealth of nations, 75-99.

Foster-McGregor, N., Kaba, I., \& Szirmai, A. (2015). Structural change and the ability to sustain growth (MERIT Working Paper No. 048). United Nations University - Maastricht Economic and Social Research Institute on Innovation and Technology (MERIT).

Furtado, C. (1965). Development and stagnation in Latin America: A structuralist approach. Studies in Comparative International Development, 1, 159-175.

Gabriel, L. F., Jayme, F. G., \& Oreiro, J. L. (2016). A North-South Model of Economic Growth, Technological Gap, Structural Change and Real Exchange Rate. Structural Change and Economic Dynamics, 38, 83-94.

Gaffeo, E., Gallegati, M., Giulioni, G., \& Palestrini, A. (2008). Emergent Macroeconomics: An Agent-Based Approach to Business Fluctuations. New Economic Windows. Springer.

Gallegati, M., Gallegati, M., Ramsey, J. B., \& Semmler, W. (2017). Long waves in prices: New evidence from wavelet analysis. Cliometrica, 11, 127-151.

Gandolfo, G. (1971). Economic Dynamics: Methods and Models. Elsevier.

Gavin, M., \& Hausmann, R. (1998). Macroeconomic Volatility and Economic Development. In S. Borner \& M. Paldam (Eds.), The Political Dimension of Economic Growth: Proceedings of the IEA Conference held in San José, Costa Rica (pp. 97-116). London: Palgrave Macmillan UK.

Glawe, L., \& Wagner, H. (2016). The Middle-Income Trap: Definitions, Theories and Countries Concerned-A Literature Survey. Comparative Economic Studies, 58, 507-538.

Goodwin, R. M. (1967). A Growth Cycle. In Essays in Economic Dynamics (pp. 165-170). Palgrave Macmillan, London.

Guzman, M., Ocampo, J. A., \& Stiglitz, J. E. (2017). Real Exchange Rate Policies for Economic Development (Working Paper No. 23868). National Bureau of Economic Research.

Habiyaremye, A. and Ziesemer, T.H. (2012). Export demand elasticities and productivity as determinants of growth: estimates for Mauritius. Applied Economics, 44(9), pp.11431158 .

Hallonsten, J.S. and Ziesemer, T.H. (2019). A semi-endogenous growth model with public factors, imported capital goods, and limited export demand for developing countries. Journal of Applied Economics, 22(1), pp.380-402. 
Hamilton, J. D. (2017). Why You Should Never Use the Hodrick-Prescott Filter. Review of Economics and Statistics, 100(5), pp.831-843.

Harvey, D. I., Kellard, N. M., Madsen, J. B., \& Wohar, M. E. (2010). The Prebisch-Singer Hypothesis: Four Centuries of Evidence. The Review of Economics and Statistics, 92, $367-377$.

Hausmann, R., \& Gavin, M. (2011). Securing Stability and Growth in a Shock Prone Region: The Policy Challenge for Latin America. Inter-American Development Bank Working Paper n.259.

Hodrick, R. J., \& Prescott, E. C. (1997). Postwar U.S. Business Cycles: An Empirical Investigation. Journal of Money, Credit and Banking, 29, 1-16.

Holland, M., Vieira Vilela, F., \& Canuto, O. (2004). Economic Growth and the Balance-ofPayments Constraint in Latin America. Investigación Económica, 247, 45-74.

Houthakker, H. S., \& Magee, S. P. (1969). Income and Price Elasticities in World Trade. The Review of Economics and Statistics, 51, 111-125.

Jadevicius, A., \& Huston, S. (2014). A "family of cycles" - major and auxiliary business cycles. Journal of Property Investment \& Finance, 32, 306-323.

Johansen, S. (1991). Estimation and Hypothesis Testing of Cointegration Vectors in Gaussian Vector Autoregressive Models. Econometrica, 59, 1551-1580.

Kaldor, N. (1954). The Relation of Economic Growth and Cyclical Fluctuations. The Economic Journal, 64, 53-71.

Kaldor, N. (1957). A Model of Economic Growth. The Economic Journal, 67, 591-624.

Kaldor, N. (1975). Economic Growth and the Verdoorn Law: A Comment on Mr Rowthorn's Article. The Economic Journal, 85, 891-896.

Kalecki, M. (1971). Selected essays on the dynamics of the capitalist economy 1933-1970. Cambridge University Press.

Keynes, J. M. (1936). General Theory Of Employment, Interest And Money. London: Macmillan.

Kitchin, J. (1923). Cycles and Trends in Economic Factors. The Review of Economics and Statistics, 5, 10-16.

Koren, M., \& Tenreyro, S. (2007). Volatility and Development. The Quarterly Journal of Economics, 122, 243-287. 
Korotayev, A. V., \& Tsirel, S. V. (2010). A Spectral Analysis of World GDP Dynamics: Kondratieff Waves, Kuznets Swings, Juglar and Kitchin Cycles in Global Economic Development, and the 2008-2009 Economic Crisis. Structure and Dynamics, 4(1).

Kriegel, H.-P., Kröger, P., \& Zimek, A. (2009). Clustering High-dimensional Data: A Survey on Subspace Clustering, Pattern-based Clustering, and Correlation Clustering. ACM Transactions on Knowledge Discovery from Data (TKDD), 3, 1-58.

Krugman, P. (1989). Differences in income elasticities and trends in real exchange rates. European Economic Review, 33, 1031-1046.

Krugman, P., \& Venables, A. J. (1995). Globalization and the Inequality of Nations. The Quarterly Journal of Economics, 110, 857-880.

Kuznets, S. (1940). Schumpeter's Business Cycles. The American Economic Review, 30, $257-$ 271.

La Marca, M. (2010). Real Exchange Rate, Distribution and Macro Fluctuations in ExportOriented Economies. Metroeconomica, 61, 124-151.

Lavopa, A., \& Szirmai, A. (2014). Structural modernization and development traps: An empirical approach. (UNU-MERIT Working Paper; No. 076)

Lee, K. (2013). Schumpeterian analysis of economic catch-up: Knowledge, path-creation, and the middle-income trap. Cambridge University Press

Lewis, W. A. (1954). Economic Development with Unlimited Supplies of Labour. The Manchester School, 22, 139-191.

Lima, G. T., \& Carvalho, V. R. (2008). Macrodinâmica do produto sob restrição externa: A experiência brasileira no período 1930-2004. Economia Aplicada, 12, 55-77.

López G., J., \& Cruz B., A. (2000). “Thirlwall's Law” and Beyond: The Latin American Experience. Journal of Post Keynesian Economics, 22, 477-495.

López, P., \& Thirlwall, A. (2006). Trade liberalization, the income elasticity of demand for imports, and growth in Latin America. Journal of Post Keynesian Economics, 29, 41-61.

Lorenz, H.-W. (1989). Nonlinear dynamical economics and chaotic motion. Berlin; New York: Springer-Verlag.

Lorentz, A., Ciarli, T., Savona, M., \& Valente, M. (2016). The effect of demand-driven structural transformations on growth and technological change. Journal of Evolutionary Economics, 26(1), 219-246. 
Maddison, A. (2001). The world economy: A millennial perspective. Paris, France: Development Centre of the Organisation for Economic Co-operation and Development.

Maddison, A. (2003). Development Centre Studies The World Economy Historical Statistics: Historical Statistics. OECD Publishing.

Marglin, S. A., \& Schor, J. B. (1992). The Golden Age of Capitalism: Reinterpreting the Postwar Experience. Oxford University Press.

Mazzucato, M., 2018. Mission-oriented innovation policies: challenges and opportunities. Industrial and Corporate Change, 27(5), pp.803-815.

Mccombie, J. S. L. (1981). Are international growth rates constrained by the balance of payments? A comment on Professor Thirlwall. PSL Quarterly Review, 34, 4550458.

Mccombie, J. S. L. (1989). 'Thirlwall's Law' and balance of payments constrained growth - a comment on the debate.' Applied Economics, 21, 611-629.

McCombie, J. S. L., \& Thirlwall, A. P. (1994). Economic Growth and the Balance-of-Payments Constraint. London: Palgrave Macmillan UK.

McCombie, J. S. L. (2012). Criticisms and Defences of the Balance of Payments Constrained Growth Model: Some Old, Some New. In E. Soukiazis \& P. A. Cerqueira (Eds.), Models of Balance of Payments Constrained Growth: History, Theory and Empirical Evidence (pp. 50-82). London: Palgrave Macmillan UK.

McCombie, J. S. L. \& Spreafico, M. R. M. (2016). Kaldor's 'technical progress function' and Verdoorn's law revisited. Cambridge Journal of Economics, 40, 1117-1136.

McCombie, J. S. L. (1997). On the Empirics of Balance-Of-Payments-Constrained Growth. Journal of Post Keynesian Economics, 19, 345-375.

McGregor, P. G., \& Swales, J. K. (1985). Professor Thirlwall and balance of payments constrained growth. Applied Economics, 17, 17-32.

McGregor, P. G., \& Swales, J. K. (1991). Thirlwall's Law and balance of payments constrained growth: Further comment on the debate. Applied Economics, 23, 9-20.

Metz, R., \& Stier, W. (1992). Filter Design in the Frequency Domain. In New Findings in LongWave Research (pp. 45-79). Palgrave Macmillan, London.

Minsky, H. (2016). Can It Happen Again? : Essays on Instability and Finance. Routledge.

Moreno-Brid, J. C. (1998). On Capital Flows and The Balance-of-Payments-Constrained Growth Model. Journal of Post Keynesian Economics, 21, 283-298. 
Moreno-Brid, J. C. (1999). Mexico's Economic Growth and the Balance of Payments Constraint: A cointegration analysis. International Review of Applied Economics, 13, 149-159.

Moreno-Brid, J. C., \& Pérez, E. (1999). Balance-of-Payments-Constrained Growth in Central America: 1950-96. Journal of Post Keynesian Economics, 22, 131-147.

Moreno-Brid, J.C. (1998). Balance-of-payments constrained economic growth: The case of Mexico. PSL Quarterly Review, 51, 433-451.

Mutz, C. and Ziesemer, T. (2008). Simultaneous estimation of income and price elasticities of export demand, scale economies and total factor productivity growth for Brazil. Applied Economics, 40(22), pp.2921-2937.

Nelson, R. R., \& Winter, S. G. (1977). In Search of a Useful Theory of Innovation. In Interdisciplinary Systems Research / Interdisziplinäre Systemforschung. Innovation, Economic Change and Technology Policies (pp. 215-245). Birkhäuser, Basel.

Ocampo, J. A. (2002). Rethinking the development agenda. Cambridge Journal of Economics, $26,393-407$.

Ocampo, J. A. (2004). Latin America's Growth and Equity Frustrations During Structural Reforms. Journal of Economic Perspectives, 18, 67-88.

Ocampo, J. A. (2011). Balance of payments dominance: Its implications for macroeconomic policy. Getulio Vargas Foundation. São Paulo.

Ocampo, J. A. (2017). Commodity-Led Development in Latin America. International Development Policy | Revue Internationale de Politique de Développement, 9, 51-76.

Ocampo, J. A., Rada, C., \& Taylor, L. (2009). Growth and Policy in Developing Countries: A Structuralist Approach. Columbia University Press.

Oreiro, J. L. (2016). Inconsistency and over-determination in balance-of-payments-constrained growth models: A note. Review of Keynesian Economics, 4, 193-200.

Palley, T. (2002). Pitfalls in the Theory of Growth: An Application to the Balance-of-PaymentsConstrained Growth Model [Chapters]. Edward Elgar Publishing.

Palley, T. (2008). Keynesian models of deflation and depression revisited. Journal of Economic Behavior \& Organization, 68, 167-177.

Papell, D. H., \& Prodan, R. (2014). Long run time series tests of constant steady-state growth. Economic Modelling, 42, 464-474. 
Pasinetti, L. L. (1983). Structural Change and Economic Growth: A Theoretical Essay on the Dynamics of the Wealth of Nations. CUP Archive.

Perez, C. (2010). Technological revolutions and techno-economic paradigms. Cambridge Journal of Economics, 34, 185-202.

Perraton, J. (2003). Balance of Payments Constrained Growth and Developing Countries: An examination of Thirlwall's hypothesis. International Review of Applied Economics, 17, $1-22$.

Perron, P., \& Wada, T. (2009). Let's take a break: Trends and cycles in US real GDP. Journal of monetary Economics, 56(6), 749-765.

Plosser, C. I. (1989). Understanding Real Business Cycles. Journal of Economic Perspectives, 3, $51-77$.

Pollock, D. S. G. (2013). Cycles, Syllogisms and Semantics: Examining the Idea of Spurious Cycles. Journal of Time Series Econometrics, 6, 81-102.

Porcile, G., \& Spinola, D. S. (2018). Natural, Effective and BOP-Constrained Rates of Growth: Adjustment Mechanisms and Closure Equations. PSL Quarterly Review, 71, 139-160.

Porcile, G., \& Yajima, G. T. (2019). New Structuralism and the Balance-of-Payments Constraint (Working Paper No. 4/19). Sapienza University of Rome, DISS.

Prebisch, R. (1950). The economic development of Latin America and its principal problems (No. 29973). Naciones Unidas Comisión Económica para América Latina y el Caribe (CEPAL).

Pritchett, L. (2000). Understanding patterns of economic growth: searching for hills among plateaus, mountains, and plains. The World Bank Economic Review, 14(2), 221-250.

Rapetti, M., Skott, P., \& Razmi, A. (2012). The real exchange rate and economic growth: Are developing countries different? International Review of Applied Economics, 26, 735-753.

Razmi, A. (2005). Balance-of-Payments-Constrained Growth Model: The Case of India. Journal of Post Keynesian Economics, 27, 655-687.

Razmi, A. (2016). Correctly analysing the balance-of-payments constraint on growth. Cambridge Journal of Economics, 40, 1581-1608.

Ribeiro, R., McCombie, J., \& Lima, G. (2016). Exchange Rate, Income Distribution and Technical Change in a Balance-of-Payments Constrained Growth Model. Review of Political Economy, 28, 545-565. 
Robinson, J. (1971). Economic heresies: some old fashioned questions in economic theory. New York Basic Books.

Rodríguez, O. (1977). Sobre la concepción del sistema centro-periferia. Revista de la CEPAL, 3, 203-248. Retrieved from https://econpapers.repec.org/article/ecrcol070/12422.htm

Rodrik, D. (2008). The Real Exchange Rate and Economic Growth. Brookings Papers on Economic Activity, 39, 365-439.

Romero, J. P., \& McCombie, J. S. L. (2016). The Multi-Sectoral Thirlwall's Law: Evidence from 14 developed European countries using product-level data. International Review of Applied Economics, 30, 301-325.

Ros, J. (2013). Rethinking Economic Development, Growth, and Institutions. Oxford University Press.

Samuelson, P. A. (1948). Foundations of Economic Analysis. Science and Society, 13, 93-95.

Schumpeter, J. A. (1939). Business Cycles: A theoretical, historical and statistical analysis of the Capitalist process. New York: McGraw-Hill.

Setterfield, M. (2006). Thirlwall's Law and Palley's Pitfalls: A Reconsideration [Chapters]. Edward Elgar Publishing.

Setterfield, M. (2011). The remarkable durability of Thirlwall's Law. PSL Quarterly Review, 64, $393-427$.

Shell, K. (1967). A model of inventive activity and capital accumulation. Essays on the Theory of Optimal Economic Growth. MIT Press, Cambridge MA.

Silverberg, G., \& Verspagen, B. (1995). An evolutionary model of long term cyclical variations of catching up and falling behind. Journal of Evolutionary Economics, 5, 209-227.

Singer, H. W. (1950). The Distribution of Gains between Investing and Borrowing Countries. The American Economic Review, 40, 473-485.

Steindl, J. (1952). Maturity and stagnation in American capitalism. Oxford: Blackwell.

Steindl, J. (1979). Stagnation theory and stagnation policy. Cambridge Journal of Economics, 3, $1-14$.

Stiglitz, J. E. (2000). Capital Market Liberalization, Economic Growth, and Instability. World Development, 28, 1075-1086.

Stockhammer, E., \& Onaran, O. (2013). Wage-led growth: Theory, evidence, policy. Review of Keynesian Economics, 1, 61-78. 
Sunkel, O. (1972). Big Business and "Dependencia": A Latin American View. Foreign Affairs, $50,517-531$.

Szirmai, A. (2015). Socio-economic development. Cambridge University Press.

Szirmai, A. (2008). Explaining Success and Failure in Development (MERIT Working Paper No. 013). United Nations University - Maastricht Economic and Social Research Institute on Innovation and Technology (MERIT).

Szirmai, A. \& Foster-McGregor, N. (2017). Understanding the Ability to Sustain Growth. Groningen Growth and Development Center. Working Paper no. 173,

Taylor, L. (1983). Structuralist macroeconomics: Applicable models for the Third World. New York: Basic Books.

Taylor, L. (1991). Income Distribution, Inflation, and Growth: Lectures on Structuralist Macroeconomic Theory. MIT Press.

Thirlwall, A. P. (1979). The balance of payments constraint as an explanation of the international growth rate differences. PSL Quarterly Review, 32. 45-53.

Thirlwall, A. P. (2011). Balance of payments constrained growth models: History and overview. PSL Quarterly Review, 64. 307-351.

Thirlwall, A. P. (2012). Balance of Payments Constrained Growth Models: History and Overview. In Models of Balance of Payments Constrained Growth (pp. 11-49). Palgrave Macmillan, London.

Thirlwall, A. P., \& Hussain, M. N. (1982). The Balance of Payments Constraint, Capital Flows and Growth Rate Differences between Developing Countries. Oxford Economic Papers, $34,498-510$.

Van Ewijk, C. (1981). The long wave — a real phenomenon? De Economist, 129, 324-372.

Verspagen, B. (1991). A new empirical approach to catching up or falling behind. Structural Change and Economic Dynamics, 2, 359-380.

Williamson, J.G. (2011). Trade and poverty: when the Third World fell behind. MIT press.

Wray, R. (2007). The employer of last resort programme: Could it work for developing countries?. Geneva: ILO.

Ziesemer, T. (1995). Growth with imported capital goods, limited export demand and foreign debt. Journal of Macroeconomics, 17(1), 31-53. 
Ziesemer, T. (2014). Country terms of trade: Trends, unit roots, over-differencing, endogeneity, time dummies, and heterogeneity. International Review of Applied Economics, 28 (6), 767-796.

Ziesemer, T. (2018). Testing the growth links of emerging economies: Croatia in a growing world economy. Bulletin of Applied Economics, 5(1), pp.1-27. 


\section{Valorisation Addendum}

In compliance with article 22.5 of the "Regulations for obtaining the doctoral degree at Maastricht University" adopted by the Board of Deans, dated 1 September 2018, this addendum discusses the valorization opportunities of this thesis with regard to the social and economic relevance of the thesis, the potential target audiences to whom the research results might be of interest and the innovativeness of this thesis in comparison with existing literature.

The structural components treated in this thesis are directly related to development challenges raised in the Sustainable Development Goals. Goals 8 (Decent work and Economic Growth) and 9 (Industry, Innovation and Infrastructure) pose challenges that demand structural changes, especially in developing countries such as in Latin America, in which basic development problems such as poverty, lack of quality education, and political and economic volatility persist. Development is a main challenge for Latin American, a region in which high instability has been the norm. This unstable environment imposes constraints to economic development, trapping economies in an under-developed situation. This thesis investigates the economic causes behind this instability, expanding the current literature on the topic, and offering alternatives on how to deal with this problem.

We argue in this thesis that there are endogenous and exogenous causes why volatility persists, which is directly related to the laggard economic structures (lack of innovative capacity, and specialization in low tech sectors), that create external constraints to developing economies. The persistence of oscillations has a reinforcement mechanism, pushing the structures towards further specialization, in a vicious causation mechanism.

This diagnostic opens the door for policy recommendations, focused on breaking the vicious causation that traps Latin American economies into under development. In Chapters 2 and 3 we investigate the causes of endogenous volatility by expanding existing Structuralist models. The results point to the need for focusing policies on the supply and the demand side of the economy. On the supply side we propose policies to foster the absorptive and innovative capacity of the Latin American economies, as well as focusing macroeconomic management in the direction of balancing stability with developing a stronger industrial sector, competitive in international terms, such as the strategy followed by East Asian countries. On the demand side, social policies that reduce income inequality are fundamental to reduce poverty, tackle volatility, and create the 
necessary effective demand to advance with the development strategy. In this sense, Latin American countries can reduce their external constraints, and at the same time push towards more inclusive societies. However, a central message of this thesis resides in the difficulties in establishing such policies in volatile countries. This is more dramatic considering the scarcity of resources needed for such strategies, which are only available during periods of boom, and that are commonly used to maintain an overvalued exchange rate, improving local living standards in the short run in lieu of the competitiveness of the productive structure in the long run, forcing strong adjustments in the recession period.

The originality of the thesis resides in: (1) the expansion of the existing literature, adding structural components to demand side economic models, offering endogenous explanations to the existence of the economic volatility; (2) the new classification of countries by cycle types presented in chapter 1 . In this chapter we show the characteristics of regular volatility in Latin America, a region that suffers from short and long run oscillations. It is an original contribution to the literature, dividing countries by their cycle characteristics into different cluster groups; and (3) empirically testing existing models, challenging them theoretically in order to improve them, and their relevance in the literature, as raised in Chapter 4.

The main target of the thesis is academic researchers and policy makers interested in discussing the theoretical channels in which long run development strategies are constrained in Latin America.

In terms of dissemination, the results of this thesis were presented in many academic events. All chapters were presented internally in the UNU-MERIT's Structural Change Research Theme group. The project of this thesis was presented in the Globelics Academy, in Tampere, Finland, 2017. Chapter 1 was presented in the The Ragnar Nurkse Department of Innovation and Governance in Tallin, Estonia, 2017; and in the Globelics Conference 2017, in Athens, Greece, 2017. Chapter 2 was presented in the International Schumpeter Society, in South Korea, 2018; in the Forum for Macroeconomics and Macroeconomic Policies (FMM), in Berlin, 2018. Chapter 3 was presented in the II Lalics conference, in Mexico City, 2018; in the 46th Conference of the Brazilian National Association of Postgraduate Programs in Economics (ANPEC), in Rio de Janeiro, Brazil, 2018, and in in the FMM in Berlin, 2019. Chapter 4 was presented in the IV Brazilian Meeting on Industrial Economics and Economics of Innovation (IV ENEI), in Campinas, 2019. 
All the chapters are available as working papers, being currently under review in academic peerreviewed high impact journals. 


\section{About the Author}

Danilo Sartorello Spinola was born in São Paulo, Brazil. He obtained a Bachelor's degree in Economics and Social Sciences from the University of Campinas (Unicamp), Brazil, and a Master's degree in Economics from the same institution, receiving the prize of best dissertation from the Brazilian Keynesian Association. After working as a consultant at the Economics Commission for Latin America and the Caribbean (ECLAC) in Santiago, Chile, he moved to the Netherlands to pursue his PhD at UNU-MERIT, Maastricht University in 2015. During his PhD, Danilo provided technical assistance for the United Nations Industrial Development Organization (UNIDO)'s Industrial Development Report (IDR). He worked as a tutor (teaching assistant) in the quantitative methods track of UNU-MERIT's Master in Public Policy (MPP) and as academic advisor for the University College Maastricht (UCM). Danilo is currently the Vice President of the Latin America's Knowledge Systems, Innovation and Capacity Building Research Network (LALICS), member of the advisory board of the Young Scholars Initiative (YSI) - Institute for New Economic Thinking (INET), and coordinator of the Complexity Economics Working Group of YSI. In 2019 he has been granted a Marie Sklodowska-Curie scholarship under the project Catching-up Along the Global Value Chain (CatChain) project. He has been awarded a postdoctoral contract from Maastricht University to continue his academic research at UNU-MERIT.

Danilo's research interests include development economics, Structuralism, macroeconomic theory and issues related to peripheral industrialization. He is very much interested in economic modeling and quantitative methods. 



\section{UNU-MERIT/MGSoG Dissertation Series}

2020

\section{Danilo Sartorello Spinola}

Cycles, Economic Structures and

External Constraints.

A Structuralist study on the causes of economic volatility in Latin America

UNU-MERIT/MGSoG Dissertation

Series № 241

2019

\section{Jemal Adem}

Livelihood Vulnerability to Shocks,

Behaviour and Investment in

Education: Essays in Behavioural

Development Economics

UNU-MERIT/MGSoG Dissertation

Series № 240

\section{Davina Osei}

Corrupt or corrupted networks?

An empirical enquiry

UNU-MERIT/MGSoG Dissertation

Series № 239

\section{Patima Chongcharoentanawat}

Beyond Static Inequality

Public policies and economic mobility in Thailand

UNU-MERIT/MGSoG Dissertation

Series № 238

\section{Charlotte Guillard}

Rethinking economic growth

and structural change.

The role of boundaries and linkages

between industries

UNU-MERIT/MGSoG Dissertation

Series № 237

\section{Nicolas Echarti}

Employment Effects or Vocational

Rehabilitation in Germany:

A quantitative analysis

UNU-MERIT/MGSoG Dissertation

Series № 236

\section{Shellie E. Solomon}

Neighborhoods Matter:

Crime, collective efficacy and

foreclosures in Miami

UNU-MERIT/MGSoG Dissertation

Series № 235

\section{Michał Kazimierczak}

Regional Innovation and

Entrepreneurship

Patents, trade marks, entry and

entrants' growth in European

manufacturing industries

UNU-MERIT/MGSoG Dissertation

Series № 234 


\section{Fernanda Soares}

The Influence of Within School and

Across Schools' Collaborative Practices on Student Learning and Teaching

Outcomes in West Africa

UNU-MERIT/MGSoG Dissertation

Series № 233

\section{Mira Bierbaum}

New Mindsets to Innovate Activation

UNU-MERIT/MGSoG Dissertation

Series № 232

\section{Norman Dytianquin}

Technology in the Asian Miracle and

Crisis Debates: Applications of and Insights from the Field of Influence Approach to Input-Output Analysis UNU-MERIT/MGSoG Dissertation Series № 231

\section{Nga Le}

The implications of health insurance for the labour market and patient satisfaction with medical care in Vietnam

UNU-MERIT/MGSoG Dissertation Series № 230

\section{Jinhyuck Park}

Intellectual Property right protection and cross-border RED investments by multinational enterprises

UNU-MERIT/MGSoG Dissertation Series № 229

\section{Richard de Groot}

Show me the Money:

Essays on the Impact of Cash Transfers on Child Nutrition and the Role of Intra-Household Dynamics UNU-MERIT/MGSoG Dissertation Series № 228

\section{Catie Lott}

Diamonds are a Women's Best Friend Broadening Measures of Women's Access to Formal Political DecisionMaking

UNU-MERIT/MGSoG Dissertation

Series № 227

\section{Ana Cristina Calderon Ramirez}

Public Management Reforms

Three stories about public procurement agencification in Latin America UNU-MERIT/MGSoG Dissertation Series № 226

\section{Camilo Nicanor Carrillo Purin}

Teachers' in-service training and student achievement:

The effect of in-service training of Peruvian teachers on student achievement UNU-MERIT/MGSoG Dissertation Series № 225

\section{Hugo Confraria}

Developing scientific capacity in the Global South UNU-MERIT/MGSoG Dissertation Series № 224 


\section{Alison Cathles}

Educational Pathways and Skills:

Past, Present, and Future

UNU-MERIT/MGSoG Dissertation

Series № 223

Ibrahima Sory Kaba

Aggregate Fluctuations and

Development: Essays on

Macroeconomic Volatility and

Economic Growth

UNU-MERIT/MGSoG Dissertation

Series № 222

\section{Charlotte Keijser}

Firm Participation, Learning and

Innovation in Heterogenous Value

Chains of IT-enabled Services

UNU-MERIT/MGSoG Dissertation

Series № 221

\section{Salih Çevikarslan}

Innovation Strategies and Their

Implications for Technological Change

and Market Outcomes:

An Evolutionary Multi-Agent Based

Modelling Approach

UNU-MERIT/MGSoG Dissertation

Series № 220

\section{Wondimagegn Mesfin Tesfaye}

Essays on the Impacts of Climate-

Smart Agricultural Innovations on

Household Welfare

UNU-MERIT/MGSoG Dissertation

Series № 219
Tatevik Poghosyan

How Board Networks Affect Firm

Performance and Innovation Incentives

in Transition Economies: The Case of

Armenia

UNU-MERIT/MGSoG Dissertation

Series № 218

\section{Arip Muttaqien}

Essays on Inequality and Polarization:

Empirical Studies in Developing Asia

UNU-MERIT/MGSoG Dissertation

Series № 217

2018

Katrin Marchand

Essays on Forced Migration and

Labour Market Participation in

Developing Countries

UNU-MERIT/MGSoG Dissertation

Series № 216

\section{Ortrun Merkle}

The Myth of Gender Neutral Power:

Corruption and Gender Norms

UNU-MERIT/MGSoG Dissertation

Series № 215

\section{Biljana Meshkovska}

Life after Trafficking:

(re)integration processes of women that have been trafficked for the purpose of sexual exploitation in Europe

UNU-MERIT/MGSoG Dissertation

Series № 214 


\section{Vincenzo Vinci}

The Relevance of Institutions and

People's Preferences for Social

Protection

UNU-MERIT/MGSoG Dissertation

Series № 213

\section{Silke Heuser}

The Effectiveness of Environmental

Policies on Reducing Deforestation in

the Brazilian Amazon

UNU-MERIT/MGSoG Dissertation

Series № 212

\section{Jennifer Waidler}

Social Assistance and Remittances and

Their Role in the Fight Against

Poverty

UNU-MERIT/MGSoG Dissertation

Series № 211

\section{Choolwe Muzyamba}

The role of community mobilization in the promotion of maternal health of women living with HIV in Zambia UNU-MERIT/MGSoG Dissertation Series № 210

Juan Carlos A. Castillo Sánchez

Assessing the Role of the Export Sector in Mexican Economic

Development,1965-2014

UNU-MERIT/MGSoG Dissertation

Series № 209

\section{Tareq Abuelhaj}

Food Security Policy Impact Analysis:

The Econometrics of Cash and Food Assistance Cost Effectiveness UNU-MERIT/MGSoG Dissertation Series № 208
Marta Férnandez de Arroyabe Arranz

Essays on MEAS and Innovation

UNU-MERIT/MGSoG Dissertation

Series № 207

\section{Clotilde Mahé}

Essays on Migration and Occupational

Choice

UNU-MERIT/MGSoG Dissertation

Series № 206

\section{Simone Sasso}

Talent on the move. Essays on Human

Capital, Graduate Mobility and

Economic Development

UNU-MERIT/MGSoG Dissertation

Series № 205

Khaled Walid Rajab

Strategic Planning under Fragility

UNU-MERIT/MGSoG Dissertation

Series № 204

Mutinta Hambayi Nseluke

A Tall Order: Improving Child Linear Growth

UNU-MERIT/MGSoG Dissertation

Series № 203

\section{Elvis Korku Avenyo}

Innovations and Firm Performance

in sub-Saharan Africa: Empirical

Analyses

UNU-MERIT/MGSoG Dissertation

Series № 202 


\section{Ni Zhen}

Employment Dynamics, Firm

Performance and Innovation

Persistence in the Context of

Differentiated Innovation Types:

Evidence from Luxembourg

UNU-MERIT/MGSoG Dissertation

Series № 201

\section{Caroline Wehner}

Too Scared to Achieve: The Relation

Between Neuroticism,

Conscientiousness

and Socioeconomic Outcomes

UNU-MERIT/MGSoG Dissertation

Series № 200

\section{Stefania Innocenti}

On Institutional Persistence

UNU-MERIT/MGSoG Dissertation

Series № 199

\section{Hassen Abda Wako}

Economic Globalization, Institutions

and Development: Essays on Aid,

Foreign Direct Investment and Trade

UNU-MERIT/MGSoG Dissertation

Series № 198

2017

\section{Hans-Erik Edsand}

Winds of Change

UNU-MERIT/MGSoG Dissertation

Series № 197

\section{Ana Patricia Silva Vara}

Redressing the Gender Gap

UNU-MERIT/MGSoG Dissertation

Series № 196

\section{Andrés Iván Mideros Mora}

Essays on the Economic Effects of Noncontributory Social Protection

UNU-MERIT/MGSoG Dissertation

Series № 195

\section{Tobias Broich}

New Actors in the Global Economy

UNU-MERIT/MGSoG Dissertation

Series № 194

\section{Bernard Nikaj}

From No-government to E-government UNU-MERIT/MGSoG Dissertation

Series № 193

\section{Ali Safarnejad}

Prioritizing the HIV Response

UNU-MERIT/MGSoG Dissertation

Series № 192

\section{Clovis Freire}

Diversification and Structural

Economic Dynamics

UNU-MERIT/MGSoG Dissertation

Series № 191

\section{Michael Verba}

Innovation and Knowledge Dynamics:

Essays on the Knowledge Economy

UNU-MERIT/MGSoG Dissertation

Series № 190

\section{Pui Hang Wong}

The Hearts and Minds in Conflict and Peace: The Economics of

Counterinsurgency and the Psychology of Reconstruction

UNU-MERIT/MGSoG Dissertation

Series № 189 


\section{Brenda Yamba}

Schooling Despite All Odds: Evidence from Lesotho on Female Child Carers who Stayed in School

UNU-MERIT/MGSoG Dissertation

Series № 188

\section{Sheng Zhong}

Moving towards An Energy Efficient

Future: Essays on Energy Efficiency,

Technology and Development

UNU-MERIT/MGSoG Dissertation

Series № 187

\section{Julieta Marotta}

Access to Justice and Legal

Empowerment of Victims of Domestic

Violence through Legal Organizations

in the City of Buenos Aires: A

Qualitative Empirical Legal Study

UNU-MERIT/MGSoG Dissertation

Series, № 186

\section{Andrea Franco-Correa}

On the Measurement of

Multidimensional Poverty as a Policy

Tool: Empirical Applications to Chile,

Colombia, Ecuador and Peru

UNU-MERIT/MGSoG Dissertation

Series, № 185

2016

\section{Yesuf Awel}

Insurance for Growth: Empirical

Essays on Insurance Demand and

Impacts in Africa

UNU-MERIT Dissertation Series, № 108

\section{Tigist Mekonnen Melesse}

Grow More Food using Fewer

Resources: Agricultural Technology

Adoption and Innovation Practices for

Inclusive and Sustainable

Development

UNU-MERIT Dissertation Series,

№ 107

\section{Eleni Yitbarek}

Getting Ahead or left Behind? Essays on Poverty Dynamics and Social

Mobility in Africa

UNU-MERIT Dissertation Series,

№ 106

\section{Thuy Dieu Nguyen}

Firm-Level Theory and Evidence of

Corruption

UNU-MERIT Dissertation Series, № 105

\section{Raquel Tsukada Lehman}

Essays on Household Production with

Labor-Saving Technology

UNU-MERIT Dissertation Series,

№ 104

\section{Eva Barteková}

Multi-Problem Challenges for a Renewable Future: Empirical Studies on Competitive Disadvantages from Electricity Price Differentials and Mineral Supply Risk in an Open Economy

UNU-MERIT Dissertation Series, № 103 


\section{Jocelyn Olivari}

Entrepreneurial Traits and Innovation:

Evidence from Chile

UNU-MERIT Dissertation Series, № 102

\section{Muhammad Shafique}

Essays on the role of knowledge, RED, and Technology-based Firms in the Evolution of Socio-techno-economic System

UNU-MERIT Dissertation Series, № 101

\section{Serdar Türkeli}

Governance of Innovation Policy:

Empirical Studies on Applied Political Economy by Multi-Methods Analysis UNU-MERIT Dissertation Series, № 100

\section{Ayokunu Adedokun}

Pathways to Sustainable Peace building in Divided Societies: Lessons and Experiences from Mozambique MGSoG Dissertation Series, № 75

\section{Luiz Rothier Bautzer}

Organizing Concurrent Engineering through ICT Platforms

Blueprinting Product Lifecycle

Management Platforms across

Disciplinary Agencies

MGSoG Dissertation Series, № 74

\section{Natalia Popova}

Migration in the Periphery of the

European Union:

Determinants of Successful and

Sustainable Labour Market Integration of Return Migrants in Albania, Egypt, Moldova and Tunisia

MGSoG Dissertations Series, № 73

\section{Richard A. Martina}

Uncertainty and Resource Constraint in the Small Island Developing States: Essays in Entrepreneurial Cognition MGSoG Dissertations Series, № 72

\section{Cécile Cherrier}

The Expansion of Basic Social

Protection in Low-income Countries:

An Analysis of Foreign Aid Actors'

Role in the Emergence of Social

Transfers in Sub-Saharan Africa

MGSoG Dissertations series, № 71

\section{Paul Caldron}

The Tacit Bargain in Short-Term Medical Missions: Why U.S. physicians go and what it costs MGSoG Dissertation Series, № 70

\section{Mahmut Kobal}

Customs E Excellence: A Comparative Approach on Administrative and Regulatory Compliance Perspectives of the EU-Turkey Customs Union

MGSoG Dissertation Series, № 69

\section{Craig Loschmann}

Essays on Conflict-related Migration and Development in the Case of Afghanistan MGSoG Dissertations Series, № 68 


\section{Andrea Milan}

Rural Livelihoods, Location and

Vulnerable Environments: Approaches to Migration in Mountain areas of

Latin America

MGSoG Dissertation Series, № 67

\section{Farida Lada}

On Guarding the Welfare of Clinical

Trial Subjects While Promoting Novel

Drug Innovation

A Game Theoretical Approach

MGSoG Dissertation Series, № 66

\section{5}

\section{Hibret Belete Maemir}

Dissecting Aggregate Productivity:

International Integration and Growth

with Heterogeneous Firms

UNU-MERIT Dissertation Series,

№ 96

\section{Giorgio Triulzi}

Looking for the Right Path: Technology

Dynamics, Inventive Strategies and

Catching-up in the Semiconductor

Industry

UNU-MERIT Dissertation Series, № 95

\section{Abdul Baseer Qazi}

Knowledge flows and networks in the

ICT sector: The case of Pakistan

UNU-MERIT Dissertation Series, № 94

\section{Ajay Thutupalli}

Technology Paradigm Shifts in

Agriculture: Drivers of Sustainability and Catch up

UNU-MERIT Dissertation Series, № 93

\section{Eduardo Urias}

Improving access to HIVIAIDS

treatment in Brazil: When are

Compulsory Licenses effective in Price

Negotiations?

UNU-MERIT Dissertation Series,

№ 92

\section{Francesca Guadagno}

Why have so few Countries

Industrialised?

UNU-MERIT Dissertation Series, № 91

\section{Daniel Opolot}

The Evolution of Beliefs and Strategic Behaviour

UNU-MERIT Dissertation Series, № 90

\section{Alejandro Lavopa}

Structural Transformation and

Economic Development: Can

Development Traps be Avoided

UNU-MERIT Dissertation Series,

№ 89

\section{Jinjin Zhao}

Urban water management reform: The

Case of China

UNU-MERIT Dissertation Series, № 88 


\section{Simona Vezzoli}

Borders, Independence and Postcolonial Ties: the Role of the State in Caribbean Migration

MGSoG Dissertation Series, № 65

\section{Silvia Consuelo Gómez Soler}

Civil Conflict and Education: How

Does Exposure to Civil Conflict Affect

Human Capital Accumulation?

Evidence from Standardized Exit

Exams in Colombia

MGSoG Dissertation Series, № 64

\section{Paula Nagler}

Occupational Choice in the Developing World

MGSoG Dissertation Series, № 63

\section{Jasmin Kientzel}

Determinants of Professional

Commitment to Environmental

Sustainability

MGSoG Dissertation Series, № 62

\section{Mehmet Güney Celbiş}

Regional Policies: Convergence, Trade, and the Allocation of Public Capital MGSoG Dissertation Series, № 61

\section{Florian Henning}

Living Up to Standard:

Interoperability Governance and

Standards Adoption in Government

Information Networks

MGSoG Dissertation Series, № 60

\section{Niels P. Groen}

The Never-Ending Project

Understanding E-Government Project

Escalation

MGSoG Dissertation Series, № 59

\section{Derek Copp}

Teacher-Based Reactivity to Provincial

Large-scale Assessment in Canada

MGSoG Dissertation Series, № 58

\section{Michaella Vanore}

Family-Member Migration and the

Psychosocial Health Outcomes of

Children in Moldova and Georgia

MGSoG Dissertation Series, № 57

\section{Sonja Fransen}

The Economic and Social Effects of Remittances and Return Migration in Conflict-Affected Areas: The Case of Burundi

MGSoG Dissertation Series, № 56

\section{Ibrahim Khalil Conteh}

The Impact of Floods on Primary

School Education in Zambia

MGSoG Dissertation Series, № 55

\section{Richard Bluhm}

Growth Dynamics and Development Essays in Applied Econometrics and Political Economy MGSoG Dissertation Series, № 54

\section{Nevena P. Zhelyazkova}

Work-Family Reconciliation and Use of Parental Leave in Luxembourg: Empirical Analysis of Administrative Records

MGSoG Dissertation Series, № 53 
2014

\section{Dirk Crass}

The Impact of Brands on Innovation and Firm Performance: Empirical

Evidence from Germany

UNU-MERIT Dissertation Series, № 87

\section{Samyukta Bhupatiraju}

The Geographic Dimensions of Growth and Development

UNU-MERIT Dissertation Series, № 86

\section{François Lafond}

The Evolution of Knowledge Systems UNU-MERIT Dissertation Series, № 85

\section{Annalisa Primi}

Promoting Innovation in Latin

America: What Countries Have

Learned (and What They Have Not) in

Designing and Implementing

Innovation and Intellectual Property

Policies

UNU-MERIT Dissertation Series, № 84

\section{Fatoumata Lamarana Diallo}

Evaluation of Meal and Deworming

Programs for Primary Schools in Rural Senegal

UNU-MERIT Dissertation Series, № 83

\section{Sachin Kumar Badkas}

Metachoice and Metadata: Innovating with Environmental Policy Analysis in Europe

MGSoG Dissertation Series, № 52

\section{Irina S. Burlacu}

An Evaluation of Tax-Benefit Systems Impact on the Welfare of Frontier

Worker:

The Case of Luxembourg and Belgium MGSoG Dissertation Series, № 51

\section{Özge Bilgili}

Simultaneity in Transnational Migration Research: Links Between Migrants' Host and Home Country Orientation

MGSoG Dissertation Series, № 50

\section{Yulia Privalova Krieger}

Reshaping the Big Agenda:

Transnational Politics and Domestic

Resistance Financial crisis and social protection reform in Bosnia and Herzegovina

MGSoG Dissertation Series, № 49

\section{Marieke van Houte}

Moving Back or Moving Forward?

Return migration after Conflict

MGSoG Dissertation Series, № 48

\section{Oxana Slobozhan}

Global Governance in the Management of Natural Resources: The Case of the Extractive Industries Transparency Initiative (EITI)

MGSoG Dissertation Series, № 47 


\section{Luis Bernardo Mejia Guinand}

The Changing Role of the Central

Planning Offices in Latin America: A

Comparative Historical Analysis

Perspective (1950-2013)

MGSoG Dissertation Series, № 46

\section{Cheng Boon Ong}

Ethnic Segregation in Housing,

Schools and Neighbourhoods in the

Netherlands

MGSoG Dissertation Series, № 45

\section{Luciana V. Cingolani}

Bureaucracies for Development:

Oxymoron or Reality? Studies on State

Capacity in Challenging Governance

Contexts

MGSoG Dissertation Series, № 44

\section{Carlos Cadena Gaitán}

Green Politics in Latin American

Cities - Sustainable Transport Agendas

MGSoG Dissertation Series, № 43

\section{Katie Kuschminder}

Female Return Migration and

Reintegration Strategies in Ethiopia

MGSoG Dissertation Series, № 42

\section{Metka Hercog}

Highly-Skilled Migration and New

Destination Countries

MGSoG Dissertation Series, № 41

\section{Margaret Agaba Rugadya}

Can Remittances Influence the Tenure and Quality of Housing in Uganda?

MGSoG Dissertation Series, № 40

\section{Ilire Agimi}

New Governance Under Limited

Statehood: The Case of Local

Government Reform in Kosovo

MGSoG Dissertation Series, № 39

\section{3}

\section{Anant Kamath}

Information Sharing through Informal Interaction in Low-Tech Clusters

UNU-MERIT Dissertation Series, № 82

\section{Flavia Pereira de Carvalho}

What we talk about when we talk about Brazilian Multinationals: An Investigation on Brazilian FDI, Economic Structure, Innovation and the Relationship between them UNU-MERIT Dissertation Series, № 81

\section{Jun Hou}

Complementarity in Innovation and Development: A Cross-country

Comparison

UNU-MERIT Dissertation Series, № 80

\section{Rufin Baghana}

Impacts of Government Incentives to $R \mathcal{E D}$, Innovation and Productivity: A Microeconometric Analysis of the Québec Case

UNU-MERIT Dissertation Series, № 79 


\section{Lilia I. Stubrin}

High-Tech Activities in Emerging

Countries: A Network perspective on

the Argentinean Biotech Activity

UNU-MERIT/MGSoG Dissertation

Series, № 78

\section{Kristine Farla}

Empirical Studies on Institutions,

Policies and Economic Development

MGSoG Dissertation Series, № 38

\section{Marina Petrovic}

Social Assistance and Activation in the

Pursuit of Happiness: Shedding New

Light on Old Policy Solutions to Social

Exclusion

MGSoG Dissertation Series, № 37

\section{Laura Torvinen}

Assessing Governance Assessments:

The Case of Mozambique: Governance

Assessments in the Context of Aid

Effectiveness Discourse

MGSoG Dissertation Series, № 36

\section{Biniam Egu Bedasso}

Institutional Change in the Long

Shadow of Elite: Essays on

Institutions, Human Capital and

Ethnicity in Developing Countries

MGSoG Dissertation Series, № 35

\section{Sepideh Yousefzadeh Faal}

\section{Deghati}

Childhoods Embargoed: Constructing and Reconstructing Multidimensional

Child Poverty in Iran 1984-2009

MGSoG Dissertation Series, № 34

\section{Robert Bauchmüller}

Investing in Early Childhood Care and

Education: The Impact of Quality on

Inequality

MGSoG Dissertation Series, № 33

\section{Martin Rehm}

Unified Yet Separated: Empirical

Study on the Impact of Hierarchical

Positions within Communities of

Learning

MGSoG Dissertation Series, № 32

2012

\author{
Abdul Waheed \\ Innovation Determinants and \\ Innovation as a Determinant: Evidence \\ from Developing Countries \\ UNU-MERIT Dissertation Series, \\ № 77
}

\section{Bilal Mirza}

Energy Poverty and Rural Energy

Markets in Pakistan

UNU-MERIT Dissertation Series,

№ 76

\section{Benjamin Engelstätter}

Enterprise Software and Video Games:

An Empirical Analysis

UNU-MERIT Dissertation Series, № 75

\section{Fulvia Farinelli}

Natural Resources, Innovation and Export Growth: The Wine Industry in Chili and Argentina

UNU-MERIT Dissertation Series 


\section{Rodolfo Lauterbach}

Innovation in Manufacturing: From

Product Variety and Labor

Productivity Growth to Economic

Development in Chile

UNU-MERIT Dissertation Series

\section{Kirsten Wiebe}

Quantitative Assessment of

Sustainable Development and Growth

in Sub-Saharan Africa

UNU-MERIT Dissertation Series,

№ 74

\section{Julio Miguel Rosa}

Organizational Strategies, Firms'

Performance and Spatial Spillovers:

The Canadian Case in Research and

Development.

UNU-MERIT Dissertation Series,

№ 73

Johannes Wilhelmus Marie Boels

Joseph Schumpeter, Honderd Jaar

Economische Ontwikkeling: Een

Historisch-theoretische Beschouwing.

UNU-MERIT Dissertation Series

\section{Dorcas Mbuvi}

Utility Reforms and Performance of the

Urban Water Sector in Africa

MGSoG Dissertation Series, № 31

\section{Lina Salanauskaite}

Distributional Impacts of Public

Policies: Essays in Ex-Ante and Ex-

Post Evaluation

MGSoG Dissertation Series, № 30

\section{Esther Schüring}

To Condition or not - is that the

Question?

An Analysis of the Effectiveness of Ex-

Ante and Ex-Post Conditionality in

Social Cash Transfer Programs

MGSoG Dissertation Series, № 29

\section{Joe Abah}

Strong Organisations in Weak States:

Atypical Public Sector Performance in

Dysfunctional Environments

MGSoG Dissertation Series, № 28

\section{Zina Samih Nimeh}

Social Citizenship Rights: Inequality and Exclusion

MGSoG Dissertation Series, № 27

2011

\section{Daniel Vertesy}

Interrupted Innovation: Emerging

Economies in the Structure of the

Global Aerospace Industry

UNU-MERIT Dissertation Series,

№ 72

\section{Tina Saebi}

Successfully Managing Alliance

Portfolios: An Alliance Capability

View

UNU-MERIT Dissertation Series,

№ 71

\section{Nora Engel}

Tuberculosis in India: A Case of

Innovation and Control

UNU-MERIT/MGSoG Dissertation

Series, № 70 


\section{Evans Mupela}

Connectivity and growth in Sub-

Saharan Africa: The Role of

Communication Satellites

UNU-MERIT Dissertation Series, № 69

\section{Nantawan Kwanjai}

Cross Cultural Intelligence amid

Intricate Cultural Webs: A Tale of the

UnDutchables in the Land of 1002

Smiles

UNU-MERIT Dissertation Series, № 68

\section{Lina Sonne}

Innovation in Finance to Finance

Innovation: Supporting Pro-poor

Entrepreneur-based Innovation

UNU-MERIT Dissertation Series, № 67

\section{Lenka Eisenhamerová}

Legitimacy of 'Humanitarian Military

Intervention'

MGSoG Dissertation Series, № 26

\section{Sonila Tomini}

Informal Payments for Health Care

Services in Albania

MGSoG Dissertation Series, № 25

\section{Jinjing Li}

Dynamic Microsimulation in Public

Policy Evaluation

MGSoG Dissertation Series, № 24

\section{Aziz Atamanov}

Rural Nonfarm Employment and

International Migration as

Alternatives to Agricultural

Employment: The Case of Kyrgyzstan

MGSoG Dissertation Series, № 23

\section{Frieda Vandeninden}

Poverty Alleviation: Aid and Social

Pensions

MGSoG Dissertation Series, № 22

\section{Juliana Nyasha Tirivayi}

The Welfare Effects of Integrating

AIDS Treatment with Food Transfers:

Evidence from Zambia

MGSoG Dissertation Series, № 21

\section{Agnieska Ewa Sowa}

Who's Left Behind? Social Dimensions of Health Transition and Utilization of Medical Care in Poland

MGSoG Dissertation Series, № 20

\section{Emmanaouil Sfakianakis}

The Role of Private Actors in the Provision of Public Goods with Applications to Infrastructure and Financial Stability

MGSoG Dissertation Series, № 19

\section{Siu Hing Lo}

White Collars Green Sleeves: An Interorganizational Comparison of Determinants of Energy-Related Behaviors among Office Workers MGSoG Dissertation Series, № 18 


\section{Treena $\mathbf{W u}$}

Constraints to Human Capital

Investment in Developing Countries:

Using the Asian Financial Crisis in

Indonesia as a Natural Experiment

MGSoG Dissertation Series, № 17

\section{Henry Espinoza Peña}

Impact Evaluation of a Job-Training

Programme for Disadvantaged Youths:

The Case of Projoven

MGSoG Dissertation Series, № 16

2010

\section{Fernando Santiago}

Human Resources Management

Practices and Learning for Innovation

in Developing Countries:

Pharmaceutical Firms in Mexico

UNU-MERIT Dissertation Series,

№ 66

\section{Zakaria Babutsidze}

Essays on Economies with

Heterogeneous Interacting Consumers

UNU-MERIT Dissertation Series, № 65

\section{Bertha Vallejo}

Learning and Innovation Under

Changing Market Conditions: The

Auto Parts Industry in Mexico

UNU-MERIT Dissertation Series, № 64

\section{Donatus Ayitey}

Technical Change, Competitiveness

and Poverty Reduction: A Study of the

Ghanaian Apparel Industry

UNU-MERIT Dissertation Series, № 63

\section{Sergey Filippov}

Multinational Subsidiary Evolution:

Corporate Change in New EU Member

States

UNU-MERIT Dissertation Series,

№ 62

\section{Asel Doranova}

Technology Transfer and Learning under the Kyoto Regime: Exploring the Technological Impact of CDM Projects in Developing Countries

UNU-MERIT Dissertation Series, № 61

\section{Florian Tomini}

Between Family and Friend:

Understanding the Interdependency of Private Transfers

MGSoG Dissertation Series, № 15

\section{Michał Polalowski}

The Institutional Transformation of Social Policy in East Central Europe: Poland and Hungary in Comparative and Historical Perspective MGSoG Dissertation Series, № 14

\section{Maha Ahmed}

Defining, Measuring and Addressing

Vulnerability: The Case of Post

Conflict Environments

MGSoG Dissertation Series, № 13 


\section{Pascal Beckers}

Local Space and Economic Success:

The Role of Spatial Segregation of

Migrants in the Netherlands

MGSoG Dissertation Series, № 12

\section{Victor Cebotari}

Conflicting Demands in Ethnically

Diverse Societies: Ethno political

Contention and Identity Values in

Europe

MGSoG Dissertation Series, № 11

\section{Dennis Gyllensporre}

Competing and Complementary

Perspectives on the EU as a Crisis

Management Actor:

An Examination of the Common

Security and Defence Policy through

the Lenses of Idealism and Realism

MGSoG Dissertation Series, № 10

\section{Judit Vall Castello}

Business Cycle and Policy Effects on Labour Market Transitions of Older and Disabled Workers in Spain

MGSoG Dissertation Series, № 9

\section{Keetie Roelen}

False Positives or Hidden Dimensions:

The Definition and Measurement of

Child Poverty

MGSoG Dissertation Series, № 8

\section{Denisa Maria Sologon}

Earning Dynamics in Europe

MGSoG Dissertation Series, № 7

\section{Melissa Siegel}

Money and Mobility: Migration and

Remittances

MGSoG Dissertation Series, № 6

Jessica S. Hagen-Zanker

Modest Expectations: Causes and

Effects of Migration on Migrant

Households inSource Countries

MGSoG Dissertation Series, № 5

\begin{abstract}
Alexis Habiyaremye
From Primary Commodity Dependence to Diversification and Growth:

Absorptive Capacity and Technological Catch Up in Botswana and Mauritius. UNU-MERIT Dissertation Series, № 60
\end{abstract}

\section{Yoseph Getachew}

The Role of Public Capital in Economic Development

UNU-MERIT Dissertation Series, № 59

\section{Sandra Leitner}

Embodied Technological Change and Patterns of Investment in Austrian Manufacturing

UNU-MERIT Dissertation Series, № 58

\section{Semih Akçomak}

The Impact of Social Capital on Economic and Social Outcomes UNU-MERIT Dissertation Series, № 57 


\section{Abraham Garcia}

The Role of Demand in Technical

Change

UNU-MERIT Dissertation Series, № 56

\section{Saurabh Arora}

Coherence in Socio-technical Systems:

A Network Perspective on the

Innovation Process

UNU-MERIT Dissertation Series,

№ 55

\section{Mirtha R. Muniz Castillo}

Human Development and Autonomy in Project Aid: Experiences from four bilateral projects in Nicaragua and El Salvador

MGSoG Dissertation Series, № 4

\section{Christiane Arndt}

Governance Indicators

MGSoG Dissertation Series, № 3

\section{Britta Augsburg}

Microfinance: Greater Good or Lesser

Evil?

MGSoG Dissertation Series, № 2

\section{8}

\section{Rutger Daems}

Medicines for the Developing World UNU-MERIT Dissertation Series, № 54

\section{Johannes Hanel}

Assessing Induced Technology:

Sombart's Understanding of Technical

Change in the History of Economics

UNU-MERIT Dissertation Series, № 53

\section{Rifka Weehuizen}

Mental Capital: the Economic Significance of Mental Health UNU-MERIT Dissertation Series, № 52

\section{Danielle Cloodt}

The Relationship between RED

Partnership Formation, Social

Embeddedness and Innovative

Performance

UNU-MERIT Dissertation Series, № 51

\section{Sabine Fuss}

Sustainable Energy Development under Uncertainty

UNU-MERIT Dissertation Series, № 50

\section{Geranda Notten}

Measuring and Managing Poverty

Risks

MGSoG Dissertation Series, № 1

2007

\section{Tobias Kronenberg}

Reconciling Environmental

Conservation with Economic

Prosperity: The Feasibility of Double

Dividends in the Short and Long Run

UNU-MERIT Dissertation Series, № 49 


\section{Viktoria Kravtsova}

Assessing the Impact of Foreign Direct Investment in Transition Economies UNU-MERIT Dissertation Series, № 48

\section{Suhail Sultan}

The Competitive Advantage of Small and Medium Sized Enterprises: The Case of Jordan's Natural Stone Industry

UNU-MERIT Dissertation Series, № 47

2006

\section{Bulat Sanditov}

Essays on Social Learning and Imitation

UNU-MERIT Dissertation Series, № 46

\section{Mamata Parhi}

Dynamics of New Technology Diffusion: A Study of the Indian Automotive Industry UNU-MERIT Dissertation Series, № 45

\section{Andreas Reinstaller}

Social Structures and the Innovation Process: Their Role in the Demand of Firms and Consumers UNU-MERIT Dissertation Series, № 44

\section{Rose Kiggundu}

Innovation systems and Development: The Journey of a Beleaguered Nile Perch Fishery in Uganda UNU-MERIT Dissertation Series, № 43

\section{Thomas Pogue}

The Evolution of Research

Collaboration in South African Gold Mining: 1886-1933

UNU-MERIT Dissertation Series, № 42

\section{Geoffrey Gachino}

Foreign Direct Investment, Spillovers and Innovation: The Case of Kenyan Manufacturing Industry

UNU-MERIT Dissertation Series, № 41

\section{Önder Nomaler}

Technological Change, International

Trade and Growth: An Evolutionary, Multi-Agents-Based Modeling

Approach

UNU-MERIT Dissertation Series, № 40

\section{5}

\section{Samia Satti Osman Mohamed-} Nour

Change and Skill Development in the Arab Gulf Countries

UNU-MERIT Dissertation Series, № 39 


\section{Elad Harison}

Intellectual Property Rights:

Economics and Policy Analysis

UNU-MERIT Dissertation Series, № 38

\section{Daniel Dalohoun}

Learning to innovate: agricultural innovation and entrepreneurship: the case of Songhaï farmers in Benin UNU-MERIT Dissertation Series, № 37

\section{Müge Ozman}

Networks, Organizations and

Knowledge

UNU-MERIT Dissertation Series, № 36

\section{Bas Straathof}

Product Variety and Economic

Growth: The Counteracting Effects of Scale and Idiosyncrasy

UNU-MERIT Dissertation Series, № 35

\section{Wilfred Schoenmakers}

Knowledge Flows between

Multinational Companies: A Patent

Data Analysis

UNU-MERIT Dissertation Series, № 34

\section{Myriam Cloodt}

Mergers and Acquisitions ( $M$ and As) in High-Tech Industries: Measuring the Post-M and A Innovative

Performance of Companies

UNU-MERIT Dissertation Series, № 33
2004

\section{Paola Criscuolo}

$R \mathcal{E} D$ Internationalisation and

Knowledge Transfer: Impact on MNEs and their Home Countries

UNU-MERIT Dissertation Series, № 32

\section{Maarten Verkerk}

Trust and Power on the Shop Floor UNU-MERIT Dissertation Series, № 31

\section{Gottfried Leibbrandt}

Adoption, Harmonization and Succession of Network Technologies across Countries

UNU-MERIT Dissertation Series, № 30

\section{Mark Sanders}

Skill Biased Technical change: Its

Origins, the Interaction with the

Labour Market and Policy Implications

UNU-MERIT Dissertation Series,

№ 29

2003

\section{Nadine Roijakkers}

Inter-firm Cooperation in High-tech Industries: a Study of RED

Partnerships in Pharmaceutical

Biotechnology

UNU-MERIT Dissertation Series, № 28 
Viki Sonntag

Speed, Scale and Sustainability

UNU-MERIT Dissertation Series, № 27

\section{Masaru Yarime}

From End-of-Pipe Technology to Clean Technology

UNU-MERIT Dissertation Series, № 26

\section{Stéphane Malo}

The Combinatorial Chemistry Revolution: Sustaining a Superior

Performance Position through

Technological Learning

UNU-MERIT Dissertation Series,

№ 25

\section{2}

\section{Annelies Hogenbirk}

Determinants of Inward Foreign

Direct Investment: the Case of the

Netherlands

UNU-MERIT Dissertation Series, № 24

\section{Bastiaan Johan terWeel}

The Computerization of the Labour Market

UNU-MERIT Dissertation Series
2001

\section{John Adeoti}

Technology Investment in Pollution Control in Sub-Saharan Africa: The Case of the Nigerian Manufacturing Industry

UNU-MERIT Dissertation Series, № 23

\section{Edward Huizenga}

Innovation Management: How

Frontrunners Stay Ahead: An

Empirical Study on Key Success

Factors in the ICT sector

UNU-MERIT Dissertation Series, № 22

2000

\section{Machiel van Dijk}

Technological Change and the

Dynamics of Industries: Theoretical Issues and Empirical evidence from Dutch Manufacturing UNU-MERIT Dissertation Series, № 21

\section{9}

\section{Jan Cobbenhagen}

Managing Innovation at the Company Level: A Study on Non-Sector-Specific Success Factors

UNU-MERIT Dissertation Series, № 20 
Marjolein Caniëls

Regional Growth Differentials: The

Impact of Locally Bounded Knowledge

Spillovers

UNU-MERIT Dissertation Series, № 19

1998

\section{Aldo Geuna}

Resource Allocation and Knowledge production: Studies in the Economics of University Research

UNU-MERIT Dissertation Series, № 18

1996

\section{Reinoud Joosten}

Dynamics, Equilibria, and Values

UNU-MERIT Dissertation Series,

№ 17

\section{Hugo Kruiniger}

Investment, $R \mathcal{E} D$, and the Financing

Decisions of the Firm

UNU-MERIT Dissertation Series, № 16

\section{5}

\section{Hans van Meijl}

Endogenous Technological Change:

The Case of Information Technology,

Theoretical Considerations and

Empirical Results

UNU-MERIT Dissertation Series, № 15

\section{René Kemp}

Environmental Policy and Technical

Change: A Comparison of the

Technological Impact of Policy

Instruments

UNU-MERIT Dissertation Series,

№ 14

\section{Rohini Acharya}

The Impact of New Technologies on

Economic Growth and Trade: A Case

Study of Biotechnology

UNU-MERIT Dissertation Series,

№ 13

\section{Geert Duysters}

The Evolution of Complex Industrial Systems: The Dynamics of Major IT Sectors

UNU-MERIT Dissertation Series, № 12

\section{Marjan Groen}

Technology, Work and Organisation: A Study of the Nursing Process in Intensive Care Units

UNU-MERIT Dissertation Series, № 11

\section{4}

\section{Huub Meijers}

On the Diffusion of Technologies in a Vintage Framework: Theoretical Considerations and Empirical Results UNU-MERIT Dissertation Series, № 10 
Theon van Dijk

The Limits of Patent Protection: Essays on the Economics of Intellectual

Property Rights

UNU-MERIT Dissertation Series, № 9

\section{Hans Voordijk}

Naar Integrale Logistiek in

Bedrijfsketens: Ontwikkelingen in de Bouw

UNU-MERIT Dissertation Series, № 8

1993

\section{Paul Diederen}

Technological Progress in Enterprises and Diffusion of Innovation:

Theoretical Reflections and Empirical

Evidence

UNU-MERIT Dissertation Series, № 7

\section{Ben Dankbaar}

Economic Crisis and Institutional

Change: The Crisis of Fordism from the Perspective of the Automobile Industry UNU-MERIT Dissertation Series, № 6

\section{Hanno Roberts}

Accountability and Responsibility: The Influence of Organisation Design on Management Accounting UNU-MERIT Dissertation Series, № 5
1992

\section{Bart Verspagen}

Uneven Growth between

Interdependent Economies: An

Evolutionary View on Technology

Gaps, Trade and Growth

UNU-MERIT Dissertation Series,

№ 4

\section{Sjoerd Romme}

A Self-organization Perspective on

Strategy Formation

UNU-MERIT Dissertation Series, № 3

\section{9}

\section{John Spangenberg}

Economies of Scale, and Atmosphere in Research Organisations

UNU-MERIT Dissertation Series, № 2

1988

\section{John Hagedoorn}

Evolutionary and Heterodox

Innovation Analysis: A Study of

Industrial and Technological

Development in Process Control and

Information Technology

UNU-MERIT Dissertation Series, № 1 



$$
b
$$

